FELLIPE GARCIA MARQUES

MODELAGEM FENOMENOLÓGICA E CONTROLE DE UMA PLANTA PILOTO DE NEUTRALIZAÇÃO DE $\mathrm{pH}$

São Paulo

2015 - (Edição Revisada) 
FELLIPE GARCIA MARQUES

\section{MODELAGEM FENOMENOLÓGICA E CONTROLE DE UMA PLANTA PILOTO DE NEUTRALIZAÇÃO DE pH}

Dissertação apresentada à Escola Politécnica da Universidade de São Paulo para a obtenção do título de Mestre em Ciências.

São Paulo

2015 - (Edição Revisada) 


\section{FELLIPE GARCIA MARQUES}

\section{MODELAGEM FENOMENOLÓGICA E CONTROLE DE UMA PLANTA PILOTO DE}

NEUTRALIZAÇÃO DE $\mathrm{pH}$

Dissertação apresentada à Escola Politécnica da Universidade de São Paulo para a obtenção do título de Mestre em Ciências.

Área de Concentração:

Engenharia de Sistemas.

Orientador:

Prof. Dr. Claudio Garcia.

São Paulo

2015 - (Edição Revisada) 
Este exemplar foi revisado e corrigido em relação à versão original, sob responsabilidade única do autor e com a anuência de seu orientador.

São Paulo, de fevereiro de 2015.

Assinatura do autor

Assinatura do orientador

Catalogação-na-publicação

Marques, Fellipe Garcia

Modelagem fenomenológica e controle de uma planta de neutralização de pH / F.G. Marques. -- versão corr. -- São Paulo, 2015.

$160 \mathrm{p}$.

Dissertação (Mestrado) - Escola Politécnica da Universidade de São Paulo. Departamento de Engenharia de Telecomunicações e Controle.

1.Modelagem fenomenológica 2.Neutralização de pH I.Universidade de São Paulo. Escola Politécnica. Departamento de Engenharia de Telecomunicações e Controle II.t. 
Este trabalho é dedicado, com muito amor, às pessoas mais importantes da minha vida: Elza, Margarete e Maitê. 


\section{Agradecimentos}

Primeiramente agradeço ao meu orientador, Professor Dr. Claudio Garcia, pelos ensinamentos que me tornaram melhor, profissionalmente e pessoalmente.

Ao Professor Dr. Leo Kunigk, por seus comentários e sugestões, os quais foram importantes para o desenvolvimento deste trabalho.

Ao Professor Dr. Ardson dos Santos Vianna Junior, por toda a ajuda, sugestões e comentários, desde o começo da pesquisa.

Ao meu amigo Christiam Segundo Morales Alvarado, por toda a ajuda, desde o início do meu trabalho.

A todos meus amigos de laboratório, Felipe Lourenço, Jorge Alvarado, Matheus Hidalgo, Andres Camilo Velasquez, Fabián Núñez, Roy Carvajal, Oscar Rodríguez, Bruno Castro, Flávio Ceravolo, Rogério Salvático, Eduardo Romanus e Renan Giovaninni, pelas discussões técnicas e por terem tornado a minha jornada mais leve.

À Marinha do Brasil, pela compreensão e apoio. 
God created everything by number, weight and measure.

(Isaac Newton) 


\section{Resumo}

A neutralização de pH é utilizada nas indústrias, para garantir o descarte seguro de efluentes. As plantas de neutralização de pH são um problema complexo de controle, visto que a planta segue um modelo não-linear e apresenta características variantes no tempo, o que demanda sua correta modelagem para o projeto de sistemas de controle eficientes. No entanto, a teoria referente à modelagem de $\mathrm{pH}$ não é facilmente aplicada na prática, resultando frequentemente em modelos que não predizem corretamente o comportamento dinâmico da planta. O primeiro objetivo deste trabalho foi modelar matematicamente a Planta Piloto de Neutralização de pH do Laboratório de Controle de Processos Industriais (LCPI), utilizando uma metodologia que possa ser aplicada para obter o modelo matemático de outras plantas de neutralização de pH. Inicialmente a Planta Piloto de Neutralização de pH do LCPI foi modelada de acordo com a abordagem fenomenológica, utilizando-se os princípios de conservação de massa, da eletroneutralidade e os conceitos de equilíbrio químico. Em seguida, o modelo foi ajustado aos dados experimentais do processo (abordagem empírica), utilizando-se curvas de titulação dos influentes e distribuições de tempos de residência do reator. Através de experimentos, verificou-se que o modelo representou, de forma satisfatória, a dinâmica real da Planta Piloto de Neutralização de pH do LCPI. Ademais, este modelo foi utilizado para alcançar o segundo objetivo deste trabalho: projetar um sistema de controle de $\mathrm{pH}$, o qual foi composto por um observador não-linear e um controlador baseado em modelo. Esta estrutura de controle foi testada experimentalmente, onde certificou-se que os requisitos de controle foram satisfeitos.

Palavras-chave: Modelagem de processos. Invariantes de reação. Fluidodinâmica de reatores. Equilíbrio químico. Observador não-linear. Controle baseado em modelo. 


\section{Abstract}

The $\mathrm{pH}$ neutralization is used in industry to discard properly the wastewater, ensuring the environment preservation. The $\mathrm{pH}$ neutralization is a complex control problem, as the model of the plant presents a strong nonlinearity and time varying characteristics, which demands a proper modeling in order to design efficient control systems. However, the application of the theory related to $\mathrm{pH}$ modeling is not a trivial task and may result in models that can not predict the plant dynamics. The first objective of this research was to model the pH Neutralization Pilot Plant, of the Laboratory of Industrial Processes Control (LCPI), using a methodology that could be replicated to model other $\mathrm{pH}$ neutralization plants. Initially, the pH Neutralization Pilot Plant was modeled with the phenomenological approach, utilizing first principles, such as the mass conservation, electroneutrality and chemical equilibrium. Moreover, the model was adjusted to represent the process observed data (empirical approach), as its titration curves of the influent streams and its reactor residence time distribution. Through experiments, it was verified that the model could represent adequately the real process dynamics. Furthermore, this model was used to achieve the second objective of this research: to design a pH control system, which was composed of a nonlinear observer and a model-based control. This control structure was tested experimentally, ensuring that the control requirements were satisfied.

Keywords: Process modeling. Reaction invariants. Reactor fluid dynamics. Chemical equilibrium. Nonlinear observer. Model-based control. 


\section{Lista de Figuras}

Figura 3.1 - Foto da Planta Piloto de Neutralização de pH do LCPI. . . . . . . . . 30

Figura 3.2 - P\&ID da Planta Piloto. . . . . . . . . . . . . . . . . 31

Figura 3.3 - Curva da bomba dosadora, após sua calibração. . . . . . . . . . . . . . 35

Figura 4.1 - Curva de titulação teórica (simulada), sendo o titulado uma solução de $150 \mathrm{ml} \mathrm{HCl}$ a 0,0056 mol/l e o titulante uma solução de $\mathrm{NaOH}$ a

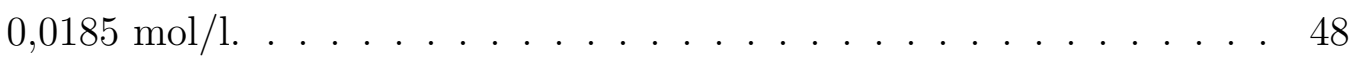

Figura 4.2 - Forma diferencial da curva de titulação da Figura 4.1. . . . . . . . . . 50

Figura 4.3 - Sensibilidade do pH em relação a pequenas quantidades de ácidos fracos - as concentrações de ácido e base fortes são as mesmas da Figura 4.1. 52

Figura 4.4 - Informações utilizadas para predizer o comportamento de um reator. . 52

Figura 4.5 - Reatores ideais de interesse para este trabalho. . . . . . . . . . . . . 54

Figura 4.6 - Curvas de distribuição de tempo de residência para um CSTR ideal. . 57

Figura 4.7 - DTR de um reator com uma fluidodinâmica próxima do ideal. . . . . . 57

Figura 4.8 - Diferentes modelagens fluidodinâmicas e suas respectivas DTR. . . . . 58

Figura 5.1 - Temperatura do TR para diversos experimentos. . . . . . . . . . . . 62

Figura 5.2 - Experimento de DTR com TR operando na condição I. . . . . . . . . 64

Figura 5.3 - Experimento de DTR com TR operando na condição I(2) - segundo experimento na condição I. . . . . . . . . . . . . . . . . . . . . . 64

Figura 5.4 - Experimento de DTR com TR operando na condição II. . . . . . . . . 65

Figura 5.5 - Experimento de DTR com TR operando na condição III. . . . . . . . 65

Figura 5.6 - Curva de titulação da solução do TAP, sendo o titulado $[\mathrm{HCl}]=0,0056$ mol $/ \mathrm{l}$ e o titulante $[\mathrm{NaOH}]=0,0185 \mathrm{~mol} / \mathrm{l} \ldots \ldots \ldots$. . . . . . . 69

Figura 5.7 - Curva de titulação da solução do TAS, sendo o titulado $\left[\mathrm{CH}_{3} \mathrm{COOH}\right]=$ $0,0068 \mathrm{~mol} / \mathrm{l}$ e o titulante $[\mathrm{NaOH}]=0,0185 \mathrm{~mol} / \mathrm{l} \ldots \ldots$. . . . . .

Figura 5.8 - Curvas de titulação realizadas $t$ horas após o preparo das soluções, sendo o titulado $[\mathrm{HCl}]=0,0056 \mathrm{~mol} / \mathrm{l}$ e o titulante $[\mathrm{NaOH}]=0,0185$ mol/l. . . . . . . . . . . . . . . . . . .

Figura 5.9 - Curvas de titulação realizadas com diferentes tempos de agitação por borbulhamento, $t_{a g}$, sendo o titulado $[\mathrm{HCl}]=0,0056 \mathrm{~mol} / \mathrm{l}$ e o titulante $[\mathrm{NaOH}]=0,0185 \mathrm{~mol} / \mathrm{l} \ldots \ldots \ldots \ldots \ldots$

Figura 5.10 - Comparação da forma diferencial das curvas de titulação experimentais e simuladas. . . . . . . . . . . . . . . . . . 74

Figura 5.11 - Excitação do pHmetro para estimação de sua dinâmica. . . . . . . . . 79

Figura 5.12 - Excitação do transmissor de vazão para estimação de sua dinâmica. . . 79

Figura 5.13 - Excitação do transmissor de nível para estimação de sua dinâmica. . 80

Figura 5.14 - Interferência do agitador mecânico na medição de nível do TR. . . . . 80 
Figura 5.15 - Visão geral do modelo da Planta Piloto.

Figura 6.1 - Validação do modelo de pH em malha fechada e valor de referência de nível do TR em $75 \%$.

Figura 6.2 - Validação do modelo de pH em malha fechada e valor de referência de nível do TR em $65 \%$.

Figura 6.3 - Validação do modelo de pH, com ácido clorídrico, em malha aberta e valor de referência de nível do TR em $75 \%$.

Figura 6.4 - Validação do modelo de pH, com ácido clorídrico, em malha aberta e valor de referência de nível do TR em $65 \%$.

Figura 6.5 - Validação do modelo de pH, com ácido acético, em malha aberta e valor de referência de nível do TR em $75 \%$.

Figura 6.6 - Validação do modelo de pH, com ácido acético, em malha aberta e valor de referência de nível do TR em $65 \%$. . . . . . . . . . . . . . . 91

Figura 6.7 - Experimento de validação do modelo de nível do TR. . . . . . . . . . . 94

Figura 7.1 - Diagrama de blocos considerado no projeto do ramo feedforward do controlador de referência. . . . . . . . . . . . . . . . . . 97

Figura 7.2 - Comparação das respostas dos modelos completo e simplificado. . . . . 100

Figura 7.3 - Simulação 1, para teste do observador da Planta Piloto - estimação do pH. . . . . . . . . . . . . . . . . . 109

Figura 7.4 - Simulação 1, para teste do observador da Planta Piloto - estimação dos invariantes de reação. . . . . . . . . . . . . . . . . . . . . 109

Figura 7.5 - Simulação 1, para teste do observador da Planta Piloto, com escalas ampliadas - estimação dos invariantes de reação, de 1000 até 6000 segundos. . . . . . . . . . . . . . . . . . . . 110

Figura 7.6 - Simulação 1, para teste do observador da Planta Piloto, com escalas ampliadas - estimação dos invariantes de reação, de 6000 até 11000 segundos. . . . . . . . . . . . . . . . . . . . 110

Figura 7.7 - Simulação 2, para teste do observador da Planta Piloto - estimação do pH. . . . . . . . . . . . . . . . . . . 111

Figura 7.8 - Simulação 2, para teste do observador da Planta Piloto - estimação dos invariantes de reação.

Figura 7.9 - Simulação 2, para teste do observador da Planta Piloto, com escalas ampliadas - estimação dos invariantes de reação, de 1000 até 6000 segundos. . . . . . . . . . . . . . . . . . . 112

Figura 7.10 - Simulação 2, para teste do observador da Planta Piloto, com escalas ampliadas - estimação dos invariantes de reação, de 6000 até 11000 segundos. . . . . . . . . . . . . . . . . . . 112

Figura 7.11 - Simulação 1 em modo servo. . . . . . . . . . . . . . . . . . . . . 119

Figura 7.12 - Simulação 2 em modo servo. . . . . . . . . . . . . . . . . . . . . 119

Figura 7.13 - Simulação 1 em modo regulatório. . . . . . . . . . . . . . . . . . . 120 
Figura 7.14 - Simulação 2 em modo regulatório. . . . . . . . . . . . . . . . . 120

Figura 7.15 - Experimento no modo servo - pH do TR. . . . . . . . . . . . . . 123

Figura 7.16 - Experimento no modo servo - Variável Manipulada (VM) . . . . . . . . 124

Figura 7.17 - Experimento no modo servo - Estimação da concentração de ácido

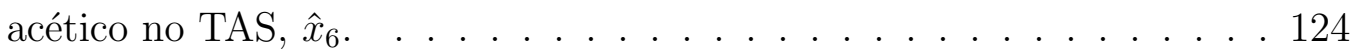

Figura 7.18 - Experimento no modo servo - Vazões dos influentes e nível do TR. . . 125

Figura 7.19 - Experimento no modo regulatório - pH do TR . . . . . . . . . . . 125

Figura 7.20 - Experimento no modo regulatório - Variável Manipulada (VM) . . . . 126

Figura 7.21 - Experimento no modo regulatório - Estimação da concentração de ácido acético no TAS, $\hat{x}_{6} \ldots \ldots \ldots$. . . . . . . . . . . . . 126

Figura 7.22 - Experimento no modo regulatório - Vazões dos influentes e nível do TR.127

Figura B.1 - Os potenciais elétricos de um eletrodo de vidro. . . . . . . . . . . . . . 159 


\section{Lista de Tabelas}

Tabela 3.1 - Vazões máximas e concentrações das soluções da Planta Piloto. . . . . 33

Tabela 3.2 - Principais características do TR . . . . . . . . . . . . . . . 34

Tabela 3.3 - Comparação das relações geométricas do TR com as sugeridas na literatura. . . . . . . . . . . . . . . . . 34

Tabela 3.4 - Vazão de saída da bomba dosadora, com uma mesma frequência de operação, quando o TBB está com diferentes níveis. . . . . . . . . . . 36

Tabela 5.1 - Características da DTR para cada condição de teste. . . . . . . . . . . 66

Tabela 5.2 - Invariantes de reação das soluções da Planta Piloto. . . . . . . . . . . 73

Tabela 5.3 - Concentrações utilizadas para a modelagem da forma diferencial das curvas de titulação da Planta Piloto. . . . . . . . . . . . . . . . 75

Tabela 5.4 - Variação das constantes de dissociação das espécies consideradas na Planta Piloto, com relação à temperatura. . . . . . . . . . . . . 76

Tabela 5.5 - Diâmetros dos instrumentos e equipamentos inseridos no TR. . . . . . 78

Tabela 6.1 - Procedimento experimental para validação do modelo, em malha fechada (MF) . . . . . . . . . . . . . . . . . 8 83

Tabela 6.2 - Procedimento experimental para validação em malha aberta (MA), utilizando ácido clorídrico. . . . . . . . . . . . . . . 8 86

Tabela 6.3 - Procedimento experimental para validação em malha aberta (MA), utilizando ácido acético. . . . . . . . . . . . . . . . 86

Tabela 6.4 - Comparações quantitativas entre o modelo e os dados experimentais

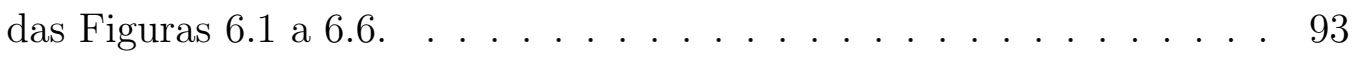

Tabela 6.5 - Concentrações das perturbações das curvas de titulação utilizadas nos experimentos de validação. . . . . . . . . . . . . . . . . 93

Tabela 6.6 - Procedimento para validação do modelo de nível. . . . . . . . . . . . . 94

Tabela 7.1 - Parâmetros do Controlador PID 2DOF. . . . . . . . . . . . . . . 97

Tabela 7.2 - Procedimento da simulação realizada para avaliar o desempenho do observador de estados. . . . . . . . . . . . . . . . . . . 107

Tabela 7.3 - Procedimento da simulação para avaliar o desempenho do controlador em modo regulatório. . . . . . . . . . . . . . . . 118

Tabela 7.4 - Valores de ISE para cada simulação e controlador, calculados a partir de 2000 segundos, até o fim da simulação. . . . . . . . . . . . . . . 122 


\section{Lista de Abreviaturas e Siglas}

CLP Controlador Lógico Programável

CSTR Reator Tanque Agitado Contínuo, do Inglês, Continuous Stirred Tank Reactor

DTR Distribuição de Tempos de Residência

EKF Filtro de Kalman Estendido, do Inglês, Extended Kalman Filter

EPUSP Escola Politécnica da Universidade de São Paulo

fit

Índice de Ajuste

HMI Interface Homem Máquina, do Inglês, Human Machine Interface

ISE do Inglês, Integrated Squared Error

LCPI Laboratório de Controle de Processos Industriais

LMI do Inglês, Linear Matrix Inequality

MA Malha Aberta

MF Malha Fechada

MPC Controle Preditivo Baseado em Modelo, do Inglês, Model Predictive Control

MRAC Controlador Adaptativo Baseado em Modelo, do Inglês, Model Reference Adaptive Control

OPC do Inglês, OLE for Process Control

P\&ID ～do Inglês, Piping and Instrumentation Diagram

PD Proporcional Derivativo

PDF Função Densidade de Probabilidade, do Inglês, Probability Density Function

PFR Reator de Fluxo em Pistão, do Inglês, Plug Flow Reactor

pH Potencial Hidrogeniônico

PI Proporcional Integral

PID 2DOF Controlador Proporcional Integral Derivativo com 2 Graus de Liberdade 
PID

Proporcional Integral Derivativo

Planta Piloto Planta Piloto de Neutralização de pH do Laboratório de Controle de Processos Industriais

PMBC Controlador Baseado em Modelo do Processo, do Inglês, Process-ModelBased Control

PWM do Inglês, Pulse Width Modulation

SDCD Sistema Digital de Controle Distribuído

SP Valor de Referência, do Inglês, Setpoint

TIC Coeficiente de Desigualdade de Theil, do Inglês, Theil's Inequality Coefficient

VC Variável Controlada

VM Variável Manipulada

\section{Identificação da Instrumentação e Equipamentos da Planta Piloto}

AE-40 Sensor de pH do TR

AIC-40 Controlador de pH do TR

AITY-40 Transmissor de $\mathrm{pH}$ do TR

FIT-31 Medidor e transmissor da vazão do TAPI para o TR

FIT-32 Medidor e transmissor da vazão do TASI para o TR

FV-31 Válvula solenoide de isolamento do TAPI

FV-32 Válvula solenoide de isolamento do TASI

FV-35 Válvula solenoide de isolamento do TAP

FV-36 Válvula solenoide de isolamento do TAS

FZ-41 Bomba dosadora de solução básica

LCV-35 Válvula boia, para controle de nível do TAPI

LCV-36 Válvula boia, para controle de nível do TASI

LIC-16 Controlador de nível do TR 
LIT-10 Medidor e transmissor de nível do TR

LV-16A Válvula de controle de nível do TR

MZ-81 Agitador do TR

TAP Tanque de Ácido Principal

TAPI Tanque de Ácido Principal Intermediário

TAS Tanque de Ácido Secundário

TASI Tanque de Ácido Secundário Intermediário

TBB Tanque de Base para a Bomba

TBV Tanque de Base para a Válvula

TE-40 Medidor de temperatura do TR

TR Tanque do Reator

UV-31B Válvula manual de isolamento do TAPI

UV-32B Válvula manual de isolamento do TASI 


\section{Sumário}

INTRODUÇÃo $\ldots \ldots \ldots \ldots \ldots \ldots \ldots \ldots$

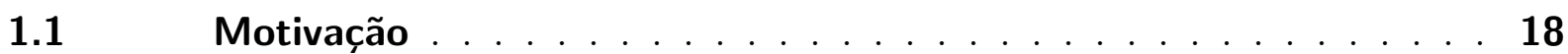

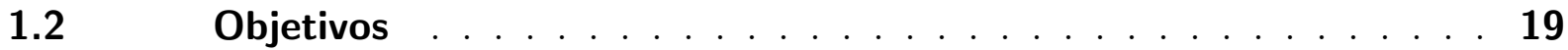

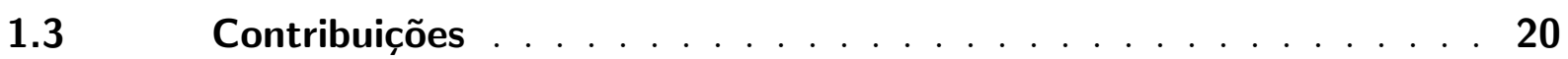

1.4 Estrutura da Dissertação . . . . . . . . . . . . . 20

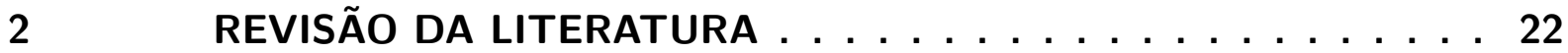

$2.1 \quad$ Literatura Referente à Modelagem de $\mathbf{p H} \ldots \ldots \ldots 22$

2.2 Literatura Referente a Controle de $\mathbf{p H} \ldots \ldots$. . . . . . . . . . . 24

3 DESCRIÇÃO DA PLANTA PILOTO DE NEUTRALIZAÇÃO DE PH DO LCPI . . . . . . . . . . . . . . . . . . . . . . . 30

3.1 Descrição Funcional $\ldots \ldots \ldots \ldots \ldots \ldots$

3.2 Soluções Utilizadas na Planta Piloto . . . . . . . . . . . 33

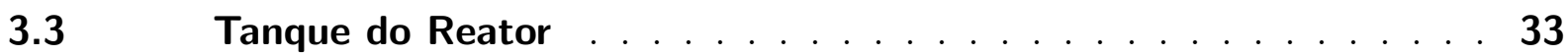

3.4 Bomba Dosadora . . . . . . . . . . . . . . . . . . . . . 34

$3.5 \quad$ Medidor de $\mathbf{p H} \ldots \ldots \ldots \ldots \ldots$

3.6 Medidores de Vazão . . . . . . . . . . . . . . . . . . . 36

$3.7 \quad$ Medidor de Nível . . . . . . . . . . . . . . . . . 36

$3.8 \quad$ Válvula Solenoide . . . . . . . . . . . . . . . . . . 36

4 FUNDAMENTOS TEÓRICOS PARA A MODELAGEM DA PLANTA

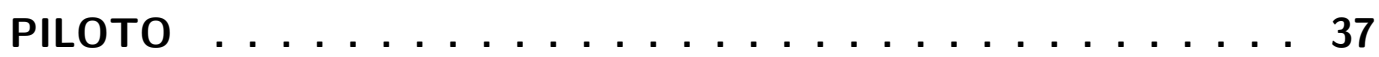

$4.1 \quad$ Fundamentos de Ácidos e Bases . . . . . . . . . . . . . . 37

4.1.1 Auto-lonização da Água e Potencial Hidrogeniônico . . . . . . . . . . . . . 38

4.1 .2 Soluções Aquosas . . . . . . . . . . . . . . . . . . . . . . . . . 39

$4.1 .3 \quad$ Ácidos e Bases Polipróticos . . . . . . . . . . . . . . . . . . . . 40

4.1 .4 Soluções Tampão . . . . . . . . . . . . . . . . . . . . . . . . 41

4.1 .5 Reações de Neutralização . . . . . . . . . . . . . . . . . . . . . . . 42

4.1 .6 Invariantes de Reação . . . . . . . . . . . . . . . . . . . . . 42

4.1.7 Emprego dos Invariantes de Reação na Modelagem de pH . . . . . . . . 43

4.1 .8 Curvas de Titulação . . . . . . . . . . . . . . . . . . . . . . . . 47

4.1 .9 Análise das Curva de Titulação . . . . . . . . . . . . . . . . . . . . . 49

4.2 Fundamentos de Cinética de Reações e Fluidodinâmica . . . . . . 52

4.2 .1 Cinética de Reações Ácido-Base . . . . . . . . . . . . . . . . . . 53

4.2.2 Fluidodinâmica de Reatores Ideais . . . . . . . . . . . . . . . . 54 
4.2.3 Fluidodinâmica de Reatores Reais . . . . . . . . . . . . . . . . 55

4.2.4 Modelagem da Fluidodinâmica a Partir da DTR . . . . . . . . . . . . . . 57

MODELAGEM dA PlANTA PILOTO . . . . . . . . . . . . . . 59

5.1 As Soluções Utilizadas na Planta Piloto . . . . . . . . . . . . . . . . 59

5.2 Análise da Termodinâmica da Planta Piloto . . . . . . . . . . . . 61

$5.3 \quad$ Análise da Fluidodinâmica do TR . . . . . . . . . . . . 62

$5.3 .1 \quad$ O Tempo de Mistura . . . . . . . . . . . . . . . 66

$5.4 \quad$ Análise das Curvas de Titulação da Planta Piloto . . . . . . . . . . . 67

$5.5 \quad$ Modelagem Estática do pH . . . . . . . . . . . . . . . 69

5.5.1 A Absorção de Gás Carbônico . . . . . . . . . . . . . . . . . . 70

5.5.2 Estimação das Concentrações das Perturbações . . . . . . . . . . . . . . 72

5.5.3 Análise das Variações das Constantes de Dissociação com a Temperatura . 75

5.5.4 Análise do Coeficiente de Atividade da Planta Piloto . . . . . . . . . . . 76

5.6 Modelagem do Nível do TR . . . . . . . . . . . . . . 77

5.7 Modelagem da Instrumentação e Bomba Dosadora . . . . . . . . . . 78

$5.8 \quad$ O Modelo da Planta Piloto . . . . . . . . . . . . . . . . . . . . 81

6 VALIDAÇÃO dO MODELO DA PLANTA PILOTO . . . . . . . 82

6.1 Experimentos de Validação do Modelo de pH em Malha Fechada . 82

6.2 Experimentos de Validação do Modelo de pH em Malha Aberta . . 86

6.3 Resultados Quantitativos dos Experimentos de Validação do Modelo de $\mathbf{p H} \ldots \ldots \ldots$. . . . . . . . . . . . . . . . . . . 92

6.4 Experimento para Validação do Modelo de Nível . . . . . . . . . . . 93

7 PROJETO E VALIDAÇÃO DO SISTEMA DE CONTROLE DE PH 95

$7.1 \quad$ Descrição do Problema de Controle . . . . . . . . . . . . . . . . . . 95

$7.2 \quad$ O Controlador de Referência . . . . . . . . . . . . . . . . 96

$7.3 \quad$ Projeto do Observador de Estados . . . . . . . . . . . . . . . . . 98

7.3.1 Simplificação do Modelo Matemático da Planta Piloto . . . . . . . . . . . 98

7.3.2 A Estrutura e as Propriedades do Observador de Estados . . . . . . . . . . 100

7.3.3 Determinação do Vetor de Ganho L . . . . . . . . . . . . . . . . . . . 106

7.3.4 Simulações do Observador de Estados da Planta Piloto . . . . . . . . . . . 107

$7.4 \quad$ Projeto do Controlador de pH . . . . . . . . . . . . . 113

7.4.1 Reformulação do Problema de Controle . . . . . . . . . . . . . . . . 113

7.4.2 A Relação entre o Ácido Forte Equivalente e a Dinâmica da Planta Piloto . 114

7.4.3 Determinação da Lei de Controle . . . . . . . . . . . . . . . . . 116

7.4.4 Sintonia do Controlador . . . . . . . . . . . . . . . . . . 117

7.4.5 Simulações do Controlador . . . . . . . . . . . . . . . . . . . . 118

7.5 Experimentos de Validação do Controlador . . . . . . . . . . . . 122 
Referências Bibliográficas . . . . . . . . . . . . . . . 131

APÊNDICE A - FUNDAMENTOS DE TERMODINÂMICA . . . 135

A.1 Primeira Lei da Termodinâmica . . . . . . . . . . . . 136

A.2 Segunda Lei da Termodinâmica $\ldots \ldots \ldots \ldots$

A.3 Terceira Lei da Termodinâmica . . . . . . . . . . . . . . . . 140

A.4 Transformações Espontâneas . . . . . . . . . . . . . . . 140

A.5 Equilíbrio Químico . . . . . . . . . . . . . . . . . . . . . 142

A.5.1 Potencial Químico de Gases Ideais . . . . . . . . . . . . . . . . . 143

A.5.2 Potencial Químico do Solvente em Soluções Diluídas Ideais . . . . . . . . 144

A.5.3 Potencial Químico dos Solutos em Soluções Diluídas Ideais . . . . . . . . 145

A.5.4 Potencial Químico de Solutos em Função de Concentrações . . . . . . . . . 146

A.5.5 Equilíbrio Dinâmico de Reações Químicas . . . . . . . . . . . . . . . 148

A.5.6 Equilíbrio Dinâmico de Reações Químicas em Soluções Diluídas . . . . . . 150

A.5.7 As Variações da Constante de Equilíbrio Devido a Variações na Temperatura 151

A.5.8 O Conceito de Atividade para Soluções Reais . . . . . . . . . . . . . 151

A.5.9 Atividade em Soluções Eletrolíticas . . . . . . . . . . . . . . . . 152

A.5.10 Constante de Equilíbrio em Soluções Eletrolíticas . . . . . . . . . . . 154

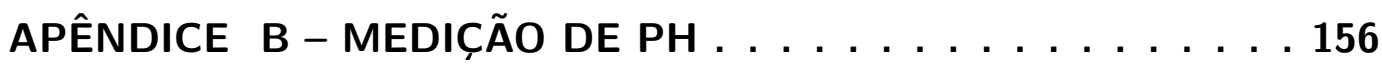

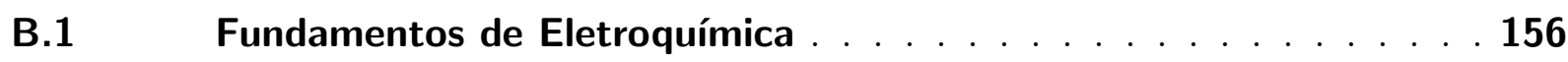

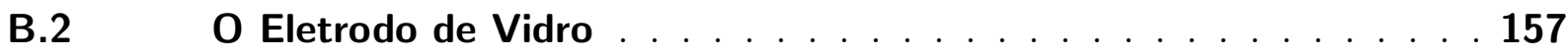




\section{Introdução}

A literatura científica apresenta diversas pesquisas teóricas e experimentais relativas à modelagem e controle do potencial hidrogeniônico $(\mathrm{pH})$. A partir da década de 50, quando as aplicações práticas do controle de pH começaram a ser exploradas (MCAVOY, 1972a), este tópico de pesquisa tornou-se cada vez mais frequente, principalmente por dois motivos. O primeiro é o vasto campo de aplicação, como o tratamento de efluentes e prevenção de danos por corrosão. O segundo motivo é que o controle de $\mathrm{pH}$ é propício para validar experimentalmente novos métodos de controle para plantas não-lineares e variantes no tempo (ALVAREZ et al., 2001), pois é possível desenvolver um laboratório de testes com equipamentos simples e baratos (GUSTAFSSON; WALLER, 1992).

Dentre as possíveis aplicações do controle de pH, este trabalho versa especificamente a respeito da neutralização de pH para descarte seguro de efluentes. Uma planta de neutralização de pH é geralmente um sistema auxiliar na indústria de processos, que recebe fluidos (influentes) de diversos outros sistemas do processo. De maneira geral, estes influentes podem ter variadas composições (inúmeros ácidos e bases) e a concentração de determinado composto pode variar ao longo do tempo. Assim, o objetivo da planta é neutralizar o pH destes fluidos, para que eles possam ser descartados de maneira segura ou no esgoto ou em corpos d'água. Isto se faz necessário para garantir a eficiência do processo de tratamento de esgoto ou para evitar a eutrofização dos rios. Neste trabalho, os experimentos são realizados em uma Planta Piloto de Neutralização de pH, que se localiza no Laboratório de Controle de Processos Industriais (LCPI) da Escola Politécnica da Universidade de São Paulo (EPUSP).

Este trabalho pode ser dividido em duas partes. A primeira aborda a modelagem da Planta Piloto de Neutralização de pH do LCPI. A segunda parte trata do projeto de um sistema de controle de $\mathrm{pH}$ para a planta.

\subsection{Motivação}

Em geral, os processos químicos possuem inúmeras características que dificultam o projeto de sistemas de controle adequados (BEQUETTE, 1991). De forma específica, uma planta de neutralização de $\mathrm{pH}$ também apresenta algumas particularidades, que aumentam a complexidade do projeto de um sistema de controle, como: (i) interações entre variáveis controladas e manipuladas, (ii) variáveis de estado não medidas, (iii) perturbações frequentes e não medidas, (iv) parâmetros incertos e variantes no tempo, (v) restrições nas variáveis manipuladas e de estado e (vi) dinâmica das medições possuem tempo morto.

Uma etapa fundamental para o projeto de um sistema de controle adequado para 
determinada planta é a obtenção de seu modelo matemático, o mais preciso e simples possível. Segundo Gustafsson et al. (1995), quanto mais difícil é o problema de controle, mais preponderante é a qualidade do modelo da planta no desempenho do controlador. Assim, a complexidade encontrada em processos de neutralização de $\mathrm{pH}$ demanda o desenvolvimento de um modelo que represente com exatidão a dinâmica que a planta apresenta na prática. No entanto, verifica-se que a teoria existente para a modelagem de processos de neutralização de $\mathrm{pH}$ não é facilmente aplicada para casos práticos, necessitando de inúmeros ajustes (IBRAHIM, 2008). Uma evidência disto pode ser vista no trabalho de Ceravolo (2012), que modelou a Planta de Neutralização de pH do LCPI utilizando a teoria de invariantes de reação (GUSTAFSSON; WALLER, 1983), pois os dados gerados por seu modelo diferiram consideravelmente dos dados obtidos através de experimentos com essa planta. Desta forma, conclui-se que a modelagem de processos de neutralização de pH não é uma tarefa trivial e que a teoria referente a este tema pode ser aprimorada.

Adicionalmente, a obtenção de um modelo adequado para a Planta Piloto de Neutralização de pH do LCPI melhora a eficiência de outras pesquisas conduzidas no LCPI. A realização de experimentos na planta do LCPI, além de consumir reagentes, demanda um tempo considerável, visto que a planta possui uma dinâmica lenta. Assim, a possibilidade de realizar testes em um ambiente simulado é uma grande vantagem, pois gera economia de tempo e de reagentes.

\subsection{Objetivos}

Esta pesquisa possui dois objetivos gerais. O primeiro é o desenvolvimento de um modelo matemático para a Planta Piloto de Neutralização de pH do LCPI, que seja adequado para o projeto e validação de controladores, bem como testes de identificação de sistemas. O segundo objetivo é projetar e validar um controlador de $\mathrm{pH}$ que atenda a determinados requisitos de controle.

Ainda, esta pesquisa pretende atingir os seguintes objetivos específicos:

(i) Desenvolver uma metodologia que possa ser reproduzida em outras aplicações práticas de modelagem de $\mathrm{pH}$;

(ii) Evidenciar as complexidades do processo de neutralização que devam ser levadas em consideração no projeto do sistema de controle e

(iii) Obter um modelo simplificado da Planta Piloto de Neutralização de pH do LCPI, suficientemente preciso para ser utilizado no projeto de sistemas de controle. 


\subsection{Contribuições}

Esta pesquisa pretende contribuir para a teoria, através do desenvolvimento de uma metodologia que possa ser aplicada para a modelagem de outros processos de neutralização de $\mathrm{pH}$.

Adicionalmente, percebe-se que a literatura disponível, referente ao controle de $\mathrm{pH}$, apresenta muitas pesquisas conduzidas apenas em ambiente simulado, não levando em consideração muitas das dificuldades inerentes à aplicação real. Como a Planta Piloto do LCPI utiliza equipamentos e instrumentos de padrão industrial, espera-se que as características da planta, observadas neste trabalho, sejam equivalentes às encontradas na prática. Portanto, o modelo desenvolvido neste trabalho pode contribuir para que os modelos utilizados nas pesquisas conduzidas em ambientes simulados sejam mais realistas.

O sistema de controle de $\mathrm{pH}$, desenvolvido nesta pesquisa, utiliza um observador de estados e um controlador não-lineares. O observador foi desenvolvido recentemente por Glaria et al. (2012) e ainda não havia sido testado em uma aplicação real.

\subsection{Estrutura da Dissertação}

Os três primeiros Capítulos apresentam informações relevantes para as duas partes da dissertação. O Capítulo 1, Introdução, contextualiza a pesquisa e apresenta seus objetivos e motivações. O Capítulo 2, Revisão da Literatura, apresenta as contribuições das principais pesquisas referentes aos temas abordados nesta pesquisa. O Capítulo 3, Descrição da Planta Piloto de Neutralização de pH do LCPI, apresenta uma descrição funcional dessa planta, incluindo seus equipamentos e instrumentos. Os Capítulos 4, 5 e 6 são referentes à modelagem da Planta Piloto de Neutralização de pH do LCPI. O Capítulo 4, Fundamentos Teóricos para a Modelagem da Planta Piloto, tem por objetivo apresentar os principais conceitos utilizados na modelagem da Planta Piloto de Neutralização de pH do LPCI. O Capítulo 5, Modelagem da Planta Piloto, corresponde ao desenvolvimento do modelo matemático da Planta Piloto de Neutralização de pH do LCPI. O Capítulo 6, Validação do Modelo da Planta Piloto, tem o objetivo de certificar que o modelo matemático desenvolvido para a Planta Piloto de Neutralização de pH do LCPI apresenta resultados satisfatórios. A segunda parte da dissertação corresponde ao Capítulo \%, Projeto e Validação do Sistema de Controle de $p H$, o qual apresenta os requisitos de controle, o desenvolvimento do controlador e as teorias utilizadas, bem como atesta experimentalmente que os requisitos de controle foram atendidos. O Capítulo 8, Conclusões e Perspectivas de Trabalhos Futuros, apresenta as conclusões gerais deste trabalho e algumas sugestões para trabalhos futuros. Os Apêndices A e B exibem teorias básicas, utilizadas para o desenvolvimento da teoria de equilíbrio químico e da medição de $\mathrm{pH}$. O Apêndice A, Fundamentos de Termodinâmica, apresenta conceitos elementares de termodinâmica, necessários para entender o conceito de 
equilíbrio químico, amplamente utilizado nas reações de neutralização de $\mathrm{pH}$. O Apêndice $B$, Medição de $p H$, expõe os princípios de funcionamento de um eletrodo de vidro, o qual é empregado para a medição de $\mathrm{pH}$. 


\section{Revisão da Literatura}

Neste capítulo são apresentados os resultados de pesquisas relacionadas a esta dissertação. O objetivo é construir uma base com a literatura, necessária para o desenvolvimento deste trabalho. Adicionalmente, pretende-se obter um panorama do conhecimento disponível, referente à modelagem e controle de $\mathrm{pH}$, o que é importante para dar suporte às motivações apresentadas no Capítulo 1. O detalhamento da literatura é realizado, quando necessário, nos capítulos subsequentes. Caso o leitor não esteja familiarizado com os conceitos básicos relativos à neutralização de $\mathrm{pH}$, sugere-se que a leitura do Capítulo 4 e Apêndices A e B precedam a leitura deste capítulo.

Em conformidade com a estrutura proposta para esta dissertação, a revisão da literatura também está dividida entre modelagem e controle de pH. Como a modelagem (ou identificação) da planta é uma etapa importante para a maioria dos métodos de projeto de sistemas de controle, muitos artigos tratam simultaneamente tanto da modelagem quanto do controle de $\mathrm{pH}$. Assim, as informações destes artigos foram divididas para serem discutidas na seção pertinente.

\subsection{Literatura Referente à Modelagem de pH}

A modelagem matemática de processos reais pode ser feita de inúmeras maneiras, podendo apresentar os seguintes aspectos: (i) dinâmica linear ou não-linear; (ii) parâmetros distribuídos ou concentrados; (iii) parâmetros invariantes ou variantes no tempo e (iv) dinâmica determinística ou estocástica. Geralmente, os aspectos são escolhidos de forma a obter a precisão desejada para o modelo e esta, por sua vez, é determinada pela finalidade do modelo (GARCIA, 2005). Assim, quando é necessário um modelo mais preciso, este apresentará aspectos de maior complexidade matemática. É importante ressaltar que o modelo matemático é uma representação abstrata do processo real, devendo-se buscar um modelo que seja útil para sua finalidade (LJUNG, 1999).

No caso da Planta de Neutralização de pH do LCPI, o propósito do modelo é auxiliar no projeto de sistemas de controle e no desenvolvimento de experimentos de identificação de sistemas. Desta forma, conclui-se que variações espaciais das variáveis de estado não são relevantes para o propósito do modelo. Assim, a literatura exposta nesta seção trata da modelagem de pH através de equações diferenciais ordinárias, com parâmetros concentrados.

Os princípios físicos e relações constitutivas utilizados na modelagem são provenientes de conceitos amplamente aceitos pela comunidade científica, conforme abordado nos trabalhos de Castellan (1983), Rosemberg e Epstein (1997), Dean (1999) e Atkins e Paula 
(2010).

O livro de Garcia (2005) apresenta um compêndio de metodologias para realizar a modelagem de processos, o qual é utilizado como um roteiro alicerçador para o desenvolvimento desta dissertação.

Juliani (2011) desenvolveu um manual de operação e documentou o projeto da Planta Piloto de Neutralização de pH do LCPI, sendo seu trabalho fundamental para o desenvolvimento desta dissertação.

McAvoy, Hsu e Lowenthal (1972c) modelaram um sistema dinâmico de neutralização de $\mathrm{pH}$ através do princípio da eletroneutralidade e de balanço de massa, para uma reação entre ácido fraco e base forte. Através de uma comparação entre os dados de simulação e os dados experimentais, demonstraram que o modelo representava adequadamente a planta de neutralização de pH. Além disso, McAvoy (1972b) publicou um trabalho a respeito da modelagem dinâmica de reações químicas rápidas, que é o caso das reações ácido-base.

Hershkovitch, McAvoy e Liapis (1978) estudaram a resposta dinâmica dos eletrodos de vidro, que são normalmente empregados para medir o $\mathrm{pH}$ de fluidos. Eles modelaram a mobilidade de espécies iônicas a partir de equações diferenciais parciais, levando em consideração fenômenos de difusão, convecção e migração (mobilidade dos íons devido à influência de campos elétricos). Neste artigo, puderam demonstrar experimentalmente que o modelo desenvolvido apresentou bons resultados para ácidos e bases fortes. Contudo, o modelo mostrou-se ineficiente para predizer a resposta dinâmica de ácidos fracos, devido à presença de moléculas não dissociadas - não possuem carga elétrica - o que facilita a transposição da dupla camada elétrica, que é uma região próxima do eletrodo e que possui potencial elétrico.

Em seguida, Jacobs, Hewkin e While (1980) modelaram uma reação de neutralização entre ácido e base fortes, utilizando o princípio da eletroneutralidade e assumindo que a fluidodinâmica do reator era ideal. O modelo se mostrou adequado para representar um processo industrial de neutralização de $\mathrm{pH}$ com ácidos e bases fortes.

Jutila, Orava e Salmelin (1981) generalizaram o trabalho de McAvoy, Hsu e Lowenthal (1972c), obtendo um modelo dinâmico para inúmeros ácidos e bases. Adicionalmente, eles apresentaram um método para modelar reações com ácidos e bases desconhecidos, ajustando a curva de titulação do modelo às experimentais, através da adição de ácidos fracos hipotéticos no modelo matemático da planta. Além disso, eles sugeriram a utilização do modelo de tanques ideais em série para representar a fluidodinâmica do reator.

Gustafsson (1982) aplicou a teoria de invariantes de reação (FJELD; ASBJORNSEN; ÅSTRÖM, 1974; WALLER; MÄKILÄ, 1981) para determinar o pH de uma solução contendo inúmeros ácidos e bases. Em seguida, Gustafsson e Waller (1983) estenderam 
o modelo estático de pH para modelar dinamicamente uma planta de neutralização de pH. Ainda, Gustafsson e Waller (1992) discutiram inúmeros fenômenos que poderiam influenciar na modelagem de $\mathrm{pH}$, como a temperatura da solução.

O trabalho de McMillan e Cameron (2004) aborda muitas características práticas do processo de neutralização de $\mathrm{pH}$. Eles discutiram os diferentes tipos de sensores de $\mathrm{pH}$ e seu funcionamento, informações que podem ser inferidas das curvas de titulação e aspectos do projeto do processo de neutralização de $\mathrm{pH}$. Outra referência prática é o trabalho de Ibrahim (2008), que consistiu na modelagem e controle de uma planta piloto de neutralização de $\mathrm{pH}$ de grande escala. Para que os dados de seu modelo se aproximassem dos dados experimentais, as constantes de equilíbrio de seu modelo tiveram que ser ajustadas, resultando em valores diferentes dos teóricos. Ainda, esta pesquisa sugere que são necessários ajustes para o desenvolvimento de um modelo matemático de $\mathrm{pH}$, que se assemelhe à realidade, demonstrando que este não é um problema trivial e que tem possibilidade de aperfeiçoamento. A monografia de Ceravolo (2012) contribuiu para esta afirmação, pois a aplicação da teoria de invariantes de reação na Planta Piloto de Neutralização de pH do LCPI resultou em um modelo que diferiu consideravelmente dos dados experimentais.

As publicações na área de modelagem de reatores químicos, como Levenspiel (1999) e Fogler (2004), também são importantes para a condução deste trabalho, pois a Planta Piloto é essencialmente um reator químico.

Após a construção do modelo matemático da Planta Piloto de Neutralização de pH do LCPI, os trabalhos de Murray-Smith (1998) e Ljung (1999) são utilizados para a validação do modelo matemático do processo.

\subsection{Literatura Referente a Controle de pH}

Uma planta de neutralização de pH apresenta algumas características experimentais, que são atrativas para o teste de novos métodos de controle. Entre elas, um processo de neutralização de $\mathrm{pH}$ segue um modelo fortemente não-linear, possibilitando o teste de métodos de controle não-linear, ou a avaliação do desempenho de controladores lineares aplicados a plantas não-lineares. Outra característica é a possibilidade de apresentar dinâmica variante no tempo, que ocorre quando a composição da solução a ser neutralizada varia no tempo. Assim, uma planta de neutralização de $\mathrm{pH}$ é útil para testar experimentalmente sistemas de controle clássico, adaptativo, preditivo, fuzzy, entre outros.

Especificamente, na Planta Piloto de Neutralização de pH do LCPI, foram testados métodos de controle clássicos, como o Proporcional Integral Derivativo (PID), bem como métodos de controle avançados, como por exemplo o Controle Preditivo Baseado em Modelo (MPC - do Inglês, Model Predictive Control) (ALVARADO; GARCIA, 2013). 
McAvoy (1972a) utilizou um controlador PID, com sintonia baseada no método de Ziegler-Nichols, para controlar uma planta piloto de neutralização de pH. Adicionalmente, foi testado experimentalmente um controlador ótimo. O desempenho de ambos controladores foi comparado. Apesar do controlador ótimo ter apresentado oscilações constantes em torno do valor de referência quando em regime permanente, sua resposta dinâmica apresentou melhores resultados que o controlador PID. Segundo o autor, isto ocorreu pois houve dinâmicas do processo que foram desprezadas no modelo da planta, por não influírem significativamente na resposta do modelo, mas eram significativas para o projeto do controlador ótimo. Ademais, ele observou que a resposta obtida com um controlador Proporcional Derivativo (PD) foi similar à resposta obtida com o controlador ótimo. Por fim, ele concluiu que a resposta dinâmica de um controlador PID irá sempre resultar em respostas piores que as obtidas com o controlador ótimo.

Jacobs, Hewkin e While (1980) projetaram um sistema de controle para uma planta de neutralização de pH industrial. Como os influentes da planta não apresentavam características variantes no tempo, projetaram um controlador utilizando uma combinação de controle por retroalimentação com controle antecipatório (do tipo feedforward). O controle antecipatório foi projetado a partir de medições da vazão de entrada de ácido no tanque do reator e o sinal de $\mathrm{pH}$ foi linearizado, antes de ser utilizado no algoritmo de controle. Adicionalmente, compararam os resultados do controlador proposto com os de um controlador auto-sintonizante. Os resultados dos dois controladores foram satisfatórios e apresentaram desempenhos equivalentes.

Como a dinâmica do pH pode ser decomposta em componentes linear e não-linear, alguns pesquisadores propuseram a utilização de um observador de estados para estimar seus componentes lineares, a partir de medições de pH, que são não-lineares. Jutila, Orava e Salmelin (1981) e Jutila e Visala (1984) combinaram um estimador de Kalman com um algoritmo adaptativo para projetar um controlador para um processo de neutralização de $\mathrm{pH}$ industrial. Adicionalmente, eles concluíram que o controle adaptativo é necessário, caso o influente possua uma composição desconhecida ou variante no tempo. Girardot (1989) utilizou a teoria de invariantes de reação e um estimador de Kalman para projetar um controlador linear. Este controlador foi aplicado experimentalmente em uma planta piloto de neutralização de $\mathrm{pH}$, apresentando um resultado satisfatório.

Henson e Seborg (1994) também sugeriram a utilização de um observador de estados e um algoritmo adaptativo, para determinar a concentração dos compostos de um reator de neutralização de pH. Devido ao fato da planta linearizada não ser observável, sugeriram a utilização de um observador de malha aberta, combinado com a estimação de parâmetros via mínimos quadrados. Para validar o controle, realizaram experimentos em que a composição do influente variava no tempo, demandando que o observador se adequasse à nova composição do influente. Com base em resultados experimentais, concluíram que o controlador proposto apresentou um desempenho melhor que um controlador PID, através 
de um experimento.

Biagiola e Figueroa (2002) desenvolveram um observador de estados não-linear, utilizando a função derivativa de Lie e provaram que o erro de estimação diminuía exponencialmente, através de equações de Lyapunov. Adicionalmente, aplicaram o observador em um modelo simulado de uma planta de neutralização de pH para estimar os invariantes de reação. Ademais, projetaram um controlador preditivo baseado no modelo do processo e das estimações do observador. Por fim, através de simulações, demonstraram que o controlador possui desempenho satisfatório, bem como é robusto no que diz respeito a ruídos de medição.

Yoo, Lee e Yang (2004) exploraram o desempenho do Filtro de Kalman Estendido (EKF - do Inglês, Extended Kalman Filter), para estimar os estados de uma planta de neutralização de pH. Este observador é caracterizado pela linearização do modelo a cada instante de tempo, com o objetivo de melhorar o desempenho do observador de Kalman para plantas não-lineares. Eles demonstraram, por meio de simulações e experimentos, que o EKF estimou corretamente os estados de uma planta de neutralização de $\mathrm{pH}$ variante no tempo. Desta forma, sugeriram que este observador pode ser utilizado para projeto de controladores através da realimentação de estados.

Glaria et al. (2012) desenvolveram um método simples para o projeto de um observador de estados para sistemas não-lineares, com a função entrada-saída implícita, utilizando uma estrutura comumente empregada na construção de observadores de estados para sistemas lineares. Ademais, estimaram os invariantes de reação de uma planta de neutralização de pH simulada, para ilustrar a aplicação do observador, demonstrando a eficiência do método proposto.

Muitos pesquisadores enfatizaram o fato de que frequentemente os processos de neutralização de $\mathrm{pH}$ apresentam características variantes no tempo. Assim, é natural que muitos pesquisadores tenham utilizado algoritmos de controle adaptativo para superar esta dificuldade. Pajunen (1987) simulou uma planta de neutralização de pH, na qual a composição do influente variava no tempo e demonstrou que não era possível controlá-la com um controlador PID. Em seguida, testou controladores adaptativos baseados em modelo (MRAC - do Inglês, Model Reference Adaptive Control) e auto-sintonizantes, sendo que apenas o primeiro foi estável. Por fim, concluiu que a variação não-linear do MRAC é menos robusta que a linear, quando a composição do influente muda frequentemente.

Williams, Rhinehart e Riggs (1990) simularam um processo de neutralização de pH em reator tubular, sendo que os influentes eram ácidos e possuíam composição incerta e variante no tempo. Para o controle do pH, eles utilizaram um Controlador Baseado em Modelo do Processo (PMBC - do Inglês, Process-Model-Based Control). A dinâmica do reator foi desprezada, devido ao baixo tempo de residência do reator e as concentrações e constantes de equilíbrio do influente eram estimadas através do método dos mínimos 
quadrados. Por meio de simulações, demonstraram que o controlador proposto apresentou resultados satisfatórios.

Gustafsson e Waller (1992) também exploraram a utilização de controladores adaptativos para obter resultados satisfatórios, quando a planta de neutralização de $\mathrm{pH}$ apresenta características variantes no tempo. Eles sugeriram que, de maneira geral, o controlador de $\mathrm{pH}$ pode ser classificado entre linear ou não-linear com parâmetros fixos ou adaptativos. Entre os controladores de parâmetro fixo, eles sugeriram que o controle linear é o mais indicado quando as características do processo são incertas. Dentre os controladores adaptativos (baseados em modelo), concluíram que os lineares apresentam uma robustez maior que os não-lineares, já que os não-lineares necessitam de informações em diferentes estados de operação da planta para estimar corretamente seus parâmetros, o que é difícil de ser alcançado na prática.

Yoon et al. (2002) projetaram um controlador para uma planta de neutralização de $\mathrm{pH}$ variante no tempo, utilizando um observador de estados não-linear e um método de controle adaptativo baseado na técnica de backstepping e provaram matematicamente a estabilidade do sistema em malha fechada. Através de simulações, provaram que o controlador proposto apresentava desempenho melhor que um controlador não linear e não adaptativo.

Wright, Soroush e Kravaris (1991) e Wright e Kravaris (1991) obtiveram a realização de mínima ordem para o processo de neutralização de pH, através da manipulação matemática dos invariantes de reação. A partir desta realização, que utiliza a curva de titulação do processo, puderam projetar um observador de malha aberta para estimar a concentração de ácido fraco dissociado presente no sistema, ou como definido por eles, ácido forte equivalente. Com bases nesta estimativa, que pode ser realizada através de um estimador ou um titulador automático, pode-se utilizar um controlador linear para obter bons resultados, independentemente do valor de referência do pH. Adicionalmente, demonstraram experimentalmente que este método possui certa robustez com respeito a variações nas características do influente, como a inclusão de um ácido forte. O método proposto por Wright e Kravaris (1991) assume que a curva de titulação do processo é estática. Apesar de terem demonstrado que o controlador é robusto para incertezas de modelagem, seu desempenho é degradado caso a curva de titulação do processo difira da curva de titulação utilizada para estimar o ácido forte equivalente. Desta forma, para melhorar o desempenho do controlador para plantas de neutralização de pH com características variantes no tempo, Sung e Lee (1995b) propuseram a utilização de um reator de titulação. O objetivo deste reator é obter uma curva de titulação a partir de uma amostra dos influentes, para utilizá-la no controlador. Assim, a curva de titulação utilizada pelo controlador é atualizada constantemente, fazendo com que este se adapte às características da planta. Concluíram, através da análise de simulações, que o método proposto apresenta bom desempenho, mesmo quando a planta possui características variantes no tempo. 
Outro método visou prover adaptabilidade ao controlador baseado em ácido forte equivalente e foi desenvolvido por Sung e Lee (1995a). Eles desenvolveram um algoritmo para identificar, com base no método dos mínimos quadrados, a curva de titulação de uma planta de neutralização de pH durante sua operação normal, através de uma pequena excitação no valor de referência do controlador. A identificação da curva de titulação consistiu na estimativa da concentração e da constante de equilíbrio de dois ácidos fracos hipotéticos e em posse da curva de titulação, desenvolveram um controlador baseado em ácido forte equivalente. Como a excitação era realizada em uma frequência previamente determinada, concluíram que este algoritmo é aconselhável apenas para plantas que variam lentamente no tempo. Por fim, demonstraram por meio de simulações, que o algoritmo de identificação da curva de titulação gera resultados adequados.

Wright e Kravaris (2001) também exploraram a adaptabilidade do controlador que haviam proposto anteriormente. Para tanto, utilizaram um algoritmo para identificar a curva de titulação do processo em uma pequena faixa de $\mathrm{pH}$, através da estimação de duas constantes de dissociação de dois ácidos fracos hipotéticos. Tendo estimado estes parâmetros, puderam aplicar o método de controle baseado em ácido forte equivalente. Este controlador foi testado em uma planta industrial com características variantes no tempo, apresentando resultados satisfatórios durante quatro anos, o que demonstrou a robustez do método.

Tan et al. (2005) utilizaram um algoritmo genético para identificar a curva de titulação de um planta de neutralização de pH com características constantes, aplicando-a em um controlador similar ao proposto no método de controle por ácido forte equivalente. Através de experimentos, evidenciaram que a resposta do controlador proposto resultou em um melhor desempenho que um controlador PID convencional, sintonizado pelo método de Ziegler-Nichols.

A lógica de controle fuzzy também é bastante explorada na literatura. Um controlador fuzzy regula o processo através de conhecimentos empíricos da planta. Karr e Gentry (1993) mostraram, por meio de simulações, que uma lógica de controle fuzzy com parâmetros fixos não é adequada para regular uma planta de neutralização de pH com características variantes no tempo. Para solucionar este problema, propuseram um controlador em que as funções da lógica fuzzy fossem modificadas de acordo com a dinâmica da planta, utilizando um algoritmo genético. Por fim, demonstraram através de simulações, que o algoritmo genético melhora o desempenho do controlador fuzzy, quando a planta é variante no tempo.

Ibrahim (2008) empregou o método fuzzy para desenvolver um algoritmo de controle combinando realimentação e pré-alimentação (feedforward). O controlador foi desenvolvido e testado em ambiente simulado para então ser aplicado para regular o $\mathrm{pH}$ de uma planta piloto de neutralização de $\mathrm{pH}$, de características invariantes no tempo. Pela análise 
dos resultados experimentais, demonstrou que o algoritmo de controle fuzzy apresentou desempenho superior a um controlador PID convencional. Entretanto, concluiu que para empregar a metodologia fuzzy, é necessário um conhecimento extenso da planta a ser controlada.

Åkesson et al. (2005) desenvolveram um controlador MPC não-linear para um simulador de uma planta de neutralização de $\mathrm{pH}$ de características constantes. Com o objetivo de minimizar a demanda computacional do controlador MPC, treinaram uma rede neural com dados obtidos a partir da excitação da planta em malha fechada, controlada pelo MPC não-linear. Por meio de simulações, demonstraram que a rede neural apresenta desempenho equivalente ao apresentado pelo MPC não-linear.

Galán, Romagnoli e Palazoglu (2000) utilizaram a técnica de controle robusto $H^{\infty}$ para projetar o controlador de uma planta piloto de neutralização de pH. Para aplicar a técnica, compartimentaram o modelo da planta de neutralização de $\mathrm{pH}$ em vários modelos lineares e projetaram um controlador que garantisse os requisitos de controle para cada um dos modelos lineares. Concluíram, com base em dados experimentais, que o controlador proposto apresentava desempenho superior quando comparado a um PID convencional. 


\section{Descrição da Planta Piloto de Neutraliza- ção de pH do LCPI}

A Planta Piloto de Neutralização de pH do LCPI, ou apenas Planta Piloto, foi construída com o intuito de representar, em escala reduzida, as condições encontradas em uma aplicação industrial. Desta forma, seus sensores, instrumentos, atuadores, controladores e equipamentos possuem as mesmas características dos encontrados na indústria. Isto é relevante pois, conforme visto no Capítulo 2, algumas pesquisas relacionadas a controle de pH são conduzidas apenas em ambiente simulado, desconsiderando os componentes estocásticos nas medições e dinâmicas da planta e as incertezas de modelagem. Ainda, existem pesquisas que são desenvolvidas em escala laboratorial, reduzindo as perturbações que podem estar presentes nos processos de grande escala, como por exemplo imperfeições na mistura do reator.

Este capítulo descreve o funcionamento e os equipamentos utilizados na Planta Piloto, a qual pode ser vista na Figura 3.1.

Figura 3.1 - Foto da Planta Piloto de Neutralização de pH do LCPI.

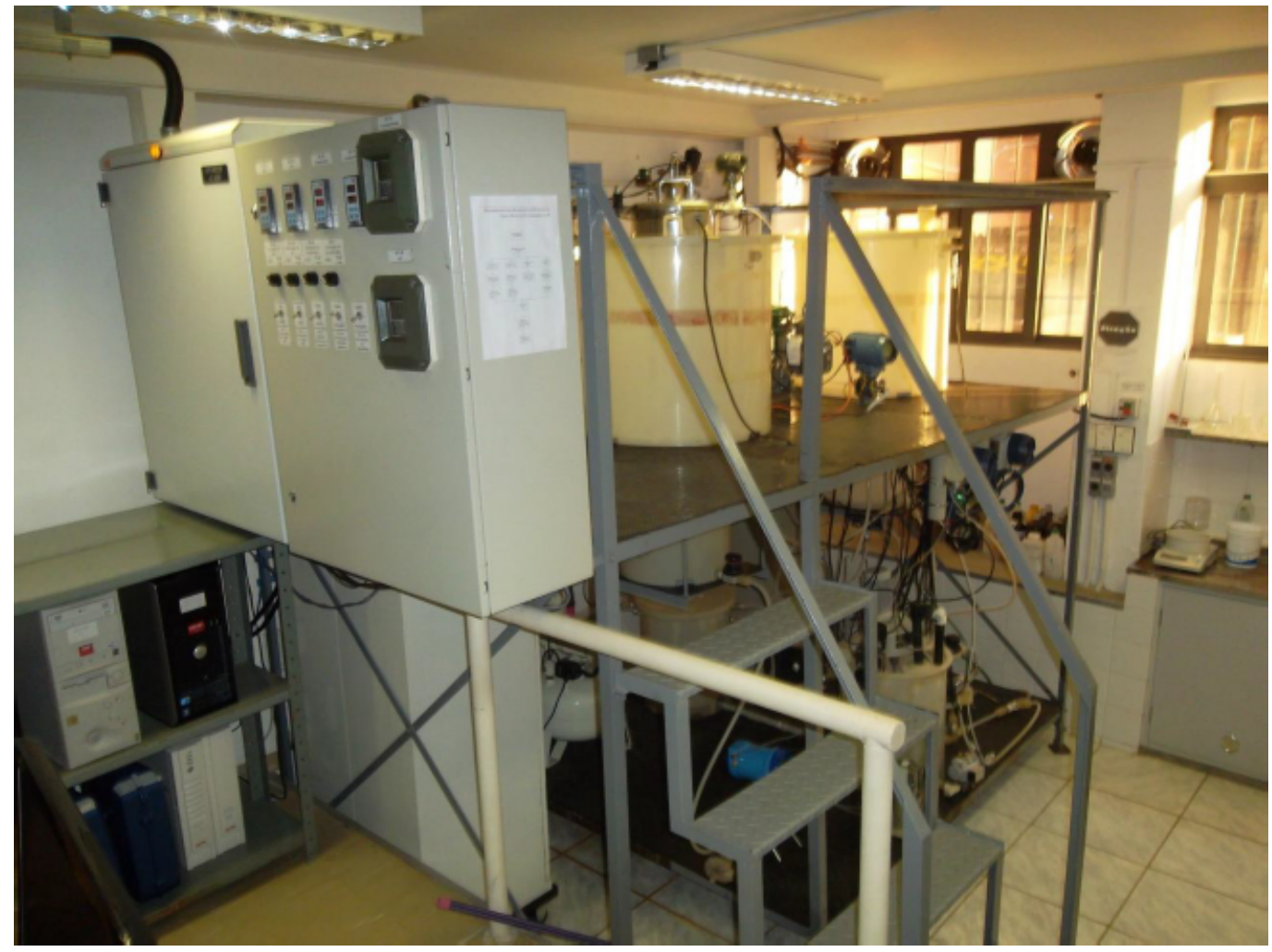

Fonte: Salvático (2012). 


\subsection{Descrição Funcional}

A planta piloto é composta de um Tanque do Reator (TR), onde ocorre a reação de neutralização. Para homogeneizar a solução, o TR é agitado mecanicamente, através de um propulsor naval impulsionado por um motor elétrico (MZ-81) de 255 W. O nível do TR é medido através de um transmissor e indicador de nível (LIT-10) e é controlado através de uma válvula solenoide (LV-16A). O controlador de nível (LIC-16) abre e fecha a válvula LV-16A, de modo a manter o nível do TR próximo a um Valor de Referência (SP - do Inglês, Setpoint). A Figura 3.2 apresenta o P\&ID (do Inglês, Piping and Instrumentation Diagram) da Planta Piloto.

Figura 3.2 - P\&ID da Planta Piloto.

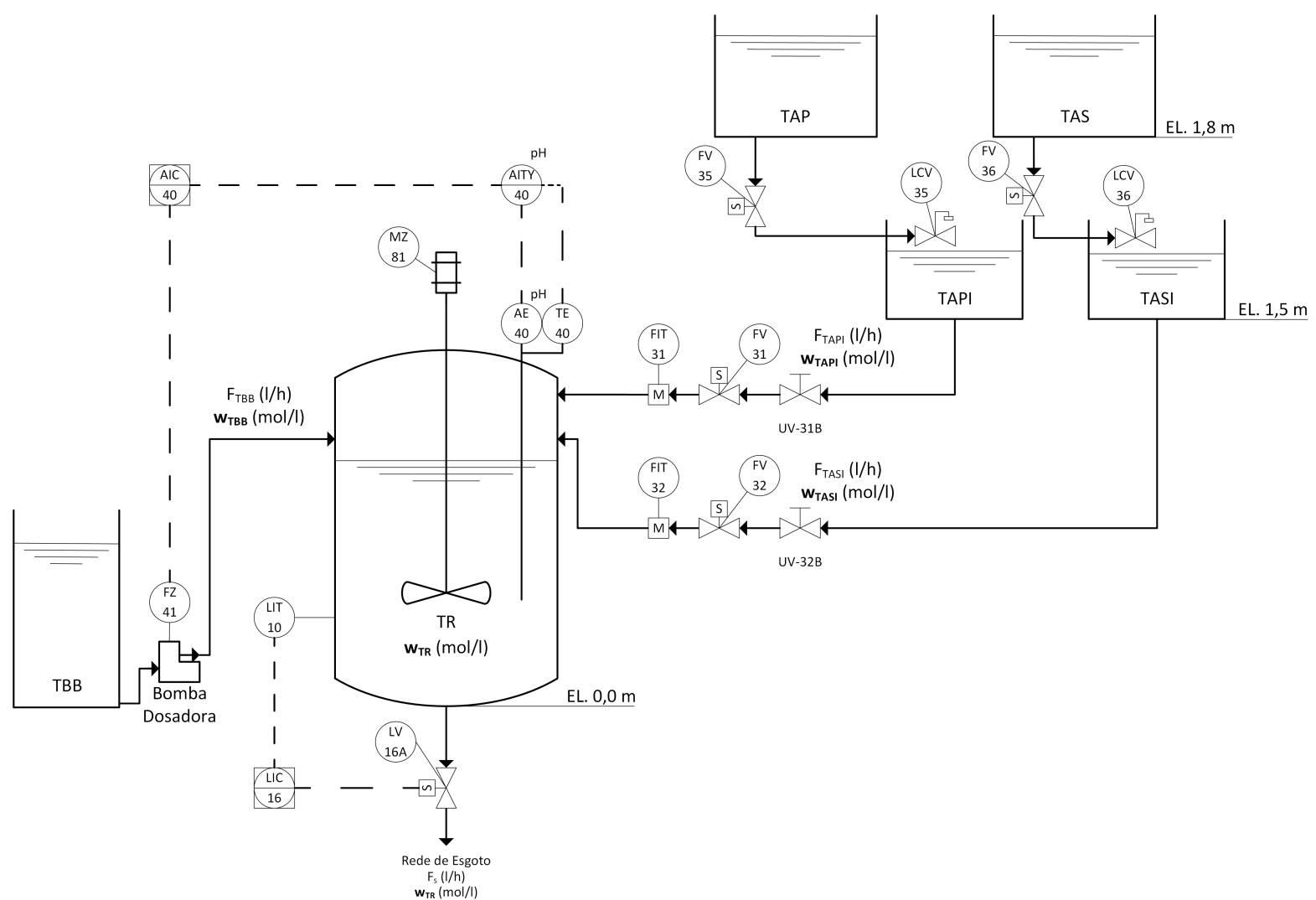

Adaptado de: Juliani (2011).

As soluções influentes são preparadas em três tanques principais: o Tanque de Ácido Principal (TAP), o Tanque de Ácido Secundário (TAS) e o Tanque de Base para a Bomba (TBB), todos com volume igual a 180 l. Assim, percebe-se que é possível preparar duas soluções ácidas distintas (simulando dois influentes de composições diferentes) e um tipo de solução básica.

A solução preparada no TAP flui, devido à diferença de elevação, para o Tanque de Ácido Principal Intermediário (TAPI). Uma válvula solenoide, localizada na linha de conexão destes tanques (FV-35), possibilita que o operador libere a vazão entre os tanques. Em operação normal, a FV-35 fica aberta. O TAPI possui uma válvula com boia (LCV-35), 
a qual mantém seu nível constante, enquanto houver fluido no TAP. A solução contida no TAPI flui para o TR, também devido à diferença de elevação, sendo um influente para o TR. Na linha de conexão destes tanques estão instaladas uma válvula manual (UV-31B) e uma válvula solenoide (FV-31), em série. Em operação normal, a UV-31B é mantida em determinada abertura e a FV-31 é comandada de maneira a permitir ou bloquear a vazão da solução do TAPI para o TR. A vazão do TAPI para o TR depende da abertura da UV-31B e é medida por um transmissor magnético de vazão (FIT-31). Estando a UV-31B fixada em determinado valor, a vazão do TAPI para o TR é constante, devido ao nível constante no TAPI. Excetuando-se as identificações dos instrumentos, as mesmas funcionalidades podem ser estendidas para TAS e o Tanque de Ácido Secundário Intermediário (TASI), conforme pode ser visto na Figura 3.2.

Já a solução preparada no TBB flui para o TR através de uma bomba dosadora (FZ-41). O pH do TR é medido através de um sensor de pH (AE-40) e o transmissor de pH (AITY-40) corrige automaticamente a medição de pH em relação a variações de temperatura (TE-40). A vazão da solução básica é ajustada através de um sinal de controle, gerado por um controlador de pH (AIC-40), com objetivo de manter o pH no TR em um valor de referência.

As soluções da Planta Piloto são preparadas utilizando-se água filtrada, proveniente do sistema de distribuição público. Nesta dissertação são utilizadas três soluções: (i) Ácido Clorídrico, no TAP (influente); (ii) Ácido Acético, no TAS (influente) e (iii) Hidróxido de Sódio, no TBB (reagente).

Um Sistema Digital de Controle Distribuído (SDCD), da marca ABB ${ }^{\circledR}$, modelo 800xA, é utilizado para realizar as funções de controle e aquisição de dados da planta. A operação da Planta Piloto se dá através de uma Interface Homem Máquina (HMI do Inglês, Human Machine Interface), construído em plataforma proprietária da $\mathrm{ABB}^{\circledR}$. Ademais, um servidor OLE for Process Control (OPC) possibilita a troca de informações entre a Planta Piloto e softwares de computação matemática, como o Matrix Laboratory ${ }^{\circledR}$ $\left(\right.$ MATLAB $\left.^{\circledR}\right)$. Neste trabalho, toda a aquisição de sinais e controle automático da planta piloto são realizados através do MATLAB ${ }^{\circledR}$.

Adicionalmente, a Planta Piloto possui um sistema de segurança, implementado em um Controlador Lógico Programável (CLP), da marca Rockwell ${ }^{\circledR}$, modelo SLC 500. O sistema de segurança garante que os limites de projeto da planta piloto não sejam excedidos, minimizando o risco de perda de materiais devido a falha humana ou de mau funcionamento de equipamentos. 


\subsection{Soluções Utilizadas na Planta Piloto}

A Planta Piloto pode operar com até três soluções distintas. O TAP tem uma capacidade de 180 l e a sua solução é preparada com ácido clorídrico, que é um ácido forte, com fórmula química $\mathrm{HCl}$, de forma a obter uma concentração de 0,0056 mol/l. O TAS também possui capacidade de 180 l, porém sua solução é preparada com ácido acético, que é um ácido fraco, com fórmula química $\mathrm{CH}_{3} \mathrm{COOH}$, de modo a obter uma concentração de 0,0068 mol/l. Por fim, o TBB tem capacidade de 180 l e sua solução é preparada com hidróxido de sódio, que é uma base forte e tem fórmula química $\mathrm{NaOH}$, de forma a obter uma concentração de $0,0185 \mathrm{~mol} / \mathrm{l}$. A combinação destas três soluções permite a simulação de um processo de neutralização de $\mathrm{pH}$ com características variantes no tempo. As vazões máximas das soluções estão apresentadas na Tabela 3.1.

Tabela 3.1 - Vazões máximas e concentrações das soluções da Planta Piloto.

\begin{tabular}{lcc}
\hline Solução & Vazão Máxima & Concentração \\
\hline Ácido Clorídrico & $50 \mathrm{l} / \mathrm{h}$ & $0,0056 \mathrm{~mol} / \mathrm{l}$ \\
Ácido Acético & $50 \mathrm{l} / \mathrm{h}$ & $0,0068 \mathrm{~mol} / 1$ \\
Hidróxido de Sódio & $30 \mathrm{l} / \mathrm{h}$ & $0,0185 \mathrm{~mol} / \mathrm{l}$ \\
\hline
\end{tabular}

Fonte: do Autor.

As concentrações de ácido acético e clorídrico utilizadas na Planta Piloto foram escolhidas de forma a possibilitar a simulação de um processo de neutralização de $\mathrm{pH}$, com o menor consumo de produtos químicos exequível. Já a concentração de hidróxido de sódio foi determinada de forma a possibilitar a neutralização do pH, quando ambos os influentes ácidos estiverem simultaneamente com vazão máxima.

\subsection{Tanque do Reator}

A reação de neutralização ocorre dentro do TR, sendo importante que os reagentes e influentes sejam perfeitamente homogenizados para favorecer a reação. A forma do reator e o método empregado para sua homogenização influem na eficiência da mistura do reator. O TR possui forma cilíndrica, fundo achatado e apresenta chicanas. As chicanas são utilizadas para gerar turbulências, melhorando assim a homogeneidade da mistura. No entanto, os reatores químicos normalmente possuem fundo abaulado, o que contribui para a homogenização dos influentes, pois evita o surgimento de regiões sem agitação. O impelidor empregado para homogeneizar o TR é do tipo propulsão naval, gerando um fluxo axial, o qual é ideal para a mistura de líquidos. Devido à forma geométrica do TR, espera-se que sua homogeneidade não seja ideal.

Ramos (2013) analisou as características do TR e, objetivando uma melhora na homogeneidade do fluido, sugeriu que o SP do nível do TR fosse elevado para $37 \mathrm{~cm}$ 
(medido da base do reator até a superfície do fluido) e que a velocidade do impelidor fosse aumentada para $800 \mathrm{rpm}$ (anteriormente estes valores eram de $32 \mathrm{~cm}$ e $400 \mathrm{rpm}$, respectivamente). As características do TR, após terem sido adotadas estas sugestões, são apresentadas na Tabela 3.2.

Tabela 3.2 - Principais características do TR.

\begin{tabular}{ll}
\hline Característica & Valor \\
\hline Diâmetro interno (T) & $40 \mathrm{~cm}$ \\
Altura & $50 \mathrm{~cm}$ \\
Diâmetro do impelidor (D) & $10,5 \mathrm{~cm}$ \\
Distância entre o fundo do TR e o impelidor (C) & $15 \mathrm{~cm}$ \\
Altura do fluido (Z) & $37 \mathrm{~cm}$ \\
Largura das chicanas (B) & $4 \mathrm{~cm}$ \\
Velocidade do impelidor & $800 \mathrm{rpm}$ \\
\hline
\end{tabular}

Fonte: do Autor.

Geralmente, a escolha das dimensões de um reator segue algumas regras empíricas, baseadas em relações geométricas. Na prática, se estas regras são atendidas, o reator tende a apresentar uma mistura homogênea. A Tabela 3.3 apresenta uma comparação entre as relações sugeridas na literatura (ALBRIGHT, 2008) e as do TR.

Tabela 3.3 - Comparação das relações geométricas do TR com as sugeridas na literatura.

\begin{tabular}{ccc}
\hline Relação & TR & Ideal \\
\hline $\mathrm{D} / \mathrm{T}$ & 0,2625 & de $1 / 4$ a $1 / 2$ \\
$\mathrm{Z} / \mathrm{T}$ & 0,925 & 1 \\
$\mathrm{C} / \mathrm{T}$ & 0,375 & de $1 / 6$ a $1 / 2$ \\
$\mathrm{~B} / \mathrm{T}$ & 0,1 & de $1 / 12$ a $1 / 10$ \\
\hline Relações ideais de Albright (2008).
\end{tabular}

Assim, percebe-se que as relações geométricas do TR estão dentro da faixa sugerida na literatura, ou muito próximo destas, como é o caso da relação Z/T.

\subsection{Bomba Dosadora}

A bomba dosadora (FZ-41), de fabricação da Pulsafeeder ${ }^{\circledR}$, modelo LPK7, é do tipo pistão (ou diafragma) e seu princípio de funcionamento é através de um solenoide. Quando desenergizada, a solenoide retorna à posição inicial, permitindo o preenchimento do êmbolo com a solução básica. Quando energizada, a solenoide força a saída da solução contida no êmbolo. A vazão da bomba dosadora é regulada, portanto, através da frequência de acionamento da solenoide. A vazão de saída da bomba pode ser aproximada como uma função linear da frequência de acionamento da solenoide e esta é, por sua vez, função linear do sinal de controle de 4-20 mA, proveniente do SDCD. A vazão da bomba pode 
ser aproximada como

$$
F_{b}(t)=\frac{S \cdot C(t)}{10000} F_{\max },
$$

onde $F_{b}(t)$ é a vazão de saída da bomba, $S$ é a regulagem da distância de curso da solenoide em $\%, C(t)$ é o sinal de controle do SDCD em \% e $F_{\text {max }}$ é a vazão máxima da bomba.

A vazão máxima da bomba é obtida quando seu sinal de controle é máximo e, por consequência, a frequência de acionamento de sua solenoide é máxima. É possível calibrar a vazão máxima da bomba através da regulagem do curso do pistão. O manual da bomba dosadora afirma que sua vazão máxima é de $30,3 \mathrm{l} / \mathrm{h}$, entretanto enfatiza que este valor é válido apenas quando a pressão à jusante da bomba é de 3,3 bar. Como a descarga da bomba está à pressão ambiente (aproximadamente 1 bar), foi necessário calibrar a bomba. Após a calibração, a curva da bomba foi obtida experimentalmente, conforme Figura 3.3.

Figura 3.3 - Curva da bomba dosadora, após sua calibração.

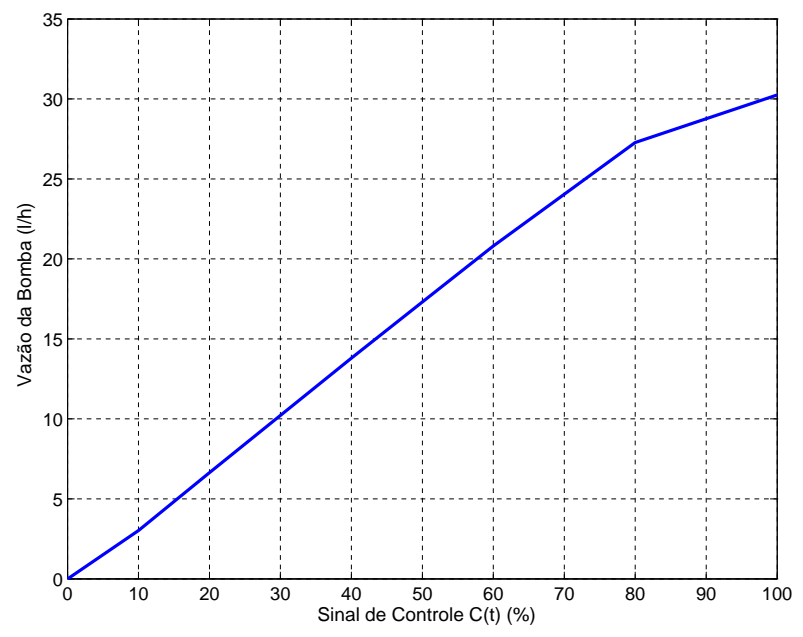

Fonte: do Autor.

Para determinar se a vazão de saída da bomba dosadora é função de sua pressão à montante, realizou-se um experimento. Caso esta hipótese se confirme, com uma mesma frequência de operação, a vazão da bomba dosadora diferirá quando o nível do TBB está alto ou baixo. A Tabela 3.4 exibe o resultado de um experimento realizado com o objetivo de determinar se o nível do TBB teria grande influência na vazão de saída da bomba dosadora. Percebe-se que o nível do TBB não interfere significativamente na vazão de saída da bomba dosadora. 
Tabela 3.4 - Vazão de saída da bomba dosadora, com uma mesma frequência de operação, quando o TBB está com diferentes níveis.

\begin{tabular}{cc}
\hline Nível do TBB & Vazão \\
\hline Nível Máximo & $12,08 \mathrm{l} / \mathrm{h}$ \\
$1 / 2$ do Nível Máximo & $11,88 \mathrm{l} / \mathrm{h}$ \\
$1 / 16$ do Nível Máximo & $11,86 \mathrm{l} / \mathrm{h}$ \\
\hline \multicolumn{2}{c}{ Fonte: do Autor. }
\end{tabular}

\subsection{Medidor de $\mathrm{pH}$}

O elemento sensor de $\mathrm{pH}$ (AE-40) é do tipo eletrodo de vidro e foi fabricado pela Yokogawa $^{\circledR}$, modelo PH8EPR. Sua precisão é de $\pm 0,15$ pH e seu tempo de resposta (a 90\% do valor final) é de 10 segundos. O transmissor de pH, modelo PH202G, recebe informações da temperatura do processo através do sensor TE-40 e a utiliza em um algoritmo para correção do desvio na medição do $\mathrm{pH}$, com respeito às variações na temperatura do processo.

\subsection{Medidores de Vazão}

Os medidores da vazão de saída do TAPI e TASI (FIT-31 e FIT-32) são do tipo magnético e foram fabricados pela Tecnofluid ${ }^{\circledR}$, modelo Flomid-MX. O manual do medidor afirma que sua precisão é de $\pm 0,5 \%$ do valor medido e sua faixa de medição é de 0 - 100 l/h, porém não possui informações a respeito de seu tempo de resposta.

\subsection{Medidor de Nível}

O medidor de nível do TR é do tipo pressão diferencial e foi fabricado pela Yokogawa ${ }^{\circledR}$, modelo EJA110A. Conforme o manual do medidor, sua precisão é de $\pm 0,0065 \%$ do fundo de escala e sua faixa de medição é de 0 - 100\% do nível do TR, ou seja, 0 - 0,5 m. O tempo de resposta do medidor não está discriminado em seu manual.

\subsection{Válvula Solenoide}

A válvula de saída do TR é pneumática, atuada por uma solenoide e foi fabricada pela $\operatorname{VARB}^{\circledR}$. O corpo da válvula é de ${ }^{1 / 2}$ polegada e é do tipo globo. O fabricante não disponibiliza o tempo de resposta da válvula. 


\section{Fundamentos Teóricos para a Modelagem da Planta Piloto}

A modelagem dinâmica de uma reação de neutralização ocorrendo em um reator é uma atividade que envolve a aplicação de conhecimentos multidisciplinares, como termodinâmica, equilíbrio químico, cinética de reações, eletroquímica e fluidodinâmica. Neste capítulo, que foi baseado nos trabalhos de Castellan (1983), Rosemberg e Epstein (1997), Levenspiel (1999), Fogler (2004), Atkins e Paula (2010), McMillan e Cameron (2004), são expostos os princípios de Física e Química, relevantes para a modelagem da Planta Piloto. Adicionalmente, os Apêndices A e B fornecem informações complementares, relativas à Termodinâmica e medição de pH, respectivamente.

\subsection{Fundamentos de Ácidos e Bases}

Segundo a definição de Arrhenius (ROSEMBERG; EPSTEIN, 1997), um ácido é uma substância que se dissocia e libera um íon de hidrogênio $\left(\mathrm{H}^{+}\right.$, que é essencialmente um próton) quando dissolvido em uma solução. De maneira similar, uma base é uma substância que se dissocia quando dissolvida em solução, liberando uma molécula de hidroxila $\left(\mathrm{OH}^{-}\right)$.

O conceito de Arrhenius foi estendido por Brönsted-Lowry (ROSEMBERG; EPSTEIN, 1997), definindo um ácido como uma substância que doa um próton a outra substância. Já uma base é uma substância que aceita um próton de um ácido. Desta forma, toda reação de dissociação gera um par ácido-base conjugado. Considere uma reação de dissociação de um ácido genérico, HA, ocorrendo na presença de um solvente genérico, $\mathrm{HB}$,

$$
\mathrm{HA}+\mathrm{HB} \rightleftharpoons \mathrm{A}^{-}+\mathrm{H}_{2} \mathrm{~B}^{+} .
$$

Nesta reação, $\mathrm{HA}-\mathrm{A}^{-}$e $\mathrm{H}_{2} \mathrm{~B}^{+}-\mathrm{HB}$ são os pares ácido-base conjugados. A base conjugada de HA tem sempre uma unidade de carga a menos que HA e o ácido conjugado de $\mathrm{H}_{2} \mathrm{~B}^{+}$tem sempre uma unidade de carga a mais que HB. As reações de dissociação são caracterizadas por atingirem um equilíbrio dinâmico, definido conforme o Apêndice A,

$$
\begin{gathered}
K_{a}=\frac{a_{\mathrm{A}^{-}} a_{\mathrm{H}_{2} \mathrm{~B}^{+}}}{a_{\mathrm{HA}} a_{\mathrm{HB}}} \approx \frac{\left[\mathrm{A}^{-}\right]\left[\mathrm{H}_{2} \mathrm{~B}^{+}\right]}{[\mathrm{HA}][\mathrm{HB}]} \\
K_{b}=\frac{a_{\mathrm{HA}} a_{\mathrm{B}^{-}}}{a_{\mathrm{A}^{-}} a_{\mathrm{HB}}} \approx \frac{[\mathrm{HA}]\left[\mathrm{B}^{-}\right]}{\left[\mathrm{A}^{-}\right][\mathrm{HB}]},
\end{gathered}
$$

onde o índice $a$ corresponde a um ácido genérico, o índice $b$ corresponde a uma base genérica, $K_{a}$ é a constante de equilíbrio de dissociação do ácido, $K_{b}$ é a constante de equilíbrio de associação da base e o colchete corresponde à concentração molar da substância, em 
mol/l. Note que, como a reação ocorre nos sentidos direto e reverso, é possível caracterizar a reação pela constante de dissociação de ácido ou de sua respectiva base conjugada. Adicionalmente, para soluções diluídas, pode-se desprezar o coeficiente de atividade das substâncias.

Um ácido forte é aquele que possui uma constante de dissociação grande. Ácidos fortes são aqueles que possuem $K_{a}>10^{2}$, o que equivale a dizer que, na prática, todos os reagentes são convertidos em produtos. Conclui-se, então, que um ácido forte se dissocia completamente na solução. Por outro lado, se $K_{a}<10^{2}$, o ácido é fraco, o que significa que o ácido se dissocia parcialmente na solução. O mesmo argumento pode ser estendido para bases fortes e fracas, porém utilizando a constante de dissociação de base $K_{b}$.

\subsubsection{Auto-lonização da Água e Potencial Hidrogeniônico}

A água é uma substância anfiprótica, ou seja, ela se comporta como ácido e base, podendo aceitar ou doar prótons de outras substâncias. Além disso, a água apresenta um processo de auto-ionização, que também possui uma constante de equilíbrio:

$$
2 \mathrm{H}_{2} \mathrm{O}_{(\mathrm{l})} \rightleftharpoons \mathrm{H}_{3} \mathrm{O}_{(\mathrm{aq})}^{+}+\mathrm{OH}^{-}{ }_{(\mathrm{aq})} \text {. }
$$

Note que as notações $\mathrm{H}^{+}$e $\mathrm{H}_{3} \mathrm{O}^{+}$são equivalentes. Entretanto, a última é mais correta, visto que o próton interage com as outras moléculas da água, devido ao fato destas serem polares. A constante de equilíbrio da água é

$$
K_{w}=a_{\mathrm{H}_{3} \mathrm{O}^{+}} a_{\mathrm{OH}^{-}} \approx\left[\mathrm{H}_{3} \mathrm{O}^{+}\right]\left[\mathrm{OH}^{-}\right]
$$

onde o índice $w$ corresponde a água. Note que a água como solvente não foi considerada no cálculo da constante de equilíbrio do processo de auto-ionização da água. Esta aproximação pode ser feita para soluções diluídas, visto que a fração molar da água é muito próxima da unidade. A constante de equilíbrio da água à temperatura de $25{ }^{\circ} \mathrm{C}$ e pressão de $1 \mathrm{~atm}$ é $K_{w}=1,00 \cdot 10^{-14}$.

A água pura é considerada neutra, pois a concentração de íons $\mathrm{H}_{3} \mathrm{O}^{+}$e $\mathrm{OH}^{-}$é equivalente. Neste caso, à temperatura de $25^{\circ} \mathrm{Ce}$ pressão de $1 \mathrm{~atm}$,

$$
\left[\mathrm{H}_{3} \mathrm{O}^{+}\right]\left[\mathrm{OH}^{-}\right]=\sqrt{1,00 \cdot 10^{-14}}=1,00 \cdot 10^{-7} .
$$

Uma solução é considerada ácida se $\left[\mathrm{H}_{3} \mathrm{O}^{+}\right]>10^{-7}$ e é considerada básica se $\left[\mathrm{H}_{3} \mathrm{O}^{+}\right]<10^{-7}$. A constante de equilíbrio de auto-ionização da água, na Eq. (4.5), sugere que a concentração do íon de hidrogênio pode variar dentro da faixa $10^{0} \leq\left[\mathrm{H}_{3} \mathrm{O}^{+}\right] \leq 10^{-14}$. Como a faixa de concentrações que o $\mathrm{H}_{3} \mathrm{O}^{+}$pode apresentar é extensa, é comum utilizar uma escala logarítmica para medir sua concentração. Desta forma, introduz-se o conceito de potencial hidrogeniônico $(\mathrm{pH})$, definido como:

$$
\mathrm{pH}=-\log \left[\mathrm{H}_{3} \mathrm{O}^{+}\right] \quad \text { e } \quad\left[\mathrm{H}_{3} \mathrm{O}^{+}\right]=10^{-\mathrm{pH}} .
$$


De maneira similar, define-se o potencial dos íons $\left[\mathrm{OH}^{-}\right]$como:

$$
\mathrm{pOH}=-\log \left[\mathrm{OH}^{-}\right] \quad \text { e } \quad\left[\mathrm{OH}^{-}\right]=10^{-\mathrm{pOH}} .
$$

É conveniente representar as constantes de equilíbrio de base e de ácido na forma $p K_{i}=-\log K_{i}$, podendo o índice $i$ se referir a ácido, base ou água. Portanto, a constante de equilíbrio da reação de auto-ionização da água pode ser escrita como:

$$
\mathrm{pH}+\mathrm{pOH}=-\log K_{w}=p K_{w}=14 .
$$

\subsubsection{Soluções Aquosas}

Considere as reações envolvidas na dissociação de um ácido fraco em solução aquosa diluída, ocorrendo à temperatura de $25^{\circ} \mathrm{C}$ e pressão de 1 atm:

$$
\begin{gathered}
2 \mathrm{H}_{2} \mathrm{O}_{(\mathrm{l})} \stackrel{K_{w}}{\rightleftharpoons} \mathrm{H}_{3} \mathrm{O}_{(\mathrm{aq})}^{+}+\mathrm{OH}_{(\mathrm{aq})}^{-} \\
\mathrm{HA}_{(\mathrm{aq})}+\mathrm{H}_{2} \mathrm{O}_{(\mathrm{l})} \stackrel{K_{a}}{\rightleftharpoons} \mathrm{H}_{3} \mathrm{O}_{(\mathrm{aq})}^{+}+\mathrm{A}_{(\mathrm{aq})}^{-}
\end{gathered}
$$

A reação líquida é:

$$
\mathrm{HA}_{(\mathrm{aq})}+3 \mathrm{H}_{2} \mathrm{O}_{(\mathrm{l})} \rightleftharpoons \mathrm{A}_{(\mathrm{aq})}^{-}+2 \mathrm{H}_{3} \mathrm{O}_{(\mathrm{aq})}^{+}+\mathrm{OH}_{(\mathrm{aq})}^{-}
$$

As constantes de equilíbrio podem ser escritas como:

$$
\begin{gathered}
K_{w}=\frac{\left[\mathrm{H}_{3} \mathrm{O}^{+}\right]\left[\mathrm{OH}^{-}\right]}{\left[\mathrm{H}_{2} \mathrm{O}\right]^{2}} \\
K_{a}=\frac{\left[\mathrm{A}^{-}\right]\left[\mathrm{H}_{3} \mathrm{O}^{+}\right]}{[\mathrm{HA}]\left[\mathrm{H}_{2} \mathrm{O}\right]} \\
K_{b}=\frac{[\mathrm{HA}]\left[\mathrm{OH}^{-}\right]}{\left[\mathrm{A}^{-}\right]\left[\mathrm{H}_{2} \mathrm{O}\right]} \\
K_{l i q}=\frac{\left[\mathrm{A}^{-}\right]\left[\mathrm{H}_{3} \mathrm{O}^{+}\right]^{2}\left[\mathrm{OH}^{-}\right]}{[\mathrm{HA}]\left[\mathrm{H}_{2} \mathrm{O}\right]^{3}},
\end{gathered}
$$

onde o índice liq corresponde à constante de equilíbrio da reação líquida no sentido direto. Note que a água está em grande excesso, com fração molar aproximadamente igual à unidade, podendo ser desconsiderada no cálculo das constantes de equilíbrio. Analisando-se as constantes de equilíbrio, percebe-se que:

$$
K_{l i q}=K_{w} K_{a} \quad \text { e } \quad K_{a} K_{b}=K_{w}
$$

Conforme as Subseções A.5.5 e A.5.6, a variação da energia de Gibbs de uma reação, ocorrendo à pressão e temperatura constantes é:

$$
\mathrm{d} G=\mathrm{d} \xi \nu_{1} \mu_{1}+\mathrm{d} \xi \nu_{2} \mu_{2}=\mathrm{d} G_{1}+\mathrm{d} G_{2}
$$


sendo os índices 1 e 2 correspondentes ao solvente e ao soluto, respectivamente. Porém, sabe-se que:

$$
\begin{gathered}
\mathrm{d} G_{1}=\mathrm{d} \xi\left(\nu_{w} \mu_{w}+\nu_{\mathrm{H}^{+}} \mu_{\mathrm{H}^{+}}+\nu_{\mathrm{OH}^{-}} \mu_{\mathrm{OH}^{-}}\right) \\
\mathrm{d} G_{2}=\mathrm{d} \xi\left(n_{s} \mu_{s}+n_{\mathrm{H}^{+}} \mu_{\mathrm{H}^{+}}+n_{\mathrm{A}^{-}} \mu_{\mathrm{A}^{-}}\right),
\end{gathered}
$$

sendo os índices $w$ e $s$ referentes à água pura e ao soluto puro, respectivamente. $\mathrm{Na}$ condição de equilíbrio químico, a energia de Gibbs deve ser mínima, ou seja,

$$
\left(\frac{\mathrm{d} G}{\mathrm{~d} \xi}\right)_{e q}=\left(\frac{\mathrm{d} G_{1}}{\mathrm{~d} \xi}\right)_{e q}+\left(\frac{\mathrm{d} G_{2}}{\mathrm{~d} \xi}\right)_{e q}=0 .
$$

A Eq. (4.14) indica que o equilíbrio químico do sistema é atingido quando as constantes de equilíbrio de cada reação individual - auto-ionização da água e dissociação do ácido HA - forem satisfeitas.

\subsection{3 Ácidos e Bases Polipróticos}

Um ácido poliprótico possui dois ou mais átomos de hidrogênio, que podem se dissociar quando dissolvidos em uma solução. Cada dissociação é representada individualmente, possuindo uma constante de equilíbrio. Suponha um ácido fraco com três prótons passíveis de dissociação, em solução aquosa diluída:

$$
\begin{aligned}
& \mathrm{H}_{3} \mathrm{~A}_{(\mathrm{aq})}+\mathrm{H}_{2} \mathrm{O}_{(\mathrm{l})} \stackrel{K_{a 1}}{\rightleftharpoons} \mathrm{H}_{2} \mathrm{~A}_{(\mathrm{aq})}^{-}+\mathrm{H}_{3} \mathrm{O}^{+}{ }_{(\mathrm{aq})} \\
& \mathrm{H}_{2} \mathrm{~A}_{(\mathrm{aq})}^{-}+\mathrm{H}_{2} \mathrm{O}_{(\mathrm{l})} \stackrel{K_{a 2}}{\rightleftharpoons} \mathrm{HA}^{2-}{ }_{(\mathrm{aq})}+\mathrm{H}_{3} \mathrm{O}_{(\mathrm{aq})}^{+} \\
& \mathrm{HA}^{2-}{ }_{(\mathrm{aq})}+\mathrm{H}_{2} \mathrm{O}_{(\mathrm{l})} \stackrel{K_{a 3}}{\rightleftharpoons} \mathrm{A}^{3-}{ }_{(\mathrm{aq})}+\mathrm{H}_{3} \mathrm{O}^{+}{ }_{(\mathrm{aq})} .
\end{aligned}
$$

As constantes de dissociação são definidas como:

$$
\begin{aligned}
K_{a 1} & =\frac{\left[\mathrm{H}_{2} \mathrm{~A}^{-}\right]\left[\mathrm{H}_{3} \mathrm{O}^{+}\right]}{\left[\mathrm{H}_{3} \mathrm{~A}\right]} \\
K_{a 2} & =\frac{\left[\mathrm{HA}^{2-}\right]\left[\mathrm{H}_{3} \mathrm{O}^{+}\right]}{\left[\mathrm{H}_{2} \mathrm{~A}^{-}\right]} \\
K_{a 3} & =\frac{\left[\mathrm{A}^{3-}\right]\left[\mathrm{H}_{3} \mathrm{O}^{+}\right]}{\left[\mathrm{HA}^{2-}\right]} .
\end{aligned}
$$

A ordem de grandeza das constantes de dissociação é sempre $K_{a 3}<K_{a 2}<K_{a 1}$. Neste ponto, deve estar claro que $\left[\mathrm{H}_{3} \mathrm{O}^{+}\right]$é a concentração do íon de hidrogênio presente na solução, sendo que cada ácido contido na solução, seja ele forte ou fraco, contribui para a concentração do íon de hidrogênio na solução.

As bases polipróticas são definidas de forma análoga: são bases que têm duas ou mais constantes de associação. Note que é possível escrever as reações na forma direta ou reversa. Isto dá a possibilidade de transformar a constante de associação de determinada base em constante de dissociação de seu ácido conjugado, conforme a Eq. (4.10). 
Analisando-se constantes de equilíbrio do ácido fraco, é possível obter informações importantes da dinâmica da associação/dissociação do ácido fraco. Caso ocorra um aumento na concentração de $\mathrm{H}_{3} \mathrm{O}^{+}$, a reação ocorrerá no processo reverso, acarretando em um aumento na concentração dos reagentes através da associação de moléculas previamente dissociadas. Por outro lado, se a concentração de $\mathrm{H}_{3} \mathrm{O}^{+}$diminui, a reação tende a gerar mais produtos, dissociando mais moléculas do ácido fraco.

\subsubsection{Soluções Tampão}

Se o pH de uma solução não se modificar significativamente com uma pequena adição de ácidos e bases, é dito que esta é uma solução tampão. Este tipo de comportamento é apresentado por soluções que possuam grandes quantidades de um determinado ácido fraco e sua respectiva base conjugada. Suponha um solução composta de um determinado ácido fraco monoprótico e de um sal que se dissocie, produzindo a base conjugada do ácido fraco em questão:

$$
\begin{gathered}
\mathrm{HA}_{(\mathrm{aq})}+\mathrm{H}_{2} \mathrm{O}_{(\mathrm{l})} \stackrel{K_{a}}{\rightleftharpoons} \mathrm{A}^{-}{ }_{(\mathrm{aq})}+\mathrm{H}_{3} \mathrm{O}^{+}{ }_{(\mathrm{aq})} \\
\mathrm{BA}_{(\mathrm{aq})}+\mathrm{H}_{2} \mathrm{O}_{(\mathrm{l})} \longrightarrow \mathrm{A}^{-}{ }_{(\mathrm{aq})}+\mathrm{B}^{+}{ }_{(\mathrm{aq})} .
\end{gathered}
$$

A constante de equilíbrio $K_{a}$ do ácido fraco é:

$$
K_{a}=\frac{\left[\mathrm{A}^{-}\right]\left[\mathrm{H}_{3} \mathrm{O}^{+}\right]}{[\mathrm{HA}]}
$$

Analisando-se a Eq. (4.15), percebe-se que caso um ácido seja misturado na solução, parte dos íons de hidrogênio adicionados irão se combinar com a base conjugada, aumentando a concentração do ácido. De maneira similar, se uma base for adicionada na solução, parte das moléculas de hidroxila adicionados irão se combinar com o ácido, aumentando a concentração da base conjugada. Assim, a solução tampão mantém sua concentração de $\mathrm{H}_{3} \mathrm{O}^{+}$aproximadamente constante.

Isolando-se o íon de hidrogênio e extraindo-se o logaritmo da Eq. (4.15), resulta em uma relação entre o pH da solução e as concentrações do ácido e de sua base conjugada:

$$
\mathrm{pH}=p K_{a}+\log \frac{\left[\mathrm{A}^{-}\right]}{[\mathrm{HA}]}
$$

Como ácidos fracos são caracterizados por sua dissociação parcial, a Eq. (4.16) sugere que estes também se comportam como uma solução tampão, quando o pH da solução está próximo do valor de $p K_{a}$ do ácido (CHRISTIAN, 2004). A diferença é, apenas, que uma solução de ácido fraco possui uma capacidade menor de manter o pH da solução constante, quando comparado a uma solução contendo ácido fraco e um sal com sua respectiva base conjugada. 


\subsubsection{Reações de Neutralização}

Quando uma pequena quantidade de base forte é adicionada a uma solução contendo ácido forte, a condição de equilíbrio da água é desfeita. A condição de equilíbrio químico é estabelecida novamente, com a associação dos íons $\mathrm{OH}^{-}$excedentes com os íons $\mathrm{H}_{3} \mathrm{O}^{+}$, produzindo água. Caso a base seja adicionada continuamente, quando o número de mols de $\mathrm{H}_{3} \mathrm{O}^{+}$proveniente do ácido for igual ao número de mols de $\mathrm{OH}^{-}$proveniente da base, a condição neutra $(\mathrm{pH}=7)$ é atingida. Neste ponto, $\left[\mathrm{H}_{3} \mathrm{O}^{+}\right]=\left[\mathrm{OH}^{-}\right]$e a solução não apresenta as características ácidas que possuía inicialmente. Se, a partir deste ponto, a base continuar a ser adicionada, a solução passará a apresentar características básicas.

Suponha uma solução aquosa de $\mathrm{HCl}$, sendo neutralizada por uma solução aquosa de $\mathrm{NaOH}$. As reações envolvidas são:

$$
\begin{gathered}
\mathrm{HCl}(\mathrm{aq})+\mathrm{H}_{2} \mathrm{O}(\mathrm{l}) \rightleftharpoons \mathrm{Cl}-(\mathrm{aq})+\mathrm{H}_{3} \mathrm{O}^{+}(\mathrm{aq}) \\
\mathrm{NaOH}(\mathrm{aq}) \rightleftharpoons \mathrm{Na}^{+}(\mathrm{aq})+\mathrm{OH}-(\mathrm{aq}) \\
2 \mathrm{H}_{2} \mathrm{O}(\mathrm{l}) \rightleftharpoons \mathrm{H}_{3} \mathrm{O}^{+}(\mathrm{aq})+\mathrm{OH}-(\mathrm{aq}) .
\end{gathered}
$$

Considerando-se que o $\mathrm{HCl}$ e o $\mathrm{NaOH}$ estão completamente dissociados na solução, a reação de neutralização é:

$$
\mathrm{Na}^{+}(\mathrm{aq})+\mathrm{OH}-(\mathrm{aq})+\mathrm{Cl}-(\mathrm{aq})+\mathrm{H}_{3} \mathrm{O}^{+}(\mathrm{aq}) \rightleftharpoons \mathrm{Na}^{+}(\mathrm{aq})+\mathrm{Cl}-(\mathrm{aq})+2 \mathrm{H}_{2} \mathrm{O}(\mathrm{l}) .
$$

Assim, a reação de neutralização (ou reação ácido-base) líquida é:

$$
\mathrm{OH}-(\mathrm{aq})+\mathrm{H}_{3} \mathrm{O}^{+}(\mathrm{aq}) \rightleftharpoons 2 \mathrm{H}_{2} \mathrm{O}(\mathrm{l})
$$

Caso ácidos e bases fracos estivessem envolvidos na reação, suas respectivas reações de dissociação teriam que ser incluídas na reação de neutralização líquida.

\subsubsection{Invariantes de Reação}

A teoria referente a invariantes de reação é importante para análise, modelagem e controle de reações químicas, pois facilita a solução numérica do sistema (WALLER; MÄKILÄ, 1981). Para a modelagem de pH, a abordagem através de invariantes de reação é interessante, pois facilita a solução numérica de sistemas com vários ácidos e bases.

Suponha um sistema descrito pela equação diferencial não-linear:

$$
\dot{\mathbf{x}}(t)=f(\mathbf{x}(t), \mathbf{u}(t), t),
$$

sendo $\mathbf{x} \in \Re^{n}$ o vetor de estados do sistema, $\mathbf{u} \in \Re^{p}$ um vetor de entrada, $f: \Re^{n} \times p \rightarrow \Re^{n}$ uma função contínua e $t \geq 0$. Por definição, uma solução invariante verdadeira da Eq. (4.17) é uma função do vetor de estados, $h(\mathbf{x})$, tal que:

$$
h(\mathbf{x})=\nabla_{\dot{\mathbf{x}}} h(\mathbf{x})=\nabla_{f} h(\mathbf{x})=0 .
$$


Se $\lim _{t \rightarrow \infty} \nabla_{f} h(\mathbf{x}) \rightarrow 0$, então a função $h(\mathbf{x})$ é denominada solução assintoticamente invariante da Eq. (4.17). Se $\mathbf{x}(t)$ for o vetor de estados de um reator químico, então a função $h(\mathbf{x})$ é denominada invariante de reação, verdadeira ou assintótica (FJELD; ASBJORNSEN; ÅSTRÖM, 1974). Assim, uma função invariante de reação não é afetada pela reação química que ocorre no sistema.

Existem métodos matemáticos para decompor o vetor de estados de um reator em um componente variante e outro invariante. No entanto, os invariantes de reação originam-se dos princípios fundamentais de conservação de massa, energia, carga, etc. que são comumente empregados na análise de sistemas (WALLER; MÄKILÄ, 1981). Os invariantes de reação são construídos de forma a facilitar a solução numérica do sistema, podendo ser transformados ao final destes cálculos para obter-se as variáveis de interesse.

\subsubsection{Emprego dos Invariantes de Reação na Modelagem de pH}

A modelagem de reatores químicos para uso em controle, usualmente, se baseia na obtenção de equações diferenciais das variáveis de interesse do reator, como por exemplo, a concentração de certa substância. Em um reator de neutralização de pH, é evidente que a concentração do íon de hidrogênio é a principal variável de interesse, bem como a concentração de cada ácido ou base presente no sistema. Adicionalmente, pode-se ter interesse em variáveis que interfiram no processo de neutralização, como a temperatura da solução e a concentração dos íons presentes na solução. Por hora, suponha que as variações de temperatura e da concentração dos íons possa ser desprezada. Caso a reação envolva apenas ácidos e bases fortes, a concentração dos íons de hidrogênio no reator pode ser obtida através do princípio da conservação de massa, conforme abordado em (JACOBS; HEWKIN; WHILE, 1980). Supondo que a mistura do reator seja ideal, que a reação de neutralização ocorra instantaneamente, que a solução que entra no reator possua a mesma densidade que a solução presente no reator e que os ácidos e bases fortes estejam completamente dissociados, então:

$$
V_{r} \frac{\mathrm{d}\left(\left[\mathrm{H}_{3} \mathrm{O}^{+}\right]-\left[\mathrm{OH}^{-}\right]\right)_{r}}{\mathrm{~d} t}=\left(\left[\mathrm{H}_{3} \mathrm{O}^{+}\right]-\left[\mathrm{OH}^{-}\right]\right)_{e} \frac{\mathrm{d} V_{e}}{\mathrm{~d} t}-\left(\left[\mathrm{H}_{3} \mathrm{O}^{+}\right]-\left[\mathrm{OH}^{-}\right]\right)_{r} \frac{\mathrm{d} V_{s}}{\mathrm{~d} t}
$$

sendo $V_{r}$ o volume do reator, $V_{e}$ o volume que entra no reator, $V_{s}$ o volume que sai do reator e os índices $r$, e e $s$ correspondentes ao reator, entrada e saída, respectivamente. Após o balanço de massa, pode-se utilizar a constante de equilíbrio da água, $K_{w}$, para calcular os valores de $\left[\mathrm{H}_{3} \mathrm{O}^{+}\right]$e $\left[\mathrm{OH}^{-}\right]$(JACOBS; HEWKIN; WHILE, 1980).

Note que o fato do sistema possuir apenas ácidos e bases fortes facilita a obtenção da equação de estados do reator, pois estes podem ser considerados totalmente dissociados, eliminando a necessidade de se calcular numericamente a condição de equilíbrio de diversas reações. Este é o caso mais simples no emprego dos invariantes de reação para a modelagem de $\mathrm{pH}$, sendo que esta formulação inicial é generalizada a seguir. 
Gustafsson (1982), Gustafsson e Waller (1983) desenvolveram a teoria para obter os invariantes de reação de uma reação de neutralização de pH. Apesar de terem sido os primeiros a utilizar a teoria de Álgebra Linear para determinar os invariantes das reações de neutralização, outras pesquisas, como as de McAvoy (1972a) e Jutila, Orava e Salmelin (1981), já haviam chegado a resultados semelhantes, utilizando os princípios de conservação de massa e carga. O desenvolvimento dos invariantes de reação de uma reação de neutralização genérica é apresentado a seguir, utilizando os princípios de conservação de massa e carga, conforme visto em Gustafsson e Waller (1992), pois propicia um entendimento melhor do que ocorre fisicamente no sistema.

Considere uma reação de neutralização genérica, em solução aquosa diluída, contendo $\alpha$ ácidos e bases fracos, $\beta$ ácidos fortes e $\gamma$ bases fortes. Suponha ainda que todas as reações de associação das bases fracas foram transformadas em reações de dissociação de seus ácidos conjugados. Assim, a reação de neutralização do sistema é:

$$
\begin{gathered}
2 \mathrm{H}_{2} \mathrm{O}_{(\mathrm{l})} \rightleftharpoons \mathrm{H}_{3} \mathrm{O}^{+}{ }_{(\mathrm{aq})}+\mathrm{OH}^{-}{ }_{(\mathrm{aq})} \\
\mathrm{H}_{3} \mathrm{~A}_{\mathrm{i}(\mathrm{aq})}+\mathrm{H}_{2} \mathrm{O}_{(\mathrm{l})} \stackrel{K_{a_{\mathrm{i}, 1}}}{\rightleftharpoons} \mathrm{H}_{2} \mathrm{~A}_{\mathrm{i}}{ }_{(\mathrm{aq})}+\mathrm{H}_{3} \mathrm{O}^{+}{ }_{(\mathrm{aq})} \\
\mathrm{H}_{2} \mathrm{~A}_{\mathrm{i}}{ }_{(\mathrm{aq})}+\mathrm{H}_{2} \mathrm{O}_{(\mathrm{l})} \stackrel{K_{a_{\mathrm{i}, 2}}}{\rightleftharpoons} \mathrm{HA}_{\mathrm{i}}{ }^{2-}{ }_{(\mathrm{aq})}+\mathrm{H}_{3} \mathrm{O}^{+}{ }_{(\mathrm{aq})} \\
\mathrm{HA}_{\mathrm{i}}{ }^{2-}{ }_{(\mathrm{aq})}+\mathrm{H}_{2} \mathrm{O}_{(\mathrm{l})} \stackrel{K_{a_{\mathrm{i}, 3}}}{\rightleftharpoons} \mathrm{A}_{\mathrm{i}}{ }^{3-}{ }_{(\mathrm{aq})}+\mathrm{H}_{3} \mathrm{O}^{+}{ }_{(\mathrm{aq})},
\end{gathered}
$$

onde a letra $A_{i}$ corresponde à fórmula química do ácido fraco $i$ e $K_{a_{i, n}}$ representa a constante de dissociação número $n$ do ácido fraco $i$. Independentemente do grau de dissociação dos ácidos fracos (e bases fracas), aplicando-se a lei da conservação de massa, pode-se concluir que:

$$
\left[\mathrm{H}_{3} \mathrm{~A}_{\mathrm{i}}\right]+\left[\mathrm{H}_{2} \mathrm{~A}_{\mathrm{i}}^{-}\right]+\left[\mathrm{HA}_{\mathrm{i}}^{2-}\right]+\left[\mathrm{A}_{\mathrm{i}}^{3-}\right]=\text { constante }
$$

para todos os $\alpha$ ácidos fracos presentes no sistema. Ou seja, a função da Eq. (4.20) é invariante da reação de neutralização do sistema e corresponde ao valor da concentração total do ácido fraco $i$ presente no sistema, caso todas suas moléculas estivessem completamente associadas.

Considerando que os ácidos e bases fortes estão completamente dissociados na solução, que é uma aproximação plausível, tem-se:

$$
\begin{gathered}
\mathrm{HAf}_{\mathrm{k}(\mathrm{aq})}+\mathrm{H}_{2} \mathrm{O}_{(\mathrm{l})} \longrightarrow \mathrm{Af}_{\mathrm{k}}{ }_{(\mathrm{aq})}+\mathrm{H}_{3} \mathrm{O}^{+}{ }_{(\mathrm{aq})} \\
\mathrm{Bf}_{\mathrm{j}} \mathrm{OH}_{(\mathrm{aq})}+\mathrm{H}_{2} \mathrm{O}_{(\mathrm{l})} \longrightarrow \mathrm{Bf}_{\mathrm{j}}^{+}{ }_{(\mathrm{aq})}+\mathrm{OH}^{-}{ }_{(\mathrm{aq})}+\mathrm{H}_{2} \mathrm{O}_{(\mathrm{l})},
\end{gathered}
$$

onde $\mathrm{Af}_{\mathrm{k}}$ é a fórmula química do ácido forte $k$ e $\mathrm{Bf}_{\mathrm{j}}$ é a fórmula química da base forte $j$. Assim, a soma de todos os íons dos diversos ácidos fortes presentes no sistema é uma constante. De forma análoga, a soma de todos os íons de bases fortes presentes no sistema 
também é uma constante,

$$
\sum_{\mathrm{k}=1}^{\beta}\left[\mathrm{Af}_{\mathrm{k}}{ }^{-}\right]=\text {constante } \quad \text { e } \sum_{\mathrm{j}=1}^{\gamma}\left[\mathrm{Bf}_{\mathrm{j}}^{+}\right]=\text {constante }
$$

Pode-se concluir, então, que as funções da Eq. (4.21) também são invariantes da reação de neutralização.

De acordo com o princípio da conservação de carga, a soma de todos os íons de uma determinada solução deve ser igual a zero, portanto:

$$
\sum_{\mathrm{j}=1}^{\gamma}\left[\mathrm{Bf}_{\mathrm{j}}^{+}\right]+\left[\mathrm{H}_{3} \mathrm{O}^{+}\right]=\sum_{\mathrm{k}=1}^{\beta}\left[\mathrm{Af}_{\mathrm{k}}{ }^{-}\right]+\sum_{\mathrm{i}=1}^{\alpha}\left[\mathrm{H}_{2} \mathrm{~A}_{\mathrm{i}}^{-}\right]+2 \sum_{\mathrm{i}=1}^{\alpha}\left[\mathrm{HA}_{\mathrm{i}}{ }^{2-}\right]+3 \sum_{\mathrm{i}=1}^{\alpha}\left[\mathrm{A}_{\mathrm{i}}{ }^{3-}\right]+\left[\mathrm{OH}^{-}\right]
$$

Rearranjando a Eq. (4.22), obtém-se:

$$
\sum_{\mathrm{k}=1}^{\beta}\left[\mathrm{Af}_{\mathrm{k}}^{-}\right]-\sum_{\mathrm{j}=1}^{\gamma}\left[\mathrm{Bf}_{\mathrm{j}}^{+}\right]=\left[\mathrm{H}_{3} \mathrm{O}^{+}\right]-\left[\mathrm{OH}^{-}\right]-\sum_{\mathrm{i}=1}^{\alpha}\left[\mathrm{H}_{2} \mathrm{~A}_{\mathrm{i}}^{-}\right]-2 \sum_{\mathrm{i}=1}^{\alpha}\left[\mathrm{HA}_{\mathrm{i}}{ }^{2-}\right]-3 \sum_{\mathrm{i}=1}^{\alpha}\left[\mathrm{A}_{\mathrm{i}}^{3-}\right] .
$$

Levando-se em consideração a Eq. (4.21), o lado esquerdo da igualdade da Eq. (4.23) é também um invariante da reação de neutralização. Assim, pode-se definir, convenientemente, um vetor de invariantes de reação, $\mathbf{w} \in \Re^{\alpha+1}$, como:

$$
\begin{aligned}
w_{1} & =\sum_{k=1}^{\beta}\left[\mathrm{Af}_{\mathrm{k}}{ }^{-}\right]-\sum_{j=1}^{\gamma}\left[\mathrm{Bf}_{\mathrm{j}}^{+}\right] \\
w_{\mathrm{i}+1} & =\left[\mathrm{H}_{3} \mathrm{~A}_{\mathrm{i}}\right]+\left[\mathrm{H}_{2} \mathrm{~A}_{\mathrm{i}}{ }^{-}\right]+\left[\mathrm{HA}_{\mathrm{i}}{ }^{2-}\right]+\left[\mathrm{A}_{\mathrm{i}}{ }^{3-}\right] \\
\vdots & \\
w_{\alpha+1} & =\left[\mathrm{H}_{3} \mathrm{~A}_{\alpha}\right]+\left[\mathrm{H}_{2} \mathrm{~A}_{\alpha}{ }^{-}\right]+\left[\mathrm{HA}_{\alpha}{ }^{2-}\right]+\left[\mathrm{A}_{\alpha}{ }^{3-}\right] .
\end{aligned}
$$

Analisando-se a Eq. (4.24), percebe-se que os invariantes de reação são funções lineares e independem de qualquer constante de equilíbrio, o que facilita a simulação numérica do sistema. No entanto, estes não fornecem informações a respeito das variáveis de interesse, como por exemplo o pH da solução. Assim sendo, é necessário obter uma relação entre os invariantes de reação e o pH da solução, utilizando-se as constantes de equilíbrio de cada ácido e base fracos e da Eq. (4.23). Note que pela definição dos invariantes da reação de neutralização,

$$
\begin{aligned}
w_{1}=\sum_{\mathrm{k}=1}^{\beta}\left[\mathrm{Af}_{\mathrm{k}}^{-}\right]-\sum_{\mathrm{j}=1}^{\gamma}\left[\mathrm{Bf}_{\mathrm{j}}^{+}\right] & \\
& {\left[\mathrm{H}_{3} \mathrm{O}^{+}\right]-\left[\mathrm{OH}^{-}\right]-\sum_{\mathrm{i}=1}^{\alpha}\left[\mathrm{H}_{2} \mathrm{~A}_{\mathrm{i}}^{-}\right]-2 \sum_{\mathrm{i}=1}^{\alpha}\left[\mathrm{HA}_{\mathrm{i}}{ }^{2-}\right]-3 \sum_{\mathrm{i}=1}^{\alpha}\left[\mathrm{A}_{\mathrm{i}}^{3-}\right] . }
\end{aligned}
$$


Considera-se que as concentrações dos ácidos e bases presentes no sistema, bem como suas respectivas constantes de equilíbrio sejam conhecidas. Assim, a função desejada deve relacionar a concentração de $\mathrm{H}_{3} \mathrm{O}^{+}$com o vetor de invariantes de reação, resultando em uma equação com uma incógnita. A concentração de $\mathrm{OH}^{-}$pode ser obtida facilmente através da constante de auto-ionização da água,

$$
\left[\mathrm{OH}^{-}\right]=\frac{K_{w}}{\left[\mathrm{H}_{3} \mathrm{O}^{+}\right]}
$$

Resta agora obter a relação entre o grau de dissociação dos $\alpha$ ácidos ou bases fracos, com seus respectivos invariantes de reação. Isto equivale a dizer que o objetivo é determinar uma função $f_{\mathrm{i}}: \Re \rightarrow \Re$, tal que:

$$
w_{\mathrm{i}+1} f_{\mathrm{i}}\left(\left[\mathrm{H}_{3} \mathrm{O}^{+}\right]\right)=\left[\mathrm{H}_{2} \mathrm{~A}_{\mathrm{i}}^{-}\right]+2\left[\mathrm{HA}_{\mathrm{i}}^{2-}\right]+3\left[\mathrm{~A}_{\mathrm{i}}^{3-}\right] .
$$

A obtenção da função $f_{\mathrm{i}}$ se inicia através da análise das constantes de equilíbrio dos ácidos e bases fracos, que por definição são:

$$
\begin{aligned}
K_{a_{\mathrm{i}, 1}} & =\frac{\left[\mathrm{H}_{2} \mathrm{~A}_{\mathrm{i}}^{-}\right]\left[\mathrm{H}_{3} \mathrm{O}^{+}\right]}{\left[\mathrm{H}_{3} \mathrm{~A}_{\mathrm{i}}\right]} \\
K_{a_{\mathrm{i}, 2}} & =\frac{\left[\mathrm{HA}_{\mathrm{i}}{ }^{2-}\right]\left[\mathrm{H}_{3} \mathrm{O}^{+}\right]}{\left[\mathrm{H}_{2} \mathrm{~A}_{\mathrm{i}}^{-}\right]} \\
K_{a_{\mathrm{i}, 3}} & =\frac{\left[\mathrm{A}_{\mathrm{i}}^{3-}\right]\left[\mathrm{H}_{3} \mathrm{O}^{+}\right]}{\left[\mathrm{HA}_{\mathrm{i}}^{2-}\right]} .
\end{aligned}
$$

A concentração de cada estágio de dissociação do ácido $\mathrm{H}_{3} \mathrm{~A}_{\mathrm{i}}$ pode ser calculada utilizandose a Eq. (4.27):

$$
\begin{aligned}
{\left[\mathrm{H}_{2} \mathrm{~A}_{\mathrm{i}}^{-}\right] } & =\frac{K_{a_{i, 1}}}{\left[\mathrm{H}_{3} \mathrm{O}^{+}\right]}\left[\mathrm{H}_{3} \mathrm{~A}_{\mathrm{i}}\right] \\
{\left[\mathrm{HA}_{\mathrm{i}}{ }^{2-}\right] } & =\frac{K_{a_{i, 2}}\left[\mathrm{H}_{2} \mathrm{~A}_{\mathrm{i}}^{-}\right]}{\left[\mathrm{H}_{3} \mathrm{O}^{+}\right]}=\frac{K_{a_{i, 1}} K_{a_{i, 2}}}{\left[\mathrm{H}_{3} \mathrm{O}^{+}\right]^{2}}\left[\mathrm{H}_{3}\right] \\
{\left[\mathrm{A}_{\mathrm{i}}{ }^{3-}\right] } & =\frac{K_{a_{i, 3}}\left[\mathrm{HA}_{\mathrm{i}}{ }^{2-}\right]}{\left[\mathrm{H}_{3} \mathrm{O}^{+}\right]}=\frac{K_{a_{i, 1}} K_{a_{i, 2}} K_{a_{i, 3}}}{\left[\mathrm{H}_{3} \mathrm{O}^{+}\right]^{3}}\left[\mathrm{H}_{3} \mathrm{~A}_{\mathrm{i}}\right] .
\end{aligned}
$$

Colocando-se $\mathrm{H}_{3} \mathrm{~A}_{\mathrm{i}}$ em evidência na Eq. (4.24), resulta:

$$
w_{\mathrm{i}+1}=\left(1+\frac{K_{a_{\mathrm{i}, 1}}}{\left[\mathrm{H}_{3} \mathrm{O}^{+}\right]}+\frac{K_{a_{\mathrm{i}, 1}} K_{a_{\mathrm{i}, 2}}}{\left[\mathrm{H}_{3} \mathrm{O}^{+}\right]^{2}}+\frac{K_{a_{\mathrm{i}, 1}} K_{a_{\mathrm{i}, 2}} K_{a_{\mathrm{i}, 3}}}{\left[\mathrm{H}_{3} \mathrm{O}^{+}\right]^{3}}\right)\left[\mathrm{H}_{3} \mathrm{~A}_{\mathrm{i}}\right] .
$$

A partir das Eq. (4.29) e (4.28), pode-se determinar a relação entre $w_{i+1}$ e a concentração de cada estágio de dissociação do ácido $i$,

$$
\begin{aligned}
{\left[\mathrm{H}_{2} \mathrm{~A}_{\mathrm{i}}^{-}\right] } & =w_{\mathrm{i}+1} \frac{K_{a_{\mathrm{i}, 1}}\left[\mathrm{H}_{3} \mathrm{O}^{+}\right]^{2}}{\left[\mathrm{H}_{3} \mathrm{O}^{+}\right]^{3}+K_{a_{\mathrm{i}, 1}}\left[\mathrm{H}_{3} \mathrm{O}^{+}\right]^{2}+K_{a_{\mathrm{i}, 1}} K_{a_{\mathrm{i}, 2}}\left[\mathrm{H}_{3} \mathrm{O}^{+}\right]+K_{a_{\mathrm{i}, 1}} K_{a_{\mathrm{i}, 2}} K_{a_{\mathrm{i}, 3}}} \\
{\left[\mathrm{HA}_{\mathrm{i}}{ }^{2-}\right] } & =w_{\mathrm{i}+1} \frac{K_{a_{\mathrm{i}, 1}} K_{a_{\mathrm{i}, 2}}\left[\mathrm{H}_{3} \mathrm{O}^{+}\right]}{\left[\mathrm{H}_{3} \mathrm{O}^{+}\right]^{3}+K_{a_{\mathrm{i}, 1}}\left[\mathrm{H}_{3} \mathrm{O}^{+}\right]^{2}+K_{a_{\mathrm{i}, 1}} K_{a_{\mathrm{i}, 2}}\left[\mathrm{H}_{3} \mathrm{O}^{+}\right]+K_{a_{\mathrm{i}, 1}} K_{a_{\mathrm{i}, 2}} K_{a_{\mathrm{i}, 3}}} \\
{\left[\mathrm{~A}_{\mathrm{i}}^{3-}\right] } & =w_{\mathrm{i}+1} \frac{K_{a_{\mathrm{i}, 1}} K_{a_{\mathrm{i}, 2}} K_{a_{\mathrm{i}, 3}}}{\left[\mathrm{H}_{3} \mathrm{O}^{+}\right]^{3}+K_{a_{\mathrm{i}, 1}}\left[\mathrm{H}_{3} \mathrm{O}^{+}\right]^{2}+K_{a_{\mathrm{i}, 1}} K_{a_{\mathrm{i}, 2}}\left[\mathrm{H}_{3} \mathrm{O}^{+}\right]+K_{a_{\mathrm{i}, 1}} K_{a_{\mathrm{i}, 2}} K_{a_{\mathrm{i}, 3}}} .
\end{aligned}
$$


Combinando-se os resultados da Eq. (4.30), chega-se ao objetivo apresentado na Eq. (4.26),

$$
\begin{aligned}
{\left[\mathrm{H}_{2} \mathrm{~A}_{\mathrm{i}}^{-}\right]+2\left[\mathrm{HA}_{\mathrm{i}}^{2-}\right]+3\left[\mathrm{~A}_{\mathrm{i}}{ }^{3-}\right]=} \\
w_{\mathrm{i}+1} \frac{K_{a_{\mathrm{i}, 1}}\left[\mathrm{H}_{3} \mathrm{O}^{+}\right]^{2}+2 K_{a_{\mathrm{i}, 1}} K_{a_{\mathrm{i}, 2}}\left[\mathrm{H}_{3} \mathrm{O}^{+}\right]+3 K_{a_{\mathrm{i}, 1}} K_{a_{\mathrm{i}, 2}} K_{a_{\mathrm{i}, 3}}}{\left[\mathrm{H}_{3} \mathrm{O}^{+}\right]^{3}+K_{a_{\mathrm{i}, 1}}\left[\mathrm{H}_{3} \mathrm{O}^{+}\right]^{2}+K_{a_{\mathrm{i}, 1}} K_{a_{\mathrm{i}, 2}}\left[\mathrm{H}_{3} \mathrm{O}^{+}\right]+K_{a_{\mathrm{i}, 1}} K_{a_{\mathrm{i}, 2}} K_{a_{\mathrm{i}, 3}}}
\end{aligned}
$$

Dividindo-se o numerador e o denominador do lado direito da Eq. (4.31) por $K_{a_{\mathrm{i}, 1}}\left[\mathrm{H}_{3} \mathrm{O}^{+}\right]^{2}$, obtém-se a função $f_{\mathrm{i}}\left(\left[\mathrm{H}_{3} \mathrm{O}^{+}\right]\right)$na forma mais comumente utilizada:

$$
f_{\mathrm{i}}\left(\left[\mathrm{H}_{3} \mathrm{O}^{+}\right]\right)=\frac{1+2 K_{a_{\mathrm{i}, 2}}\left[\mathrm{H}_{3} \mathrm{O}^{+}\right]^{-1}+3 K_{a_{\mathrm{i}, 2}} K_{a_{\mathrm{i}, 3}}\left[\mathrm{H}_{3} \mathrm{O}^{+}\right]^{-2}}{1+K_{a_{\mathrm{i}, 1}}^{-1}\left[\mathrm{H}_{3} \mathrm{O}^{+}\right]+K_{a_{\mathrm{i}, 2}}\left[\mathrm{H}_{3} \mathrm{O}^{+}\right]^{-1}+K_{a_{\mathrm{i}, 2}} K_{a_{\mathrm{i}, 3}}\left[\mathrm{H}_{3} \mathrm{O}^{+}\right]^{-2}} .
$$

Assim, pode-se escrever a relação entre os invariantes de reação e $\left[\mathrm{H}_{3} \mathrm{O}^{+}\right]$,

$$
w_{1}=g\left(\left[\mathrm{H}_{3} \mathrm{O}^{+}\right]\right)-\sum_{\mathrm{i}=1}^{\alpha} w_{\mathrm{i}+1} f_{\mathrm{i}}\left(\left[\mathrm{H}_{3} \mathrm{O}^{+}\right]\right),
$$

sendo:

$$
g\left(\left[\mathrm{H}_{3} \mathrm{O}^{+}\right]\right)=\left[\mathrm{H}_{3} \mathrm{O}^{+}\right]-\frac{10^{-14}}{\left[\mathrm{H}_{3} \mathrm{O}^{+}\right]} .
$$

Para ácidos monopróticos, atribui-se o valor zero para as constantes de equilíbrio $K_{a_{\mathrm{i}, 2}}$ e $K_{a_{\mathrm{i}, 3}}$. Para ácidos dipróticos, atribui-se o valor zero para a constante de equilíbrio $K_{a_{\mathrm{i}, 3}}$.

É possível, também, relacionar os invariantes da reação de neutralização diretamente com o pH da solução, utilizando-se as relações obtidas na Subseção 4.1.1, resultando em uma equação conhecida como equação do pH:

$$
w_{1}=A(\mathrm{pH})-\sum_{\mathrm{i}=1}^{\alpha} w_{\mathrm{i}+1} a_{\mathrm{i}}(\mathrm{pH})
$$

onde

$$
\begin{aligned}
& A(\mathrm{pH})=10^{-\mathrm{pH}}-10^{\mathrm{pH}-14} \mathrm{e}
\end{aligned}
$$

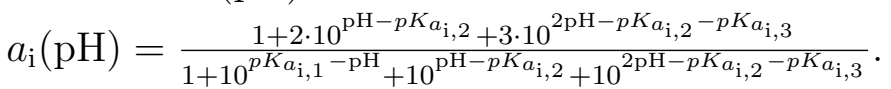

Para ácidos monopróticos, atribui-se o valor infinito para as constantes de equilíbrio $p K_{a_{i, 2}}$ e $p K_{a_{i, 3}}$. Para ácidos dipróticos, atribui-se o valor infinito para a constante de equilíbrio $p K_{a_{i, 3}}$.

\subsubsection{Curvas de Titulação}

No presente momento, deve estar evidente que os invariantes de reação são utilizados, por serem uma função linear. A determinação dos invariantes de reação de uma mistura de inúmeras soluções é a média ponderada pelo volume dos invariantes de reação de cada solução individual, ou seja,

$$
\mathbf{w}_{\text {sol }}=\frac{1}{V_{\text {sol }}} \sum_{k=1}^{m} V_{k} \mathbf{w}_{k}
$$


onde $\mathbf{w}_{\text {sol }} \in \Re^{n}$ é o vetor de invariantes de reação de uma solução obtida através da mistura de $m$ soluções, $V_{\text {sol }}$ é o volume resultante após a mistura de todas as soluções, $V_{k}$ é o volume da solução $k$ e $\mathbf{w}_{k} \in \Re^{n}$ é o vetor de invariantes de reação da solução $k$. Após a obtenção do vetor de invariantes de reação da mistura, $\mathbf{w}_{\text {sol }}$, pode-se calcular o pH da solução através da Eq. (4.35).

As curvas de titulação são construídas através da mistura de duas soluções, nomeadas titulante e titulado. O titulado é uma solução de concentração a ser determinada, ao passo que o titulante é uma solução que possui concentração conhecida. A mistura das soluções é realizada gradativamente e, para cada quantidade de volume de titulante adicionado ao titulado, mede-se o valor de pH resultante da solução. A partir dos dados de volume de titulante adicionado e pH resultante da solução, constrói-se um gráfico. A Figura 4.1 é uma curva de titulação típica, encontrada em reações de neutralização com ácidos e bases fortes, e foi construída através da simulação de um experimento de titulação, utilizando-se as Equações (4.36) e (4.35).

Figura 4.1 - Curva de titulação teórica (simulada), sendo o titulado uma solução de $150 \mathrm{ml} \mathrm{HCl} \mathrm{a} 0,0056 \mathrm{~mol} / \mathrm{l}$ e o titulante uma solução de $\mathrm{NaOH}$ a $0,0185 \mathrm{~mol} / \mathrm{l}$.

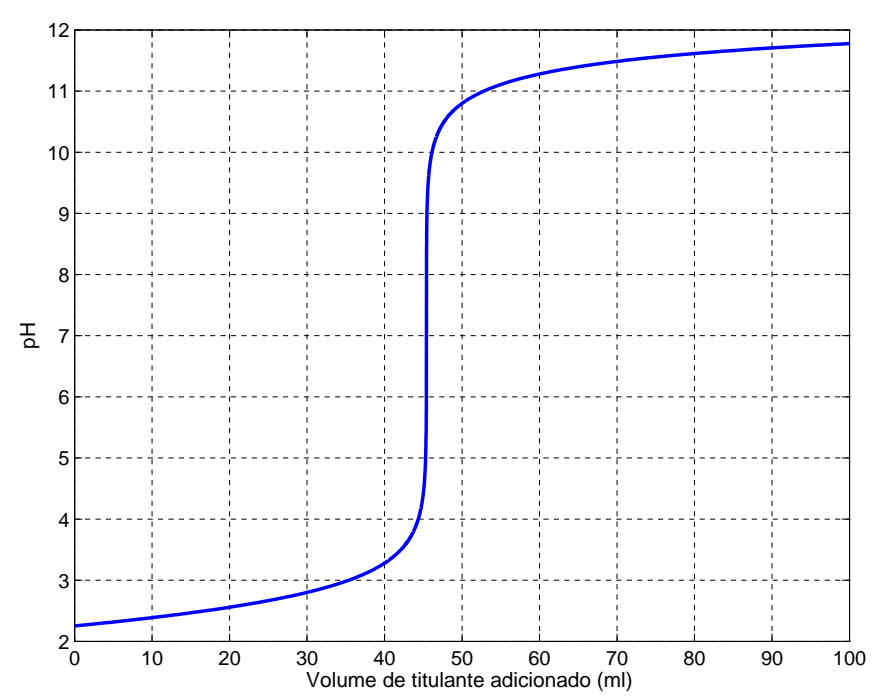

Fonte: do autor.

A curva de titulação pode ser representada matematicamente através da Eq. (4.36). Como a curva de titulação é construída com duas soluções, tem-se:

$$
\mathbf{w}_{s o l}=\frac{\mathbf{w}_{t d} V_{t d}+\mathbf{w}_{t t} V_{t t}}{V_{t d}+V_{t t}} \quad \text { ou } \quad \mathbf{w}_{s o l}=\frac{\mathbf{w}_{t d}}{V_{t t}}+\frac{\mathbf{w}_{t t}}{V_{t d}},
$$

sendo $V_{t d}$ e $V_{t t}$ o volume do titulado e do titulante, respectivamente e $\mathbf{w}_{t d}$ e $\mathbf{w}_{t t}$ são o vetor de invariantes de reação do titulado e do titulante, respectivamente. Assim, para determinar o pH da solução para cada adição gradativa do volume do titulante, aplica-se 
a Eq. (4.35), resultando em:

$$
\frac{A(\mathrm{pH})-w_{t d_{1}}-\sum_{i=1}^{\alpha} w_{t d_{i+1}} a_{i}(\mathrm{pH})}{V_{t t}}+\frac{A(\mathrm{pH})-w_{t t_{1}}-\sum_{i=1}^{\alpha} w_{t t_{i+1}} a_{i}(\mathrm{pH})}{V_{t d}}=0 .
$$

Rearranjando-se a Eq. (4.38), obtém-se a razão entre o volume do titulante e do titulado:

$$
T(\mathrm{pH})=\frac{V_{t t}}{V_{t d}}=-\frac{A(\mathrm{pH})-w_{t d_{1}}-\sum_{i=1}^{\alpha} w_{t d_{i+1}} a_{i}(\mathrm{pH})}{A(\mathrm{pH})-w_{t t_{1}}-\sum_{i=1}^{\alpha} w_{t t_{i+1}} a_{i}(\mathrm{pH})} .
$$

A Eq. (4.39) pode ser analisada de duas formas. A primeira é a obtenção do pH da solução para cada adição de titulante, $V_{t t}$. Já a função $T(\mathrm{pH})$ é a curva de titulação com os eixos invertidos, ou seja, calcula o volume relativo de titulante necessário para obter um determinado $\mathrm{pH}$ na solução titulada.

Caso existam apenas ácidos e bases fortes envolvidos na reação de neutralização, a Eq. (4.39) se resume a:

$$
-w_{t t_{1}} V_{t t}=w_{t d_{1}} V_{t d}-A(\mathrm{pH})\left(V_{t d}+V_{t t}\right) .
$$

Na condição neutra, $A(\mathrm{pH})=0$, portanto para saber o volume necessário para neutralizar uma solução contendo apenas ácidos e bases fortes, tem-se:

$$
V_{t t}=-\frac{w_{t d_{1}}}{w_{t t_{1}}} V_{t d}
$$

Quando a Eq. (4.41) é satisfeita, todo o ácido ou base presente na solução titulada foi neutralizada pelo titulante. Este é conhecido como ponto de equivalência.

\subsubsection{Análise das Curva de Titulação}

A curva de titulação de uma planta de neutralização de pH é a ferramenta mais importante para a análise do processo (MCMILLAN; CAMERON, 2004). A curva de titulação apresenta informação direta a respeito da concentração do titulado, demonstrando qual o volume necessário para neutralizar uma determinada solução. Curvas de titulação com ácidos e bases fortes sempre terão as mesmas características da curva apresentada na Figura 4.1, exceto o ponto de equivalência e o valor dos extremos da curva, que dependerão das concentrações e volumes das soluções.

Na teoria de controle o conceito de ganho da planta é bastante utilizado, que pode ser definido como a razão entre a variação da variável controlada e a variação da variável manipulada. A Planta Piloto é essencialmente uma planta integradora, ou seja, para determinadas vazões de ácido e base, o pH é mantido constante. Deste ponto de equilíbrio, se a vazão de base sofrer uma pequena mudança, fará com que a concentração do íon $\mathrm{H}_{3} \mathrm{O}^{+}$aumente ou diminua. 
A forma diferencial da curva de titulação, $\partial \mathrm{pH} / \partial V_{t t}$, pode ser utilizada para inferir o comportamento do ganho da Planta Piloto. Esta representa a taxa de variação do pH quando, a partir do ponto de equilíbrio da planta, a vazão de base sofrer um aumento na forma de impulso. Como, em geral, os volumes envolvidos na curva de titulação não são equivalentes aos utilizados na prática, sua forma diferencial é utilizada apenas para se ter uma ideia qualitativa do ganho da planta. A forma diferencial da curva de titulação da Figura 4.1 está apresentada na Figura 4.2.

Figura 4.2 - Forma diferencial da curva de titulação da Figura 4.1.

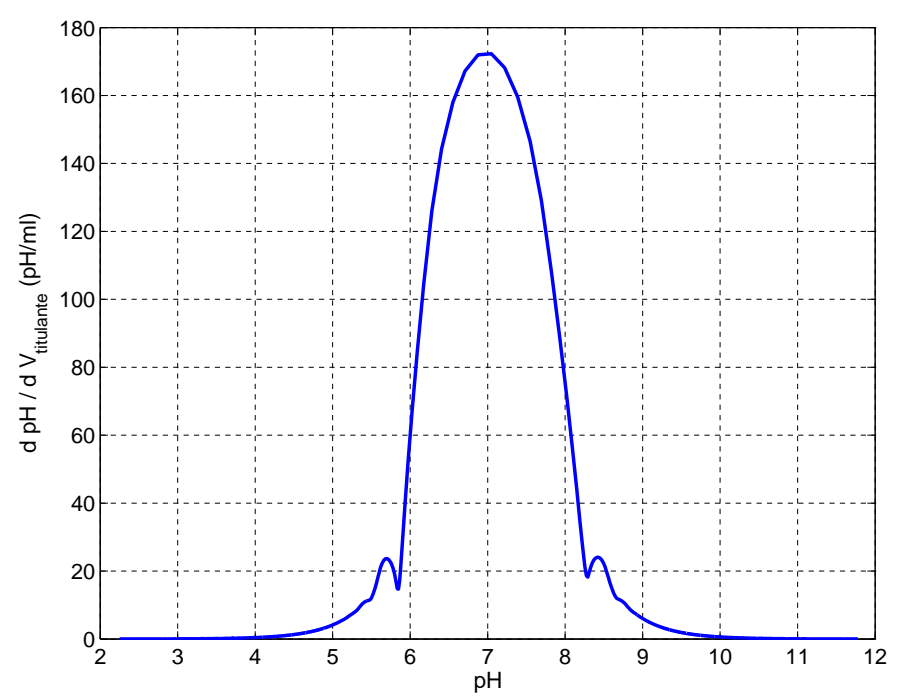

Fonte: do Autor.

A Figura 4.2 demonstra que não existem linhas retas na curva de titulação, sendo que para cada $\mathrm{pH}$ de operação a planta apresenta um ganho diferente. Percebe-se que o ganho da planta varia aproximadamente em $30 \%$ na região de $\mathrm{pH}$ entre 6 e 8 .

Além disso, a presença de ácidos e bases fracos, mesmo em baixas concentrações, modifica localmente - porém significativamente - a curva de titulação, conforme a Eq. (4.16). Esta sensibilidade fica evidente analisando-se os invariantes de reação de uma solução em duas situações: (i) contendo apenas ácidos e bases fortes e (ii) contendo ácidos e bases fortes e um ácido fraco. $\mathrm{O}$ pH de uma solução na situação (i) pode ser calculado através da equação

$$
w_{1}=A(\mathrm{pH})
$$

Já o pH de uma solução na situação (ii) pode ser calculado como:

$$
w_{1}=A(\mathrm{pH})-w_{2} a_{1}(\mathrm{pH}) \quad \text { ou } \quad w_{1}+w_{2} a_{1}(\mathrm{pH})=A(\mathrm{pH}) .
$$

Deseja-se, portanto, encontrar um escalar, $\alpha \geq 0$, que represente um limite admissível para a influência do ácido fraco no pH da solução, ou seja,

$$
\alpha>w_{2} a_{1}(\mathrm{pH})
$$


Percebe-se que a influência do ácido fraco depende da função $a_{1}(\mathrm{pH})$. Analisando-se as quatro regiões que o pH da solução pode se encontrar, com relação às constantes de equilíbrio do ácido fraco:

$$
\begin{aligned}
& \text { Se } \mathrm{pH} \ll p K_{a_{1,1}}, a_{1}(\mathrm{pH}) \approx 0, \\
& \text { Se } p K_{a_{1,1}}<\mathrm{pH}<p K_{a_{1,2}}, a_{1}(\mathrm{pH}) \approx 1, \\
& \text { Se } p K_{a_{1,2}}<\mathrm{pH}<p K_{a_{1,3}} \approx 2 \mathrm{e} \\
& \text { Se } \mathrm{pH} \gg p K_{a_{1,3}}, a_{1}(\mathrm{pH}) \approx 3 .
\end{aligned}
$$

Assim, $\max a_{1}(\mathrm{pH})=3$, o que é um resultado esperado, já que $a_{1}(\mathrm{pH})$ relaciona o estágio de dissociação do ácido fraco com relação ao pH da solução e este está completamente dissociado quando o $\mathrm{pH}$ da solução for muito maior que o maior valor de $p K_{a}$ do ácido. Considerando-se que a função $a_{1}(\mathrm{pH})$ estará em seu valor médio e substituindo-se na Eq. (4.44), resulta em:

$$
w_{2}<\frac{\alpha}{1,5}
$$

Uma dissociação de apenas $10^{-7}$ é capaz de modificar o pH da solução em $3 \%$ quando esta estiver próxima do pH neutro. Portanto, se é desejável que nenhum ácido fraco interfira mais do que $3 \%$ na curva de titulação do sistema, sua concentração não deve ultrapassar $0,67 \cdot 10^{-7}$. Isto significa que pequenas concentrações de ácido fraco podem modificar significativamente um experimento de titulação.

Para se ter uma ideia quantitativa da influência dos ácidos fracos na forma diferencial das curvas de titulação - ou ganho da planta - suponha que foram preparadas inúmeras soluções de titulante e titulado, todas contendo as mesmas concentrações de base e ácido fortes do experimento simulado de titulação da Figura 4.1. Com cada solução de titulante e titulado, dissolve-se uma determinada quantidade de ácido carbônico $\left(\mathrm{H}_{2} \mathrm{CO}_{3}\right.$, $p K_{a_{1}}=6,325$ e $p K_{a_{2}}=10,329$ ) e simula-se um experimento de titulação (da mesma forma que foi simulada a curva de titulação da Figura 4.1), sendo estes resultados apresentados na Figura 4.3. Percebe-se que a presença de ácido fraco, mesmo a concentrações duas ordens de magnitude abaixo da concentração do ácido forte, é capaz de alterar significativamente a forma diferencial da curva de titulação, ou seja, pode acarretar em drásticas mudanças no ganho da planta. 
Figura 4.3 - Sensibilidade do pH em relação a pequenas quantidades de ácidos fracos - as concentrações de ácido e base fortes são as mesmas da Figura 4.1.

(a) Curvas de titulação para diversas concentrações de ácido carbônico.

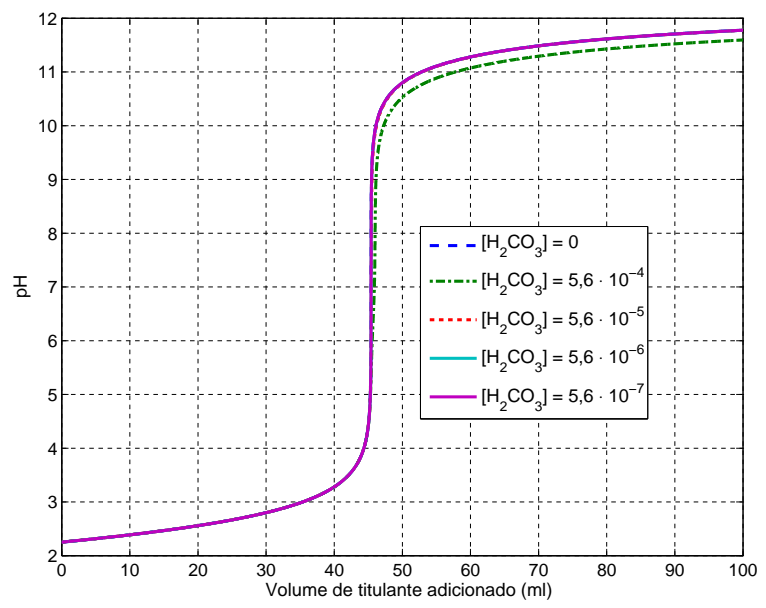

(b) Forma diferencial das curvas de titulação da Figura 4.3a.

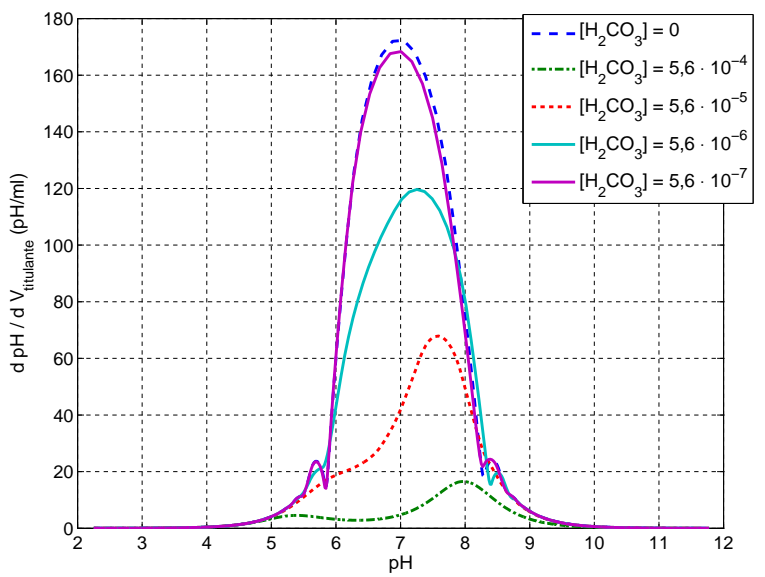

Fonte: do Autor.

\subsection{Fundamentos de Cinética de Reações e Fluidodinâmica}

A cinética das reações estuda como a reação evolui no tempo, até chegar ao ponto de equilíbrio dinâmico. Já a fluidodinâmica estuda como os materiais fluem através do reator. Esta seção é baseada nos livros de Castellan (1983), Levenspiel (1999) e Fogler (2004). Ao reunir os conhecimentos de equilíbrio químico, cinética de reações e fluidodinâmica, pode-se predizer o comportamento temporal das concentrações de cada produto e reagente no reator, conforme a Figura 4.4 .

Figura 4.4 - Informações utilizadas para predizer o comportamento de um reator.

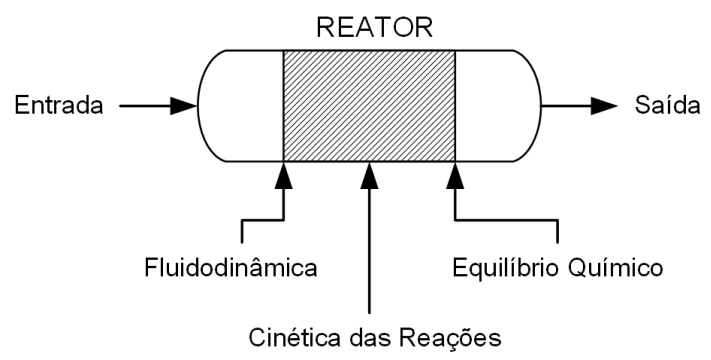

Adaptado de: Fogler (2004). 


\subsubsection{Cinética de Reações Ácido-Base}

A taxa de uma reação é definida como a taxa de desaparecimento dos reagentes ou a taxa de formação dos produtos:

$$
\frac{\mathrm{d} \xi}{\mathrm{d} t}=V f\left(T, p, c_{i}, c_{x}\right)+A F\left(T, p, c_{i}, c_{x}\right),
$$

sendo $\xi$ o grau de avanço, em mols, $T$ a temperatura, $p$ a pressão, $c_{i}$ a concentração molar da substância $i, c_{x}$ a concentração molar de catalisadores, $V$ o volume e $A$ a área ativa. A área ativa é geralmente utilizada em reações heterogêneas, ou seja, que ocorrem em mais de uma fase. Como este trabalho trata apenas de reações homogêneas, todas ocorrendo em fase líquida, pode-se simplificar a Eq. (4.47), resultando em:

$$
\frac{\mathrm{d} \xi / V}{\mathrm{~d} t}=f\left(T, p, c_{i}, c_{x}\right)
$$

A relação entre a evolução da reação e a concentração dos produtos e reagentes é:

$$
\frac{\mathrm{d} \xi / V}{\mathrm{~d} t}=\frac{1}{\nu_{i}} \frac{\mathrm{d} c_{i}}{\mathrm{~d} t}
$$

sendo $\nu_{i}$ o coeficiente estequiométrico da substância $i$.

Geralmente, a função $f$ tem a forma simples:

$$
\frac{\mathrm{d} \xi / V}{\mathrm{~d} t}=k c_{A}^{\alpha} c_{B}^{\beta} \cdots
$$

sendo $k$ a constante da taxa da reação, $c_{A}$ e $c_{B}$ a concentração da substância $A$ e $B$, respectivamente e $\alpha$ e $\beta$ é a ordem da reação com respeito à substância $A$ e $B$, respectivamente. Neste trabalho, apenas reações de ordem um e com um reagente são tratadas, portanto,

$$
\mathrm{A} \longrightarrow \text { Produtos. }
$$

Neste caso a taxa de variação da concentração do reagente $A$ é:

$$
\frac{\mathrm{d} c_{A}}{\mathrm{~d} t}=-k c_{A}
$$

Ou seja, a concentração do reagente $A$ decresce exponencialmente, de acordo com a taxa específica da reação. Para reações ácido-base, o valor de $k$ é extremamente alto. Isto significa que, de maneira prática, a reação ocorre instantaneamente tão logo as moléculas estejam próximas, seja através de difusão ou de mistura forçada. Assim, o tempo necessário para a homogenização da mistura é o tempo limitante para que a reação ocorra.

Portanto, a cinética das reações ácido-base pode ser considerada instantânea para reatores de neutralização de $\mathrm{pH}$ e seu comportamento pode ser predito através de sua fluidodinâmica e das constantes de equilíbrio químico dos ácidos e bases presentes no reator. 


\subsubsection{Fluidodinâmica de Reatores Ideais}

Os reatores são os recipientes em que as reações químicas ocorrem. Este trabalho tem interesse em dois tipos de modelos fluidodinâmicos, de reações homogêneas (ocorrendo na mesma fase da matéria): o Reator de Fluxo em Pistão (PFR - do Inglês, Plug Flow Reactor) e o Reator Tanque Agitado Contínuo (CSTR - do Inglês, Continuous Stirred Tank Reactor), que estão apresentados na Figura 4.5.

Figura 4.5 - Reatores ideais de interesse para este trabalho.

(b) Reator tanque agitado contínuo.

(a) Reator de fluxo em pistão.
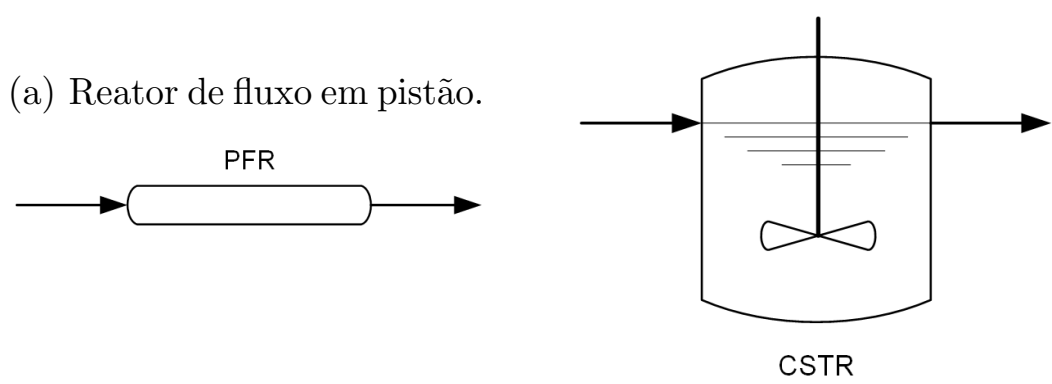

Fonte: Levenspiel (1999).

O fluido que passa em um determinado instante no PFR ideal não se mistura com os fluidos de entrada ou saída do reator. É como se as moléculas do fluido se movessem em fila através do reator. Já os CSTR ideais têm composição homogênea ao longo de sua extensão. O fluido de saída possui a mesma composição que o fluido do reator e qualquer fluido de entrada é instantaneamente homogenizado com o restante do fluido do reator.

A modelagem de qualquer um dos dois reatores pode ser realizada através de seu balanço de massa das espécies do reator,

$$
\text { [ acumulação }]=[\text { entrada }]-[\text { saída }]+[\text { geração }]-[\text { consumo }],
$$

sendo a geração e o consumo correspondentes à conversão dos reagentes em produtos. Para reações instantâneas, a conversão dos reagentes em produtos ocorre em um tempo igual a zero e portanto pode ser desprezada na Eq. (4.52). Assim, a taxa de acúmulo da espécie $i$, em mols, em qualquer um dos reatores é dada por:

$$
\frac{\mathrm{d} n_{i}}{\mathrm{~d} t}=F_{i_{e}}(t) c_{i_{e}}(t)-F_{i_{s}}(t) c_{i_{s}}(t)
$$

onde $n_{i}$ é o número de mols da espécie $i$ no reator, $F_{i_{e}}$ e $F_{i_{s}}$ é a vazão de entrada e saída, respectivamente, da espécie $i$, em unidade de volume por unidade de tempo e $c_{i_{e}}$ e $c_{i_{s}}$ são a concentração molar de entrada e saída, respectivamente, da espécie $i$. A relação entre as diversas espécies é obtida através das constantes de equilíbrio químico das reações. A Eq. (4.53) também pode ser escrita na forma:

$$
V(t) \frac{\mathrm{d} c_{i}}{\mathrm{~d} t}=F_{i_{e}}(t) c_{i_{e}}(t)-F_{i_{s}}(t) c_{i_{s}}(t),
$$


onde $c_{i}$ é a concentração molar da espécie $i$ no reator e $V(t)$ é o volume do reator em uma unidade apropriada.

Para o PFR ideal, considerando o fluido como incompressível, todos os elementos de volume permanecem o mesmo tempo dentro do reator,

$$
F_{i_{s}}(t)=F_{i_{e}}(t)=F_{i}(t)=u(t) A_{t},
$$

onde $A_{t}$ é a área da seção transversal do reator e $u$ é a velocidade linear do fluido. O tempo médio necessário para que o fluido atravesse todo o PFR é definido como tempo de residência, $\tau$,

$$
\frac{1}{\tau}=\frac{u(t)}{a}=\frac{u(t) A_{t}}{V}=\frac{F_{i}(t)}{V},
$$

sendo $a$ a distância percorrida pelo fluido no reator. Portanto, a Eq. (4.54) pode ser reescrita como:

$$
V \frac{\mathrm{d} c_{i}}{\mathrm{~d} t}=F_{i}(t)\left(c_{i_{e}}(t)-c_{i_{e}}(t-\tau)\right) .
$$

A Eq. (4.57) sugere que a saída do PFR seja igual a sua entrada, atrasada de um tempo $\tau$.

Para o modelo CSTR ideal, a concentração da espécie $i$ na vazão de saída é igual a sua concentração no interior do reator $\left(c_{i_{s}}=c_{i}\right)$ e considerando que todos os fluidos possuem densidades iguais e que o volume do reator é constante, ou seja, sua vazão de entrada é igual a sua vazão de saída, a Eq. (4.54) pode ser reescrita como:

$$
\frac{\mathrm{d} c_{i}}{\mathrm{~d} t}=\frac{1}{\tau} c_{i_{e}}(t)-\frac{1}{\tau} c_{i}(t)
$$

O tempo de residência para o reator CSTR é o mesmo que para o PFR, pois a solução da Eq. (4.58) para uma entrada impulso unitário (resultando na função de transferência da planta) é:

$$
c_{i}(t)=\frac{1}{\tau} e^{-\frac{1}{\tau} t},
$$

que possui valor médio igual a $\tau$.

\subsubsection{Fluidodinâmica de Reatores Reais}

As suposições adotadas para definir os modelos PFR e CSTR ideais são muito restritivas, sendo que na prática o comportamento dos reatores é diferente do ideal. Alguns dos fenômenos que causam este desvio são: (i) ocorrência de curto-circuito, ou seja, parte do fluido de entrada do reator é desviado diretamente para a saída; (ii) existência de zonas mortas, que não são homogêneas como a parte ativa do reator; (iii) o tempo de mistura não poder ser considerado igual a zero, como foi assumido no CSTR ideal; (iv) existe turbulência ou difusão, que gera uma mistura axial no reator PFR; (v) existe uma vazão de reciclo, que faz com que parte do fluido retorne da saída para a entrada do reator. 
Uma forma de estudar a fluidodinâmica de um reator é saber quanto cada elemento de volume permanece dentro do reator. A Distribuição de Tempos de Residência (DTR) é uma técnica que fornece tais informações e, a partir desta, é possível aproximar a fluidodinâmica real do reator como uma combinação de reatores ideais mais volume morto.

A DTR é uma ferramenta que provê informações a respeito do tempo em que os elementos de volume de determinada espécie permanecem no reator. A distribuição do tempo de residência de uma espécie, $E(t)$, é a probabilidade que um elemento de volume de determinada espécie tem de deixar o reator em um determinado tempo e é normalizada, de forma a resultar em uma Função Densidade de Probabilidade (PDF - do Inglês, Probability Density Function):

$$
\int_{0}^{\infty} E(t) \mathrm{d} t=1
$$

Uma das formas de se obter o tempo de residência é por meio da excitação da entrada do reator através da injeção de um traçador, na forma de impulso unitário e registrar a evolução de sua concentração na saída do reator. De maneira geral, este teste é conduzido mantendo-se o reator com volume constante, tendo vazões de entrada e saída idênticas. A concentração inicial de traçador no reator é dada por:

$$
c_{0}=\frac{W}{V}=\frac{F_{s} \int_{0}^{\infty} c_{s}(t) \mathrm{d} t}{V}
$$

onde $W$ é a massa de traçador, $V$ é o volume do reator, $F_{s}$ é a vazão de saída do reator e $c_{s}(t)$ é a concentração de saída do traçador na saída do reator. Para obter a curva de $E(t)$, através da curva de $c_{s}(t)$, normaliza-se a concentração de saída do reator,

$$
E(t)=\frac{c_{s}(t)}{\int_{0}^{\infty} c_{s}(t) \mathrm{d} t}
$$

É comum também representar a DTR em tempo adimensional, através da transformação

$$
\theta=\frac{t}{\tau} \quad \text { e } \quad \int_{0}^{\infty} E(\theta) \mathrm{d} \theta=1
$$

A área abaixo da curva $c_{s}(t)$ é dada por:

$$
A=\int_{0}^{\infty} c_{s}(t) \mathrm{d} t=\frac{W}{F_{s}},
$$

onde $F_{s}$ é a vazão de saída do reator. O tempo de residência médio do experimento é:

$$
\bar{t}=\frac{\int_{0}^{\infty} t c_{s}(t) \mathrm{d} t}{\int_{0}^{\infty} c_{s}(t) \mathrm{d} t},
$$

sendo que para um reator ideal, $\bar{t}=\tau$. Curvas de $E(t)$ e $E(\theta)$ de um reator CSTR ideal estão apresentadas na Figura 4.6. Já a Figura 4.7 apresenta uma DTR de um CSTR com fluidodinâmica próxima do ideal. 
Figura 4.6 - Curvas de distribuição de tempo de residência para um CSTR ideal.

(a) Curva $E(t)$ de um CSTR ideal.

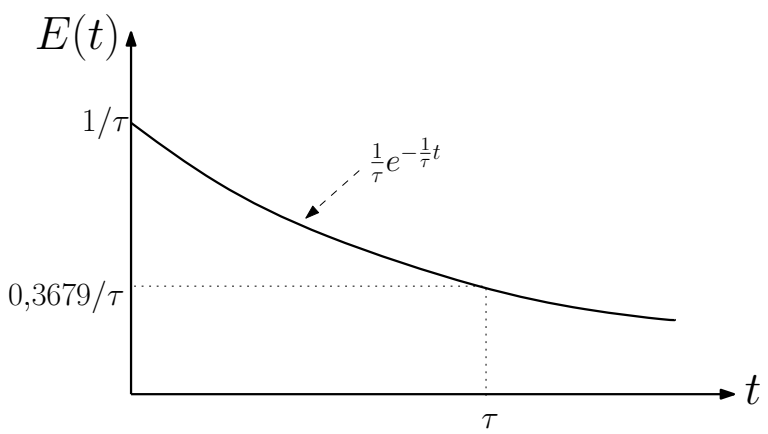

Adaptado de: Levenspiel (1999). (b) Curva $E(\theta)$ de um CSTR ideal.

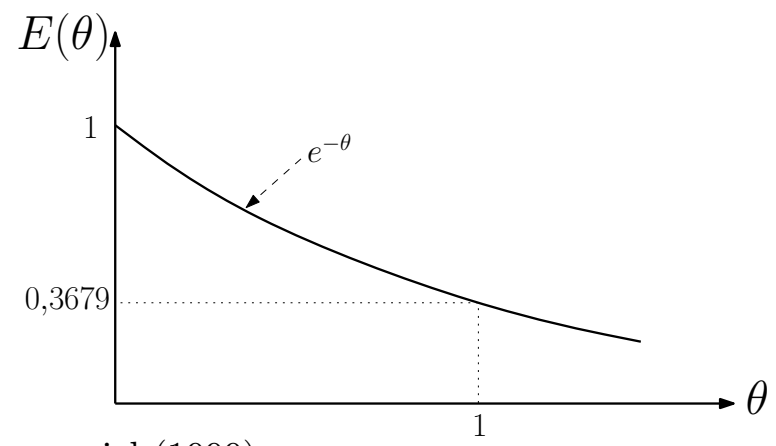

Figura 4.7 - DTR de um reator com uma fluidodinâmica próxima do ideal.

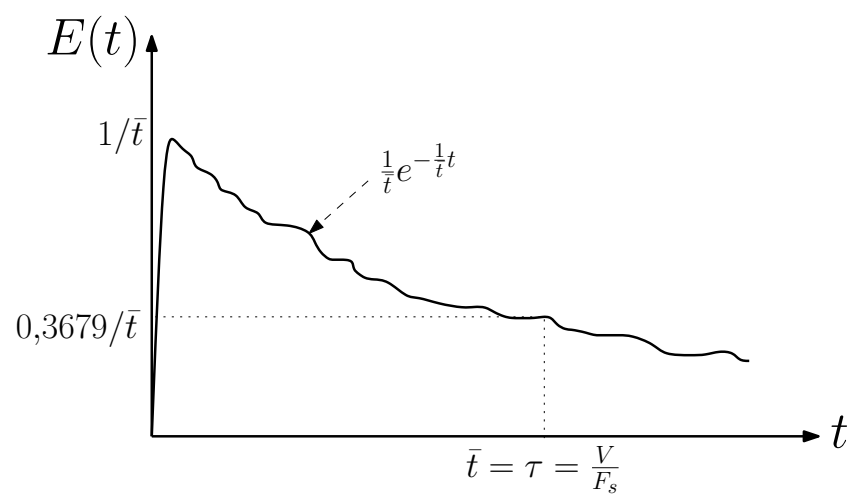

Adaptado de: Levenspiel (1999).

\subsubsection{Modelagem da Fluidodinâmica a Partir da DTR}

A diferença entre as curvas de DTR ideais e obtidas experimentalmente evidenciam quais os fenômenos que fazem a fluidodinâmica do reator diferir do ideal. Considera-se que o escoamento do reator real pode ser dividido em três regiões: (i) região de fluxo em pistão ideal, de volume $V_{p}$; (ii) região com agitação e mistura ideal, de volume $V_{m}$ e (iii) região de volume morto, sem agitação, de volume $V_{d}$. As duas primeiras regiões equivalem ao volume ativo do reator:

$$
V_{a}=V_{m}+V_{p} \quad \text { e } \quad V=V_{m}+V_{p}+V_{d}
$$

sendo $V_{a}$ o volume ativo do reator e $V$ o volume total do reator. Pelas combinações possíveis entre estas três regiões, pode-se desenvolver um modelo matemático que apresente uma fluidodinâmica próxima do que foi observado experimentalmente. Este tipo de modelagem é chamado de modelos compartimentados e foi o método escolhido para o desenvolvimento deste trabalho, devido a sua simplicidade, o que facilita o projeto de sistemas de controle. Adicionalmente, estes modelos apresentam um bom desempenho, suficiente para a modelagem da Planta Piloto. 
Caso o reator real possua uma região com fluxo em pistão, sua DTR apresentará um tempo morto entre o impulso na entrada e as observações na saída do reator. Esta região pode ser modelada conforme a Eq. (4.57), sendo que o volume da região de fluxo em pistão irá determinar o tempo morto.

O volume do CSTR com pouca ou nenhuma agitação é classificado como um volume morto, não fazendo parte da região ativa do reator. Reatores com volume morto apresentam DTR com tempo de residência médio menor que o teórico, demonstrando que o volume ativo do reator é menor que o volume do reator. Já o volume perfeitamente agitado é modelado conforme a Eq. (4.58). A Figura 4.8 apresenta curvas de DTR teóricas para algumas combinações de reatores ideais.

Figura 4.8 - Diferentes modelagens fluidodinâmicas e suas respectivas DTR.

(b) Curva $E(t)$ do modelo PFR em série com

(a) Modelo de PFR em série com CSTR.

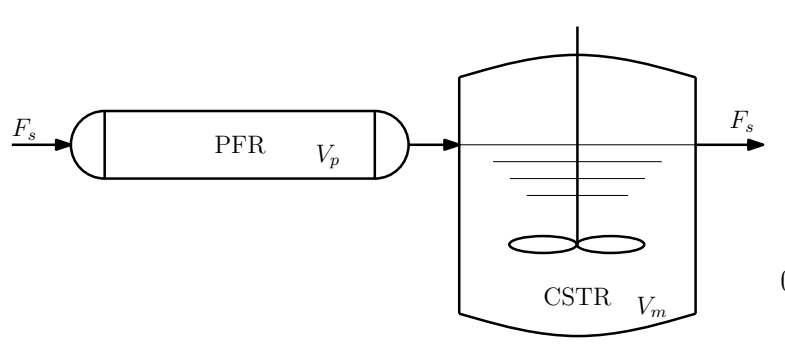
CSTR.

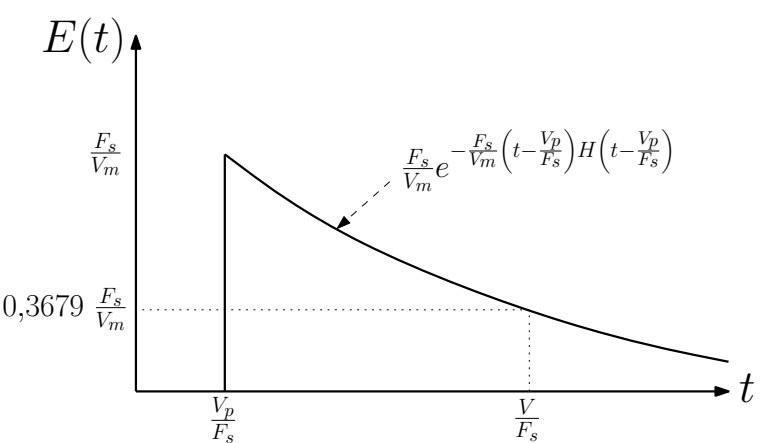

(c) Modelo de PFR em série com CSTR e vo-

(d) Curva $E(t)$ do modelo PFR em série com CSTR e volume morto. lume morto.
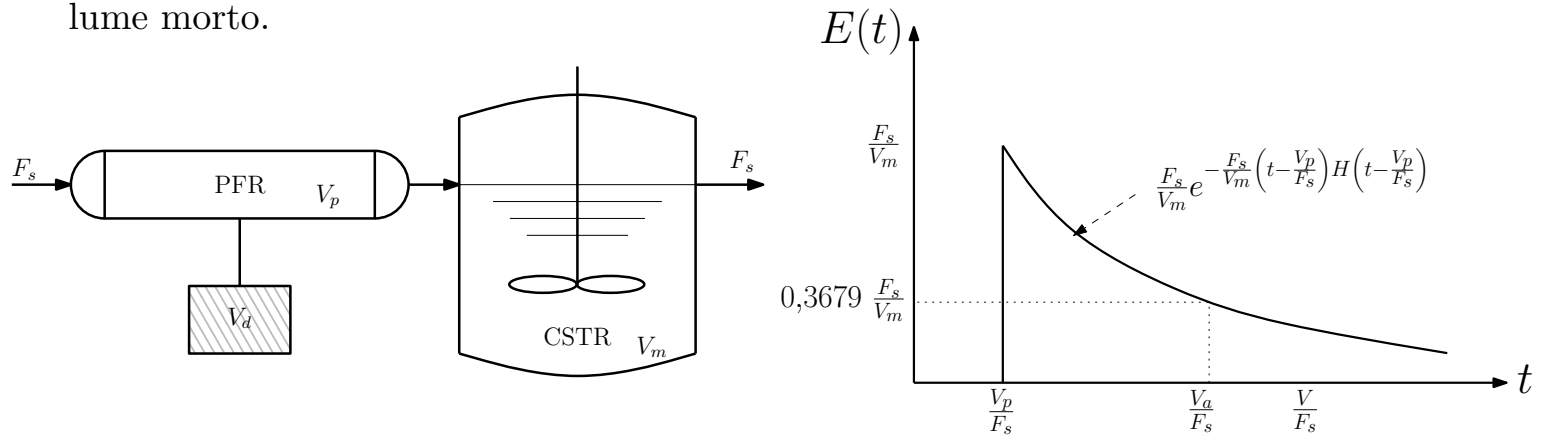

Adaptado de: Levenspiel (1999).

Caso o reator apresente uma vazão de curto-circuito, a curva de DTR apresentaria um grande pico em $t \approx 0$. Adicionalmente, caso o reator apresente vazão de reciclo, parte do fluido seria desviado para a entrada do reator, acarretando em oscilações na DTR. 


\section{Modelagem da Planta Piloto}

A modelagem da Planta Piloto é realizada através da combinação da abordagem fenomenológica - que utiliza princípios da Física e Química - com a abordagem empírica que utiliza relações matemáticas desenvolvidas através da observação de dados do processo (GARCIA, 2005).

Todas as reações da Planta Piloto ocorrem à pressão atmosférica. Neste trabalho, a pressão atmosférica é considerada constante, com valor de 1 atm. Portanto, esta é a primeira aproximação da modelagem, visto que a pressão atmosférica na local da Planta Piloto (São Paulo - SP) é da ordem de 0,92 atm, podendo sofrer pequenas variações.

\subsection{As Soluções Utilizadas na Planta Piloto}

Neste trabalho, a Planta Piloto opera com três soluções distintas, conforme abordado no Capítulo 3. O TAP é preenchido com uma solução de $\mathrm{HCl}$, de forma a obter uma concentração molar de 0,0056 mol/l. Para tanto, utiliza-se uma solução de ácido clorídrico com concentração de 30 a $33 \%$ de $\mathrm{HCl}$. O número de mols de ácido clorídrico desejado no TAP é:

$$
[\mathrm{HCl}]=\frac{n_{\mathrm{HCl}}}{V_{T A P}} \Longrightarrow n_{\mathrm{HCl}}=0,0056 \cdot 180=1,008 \mathrm{~mol} .
$$

Como a massa molar do ácido clorídrico é $M_{\mathrm{HCl}}=36,46 \mathrm{~g} / \mathrm{mol}$, a massa de $\mathrm{HCl}$ que deve ser adicionada ao TAP pode ser calculada como:

$$
W_{\mathrm{HCl}}=36,46 \cdot 1,008=36,75 \mathrm{~g} .
$$

Considerando que o ácido clorídrico possui concentração de $31,5 \%$, a massa específica do $\mathrm{HCl}$ é aproximadamente 364,44 g/l. Assim, o volume de ácido clorídrico que deve ser adicionado no TAP para obter uma concentração molar de 0,0056 mol/l é:

$$
V_{\mathrm{HCl}}=\frac{36,75}{364,44}=0,1008 \mathrm{l} \quad \text { ou } \quad 100,8 \mathrm{ml}
$$

Considerando que a água do TAP utilizada na solução é neutra, seu pH deve ser:

$$
\mathrm{pH}_{\text {TAP }}=-\log 0,0056=2,25 .
$$

Para preparar a solução do TAS, utiliza-se uma solução de ácido acético com concentração de 99,7\%. Um determinado volume de $\mathrm{CH}_{3} \mathrm{COOH}$ é adicionado ao TAS, de forma a obter uma concentração de 0,0068 mol/l. O número de mols de $\mathrm{CH}_{3} \mathrm{COOH}$ desejado no TAS é de:

$$
\left[\mathrm{CH}_{3} \mathrm{COOH}\right]=\frac{n_{\mathrm{CH}_{3} \mathrm{COOH}}}{V_{T A S}} \Longrightarrow n_{\mathrm{CH}_{3} \mathrm{COOH}}=0,0068 \cdot 180=1,224 \mathrm{~mol} .
$$


Como a massa molar do ácido acético é $M_{\mathrm{CH}_{3} \mathrm{COOH}}=60,05 \mathrm{~g} / \mathrm{mol}$, a massa de $\mathrm{CH}_{3} \mathrm{COOH}$ que deve ser adicionada ao TAS pode ser calculada como:

$$
W_{\mathrm{CH}_{3} \mathrm{COOH}}=60,05 \cdot 1,224=73,50 \mathrm{~g} \text {. }
$$

Considerando que o ácido acético possui concentração de 99,7\% e que sua massa específica é de aproximadamente $1049 \mathrm{~g} / \mathrm{l}$, o volume de ácido acético que deve ser adicionado no TAS para obter uma concentração molar de 0,0068 mol/l é:

$$
V_{\mathrm{CH}_{3} \mathrm{COOH}}=\frac{73,50}{1049 \cdot 0,997}=0,0703 \mathrm{l} \text { ou } 70,3 \mathrm{ml} \text {. }
$$

Considerando a água do TAS neutra e sendo $\xi$ o grau de avanço, na condição de equilíbrio,

$$
1,7539 \cdot 10^{-5}=\frac{\left(10^{-7}+\xi\right) \xi}{0,0068-\xi} \approx \frac{\xi^{2}}{0,0068-\xi}
$$

Assim, $\xi=0,3367 \cdot 10^{-3}$ e $\xi=-0,3542 \cdot 10^{-3}$. Desconsiderando o valor negativo de $\xi$, o pH do TAS é

$$
\mathrm{pH}_{T A S} \approx-\log 0,3367 \cdot 10^{-3}=3,47
$$

Já a solução do TBB é preparada a partir de soda cáustica em escamas, de pureza mínima de $99 \%$, de modo a obter uma concentração de 0,0185 mol/l de NaOH. O número de mols de $\mathrm{NaOH}$ desejado no TBB é de:

$$
[\mathrm{NaOH}]=\frac{n_{\mathrm{NaOH}}}{V_{T B B}} \Longrightarrow n_{\mathrm{NaOH}}=0,0185 \cdot 180=3,33 \text { mol. }
$$

Como a massa molar do hidróxido de sódio é $M_{\mathrm{NaOH}}=39,9971 \mathrm{~g} / \mathrm{mol}$, a massa de $\mathrm{NaOH}$ que deve ser adicionada ao TBB pode ser calculada como:

$$
W_{\mathrm{NaOH}}=\frac{39,9971 \cdot 3,33}{0,99}=134,5 \mathrm{~g} .
$$

Considerando que a água do TBB utilizada na solução é neutra, seu pH deve ser:

$$
\mathrm{pH}_{T B B}=-\log \frac{10^{-14}}{0,0185}=12,27 .
$$

A preparação das soluções da Planta Piloto consiste em lavar todos os tanques, garantindo que não haja contaminação com as soluções utilizadas anteriormente. Após, enche-se os tanques até que todos possuam volume igual a $180 \mathrm{l}$ e adiciona-se a quantidade de ácido ou base necessária para obter as concentrações desejadas. Para homogenizar as soluções, os tanques são agitados com borbulhamento de ar comprimido, por 10 minutos. 


\subsection{Análise da Termodinâmica da Planta Piloto}

Os ácidos e bases utilizados para preparar as soluções da Planta Piloto, quando dissociados, produzem calor, acarretando o aumento de temperatura dos tanques. No entanto, o tempo entre a preparação das soluções e sua utilização é grande o suficiente para que a temperatura dos tanques entre em equilíbrio com o ambiente novamente. Desta forma, não é necessário considerar o calor gerado pelas reações de dissociação que ocorrem na preparação dos tanques da Planta Piloto.

Para analisar o calor gerado pela reação de neutralização, suponha que a Planta Piloto esteja em estado estacionário, com vazão de ácido clorídrico de 50 l/h, vazão de ácido acético de 50 l/h e vazão de base suficiente para manter o TR com pH neutro. Note que, para análise do calor gerado pelas reações, esta condição é o pior caso possível na Planta Piloto, pois se trata da vazão máxima possível das soluções ácidas e básica, ingressantes no TR. Neste caso, a reação de neutralização é:

$$
\begin{gathered}
\mathrm{OH}^{-}{ }_{(\mathrm{aq})}+\mathrm{H}_{3} \mathrm{O}^{+}{ }_{(\mathrm{aq})} \rightleftharpoons 2 \mathrm{H}_{2} \mathrm{O}_{(\mathrm{l})} \\
\mathrm{CH}_{3} \mathrm{COOH}_{(\mathrm{aq})}+\mathrm{H}_{2} \mathrm{O}_{(\mathrm{l})} \rightleftharpoons \mathrm{CH}_{3} \mathrm{COO}_{(\mathrm{aq})}^{-}+\mathrm{H}_{3} \mathrm{O}^{+}{ }_{(\mathrm{l})} .
\end{gathered}
$$

As entalpias de formação dos produtos e reagentes, (DEAN, 1999) à pressão de 1 atm e temperatura de $25^{\circ} \mathrm{Csão:}$

$$
\begin{aligned}
\Delta H_{f}^{\circ}\left(\mathrm{H}_{2} \mathrm{O}_{(\mathrm{l})}\right) & =-285,8 \mathrm{~kJ} / \mathrm{mol} \\
\Delta H_{f}^{\circ}\left(\mathrm{H}_{(\mathrm{aq})}^{+}\right) & =0 \mathrm{~kJ} / \mathrm{mol} \\
\Delta H_{f}^{\circ}\left(\mathrm{OH}_{(\mathrm{aq})}^{-}\right) & =-230,015 \mathrm{~kJ} / \mathrm{mol} \\
\Delta H_{f}^{\circ}\left(\mathrm{CH}_{3} \mathrm{COOH}_{(\mathrm{aq})}\right) & =-484,4 \mathrm{~kJ} / \mathrm{mol} \\
\Delta H_{f}^{\circ}\left(\mathrm{CH}_{3} \mathrm{COO}^{-}{ }_{(\mathrm{aq})}\right) & =-486,34 \mathrm{~kJ} / \mathrm{mol} .
\end{aligned}
$$

Assim, a entalpia das reações pode ser calculada como:

$$
\begin{gathered}
\Delta H_{r}^{\circ}\left(\mathrm{H}_{2} \mathrm{O}\right)=-285,8-(-230)=-55,8 \mathrm{~kJ} / \mathrm{mol} \\
\Delta H_{r}^{\circ}\left(\mathrm{CH}_{3} \mathrm{COO}^{-}\right)=-486,34-(-484,4)=-1,94 \mathrm{~kJ} / \mathrm{mol} .
\end{gathered}
$$

Como a entalpia da reação de associação do ácido acético é muito menor que a entalpia da reação de associação do íon $\mathrm{H}_{3} \mathrm{O}^{+}$, esta será desprezada. Considerando que todas as moléculas de ácido acético irão se dissociar ao longo da reação de neutralização, o número de mols por segundo de $\mathrm{OH}^{-}$que deve ser adicionado no TR para manter o $\mathrm{pH}$ neutro é:

$$
\begin{gathered}
F_{\mathrm{HCl}}=F_{\mathrm{CH}_{3} \mathrm{COOH}}=50 \mathrm{l} / \mathrm{h} \quad \text { ou } \quad 0,0139 \mathrm{l} / \mathrm{s} \\
\dot{n}_{\mathrm{OH}^{-}}=0,0139 \cdot(0,0056+0,0068)=1,7236 \cdot 10^{-4} \mathrm{~mol} / \mathrm{s},
\end{gathered}
$$

sendo $F_{\mathrm{HCl}}$ e $F_{\mathrm{CH}_{3} \mathrm{COOH}}$ a vazão volumétrica da solução de ácido clorídrico e ácido acético, respectivamente. Portanto, o calor gerado a cada segundo, devido à reação de associação 
da água é:

$$
\dot{Q}_{p}=-55,8 \cdot 1,7236 \cdot 10^{-4}=-9,6 \mathrm{~J} / \mathrm{s}
$$

A capacidade térmica da água pode ser considerada constante ao longo da faixa de temperaturas em que se mantém na fase líquida e é $C_{p}=75,33 \mathrm{~J} \cdot \mathrm{mol}^{-1} \cdot \mathrm{K}^{-1}$. Um experimento na Planta Piloto, em média, tem duração de dez mil segundos, gerando um calor devido à associação do íon $\mathrm{H}_{3} \mathrm{O}^{+}$de:

$$
Q_{p}=-9,6 \cdot 10000=-96 \mathrm{~kJ}
$$

Como o volume de água nominal do TR é de 46,5 l e considerando que a massa específica da água é de $\rho_{\mathrm{H}_{2} \mathrm{O}}=1000 \mathrm{~g} / \mathrm{l}$, o número de mols de água no TR é de $n_{\mathrm{H}_{2} \mathrm{O}}=2,58 \cdot 10^{3} \mathrm{~mol}$. Considerando o TR um sistema isolado, o aumento de temperatura de sua água devido à reação de neutralização pode ser calculado através da Eq. (A.11),

$$
96 \cdot 10^{3}=2,58 \cdot 10^{3} \cdot 75,33 \cdot \Delta T \Longrightarrow \Delta T=0,5 \mathrm{~K}
$$

Note que os cálculos levaram em consideração apenas o calor gerado pelas reações químicas que ocorrem no TR, desconsiderando as diferenças de temperatura que podem existir entre os tanques e o calor gerado pela agitação mecânica. A Figura 5.1 apresenta a variação de temperatura do TR em diversos experimentos realizados na planta piloto. Nota-se que em nenhum experimento a variação de temperatura é maior que $2{ }^{\circ} \mathrm{C}$.

Figura 5.1 - Temperatura do TR para diversos experimentos.

(a) Experimentos de operação da planta piloto.

(b) Experimentos de titulação.
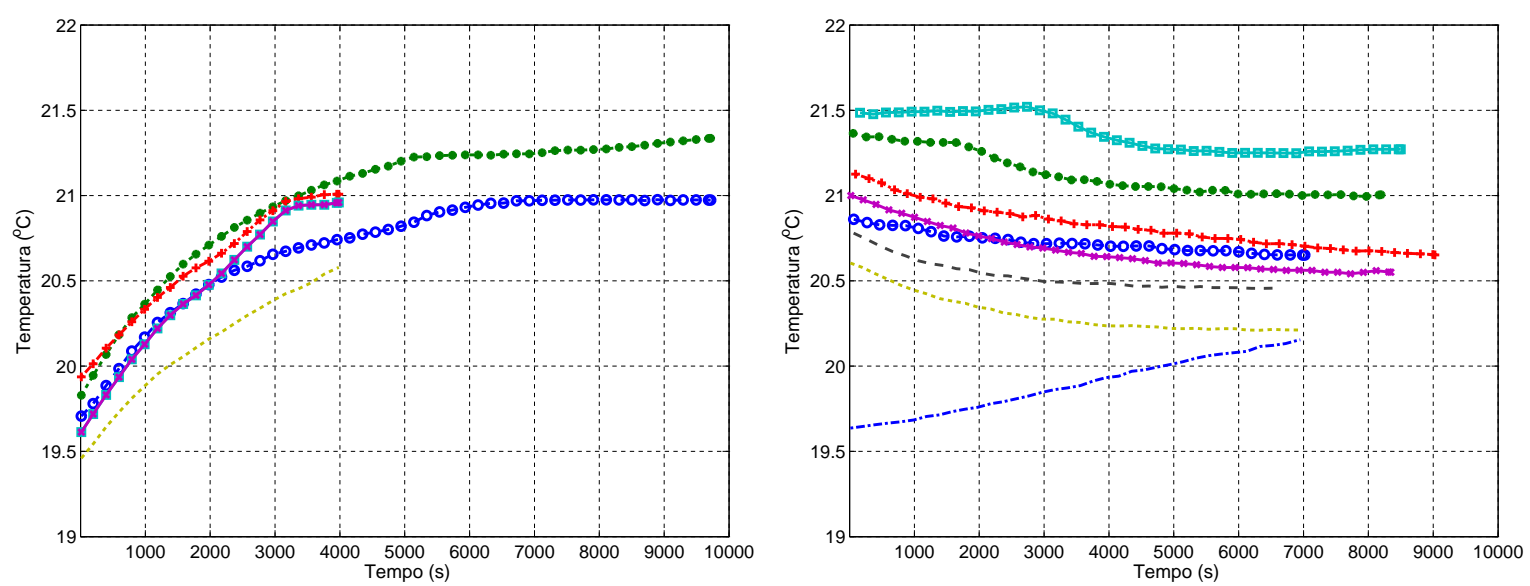

Fonte: do Autor.

\subsection{Análise da Fluidodinâmica do TR}

Como já foi dito, os resultados da modelagem de Ceravolo (2012) e os dados experimentais da Planta Piloto apresentaram diferenças consideráveis. Como uma das 
possíveis hipóteses para explicar tal desvio foi a de que a fluidodinâmica do TR diferia do ideal, decidiu-se obter curvas de DTR do TR. Ramos (2013) conduziu experimentos de DTR na Planta Piloto em diversas condições de operação, com o objetivo de avaliar sua fluidodinâmica. Nesta seção é descrito como a modelagem da fluidodinâmica do TR foi desenvolvida a partir das curvas de DTR.

Os experimentos de DTR foram realizados para cada condição de operação, através da excitação da entrada do TR através da injeção de uma determinada concentração de azul de metileno na entrada do TR em $t=0$. Em seguida, amostras foram coletadas na saída do TR, sendo que a concentração molar de azul de metileno de cada amostra foi determinada por sua absorbância (RAMOS, 2013). Nos testes, o reator foi mantido em estado estacionário com controladores de $\mathrm{pH}$ e nível ativos e vazão de ácido clorídrico constante em 48 l/h (vazão máxima de ácido observada na prática). As condições de operação foram:

I. Nível do TR em 32 cm e rotação do agitador em 400 rpm;

II. Nível do TR em $37 \mathrm{~cm}$ e rotação do agitador em $800 \mathrm{rpm}$ e

III. Nível do TR em 37 cm e rotação do agitador em $1050 \mathrm{rpm}$.

Levando em consideração a vazão de base necessária para manter o pH do TR neutro, em regime permanente, a vazão de saída do TR pode ser calculada utilizando a Equação (4.37):

$$
F_{s}=F_{\text {TAPI }}\left(1+\frac{[\mathrm{HCl}]}{[\mathrm{NaOH}]}\right)=48\left(1+\frac{0,0056}{0,0185}\right)=62,5 \mathrm{l} / \mathrm{h},
$$

sendo $F_{T A P I}$ a vazão volumétrica do TAPI para o TR observada no experimento, em l/h, [HCl] a concentração molar de ácido clorídrico no TAP e [NaOH] a concentração molar de hidróxido de sódio no TBB.

A elevação do nível de operação do TR e aumento da velocidade de rotação do agitador mecânico foram sugeridas na análise do TR, realizada por Ramos (2013), para que as características do TR se aproximassem de seus valores ideais. A elevação do nível do TR foi sugerida para que o valor da razão entre o nível e o diâmetro do TR fosse mais próximo do que é sugerido na literatura (conforme Capítulo 3). Já o aumento na rotação foi sugerida para aumentar o número de Froude, $N_{F R}$, do sistema:

$$
N_{F R}=\frac{N^{2} T}{g}
$$

onde $N$ é a rotação do agitador em Hz, $T$ é o diâmetro do TR e $g$ é a aceleração da gravidade em $\mathrm{m} / \mathrm{s}^{2}$. O número de Froude é adimensional e indica se a energia cinética é maior que a energia potencial do fluido. Desta forma, se $N_{F R}>1$ ou $N_{F R}<1$, a energia cinética é maior ou menor que a potencial, respectivamente. 
As Figuras 5.2 a 5.5 apresentam os resultados da DTR para cada condição de operação, obtidos conforme exposto na Subseção 4.2.3. Foram realizados dois experimentos na condição I, sendo o segundo experimento desta condição foi denominado I(2). Para excitar o reator, foi utilizado um volume pré-determinado de azul de metileno, sendo que sua concentração na saída do TR, $c_{s}(t)$, foi amostrada ao longo do experimento. A curva $E(t)$ de cada experimento foi calculada como na Eq. (4.62). Analisando-se qualitativamente os resultados, percebe-se que a DTR que mais se aproxima da curva teórica é aquela da condição III. Ainda, como todas as DTR apresentam comportamento que se assemelham ao de uma função exponencial, conclui-se que não existem vazões de reciclo ou curto-circuito.

Figura 5.2 - Experimento de DTR com TR operando na condição I.

(a) Curva $c_{s}(t)$ para a condição I.

(b) Curva $E(t)$ para a condição I.
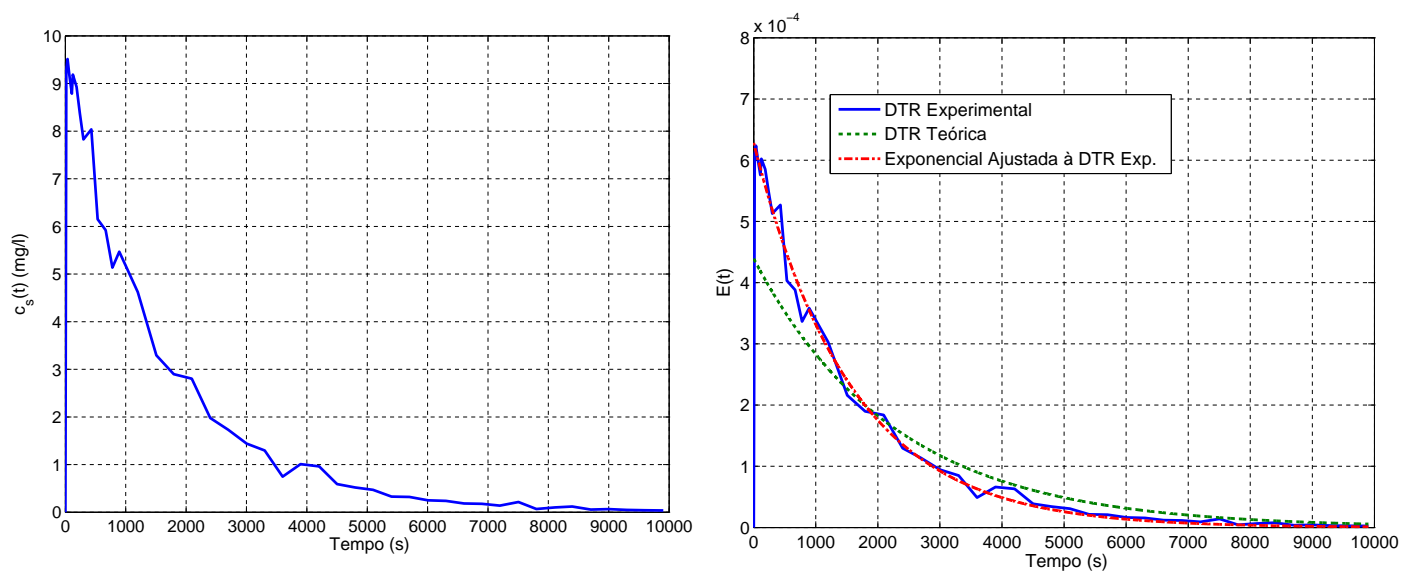

Dados experimentais, $c_{s}(t)$, de: Ramos (2013).

Figura 5.3 - Experimento de DTR com TR operando na condição $\mathrm{I}(2)$ - segundo experimento na condição I.

(a) Curva $c_{s}(t)$ para a condição $\mathrm{I}(2)$.

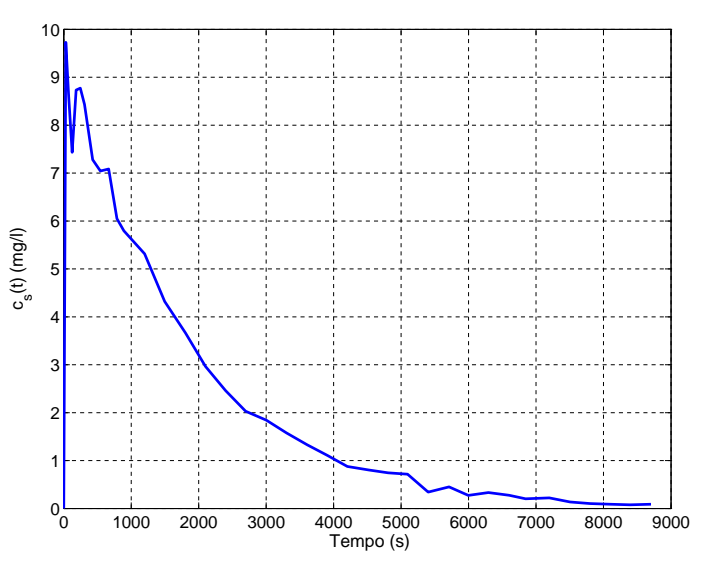

(b) Curva $E(t)$ para a condição I(2).

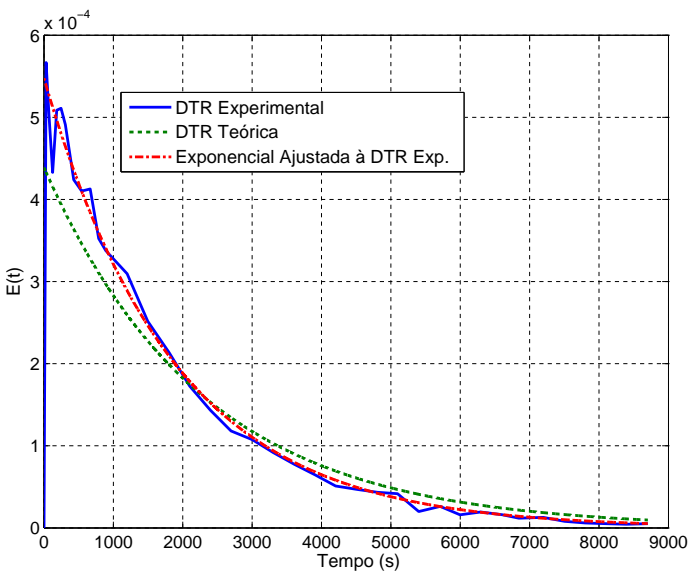

Dados experimentais, $c_{s}(t)$, de: Ramos (2013). 
Figura 5.4 - Experimento de DTR com TR operando na condição II.

(a) Curva $c_{s}(t)$ para a condição II.

(b) Curva $E(t)$ para a condição II.
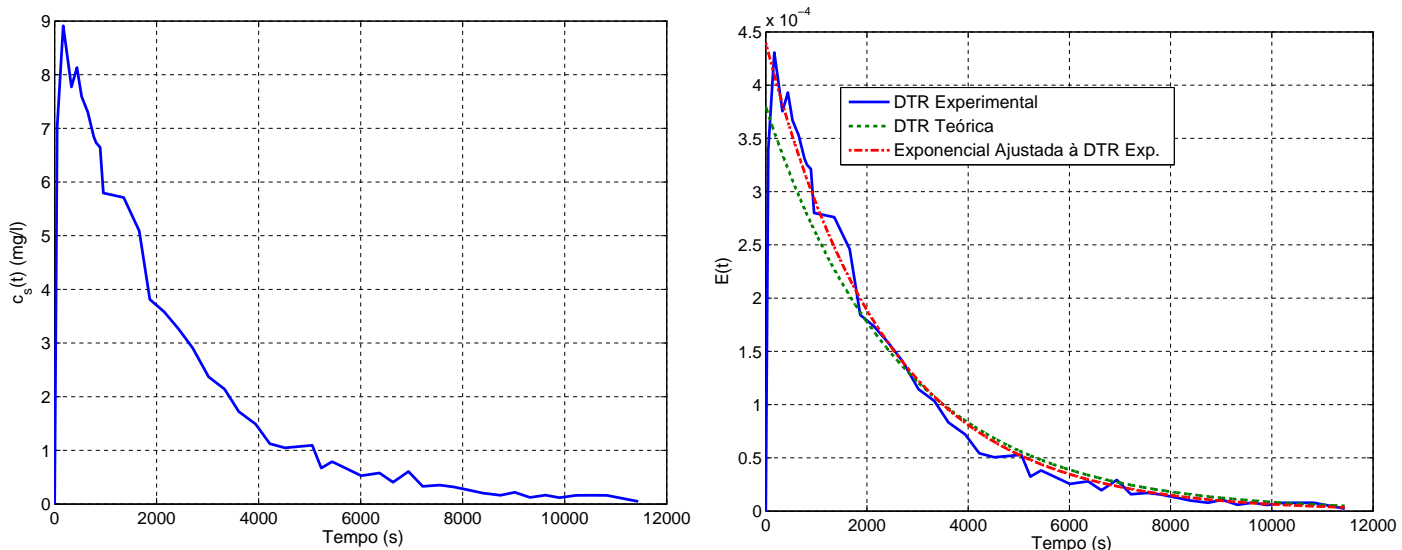

Dados experimentais, $c_{s}(t)$, de: Ramos (2013).

Figura 5.5 - Experimento de DTR com TR operando na condição III.

(a) Curva $c_{s}(t)$ para a condição III.

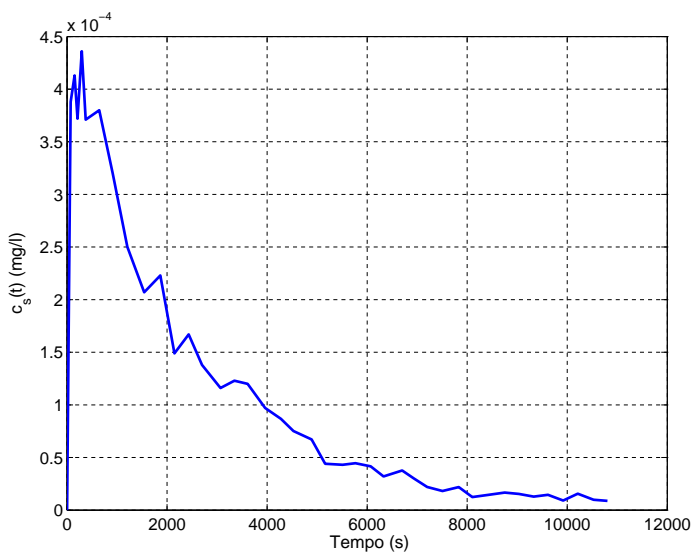

Dados experimentais, $c_{s}(t)$, de: Ramos (2013). (b) Curva $E(t)$ para a condição III.

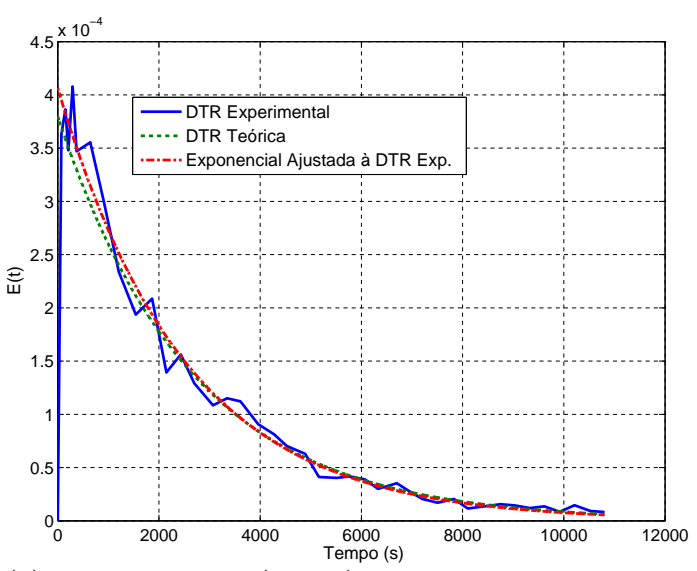

O tempo de residência médio das DTR pode ser calculado através da Eq. (4.65). Como as curvas de DTR apresentaram uma grande similaridade com a função exponencial, pode-se concluir que a região de fluxo de pistão do TR possui um volume muito baixo, podendo ser desprezado. Desta forma, o volume ativo do TR, $V_{a}$, pode ser considerado igual ao volume perfeitamente agitado, $V_{m}$. Estes volumes e o volume morto do TR, $V_{d}$, podem ser calculados através das equações:

$$
\begin{gathered}
\bar{t}=\frac{V_{a}}{F_{s}} \\
V_{d}=V-V_{a},
\end{gathered}
$$

sendo $V$ o volume do TR. A Tabela 5.1 apresenta as características de cada DTR, de onde pode-se concluir que o teste apresenta uma boa repetibilidade, visto que os dois experimentos realizados na condição I apresentaram resultados semelhantes. Percebe-se 
ainda que as sugestões de Ramos (2013) acarretaram em um aumento do volume ativo do reator, tornando-o mais próximo do ideal. Apesar da condição III ter apresentado os resultados mais próximos do ideal, devido à grande turbulência gerada pelo aumento na rotação, o sensor de nível do TR sofreu grandes perturbações, aumentando a possibilidade de ocorrência de atuação espúria do sistema de proteção da Planta Piloto. Assim, a condição II foi escolhida a padrão da Planta Piloto.

Tabela 5.1 - Características da DTR para cada condição de teste.

\begin{tabular}{lcccc}
\hline Característica & Condição I & Condição I(2) & Condição II & Condição III \\
\hline$\tau(\mathrm{s})$ & 2277,1 & 2277,1 & 2632,9 & 2632,9 \\
$\bar{t}(\mathrm{~s})$ & 1670,6 & 1747,2 & 2201,2 & 2441,4 \\
$V(\mathrm{l})$ & 39,6 & 39,6 & 45,7 & 45,7 \\
$V_{a}(\mathrm{l})$ & 29 & 30,3 & 38,2 & 42,4 \\
$V_{d}(\mathrm{l})$ & 10,6 & 9,3 & 7,5 & 3,3 \\
$\frac{V-V_{d}}{V} \cdot 100(\%)$ & 73,4 & 76,7 & 83,6 & 92,7 \\
\hline \multicolumn{5}{c}{ Fonte: do Autor. }
\end{tabular}

\subsubsection{O Tempo de Mistura}

O tempo de mistura de um reator é definido como o tempo necessário para misturar dois fluidos miscíveis até que se obtenha um valor pré-determinado de homogeneidade (GRENVILLE, 1992). Neste trabalho, o tempo de mistura é o tempo necessário para misturar dois fluidos até obter uma homogeneidade de $95 \%$ no fluido do reator. Na modelagem da fluidodinâmica, o tempo de mistura é aproximado como um tempo morto.

A partir das dimensões do reator e de seu padrão de escoamento, pode-se predizer o tempo de mistura de determinado reator. O número de Reynolds do TR pode ser calculado como (ALBRIGHT, 2008):

$$
R e=\frac{T^{2} N \rho}{\mu},
$$

sendo $T$ o diâmetro do TR em $\mathrm{m}, N$ a rotação do agitador em $\mathrm{s}^{-1}, \rho$ a massa específica do fluido do TR em $\mathrm{kg} / \mathrm{m}^{3}$ e $\mu$ a viscosidade dinâmica do fluido do TR em Pa. s. Para $25^{\circ} \mathrm{C}$, o número de Reynolds do TR é:

$$
R e=\frac{0,4^{2} \cdot 13,33 \cdot 997}{10^{-3}}=2,1 \cdot 10^{6}
$$

Como $R e>10^{4}$, o escoamento no TR pode ser considerado turbulento (ALBRIGHT, 2008).

Com base em dados experimentais, Grenville (1992) observou correlações entre a potência e rotação do agitador e as dimensões do reator com seu tempo de mistura, 
sugerindo as seguintes relações matemáticas para o escoamento turbulento:

$$
\begin{gathered}
P_{o}^{\frac{1}{3}} N \theta_{95}\left(\frac{D^{2}}{T^{1,5} Z^{0,5}}\right)=5,20 \\
P_{o}=\frac{P}{\rho N^{3} D^{5}},
\end{gathered}
$$

sendo $P_{o}$ o coeficiente de arraste do impelidor, no regime turbulento, $N$ a rotação do agitador, em rps, $\theta_{95}$ o tempo de mistura para homogeneidade de $95 \%$, em s, $D$ o diâmetro do agitador, em $\mathrm{m}, T$ o diâmetro do reator, em $\mathrm{m}, Z$ o nível de água, em $\mathrm{m}, \rho$ a massa específica da água em $\mathrm{kg} / \mathrm{m}^{3}$ e $P$ a potência do agitador, em $W$. De acordo com estes cálculos, o tempo de mistura da Planta Piloto é:

$$
\begin{gathered}
P_{o}=\frac{255}{997(800 / 60)^{3} 0,105^{5}}=67,6 \\
\theta_{95}=\frac{5,2 \cdot 0,4^{1,5} \cdot 0.37^{0,5}}{0,105^{2} \cdot 67,6^{\frac{1}{3}} \cdot(800 / 60)}=1,34 \mathrm{s.}
\end{gathered}
$$

\subsection{Análise das Curvas de Titulação da Planta Piloto}

É necessário realizar curvas de titulação das soluções utilizadas na Planta Piloto por dois motivos: i. certificar que as concentrações das soluções são aquelas como calculadas e ii. verificar o quão próximo do ideal as curvas de titulação estão pois, a presença de ácidos e bases fracos (provenientes do sistema público de distribuição de água, por exemplo) podem distorcer significativamente o ganho da planta (Seção 4.1.9).

As curvas de titulação foram realizadas no próprio TR, que para estes testes foi operado na forma de batelada. O procedimento experimental consistiu nas seguintes etapas:

1. Preparação das soluções da Planta Piloto conforme a Seção 5.1;

2. Esvaziamento completo do TR;

3. Enchimento do TR com $20 \mathrm{l}$ da solução a ser titulada, $\mathrm{HCl}$ ou $\mathrm{CH}_{3} \mathrm{COOH}$;

4. Inicialização da coleta de dados da Planta Piloto, com a vazão de base constante em aproximadamente $5 \mathrm{l} / \mathrm{h}$ e agitação contínua no TR;

5. Finalização do teste quando o pH do TR for aproximadamente 12; e

6. Anotar o valor final do nível no TR.

A vazão de base foi escolhida criteriosamente, pois necessita ser baixa para este método dinâmico de levantamento de curvas de titulação (MCMILLAN; CAMERON, 2004). Como a curva de titulação é construída de forma estática, ou seja, adicionando o volume de titulante de forma discreta, a vazão de base deve ser baixa o suficiente para que seja 
possível transformar a resposta dinâmica da planta em uma resposta estática. Para tanto, o volume de base foi calculado como:

$$
\Delta V=V_{2}-V_{1}
$$

sendo $V_{2}$ o volume final no TR e $V_{1}$ o volume inicial no TR e $\Delta V$ é o volume de base adicionado ao TR. A vazão média de base durante o experimento é

$$
\bar{F}_{b}=\frac{\Delta V}{t_{e x p}}
$$

onde $\bar{F}_{b}$ é a vazão média de base e $t_{\text {exp }}$ é a duração do experimento. Sabendo-se a vazão média de base, pode-se calcular o volume de base adicionado no TR, para cada instante de tempo:

$$
V_{b}(t)=\int_{0}^{t} \bar{F}_{b} \mathrm{~d} t,
$$

sendo $V_{b}$ o volume de base adicionado ao TR. Assim, a curva de titulação foi construída a partir das variáveis $V_{b}(t)$ e $\mathrm{pH}(t)$, sendo o último o $\mathrm{pH}$ no $\mathrm{TR}$, para cada instante de tempo. Como as medições apresentaram ruído de medição, foi necessário utilizar um algoritmo do MATLAB ${ }^{\circledR}$ para a suavização da curva de titulação obtida experimentalmente, minimizando assim os ruídos na forma diferencial da curva de titulação. Deve-se enfatizar que a suavização deve ser realizada de forma a distorcer o mínimo possível a curva de titulação experimental.

A Figura 5.6 apresenta a curva de titulação realizada com a solução proveniente do TAP. Analisando-se a curva de titulação, a primeira conclusão a que se chega é que as soluções do TAP e TBB estão com as concentrações desejadas, já que o TR apresentou pH neutro para um volume de base de 6,33 l, sendo que o volume de base teórico necessário para neutralizar a solução do TAP deveria ser (Eq. (4.41)) 6,05, o que corresponde a um desvio de menos de 5\%. Adicionalmente, comparando a Figura 5.6 com sua curva de titulação teórica, na Figura 4.1, pode-se concluir que existem ácidos e bases fracos indeterminados, nas soluções da Planta Piloto. Estes ácidos e bases fracos indeterminados são referenciados como perturbações da curva de titulação, daqui em diante.

A curva de titulação realizada com a solução proveniente do TAS está apresentada na Figura 5.7. Pode-se concluir que a solução do TAS também está com a concentração desejada pois, supondo que todas as moléculas do ácido acético estejam dissociadas no pH neutro, o volume de base teórico necessário para neutralizar a solução inicial no TR é de 7,35 l, sendo que o observado foi de 7,63 l, o que corresponde a um erro menor que 5\%. Ainda, a forma diferencial sugere que existem perturbações na curva de titulação, visto que após o pH neutro, a curva de titulação deveria ser quase vertical, o que resultaria em valores elevados na forma diferencial da curva de titulação. 
Figura 5.6 - Curva de titulação da solução do TAP, sendo o titulado $[\mathrm{HCl}]=0,0056 \mathrm{~mol} / \mathrm{l}$ e o titulante $[\mathrm{NaOH}]=0,0185$ $\mathrm{mol} / \mathrm{l}$.

(a) Curva de titulação.

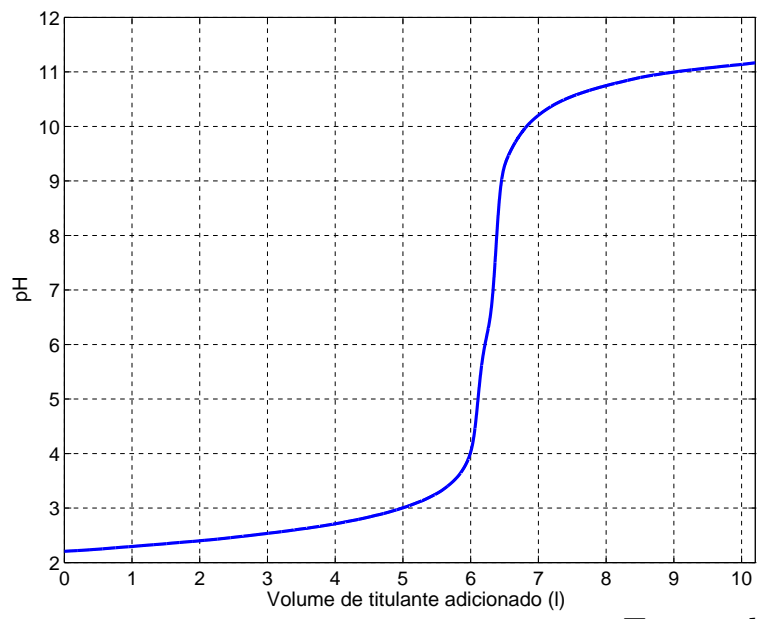

(b) Forma diferencial da curva de titulação.

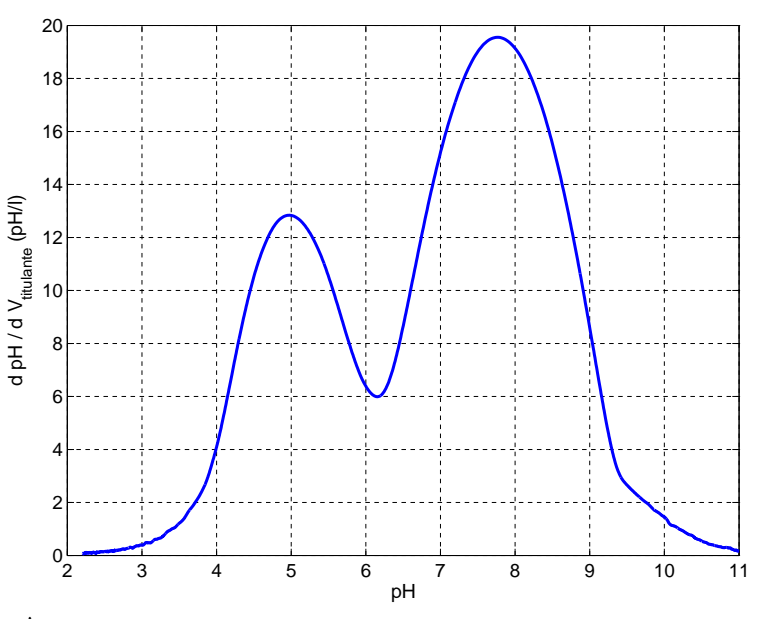

Fonte: do Autor.

Figura 5.7 - Curva de titulação da solução do TAS, sendo o titulado $\left[\mathrm{CH}_{3} \mathrm{COOH}\right]=0,0068 \mathrm{~mol} / \mathrm{l}$ e o titulante $[\mathrm{NaOH}]=$ $0,0185 \mathrm{~mol} / \mathrm{l}$.

(a) Curva de titulação.

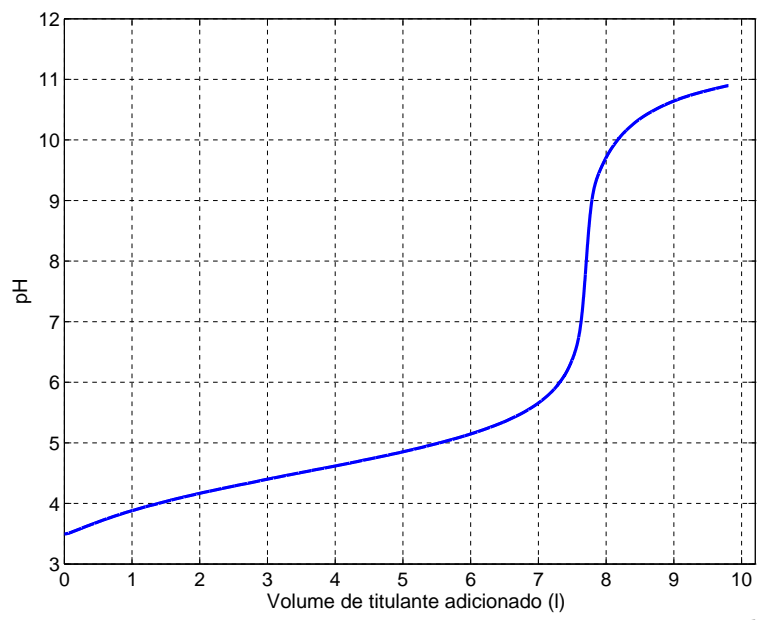

Fonte: do Autor. (b) Forma diferencial da curva de titulação.

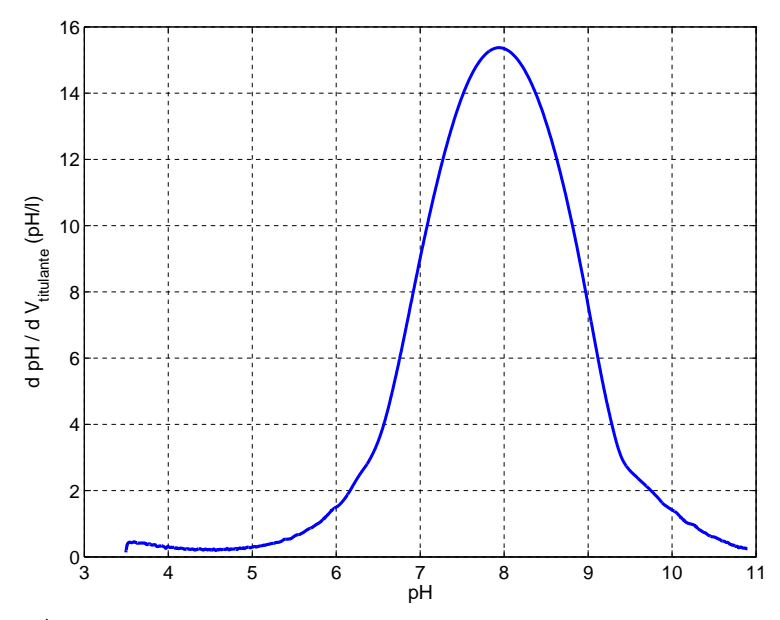

\subsection{Modelagem Estática do pH}

A modelagem estática do $\mathrm{pH}$ consiste na estimativa das perturbações que existem na curva de titulação. Caso a curva de titulação do modelo matemático não seja próxima da curva de titulação experimental, o ganho do modelo difere consideravelmente do ganho da planta. Jutila e Visala (1984) sugeriram que a curva de titulação do modelo seja ajustada utilizando-se ácidos fracos hipotéticos. Dito em outras palavras, sugeriram que ao invés de buscar conhecer os ácidos e bases fracos que estão presentes fisicamente na solução, pode-se supor que existam determinados ácidos, com dada concentração e constantes de dissociação, 
que resultam em uma curva de titulação próxima do encontrado na prática. No entanto, decidiu-se supor a existência das espécies mais prováveis de estarem presentes na Planta Piloto, ao invés de buscar livremente as constantes de dissociação e as concentrações das perturbações da curva de titulação. Desta forma, apenas a concentração de determinadas espécies foi estimada.

A primeira hipótese de espécie presente na Planta Piloto é o ácido carbônico $\mathrm{H}_{2} \mathrm{CO}_{3}$, pois esta é uma perturbação frequente em plantas de neutralização de pH (MCMILLAN; CAMERON, 2004). A água possui uma solubilidade ao gás carbônico, a qual depende de uma constante (dependente da temperatura) e da fração molar do $\mathrm{CO}_{2}$, como afirmado pela lei de Henry (Apêndice A). Apesar da fração molar de $\mathrm{CO}_{2}$ ser muito baixa na atmosfera (cerca de 0,0380\% do volume da atmosfera), as soluções básicas tendem a absorver o gás carbônico da atmosfera, através das reações (HIKITA; ASAI; TAKATSUKA, 1976; POHORECKI; MONIUK, 1988):

$$
\begin{gathered}
\mathrm{CO}_{2(\mathrm{~g})} \rightleftharpoons \mathrm{CO}_{2(\mathrm{aq})} \\
\mathrm{CO}_{2(\mathrm{aq})}+\mathrm{OH}^{-}{ }_{(\mathrm{aq})} \rightleftharpoons \mathrm{HCO}_{3}{ }^{-}{ }_{(\mathrm{aq})} \\
\mathrm{HCO}_{3}{ }_{(\mathrm{aq})}+\mathrm{OH}^{-}{ }_{(\mathrm{aq})} \rightleftharpoons \mathrm{CO}_{3}{ }^{2-}{ }_{(\mathrm{aq})}+\mathrm{H}_{2} \mathrm{O}_{(\mathrm{l})} .
\end{gathered}
$$

A constante de equilíbrio da Reação (5.33b) é da ordem de $6 \cdot 10^{7}$, podendo ser considerada irreversível na prática. Esta reação é de primeira ordem e dependente das concentrações do gás carbônico dissolvido e da hidroxila:

$$
r_{2}=k_{2}\left[\mathrm{CO}_{2}\right]\left[\mathrm{OH}^{-}\right]
$$

sendo $r_{2}$ a taxa da reação (5.33b), em s ${ }^{-1}$ e $k_{2}$ a constante da taxa da reação $(5.33 \mathrm{~b})$, que é da ordem de $12200 \mathrm{l} /(\mathrm{mol} \mathrm{s})$.

Outros íons que são prováveis de estarem presentes nas soluções da Planta Piloto são aqueles que provêm do sistema de distribuição público de água. Richter et al. (2007) detectou a presença de diversos íons na represa que abastece a região da Planta Piloto. Dentre os íons detectados, aqueles que possuem constante de dissociação na faixa de operação do pH (entre 2 e 12) são os que podem ser perturbações na curva de titulação. Assim, considera-se que os íons $\mathrm{CH}_{3} \mathrm{COO}^{-}, \mathrm{NH}_{4}{ }^{+}$e $\mathrm{PO}_{4}{ }^{3-}$ podem também estar presentes nas soluções da Planta Piloto.

\subsubsection{A Absorção de Gás Carbônico}

Para testar a hipótese relativa à absorção de $\mathrm{CO}_{2}$ nas soluções da Planta Piloto, foi realizado um experimento que consistiu em preparar as soluções da Planta Piloto e utilizá-las para realizar cinco curvas de titulação, seguindo o procedimento da Seção 5.4. Assim, cada curva de titulação corresponde a um tempo decorrido após o preparo das soluções, as quais estão apresentadas na Figura 5.8. 
Como a solubilidade do gás carbônico na água é função da temperatura, esta foi registrada ao longo de todos os experimentos, assumindo valores entre $20,5 \pm 1^{\circ} \mathrm{C}$. Assim, a temperatura foi considerada aproximadamente constante durante todo o período dos experimentos.

Figura 5.8 - Curvas de titulação realizadas $t$ horas após o preparo das soluções, sendo o titulado $[\mathrm{HCl}]=0,0056 \mathrm{~mol} / \mathrm{l} \mathrm{e}$ o titulante $[\mathrm{NaOH}]=0,0185 \mathrm{~mol} / \mathrm{l}$.

(a) Curva de titulação.

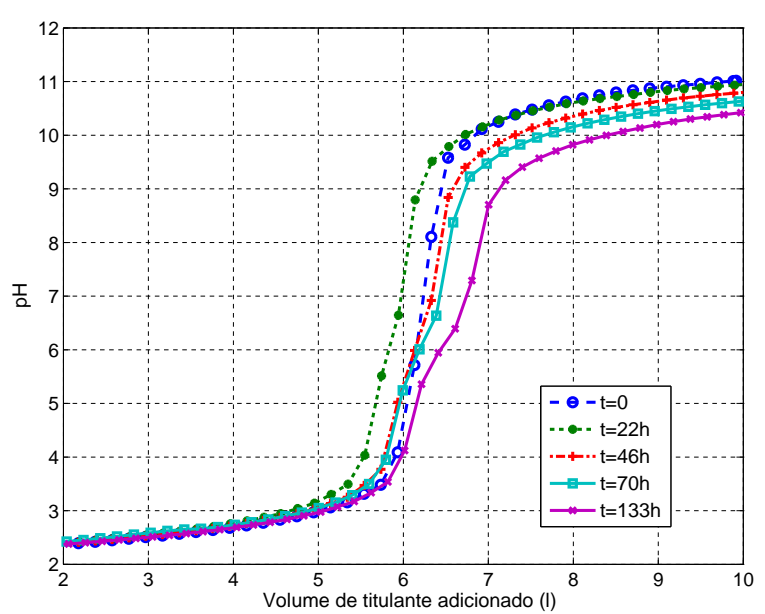

(b) Forma diferencial da curva de titulação.

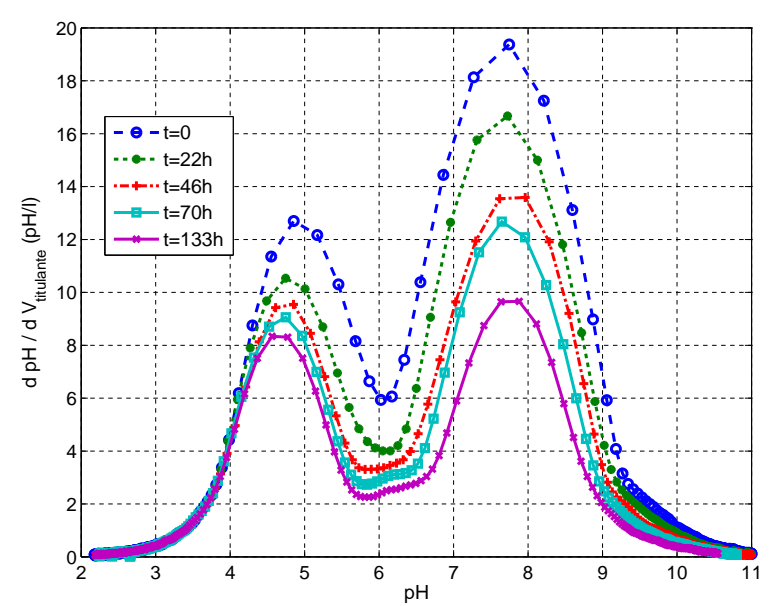

Fonte: do Autor.

Analisando-se a Figura 5.8b, pode-se notar que a forma diferencial das curvas de titulação sofreram alterações ao longo do tempo. A tendência observada é de diminuição do ganho da planta ao longo do tempo, sendo que em alguns pontos de operação chegou a ser reduzido em aproximadamente 50\%. Quanto à Figura 5.8a, analisando-se os valores de $\mathrm{pH}$ inicial e final dos experimentos, fica evidente que o $\mathrm{pH}$ da solução ácida do TAP não sofreu alterações significativas ao longo do tempo, enquanto o pH da solução básica do TBB seguiu diminuindo. Desta forma, conclui-se que principalmente a solução do TBB está sujeita à absorção de gás carbônico, conforme a Reação (5.33b).

Uma outra hipótese testada experimentalmente foi a de que a agitação por borbulhamento teria a capacidade de acelerar a cinética da Reação (5.33a). Para tanto, novas soluções foram preparadas para a Planta Piloto, conforme a Seção 5.1. Uma curva de titulação foi realizada logo após o preparo das soluções da Planta Piloto. Em seguida, as soluções foram agitadas novamente por um período de 30 minutos, sendo realizada outra curva de titulação ao final do novo período de agitação. Os resultados deste experimento estão apresentados na Figura 5.9. A Figura 5.9b, sugere que não houve diferença significativa no ganho da planta, após ter-se agitado as soluções por mais 30 minutos. Desta forma, conclui-se que a cinética da Reação (5.33b) não é significativamente alterada pela agitação por borbulhamento. 
Figura 5.9 - Curvas de titulação realizadas com diferentes tempos de agitação por borbulhamento, $t_{a g}$, sendo o titulado $[\mathrm{HCl}]=0,0056 \mathrm{~mol} / \mathrm{l}$ e o titulante $[\mathrm{NaOH}]=0,0185$ $\mathrm{mol} / \mathrm{l}$.

(a) Curva de titulação.

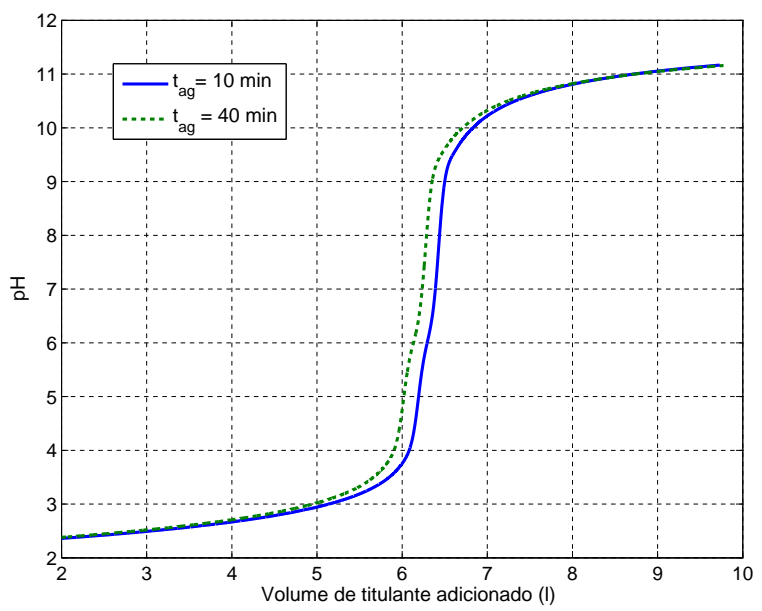

(b) Forma diferencial da curva de titulação.

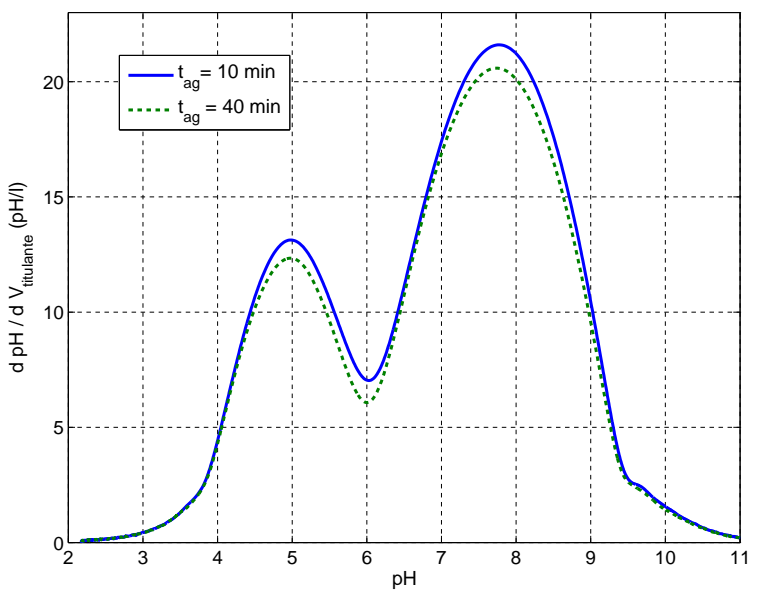

Fonte: do Autor.

\subsubsection{Estimação das Concentrações das Perturbações}

As concentrações das perturbações foram estimadas através de busca exaustiva. O método de estimativa consistiu no desenvolvimento de um algoritmo com as equações de neutralização de pH através dos invariantes de reação (Eq. (4.36) e (4.39)). Os invariantes de reação e as constantes de dissociação dos ácidos e bases (à pressão de 1 atm e temperatura de $25^{\circ} \mathrm{C}$ ) foram considerados os seguintes (DEAN, 1999):

$$
\begin{aligned}
& w_{T R_{1}}=[\mathrm{HCl}]-[\mathrm{NaOH}] \\
& p K_{a_{1}}=p K_{b_{1}}=-\infty \\
& w_{T R_{2}}=\left[\mathrm{CH}_{3} \mathrm{COOH}\right] \\
& p K_{a_{2,1}}=4,756 \\
& w_{T R_{3}}=\left[\mathrm{H}_{2} \mathrm{CO}_{3}\right] \\
& p K_{a_{3,1}}=6,352 \quad p K_{a_{3,2}}=10,329 \\
& w_{T R_{4}}=\left[\mathrm{NH}_{4}^{+}\right] \\
& p K_{a_{4,1}}=9,246 \\
& w_{T R_{5}}=\left[\mathrm{H}_{3} \mathrm{PO}_{4}\right] \\
& p K_{a_{5,1}}=2,148 \\
& p K_{a_{5,2}}=7,198 \\
& p K_{a_{5,3}}=12,32 \text {, }
\end{aligned}
$$

sendo $\mathbf{w}_{T R}$ o vetor de invariantes de reação do TR. Existe ainda os vetores de invariantes de reação de cada uma das soluções da Planta Piloto, denominados $\mathbf{w}_{T B B}, \mathbf{w}_{T A P}$ e $\mathbf{w}_{T A S}$, que são os vetores de invariantes de reação do TBB, TAP e TAS, respectivamente. O invariante de reação relativo ao ácido carbônico do TAP e TAS foi considerado diferente do TBB, em concordância com a análise da subseção anterior. Já os invariantes de reação relativos ao ácido fosfórico e amônio foram considerados os mesmos para todas as soluções da Planta Piloto, já que provêm do sistema de distribuição público de água. O invariante de reação relacionado ao ácido acético foi considerado igual para o TAP e TBB, pois também é proveniente do sistema de distribuição público de água. No entanto, apesar de ser comum a todas as soluções, esta concentração comum pode ser desprezada no TAS, 
afinal este é preparado de forma a apresentar um excesso de ácido acético. Em resumo, os invariantes de reação do TR são calculados conforme a Eq. (4.36) e os invariantes de reação de cada solução da Planta Piloto são os da Tabela 5.2, sendo que as letras gregas representam as concentrações das perturbações que devem ser estimadas.

Tabela 5.2 - Invariantes de reação das soluções da Planta Piloto.

\begin{tabular}{cccc}
\hline Invariante de Reação & TAP & TAS & TBB \\
\hline$w_{1}(\mathrm{~mol} / \mathrm{l})$ & 0,0056 & 0 & $-0,0185$ \\
$w_{2}(\mathrm{~mol} / \mathrm{l})$ & $\alpha$ & $0,0068+\alpha \approx 0,0068$ & $\alpha$ \\
$w_{3}(\mathrm{~mol} / \mathrm{l})$ & $\lambda$ & $\lambda$ & $\beta$ \\
$w_{4}(\mathrm{~mol} / \mathrm{l})$ & $\gamma$ & $\gamma$ & $\gamma$ \\
$w_{5}(\mathrm{~mol} / \mathrm{l})$ & $\zeta$ & $\zeta$ & $\zeta$ \\
\hline
\end{tabular}

Fonte: do Autor.

Com o algoritmo de neutralização e os invariantes de reação de cada solução foi possível simular as curvas de titulação obtidas nas seções anteriores. Por meio da comparação dos dados experimentais com os dados simulados, foi possível estimar as concentrações dos invariantes de reação de todas as curvas de titulação experimentais apresentadas até este momento. Em linguagem matemática, a estimativa das perturbações pode ser escrita como:

$$
\begin{aligned}
\arg _{\alpha, \lambda, \beta, \gamma, \zeta} \min & \left\|\frac{\mathrm{d} \mathrm{pH}}{\mathrm{d} V_{t t}}-\frac{\mathrm{d} \mathrm{pH}}{\mathrm{d} V_{t t}}\right\| \\
\text { sujeito a } & \alpha \in\left[0,2,8 \cdot 10^{-4}\right] \\
& \lambda, \beta \in[0, \infty] \\
& \gamma \in\left[0,21 \cdot 10^{-4}\right] \\
& \zeta \in\left[0,1 \cdot 10^{-4}\right],
\end{aligned}
$$

sendo $\alpha, \beta, \gamma$ e $\zeta$ as concentrações dos invariantes de reação a serem estimadas, $\mathrm{d}_{\mathrm{pH}} / \mathrm{d} V_{t t} \in$ $\Re^{n}$ e d $\mathrm{pH}_{s} / \mathrm{d} V_{t t} \in \Re^{n}$ são os vetores de ganho experimental e simulado, respectivamente, para cada valor de $\mathrm{pH}$ da solução titulada e $V_{t t}$ é o volume de titulante adicionado. Os limites da otimização correspondem aos valores de concentração máxima dos íons observados em Richter et al. (2007). A comparação da forma diferencial das curvas de titulação experimentais e simuladas está apresentada na Figura 5.10. Qualitativamente, o ajuste das curvas foi considerado satisfatório, de modo que para se obter um melhor ajuste das curvas de titulação seria necessário incluir novas perturbações, modelar a diminuição do pH do TBB ao longo do tempo e estimar a atividade do íon de hidrogênio da solução titulada, visto que conforme há um excesso de cátions ou ânions na solução, sua atividade tende a diminuir. 
Figura 5.10 - Comparação da forma diferencial das curvas de titulação experimentais e simuladas.

(a) Ajuste para $t=0 \mathrm{~h}$.

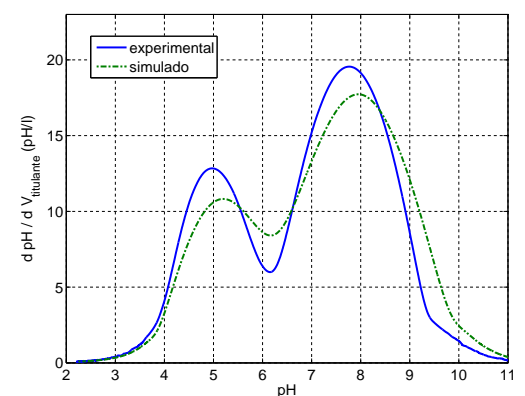

(d) Ajuste para $t=70 \mathrm{~h}$.

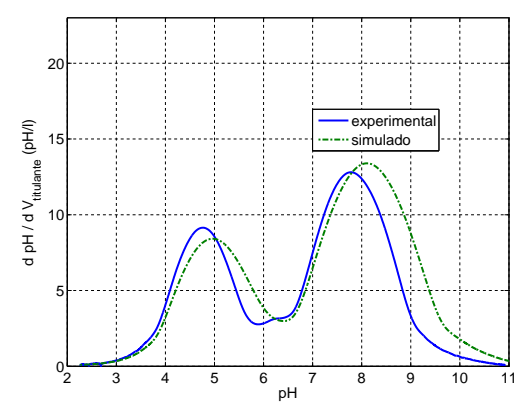

(b) Ajuste para $t=22 \mathrm{~h}$.

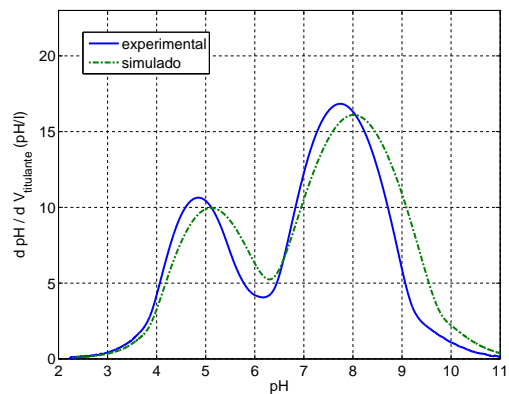

(e) Ajuste para $t=133 \mathrm{~h}$.

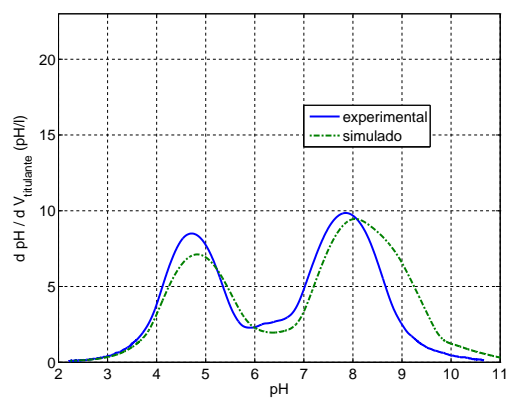

(c) Ajuste para $t=46 \mathrm{~h}$.

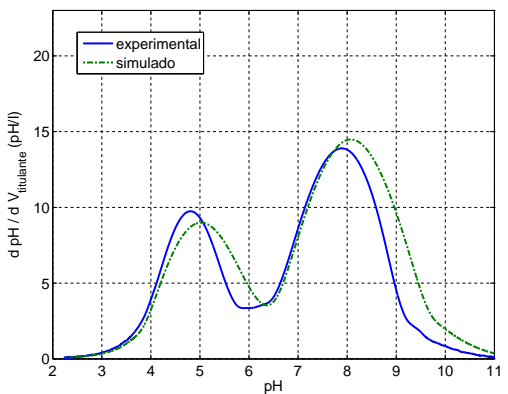

(f) Ajuste para $t_{a g}=10 \mathrm{~min}$.

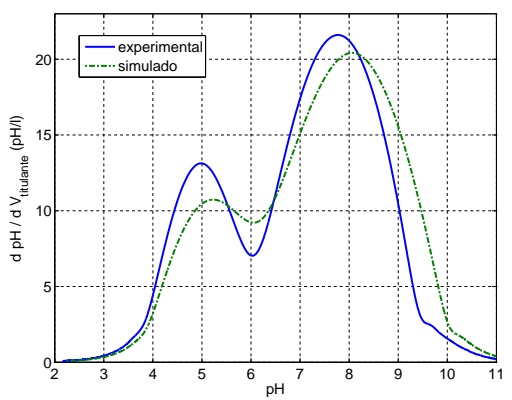

(g) Ajuste para $t_{a g}=40$ min. (h) Ajuste para $\mathrm{CH}_{3} \mathrm{COOH}$.
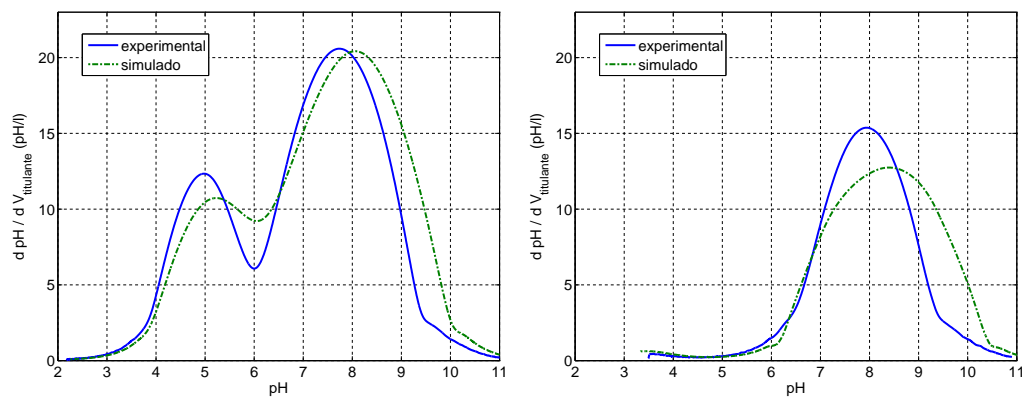

Fonte: do Autor.

A Tabela 5.3 apresenta os parâmetros utilizados na modelagem da forma diferencial das curvas de titulação da Planta Piloto, nas diversas condições de operação e os valores quantitativos do erro de modelagem. O erro de modelagem foi calculado através da soma dos quadrados dos resíduos e seu valor máximo admissível foi considerado 225, valor correspondente a um resíduo de 0,15 para cada um dos 10000 pontos de comparação entre o modelo e os dados experimentais. Como a soma dos quadrados dos resíduos foi de 113, a modelagem da forma diferencial das curvas de titulação foi considerada adequada. Adicionalmente, percebe-se que não existem concentrações únicas para as perturbações das curvas de titulação, pois as concentrações de ácidos provenientes do sistema de distribuição público de água podem variar ao longo do tempo e a concentração de gás carbônico presente no sistema varia mais de $100 \%$ em um período de 6 dias. Conclui-se, portanto, 
que a Planta Piloto possui uma resposta estática do $\mathrm{pH}$ que varia no tempo.

Tabela 5.3 - Concentrações utilizadas para a modelagem da forma diferencial das curvas de titulação da Planta Piloto.

\begin{tabular}{ccccccccc}
\hline $\begin{array}{c}\text { Concentração } \\
(\mathrm{mol} / \mathrm{l})\end{array}$ & $5.10 \mathrm{a}$ & $5.10 \mathrm{~b}$ & $5.10 \mathrm{c}$ & $5.10 \mathrm{~d}$ & $5.10 \mathrm{e}$ & $5.10 \mathrm{f}$ & $5.10 \mathrm{~g}$ & $5.10 \mathrm{~h}$ \\
\hline$\left\|\frac{\mathrm{d} \mathrm{pH} \mathrm{H}_{e}}{\mathrm{~d} V_{t t}}-\frac{\mathrm{d} \mathrm{pH}}{\mathrm{d} V_{t t}}\right\|^{2}$ & 40 & 53 & 58 & 77 & 113 & 55 & 50 & 55 \\
$\alpha$ & $2,5 \cdot 10^{-5}$ & $2,5 \cdot 10^{-5}$ & $2,5 \cdot 10^{-5}$ & $2,5 \cdot 10^{-5}$ & $2,5 \cdot 10^{-5}$ & $3 \cdot 10^{-5}$ & $3 \cdot 10^{-5}$ & 0,0068 \\
$\lambda$ & $1,7 \cdot 10^{-4}$ & $1,9 \cdot 10^{-4}$ & $2,7 \cdot 10^{-4}$ & $3 \cdot 10^{-4}$ & $5 \cdot 10^{-4}$ & $1,55 \cdot 10^{-4}$ & $1,55 \cdot 10^{-4}$ & $7 \cdot 10^{-5}$ \\
$\beta$ & $1,7 \cdot 10^{-4}$ & $3,5 \cdot 10^{-4}$ & $4,3 \cdot 10^{-4}$ & $6 \cdot 10^{-4}$ & $9 \cdot 10^{-4}$ & $1,7 \cdot 10^{-4}$ & $1,7 \cdot 10^{-4}$ & $1,3 \cdot 10^{-4}$ \\
$\gamma$ & $6,5 \cdot 10^{-5}$ & $6,5 \cdot 10^{-5}$ & $6,5 \cdot 10^{-5}$ & $6,5 \cdot 10^{-5}$ & $6,5 \cdot 10^{-5}$ & $2 \cdot 10^{-5}$ & $2 \cdot 10^{-5}$ & $2 \cdot 10^{-5}$ \\
$\zeta$ & 0 & 0 & 0 & 0 & 0 & 0 & 0 & $1 \cdot 10^{-5}$ \\
\hline \multicolumn{8}{c}{ Fonte: do Autor. }
\end{tabular}

Como a Planta Piloto apresenta características variantes no tempo, considera-se que as estimativas da Tabela 5.3 são as concentrações típicas das perturbações das curvas de titulação da Planta Piloto.

\subsubsection{Análise das Variações das Constantes de Dissociação com a Temperatura}

A Eq. (A.103), ao ser integrada, considerando-se a entalpia da reação constante ao longo da faixa de temperatura, resulta na equação de Van’t Hoff:

$$
\ln \frac{K_{2}}{K_{1}}=-\frac{\Delta_{r} H^{\circ}}{R}\left(\frac{1}{T_{2}}-\frac{1}{T_{1}}\right),
$$

onde $K_{1}$ é a constante de dissociação na temperatura $T_{1}$ e $K_{2}$ é a constante de dissociação na temperatura $T_{2}$. A equação de Van’t Hoff pode ser utilizada para pequenas variações de temperatura, pois esta se trata de uma linearização.

Ainda, é possível utilizar as informações provenientes dos manuais de propriedades químicas, como (DEAN, 1999), os quais fornecem informações a respeito das constantes de dissociação para várias temperaturas, as quais podem ser utilizadas para estimar as constantes de dissociação. A Tabela 5.4 apresenta as constantes de dissociação dos ácidos e bases considerados na modelagem da Planta Piloto, para várias temperaturas. As constantes de dissociação da Planta Piloto são calculadas através da interpolação linear dos dados da Tabela 5.4, sendo que a temperatura do TR é considerada constante, visto que as variações de temperatura observadas experimentalmente (de até $2{ }^{\circ} \mathrm{C}$ ) não alteram significativamente as constantes de dissociação. 
Tabela 5.4 - Variação das constantes de dissociação das espécies consideradas na Planta Piloto, com relação à temperatura.

\begin{tabular}{ccccc}
\hline \multirow{2}{*}{ Espécie } & $p K_{a}$ ou & $p K_{w}$ na temperatura $\left({ }^{\circ} \mathrm{C}\right)$ \\
& 15 & 20 & 25 & 30 \\
\hline $\mathrm{H}_{2} \mathrm{O}$ & 14,340 & 14,163 & 13,995 & 13,836 \\
$\mathrm{CH}_{3} \mathrm{COOH}$ & 4,758 & 4,757 & 4,756 & 4,757 \\
$\mathrm{H}_{2} \mathrm{CO}_{3}$ & 6,429 & 6,382 & 6,352 & 6,327 \\
$\mathrm{HCO}_{3}{ }^{-}$ & 10,431 & 10,377 & 10,329 & 10,290 \\
$\mathrm{NH}_{4}{ }^{+}$ & 9,564 & 9,400 & 9,245 & 9,093 \\
$\mathrm{H}_{3} \mathrm{PO}_{4}$ & 2,107 & 2,127 & 2,148 & 2,171 \\
$\mathrm{H}_{2} \mathrm{PO}_{4}{ }^{-}$ & 7,231 & 7,213 & 7,198 & 7,189 \\
$\mathrm{HPO}_{4}{ }^{2-}$ & 12,45 & 12,38 & 12,32 & 12,26 \\
\hline \multicolumn{5}{c}{ Fonte: Dean (1999). }
\end{tabular}

\subsubsection{Análise do Coeficiente de Atividade da Planta Piloto}

Conforme a Planta Piloto segue operando, há um acúmulo de íons no reator, provenientes principalmente do hidróxido de sódio, ácido clorídrico e ácido acético. Estes podem acarretar em uma diminuição da mobilidade dos íons de hidrogênio, resultando em erros de predição.

De acordo com o balanço de massa do TR, Eq. (4.58), a concentração máxima dos íons no TR são aquelas das soluções de entrada do TR. Como há possibilidade de operar com TAPI e TASI em conjunto ou isoladamente, deve-se analisar todas as condições de operação do reator:

I Apenas a solução do TAPI está entrando no TR;

II Apenas a solução do TASI está entrando no TR e

III As soluções do TAPI e TASI estão entrando simultaneamente no TR.

Para a condição I, a concentração máxima dos íons é:

$$
\left[\mathrm{Na}^{+}\right]=0,0056 \mathrm{~mol} / \mathrm{l} \text { e }\left[\mathrm{Cl}^{-}\right]=0,0056 \mathrm{~mol} / \mathrm{l} .
$$

Já para a condição II (considerando todos os íons do ácido acético dissociados):

$$
\left[\mathrm{Na}^{+}\right]=0,0068 \mathrm{~mol} / \mathrm{l} \quad \text { e }\left[\mathrm{CH}_{3} \mathrm{COO}^{-}\right]=0,0068 \mathrm{~mol} / \mathrm{l}
$$

Ainda, na condição III, a concentração máxima dos íons é:

$$
\left[\mathrm{Na}^{+}\right]=0,0124 \mathrm{~mol} / \mathrm{l}, \quad\left[\mathrm{CH}_{3} \mathrm{COO}^{-}\right]=0,0068 \mathrm{~mol} / \mathrm{l} \quad \text { e } \quad\left[\mathrm{Cl}^{-}\right]=0,0056 .
$$

Note que foram desprezadas as concentrações das perturbações, visto que estas são muito menores que as concentrações dos ácidos e bases conhecidos. 
Utilizando-se a equação de Debye-Hückel (Subseção A.5.9), é possível estimar o coeficiente de atividade do íon de hidrogênio para cada condição de operação da Planta Piloto:

$$
\begin{array}{r}
\text { Condição I }-\gamma_{\mathrm{H}^{+}}=0,93 \\
\text { Condição II }-\gamma_{\mathrm{H}^{+}}=0,92 \\
\text { Condição III }-\gamma_{\mathrm{H}^{+}}=0,90 .
\end{array}
$$

Adicionalmente, o coeficiente de atividade médio da solução do TR para condição de operação é:

$$
\begin{array}{r}
\text { Condição I }-\gamma_{ \pm}=0,92 \\
\text { Condição II }-\gamma_{ \pm}=0,92 \\
\text { Condição III }-\gamma_{ \pm}=0,91 .
\end{array}
$$

A dinâmica de acúmulo de íons no TR é de primeira ordem, com constante de tempo igual ao $\tau$ do reator, que é da ordem de 2600 segundos. Como a dinâmica é lenta em relação ao tempo médio de testes na Planta Piloto, que é de 10000 segundos, pode-se desprezar as variações de coeficiente de atividade. Esta dinâmica é ainda mais lenta caso as vazões de entrada no TR sejam menores que as máximas. No entanto, é importante ressaltar que o modelo pode apresentar maiores erros quanto maior o tempo dos experimentos.

\subsection{Modelagem do Nível do TR}

O nível do TR é modelado de acordo com seu balanço de massa, considerando que todas as soluções possuem densidades iguais:

$$
\frac{\mathrm{d} V_{T R}}{\mathrm{~d} t}=F_{T A P I}+F_{T A S I}+F_{T B B}-F_{s}
$$

sendo $V_{T R}$ o volume do reator, $F_{T A P I}$ a vazão volumétrica do TAPI para o TR, $F_{T A S I}$ a vazão volumétrica do TASI para o TR, $F_{T B B}$ a vazão volumétrica do TBB para o TR e $F_{s}$ a vazão de saída do reator. Como $V_{T R}=A_{T R} h_{T R}$, sendo $A_{T R}$ a área da seção transversal do TR e $h_{T R}$ o nível do TR, a Eq. (5.41) pode ser escrita como:

$$
A_{T R} \frac{\mathrm{d} h_{T R}}{\mathrm{~d} t}=F_{T A P I}+F_{T A S I}+F_{T B B}-F_{s}
$$

A área da seção transversal do TR foi calculada de acordo com os dados do Capítulo 3, descontando-se as áreas dos diversos instrumentos e equipamentos que nele estão inseridos, que foram todos considerados cilíndricos, com diâmetros conforme a Tabela 5.5 . 
Tabela 5.5 - Diâmetros dos instrumentos e equipamentos inseridos no TR.

\begin{tabular}{cc}
\hline Instrumento / Equipamento & Diâmetro $(\mathrm{mm})$ \\
\hline Eixo do Agitador & 9,6 \\
Condutivímetro & 33,5 \\
pHmetro & 34 \\
Aquecedor & 11,4 \\
\hline
\end{tabular}

Fonte: do Autor.

A modelagem da vazão da válvula de controle de nível do TR, LV-16A, foi feita de acordo com a equação:

$$
F_{s}=K_{v} \sqrt{\Delta P}
$$

sendo $C_{v}$ o coeficiente de vazão da válvula e $\Delta P$ a diferença de pressão entre entrada e saída da válvula. Como tanto o fluido do TR e a saída da válvula estão à pressão atmosférica, pode-se simplificar a Eq. (5.43),

$$
F_{s}=K_{v} \sqrt{\rho g h_{T R}}
$$

sendo $g$ a aceleração da gravidade e $\rho$ a massa específica do fluido no TR. Como $\rho$ e $g$ podem ser considerados constantes, pode-se definir uma nova variável $K=K_{v} \sqrt{\rho g}$. Esta constante foi estimada através de busca exaustiva, a partir de dados experimentais, sendo seu valor igual a $K=11 \cdot 10^{-2} \mathrm{l} /(\mathrm{s} \sqrt{\mathrm{m}})$.

\subsection{Modelagem da Instrumentação e Bomba Dosadora}

Todos os instrumentos foram modelados através de funções de transferência de primeira ordem com tempo morto. Para determinar suas constantes de tempo e tempos mortos, realizaram-se testes do tipo excitação ao degrau. Todos os parâmetros das funções de transferência foram estimados com a ferramenta de identificação de sistemas do MATLAB ${ }^{\circledR}$.

Os testes de excitação degrau no pHmetro foram realizados através de sua imersão em três soluções com pH distintos, sendo uma ácida, uma básica e outra neutra. A partir dos dados experimentais, foram estimados o tempo morto e a constante de tempo de cada excitação ao degrau. Os dados experimentais estão apresentados na Figura 5.11. As diversas excitações resultaram em estimativas dos parâmetros da função de transferência do pHmetro, sendo que optou-se por calcular a média destes para obter a função de transferência resultante para o pHmetro, que é:

$$
G_{\mathrm{pH}}(s)=\frac{1}{5 s+1} e^{-3,5 s} .
$$

De maneira similar, os transmissores de vazão foram excitados pela abertura e fechamento das válvulas de interligação do TAPI e TASI com o TR. Deste experimento, 
Figura 5.11 - Excitação do pHmetro para estimação de sua dinâmica.

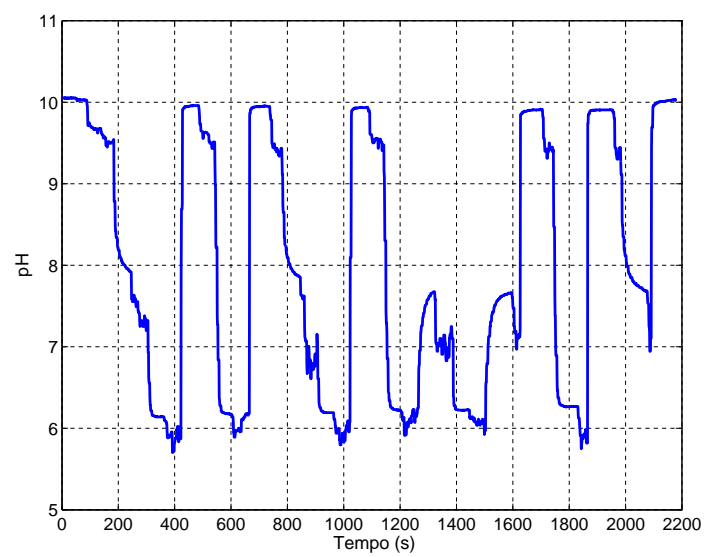

Fonte: do Autor.

cujos dados estão apresentados na Figura 5.12, estimaram-se os parâmetros da função de transferência do transmissor de vazão, que são:

$$
G_{v}(s)=\frac{1}{1,4 s+1} e^{-3,5 s} .
$$

Figura 5.12 - Excitação do transmissor de vazão para estimação de sua dinâmica.

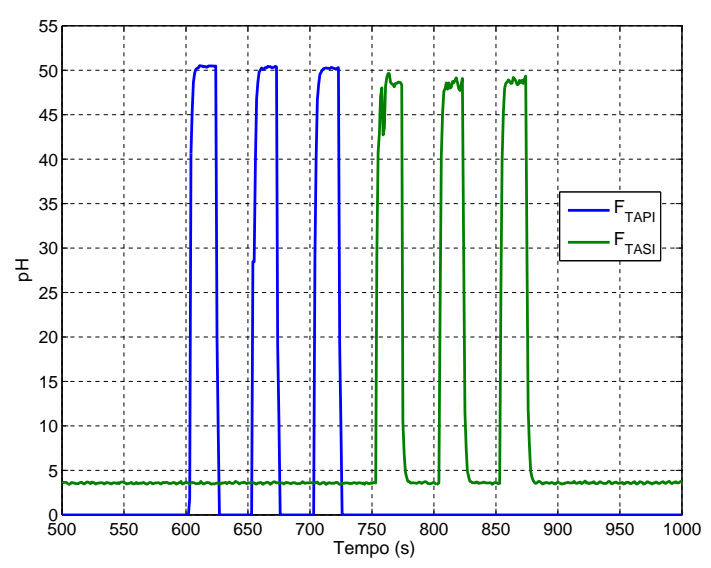

Fonte: do Autor.

Já o transmissor de nível do TR foi excitado através da adição de determinado volume, em degrau. Os resultados do experimento podem ser vistos na Figura 5.13. Deste teste, obteve-se a função de transferência do transmissor de nível:

$$
G_{n}(s)=\frac{1}{16 s+1} e^{-6 s}
$$


Figura 5.13 - Excitação do transmissor de nível para estimação de sua dinâmica.

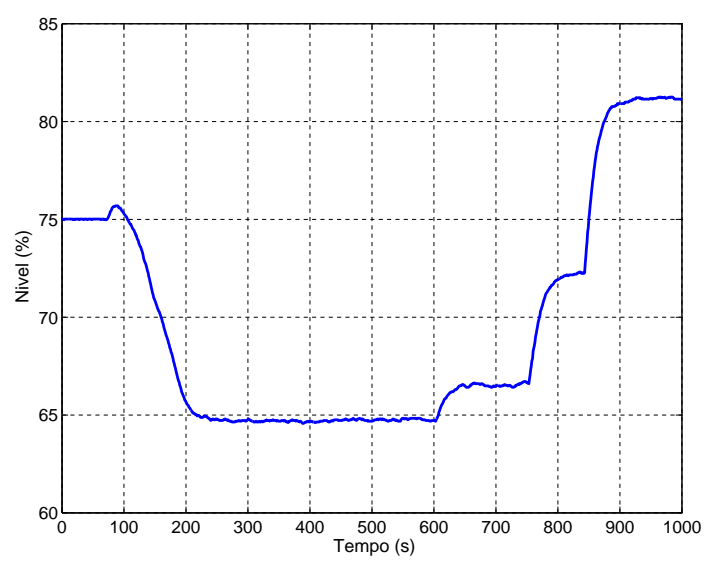

Fonte: do Autor.

Adicionalmente, notou-se que o agitador mecânico causa distúrbios na medição de nível do TR. Assim, realizou-se um experimento com o objetivo de determinar a interferência do agitador na medição de nível. O teste consistiu em comparar o valor do nível medido com e sem agitação, estando os resultados deste experimento apresentados na Figura 5.14. Assim, o deslocamento causado pelo agitador deve ser somado à resposta do transmissor de nível.

Figura 5.14 - Interferência do agitador mecânico na medição de nível do TR.

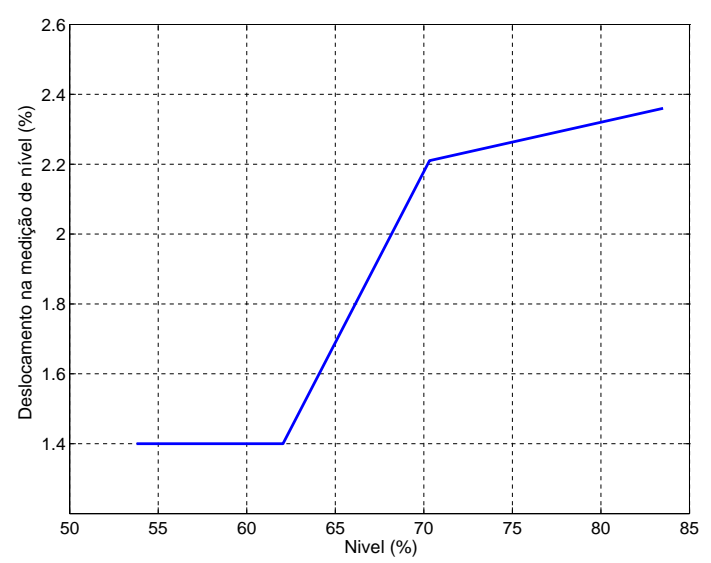

Fonte: do Autor.

A bomba dosadora é modelada de acordo com os dados da Figura 3.3 e considerandose que sua resposta seja instantânea, com relação às variações no sinal de controle.

É importante mencionar que os valores elevados de tempo morto e constante de tempo das funções de transferência, utilizadas para representar os instrumentos, são oriundas da comunicação OPC e dos filtros de medição dos transmissores.

Os ruídos de medição foram modelados como um sinal gaussiano de média zero somado à medição dos instrumentos. Sua variância foi calculada, considerando-se que $95 \%$ 
das medições do instrumento estão contidas no intervalo de precisão especificado pelo fabricante.

\subsection{O Modelo da Planta Piloto}

Esta Seção tem por objetivo apresentar como as informações contidas neste capítulo são relacionadas de forma a resultar no modelo da Planta Piloto. A Figura 5.15 apresenta uma visão geral do modelo da Planta Piloto.

Figura 5.15 - Visão geral do modelo da Planta Piloto.

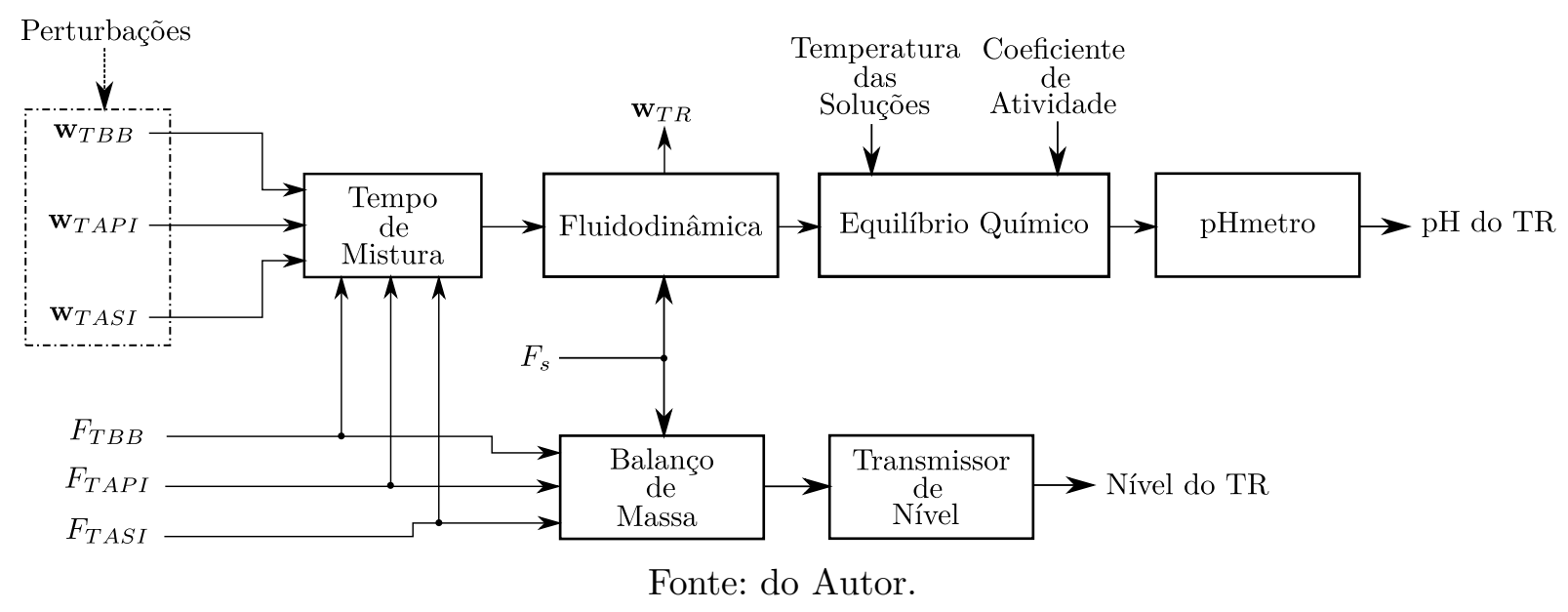

Os invariantes de reação do TR são calculados de acordo com a fluidodinâmica do reator, utilizando-se a Eq. (4.54) e o equilíbrio químico é calculado como na Eq. (4.34).

Neste ponto deve estar claro que as perturbações da Planta Piloto têm componentes estocásticas e variantes no tempo, pois dependem da composição da água do sistema de distribuição público de água e da absorção do gás carbônico. Ademais, estas perturbações têm grande importância na modelagem da Planta Piloto, pois apesar de possuírem concentração muito abaixo das concentrações utilizadas, causam grandes distúrbios nas curvas de titulação da Planta Piloto.

Este capítulo apresentou o método utilizado para modelar matematicamente a Planta Piloto, o qual consistiu principalmente na modelagem da fluidodinâmica do reator, a partir de experimentos de DTR e modelagem da resposta estática do pH, a partir de curvas de titulação realizadas com as soluções da planta de neutralização de pH. 


\section{Validação do Modelo da Planta Piloto}

Neste capítulo, o modelo matemático da Planta Piloto é validado através de comparações quantitativas e qualitativas com dados obtidos experimentalmente. Foram realizados experimentos em malha fechada e aberta para tais comparações.

O controlador de pH (AIC-40) utilizado para os testes em malha fechada é um controlador do tipo Proporcional Integral paralelo (o ganho proporcional não multiplica os termos integrais e derivativos), de ganho igual a 1,5 e tempo integral igual a $200 \mathrm{~s} / \mathrm{rep}$, sendo que o sinal de $\mathrm{pH}$ utilizado pelo controlador foi adimensionalizado para $0-100 \%$. O controlador de nível (LIC-16) é do tipo Proporcional Integral ideal (o ganho proporcional multiplica os termos integrais e derivativos), com ganho de 11,65 e tempo integral de 0,0037 s/rep e a saída deste controlador atua em um gerador de sinal do tipo Pulse Width Modulation (PWM), de forma a variar o tempo em que a válvula LV-16A fica aberta. Os controladores utilizados experimentalmente e no modelo foram idênticos, executados em MATLAB ${ }^{\circledR}$.

Para a simulação dos experimentos, os valores de referência dos controladores utilizados no experimento são idênticos aos do modelo matemático e as vazões dos influentes, medidas durante os experimentos, são entradas para modelo da Planta Piloto. Deve-se salientar que as perturbações das curvas de titulação do modelo foram escolhidas livremente dentro da faixa de concentrações observada na modelagem estática do $\mathrm{pH}$, conforme discutido na Seção 5.5 .

Nas Seções 6.1 e 6.2 são apresentados os resultados dos experimentos e sua comparação com a resposta do modelo de $\mathrm{pH}$ da Planta Piloto, sendo que apenas conclusões qualitativas são abordadas nestas seções. A Seção 6.3 apresenta as comparações quantitativas dos experimentos realizados.

\subsection{Experimentos de Validação do Modelo de pH em Malha Fe- chada}

Os experimentos em malha fechada tiveram o objetivo de validar o modelo quando a Planta Piloto está operando no modo servo, para ambos os influentes ácidos e para dois valores de referência do nível no TR distintos: $65 \%$ e $75 \%$. Desta forma, o teste foi realizado com ambos os controladores no modo automático, variando-se o valor de referência (SP) do controlador de $\mathrm{pH}$. Os primeiros 1000 segundos foram utilizados para que a Planta Piloto atingisse um ponto de equilíbrio, tornando próximas as variáveis experimentais das simuladas. O procedimento do teste está sumarizado na Tabela 6.1. 
Tabela 6.1 - Procedimento experimental para validação do modelo, em malha fechada (MF).

\begin{tabular}{cccc}
\hline $\begin{array}{c}\text { Tempo } \\
\mathrm{s}\end{array}$ & $\begin{array}{c}F_{\text {TAPI }} \\
\mathrm{l} / \mathrm{h}\end{array}$ & $\begin{array}{c}F_{\text {TASI }} \\
\mathrm{l} / \mathrm{h}\end{array}$ & $\begin{array}{c}\mathrm{SP}(\mathrm{AIC}-40) \\
\mathrm{pH}\end{array}$ \\
\hline 0 & $\approx 50$ & 0 & 7 \\
1000 & $\approx 50$ & 0 & 8 \\
2000 & $\approx 50$ & 0 & 7 \\
3000 & $\approx 50$ & 0 & 6 \\
4000 & $\approx 50$ & 0 & 7 \\
5000 & 0 & $\approx 50$ & 7 \\
6000 & 0 & $\approx 50$ & 8 \\
7000 & 0 & $\approx 50$ & 7 \\
8000 & 0 & $\approx 50$ & 6 \\
9000 & 0 & $\approx 50$ & 7 \\
\hline
\end{tabular}

Fonte: do Autor.

Os resultados destes experimentos estão apresentados nas Figuras 6.1 e 6.2. Qualitativamente, percebe-se que a resposta do modelo matemático foi muito próxima dos dados experimentais, tanto para o valor do $\mathrm{pH}$ quanto para o sinal de controle para a bomba dosadora, que são duas variáveis de grande importância para o projeto de controladores e testes de identificação de sistemas.

As Figuras 6.1c e 6.2c consistem na comparação, a cada instante de tempo, do valor do pH medido e simulado. Caso o modelo da Planta Piloto apresentasse uma resposta ideal, o gráfico seria uma linha reta a $45^{\circ}$. Portanto, pode-se concluir que o modelo exibe uma resposta próxima do ideal, podendo ser considerado satisfatório.

O modelo apresentou uma resposta de nível do TR similar ao observado experimentalmente, sendo que as diferenças são oriundas dos valores iniciais dos estados da planta. Como o nível do TR é controlado por um atuador descontínuo (válvula solenoide), qualquer diferença entre os valores iniciais de nível do modelo e da Planta Piloto acarretam em uma defasagem nas respostas. O modelo de nível do TR é validado através de um experimento específico, apresentado na Seção 6.4. 
Figura 6.1 - Validação do modelo de $\mathrm{pH}$ em malha fechada e valor de referência de nível do TR em $75 \%$.

(a) $\mathrm{pH}$.

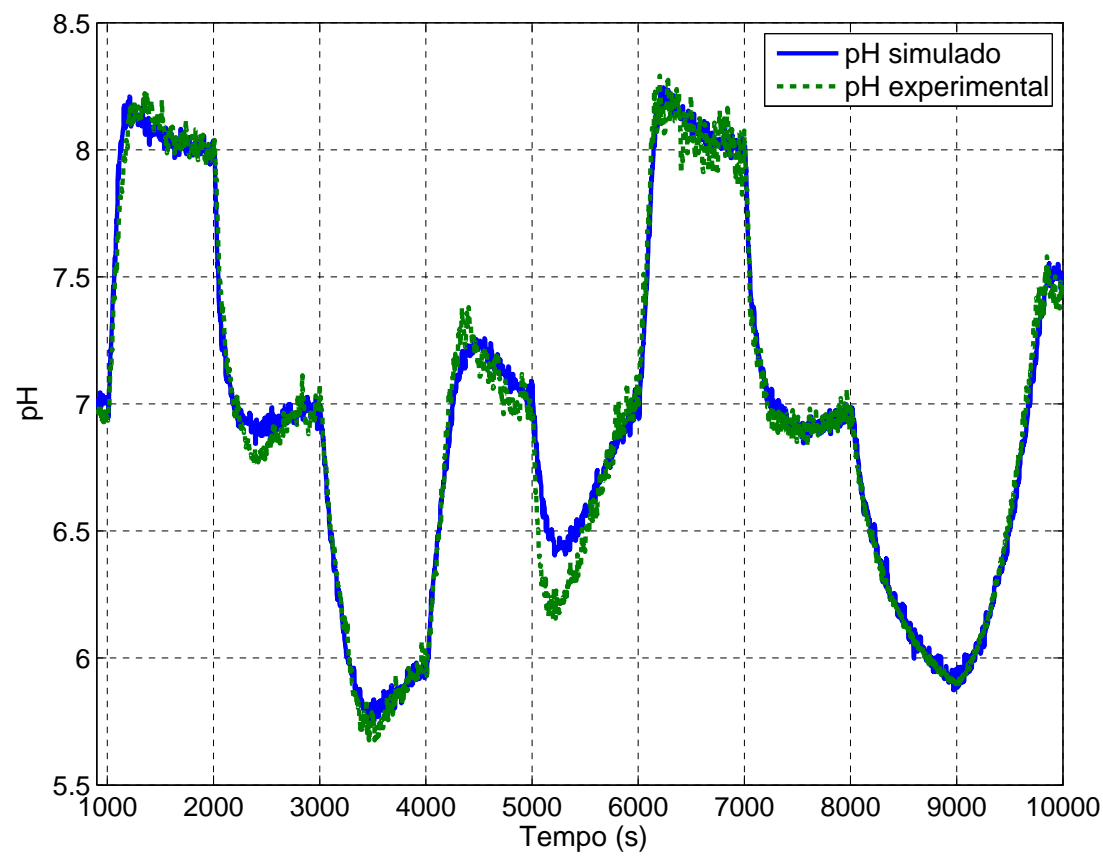

(b) Sinal de controle para a bomba dosadora (c) Comparação pH experimental e simu(MV).

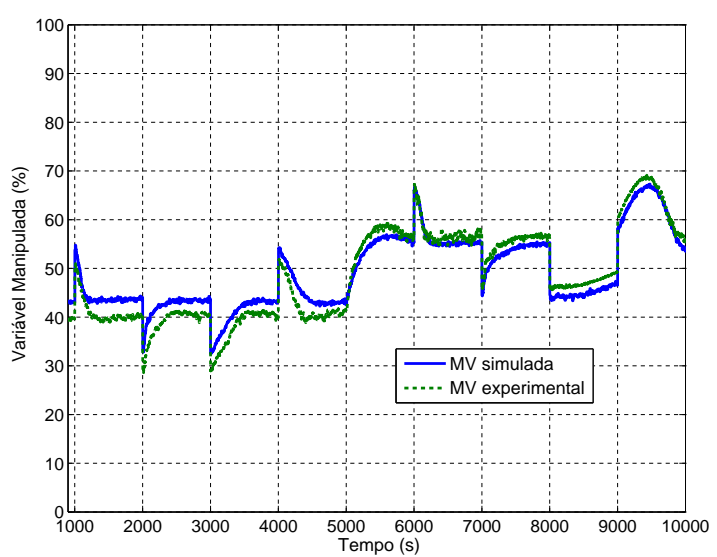

(d) Vazões dos influentes.

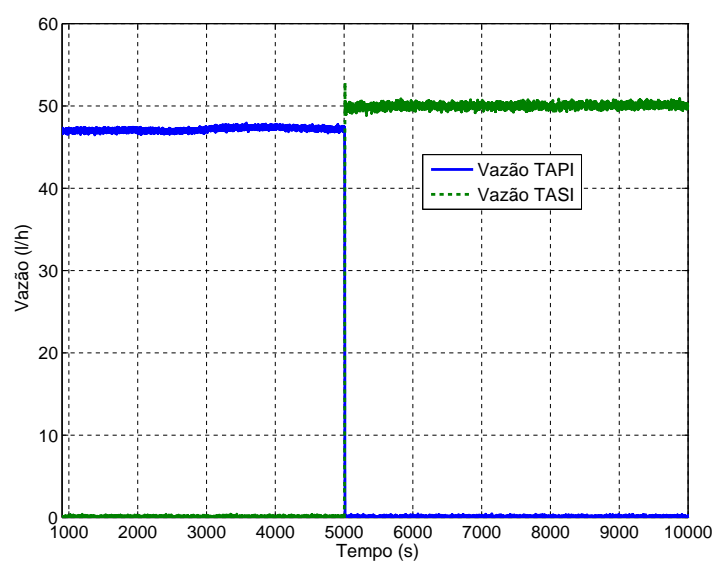
lado.

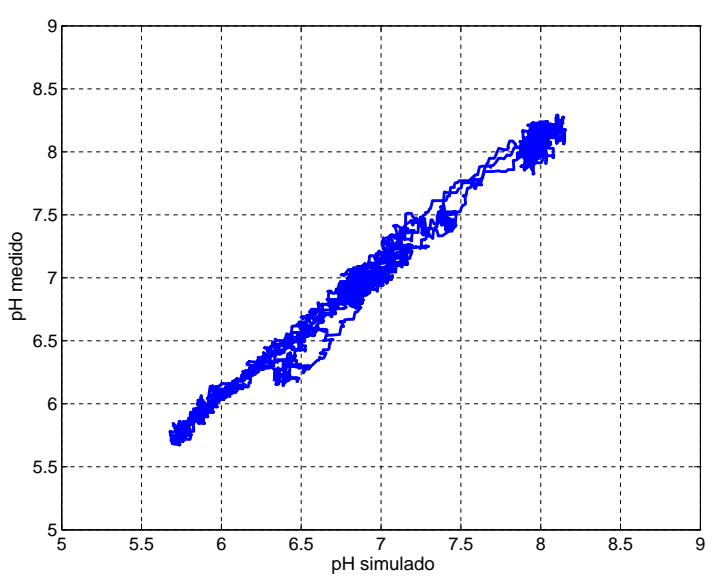

(e) Nível do TR.

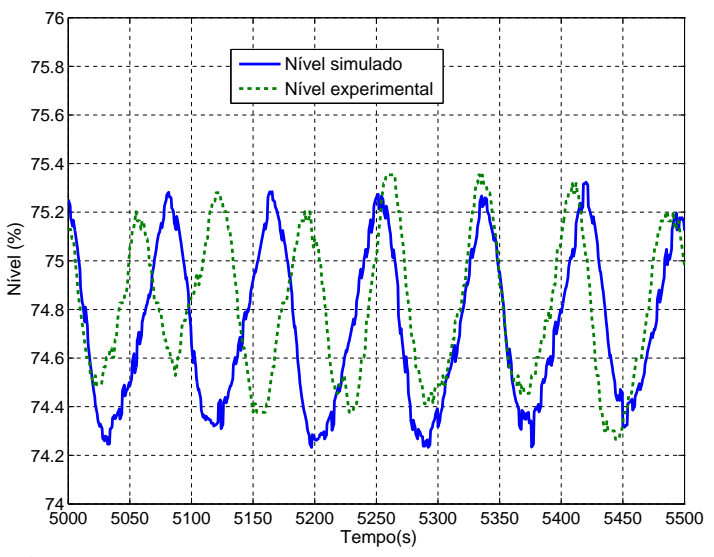

Fonte: do Autor. 
Figura 6.2 - Validação do modelo de pH em malha fechada e valor de referência de nível do TR em $65 \%$.

(a) $\mathrm{pH}$.

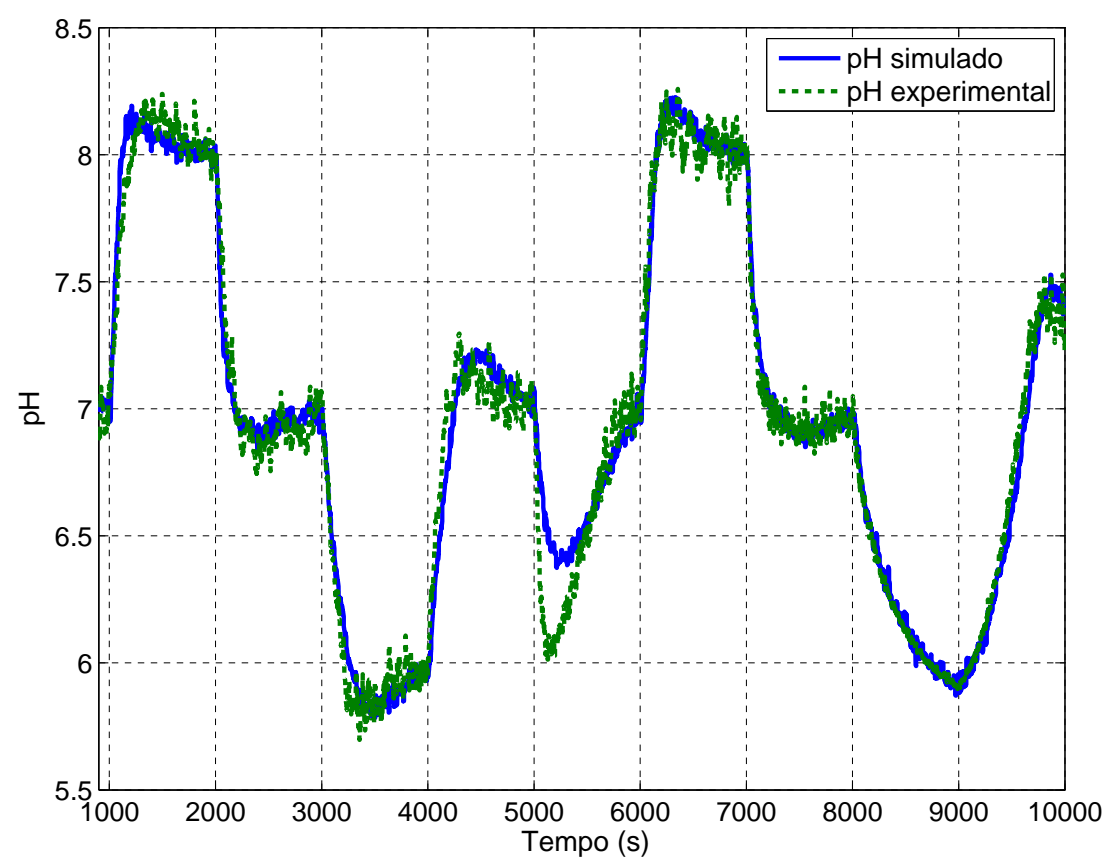

(b) Sinal de controle para a bomba dosadora (c) Comparação pH experimental e simu(MV).

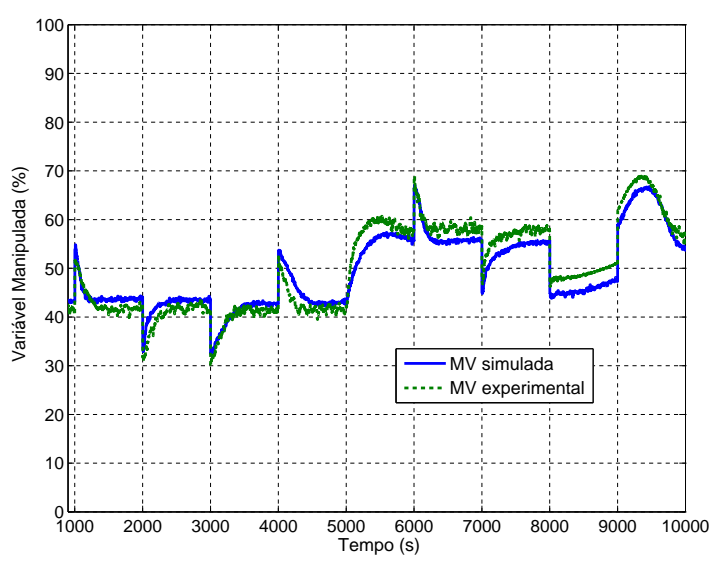

(d) Vazões dos influentes.

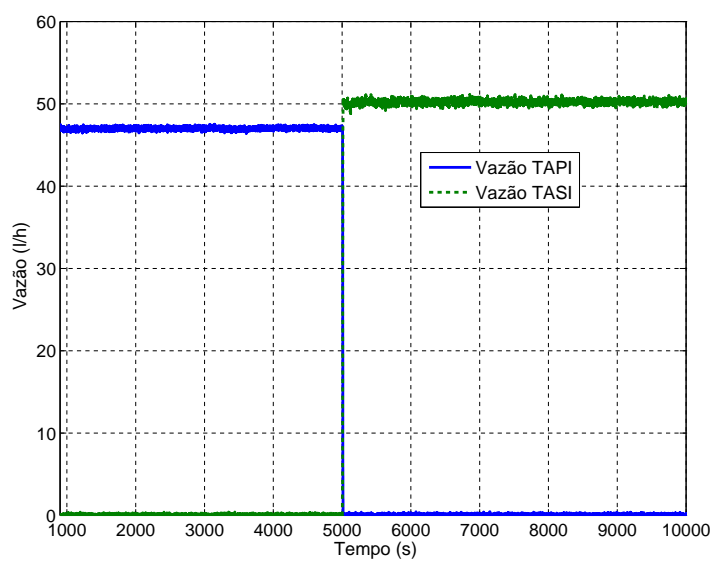
lado.

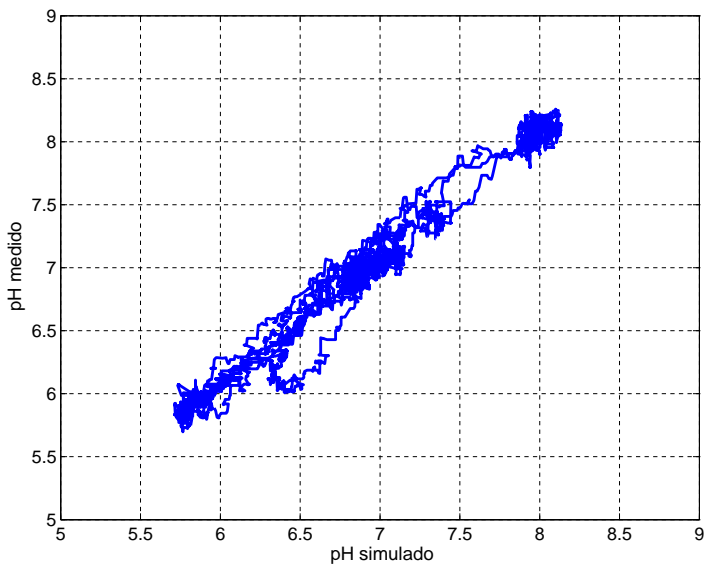

(e) Nível do TR.

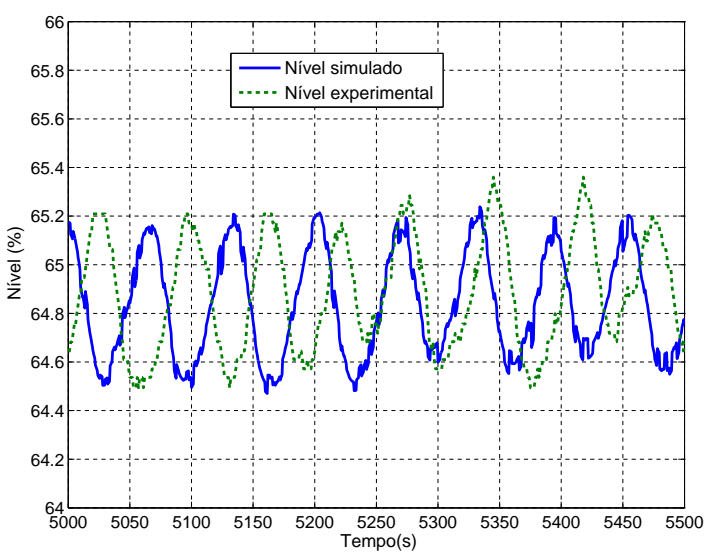

Fonte: do Autor. 


\subsection{Experimentos de Validação do Modelo de pH em Malha Aberta}

Os experimentos em malha aberta consistem em manter a malha de controle de pH aberta, porém mantendo fechada a malha de controle de nível. Foram realizados testes independentes para cada tipo de solução ácida e para dois valores de referência do nível do TR distintos: $65 \%$ e $75 \%$. O teste consistiu em manter o controlador de $\mathrm{pH}$ em malha fechada durante 1000 segundos, tempo necessário para a Planta Piloto atingir um ponto de equilíbrio. Em seguida, a malha de controle de $\mathrm{pH}$ foi aberta e a vazão de ácido foi modificada em determinados instantes. O procedimento de teste está sumarizado nas Tabelas 6.2 e 6.3 .

Tabela 6.2 - Procedimento experimental para validação em malha aberta (MA), utilizando ácido clorídrico.

\begin{tabular}{cccc}
\hline $\begin{array}{c}\text { Tempo } \\
\mathrm{s}\end{array}$ & $\begin{array}{c}F_{\text {TAPI }} \\
\mathrm{l} / \mathrm{h}\end{array}$ & $\begin{array}{c}F_{\text {TASI }} \\
\mathrm{l} / \mathrm{h}\end{array}$ & $\begin{array}{c}\mathrm{SP}(\mathrm{AIC}-40) \\
\mathrm{pH}\end{array}$ \\
\hline 0 & 34 & 0 & 7 \\
1000 & 34 & 0 & $\mathrm{MA}$ \\
1200 & 24 & 0 & $\mathrm{MA}$ \\
2200 & 48 & 0 & $\mathrm{MA}$ \\
3200 & 0 & 0 & $\mathrm{MA}$ \\
\hline
\end{tabular}

Fonte: do Autor.

Tabela 6.3 - Procedimento experimental para validação em malha aberta (MA), utilizando ácido acético.

\begin{tabular}{cccc}
\hline Tempo & $F_{\text {TAPI }}$ & $F_{\text {TASI }}$ & $\mathrm{SP}(\mathrm{AIC}-40)$ \\
$\mathrm{s}$ & $\mathrm{l} / \mathrm{h}$ & $\mathrm{l} / \mathrm{h}$ & $\mathrm{pH}$ \\
\hline 0 & 0 & 38 & 7 \\
1000 & 0 & 38 & $\mathrm{MA}$ \\
1200 & 0 & 26 & $\mathrm{MA}$ \\
2200 & 0 & 50 & $\mathrm{MA}$ \\
\hline
\end{tabular}

Fonte: do Autor.

Os resultados dos experimentos em malha aberta estão apresentados nas Figuras 6.3 a 6.6. Analisando-se qualitativamente os experimentos, conclui-se que o modelo apresentou uma resposta satisfatória, devido à proximidade entre os dados experimentais e simulados. Uma evidência disto é a proximidade que as Figuras 6.3c a 6.6c têm, em relação a uma linha reta inclinada de $45^{\circ}$. Apesar do modelo poder ser considerado satisfatório, percebe-se que a faixa de pH entre 7 e 8 é a que apresenta os maiores desvios, conforme Figuras 6.3c e 6.6c, pois esta é a faixa de maior ganho - e consequentemente maior sensibilidade aos erros de modelagem.

Outro resultado satisfatório foi que, quando a malha de controle de $\mathrm{pH}$ foi aberta, em 1000 segundos, o sinal de controle para a bomba dosadora simulada e experimental apresentarem valores muito próximos. Ainda, tanto o modelo quanto a Planta Piloto permaneceram estáveis, enquanto a vazão de ácido não foi modificada. 
De forma similar ao que ocorreu nos experimentos em malha fechada, o nível do TR simulado e experimental apresentaram tendências similares, porém não foram idênticos, devido às diferenças entre os valores iniciais de nível do TR, simulados e experimentais. 
Figura 6.3 - Validação do modelo de pH, com ácido clorídrico, em malha aberta e valor de referência de nível do TR em $75 \%$.

(a) $\mathrm{pH}$.

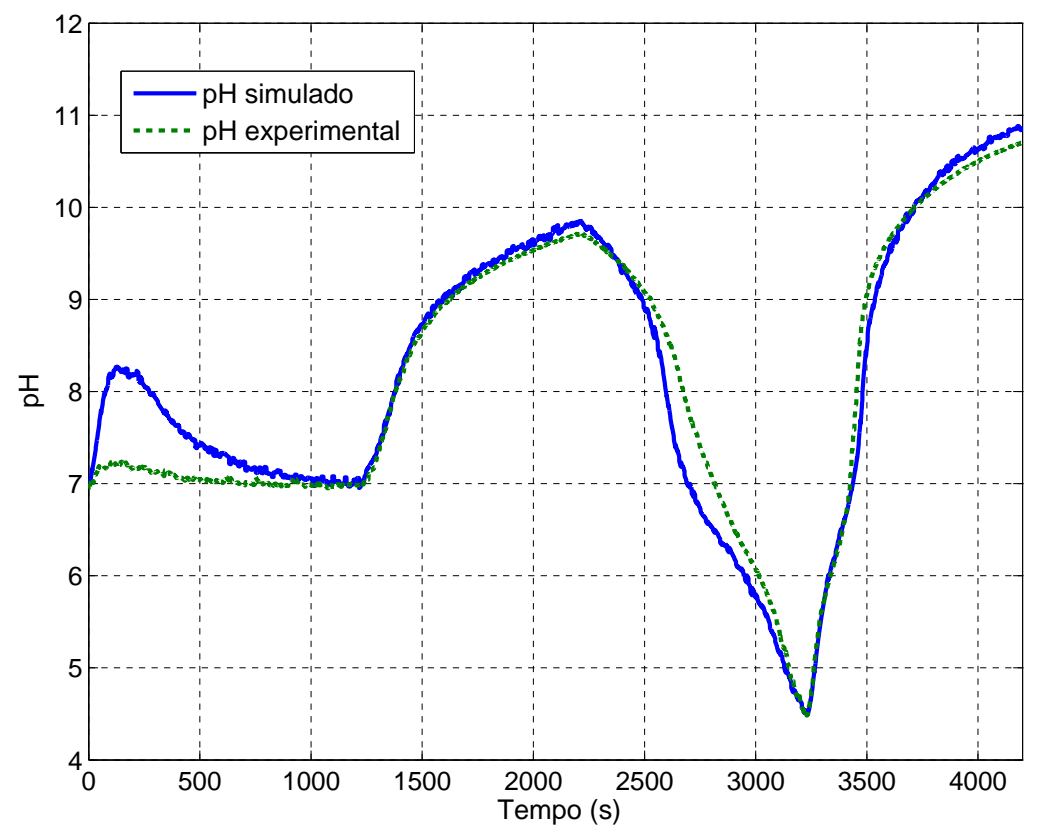

(b) Sinal de controle para a bomba dosadora (c) Comparação $\mathrm{pH}$ experimental e simu(MV). lado.

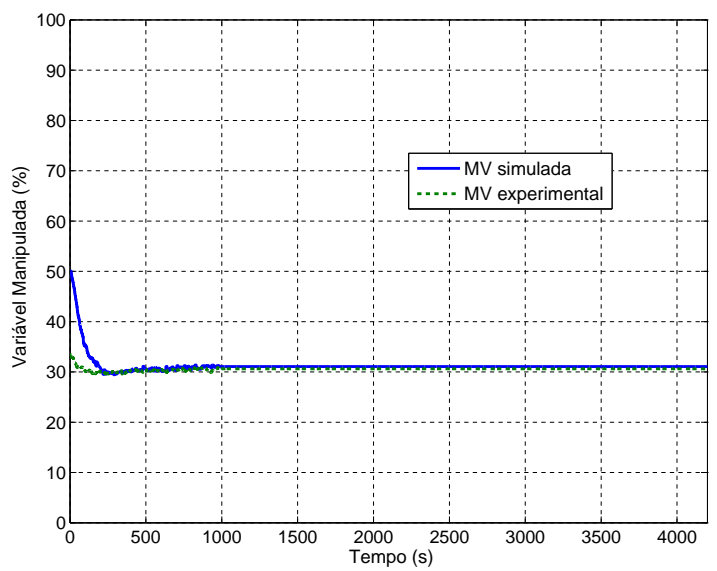

(d) Vazões dos influentes.

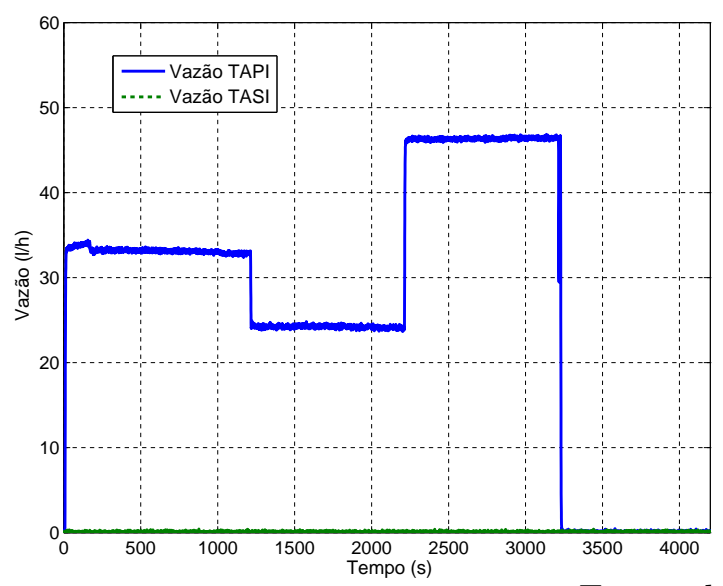

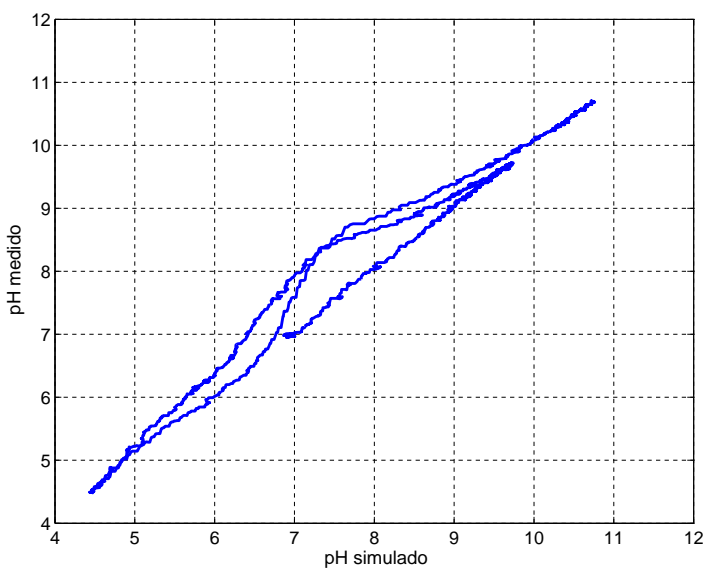

(e) Nível do TR.

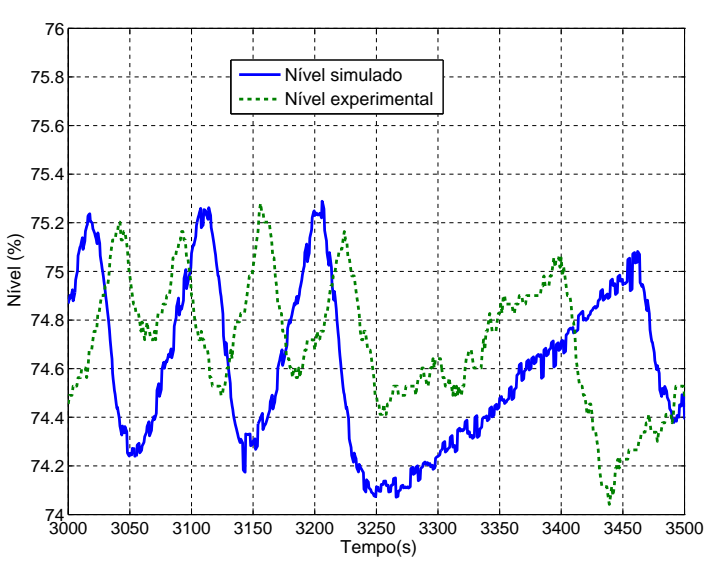

Fonte: do Autor. 
Figura 6.4 - Validação do modelo de pH, com ácido clorídrico, em malha aberta e valor de referência de nível do TR em $65 \%$.

(a) $\mathrm{pH}$.

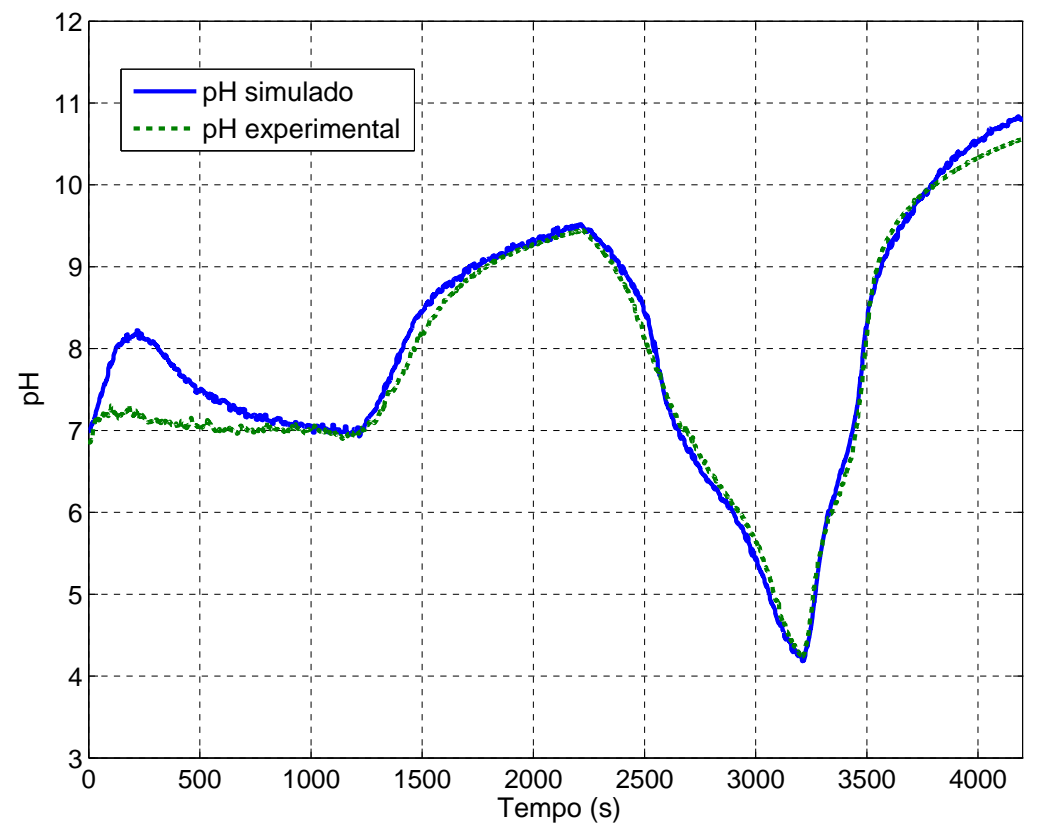

(b) Sinal de controle para a bomba dosadora (c) Comparação $\mathrm{pH}$ experimental e simu(MV). lado.

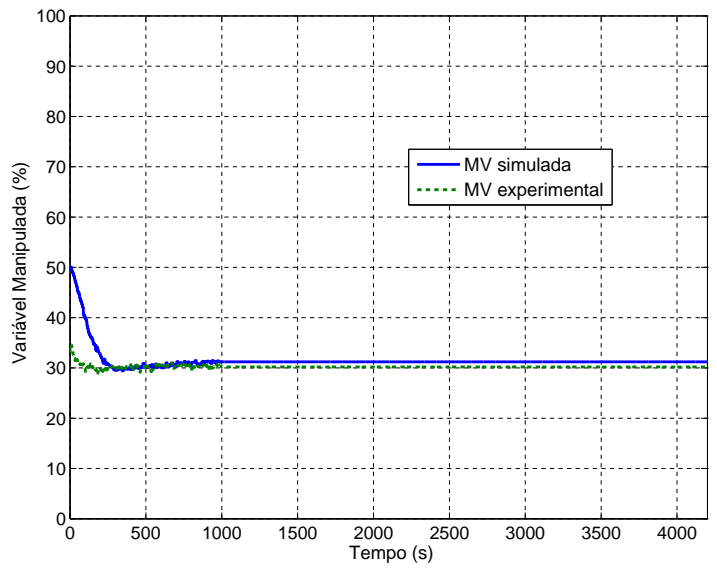

(d) Vazões dos influentes.

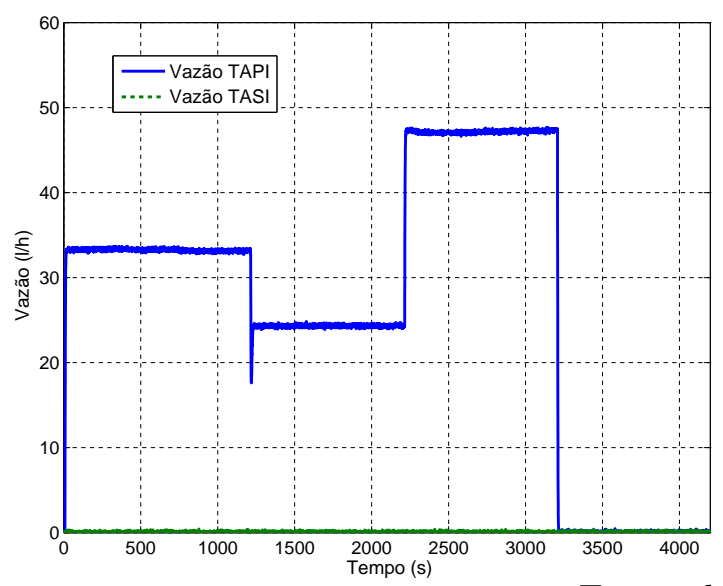

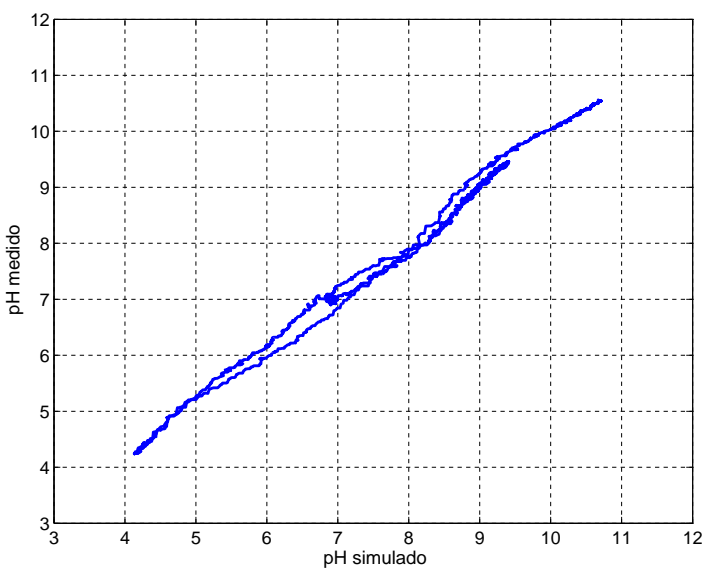

(e) Nível do TR.

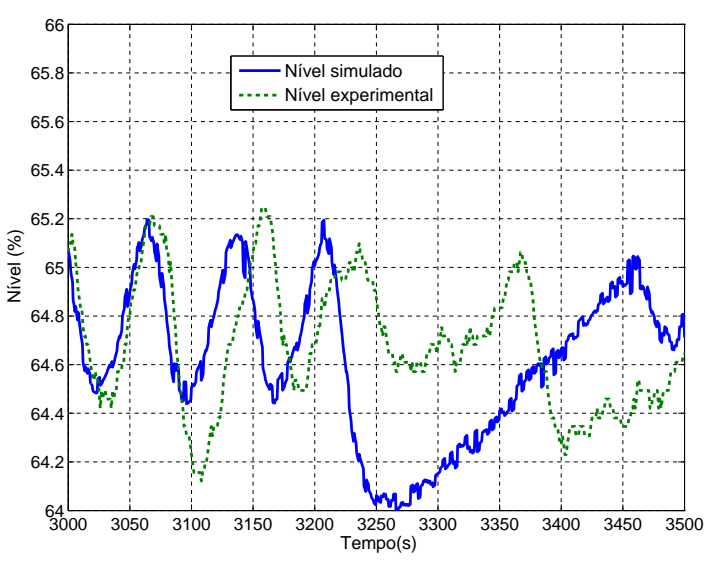

Fonte: do Autor. 
Figura 6.5 - Validação do modelo de pH, com ácido acético, em malha aberta e valor de referência de nível do TR em $75 \%$.

(a) $\mathrm{pH}$.

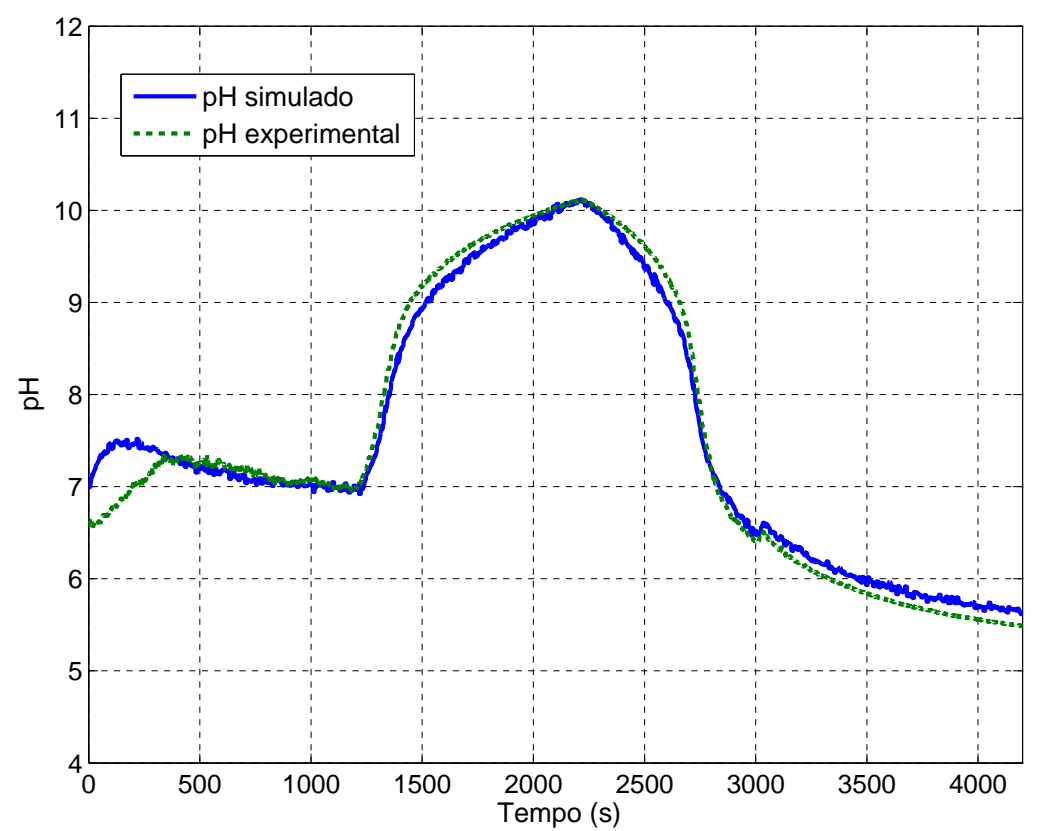

(b) Sinal de controle para a bomba dosadora (c) Comparação $\mathrm{pH}$ experimental e simu(MV). lado.

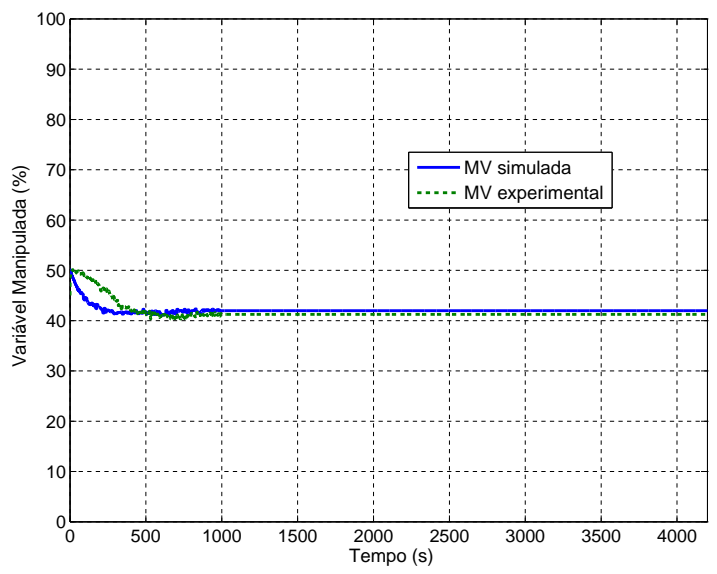

(d) Vazões dos influentes.

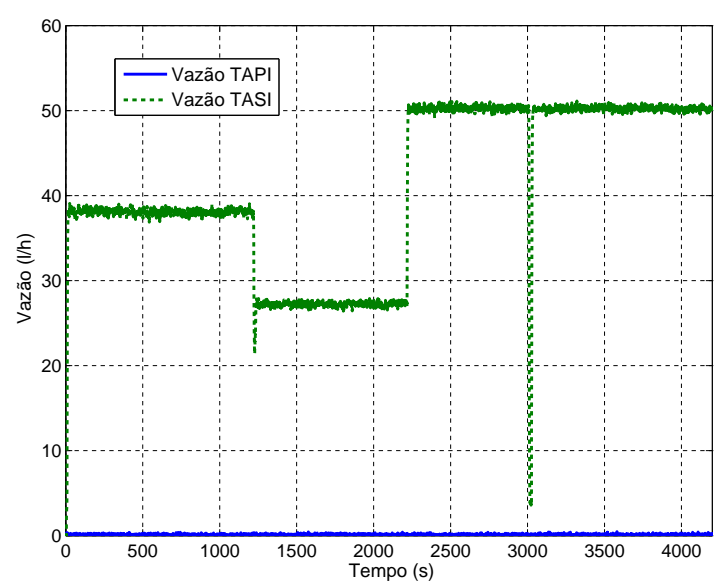

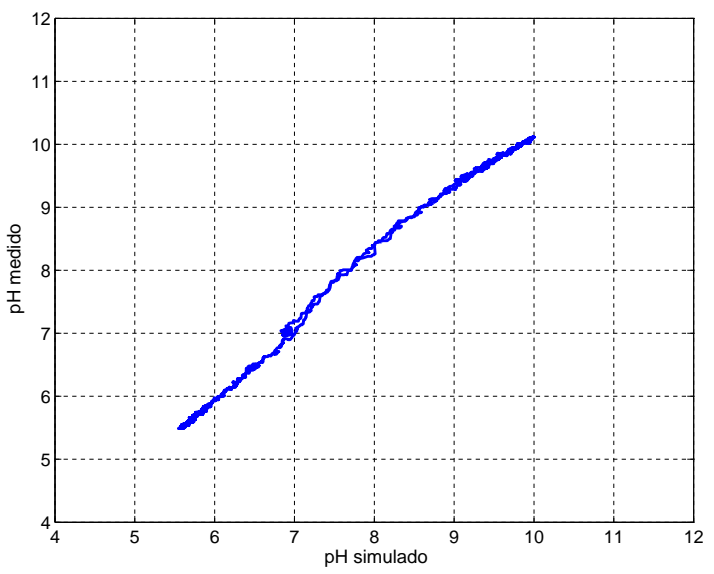

(e) Nível do TR.

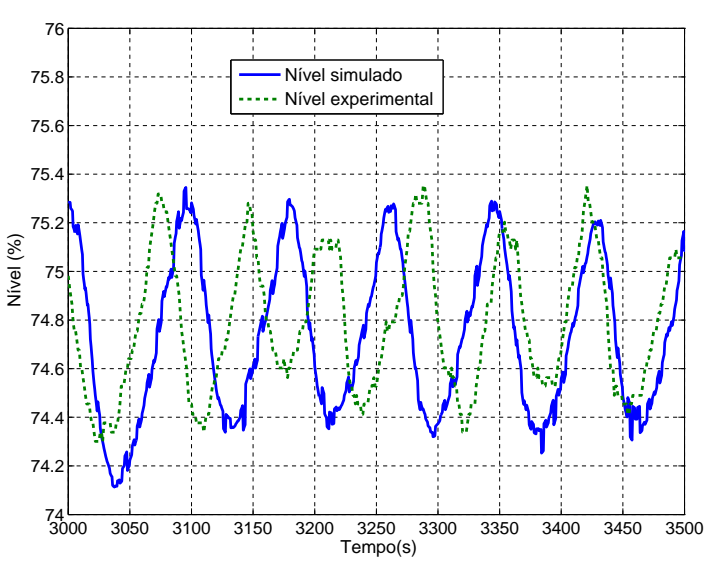

Fonte: do Autor. 
Figura 6.6 - Validação do modelo de pH, com ácido acético, em malha aberta e valor de referência de nível do TR em $65 \%$.

(a) $\mathrm{pH}$.

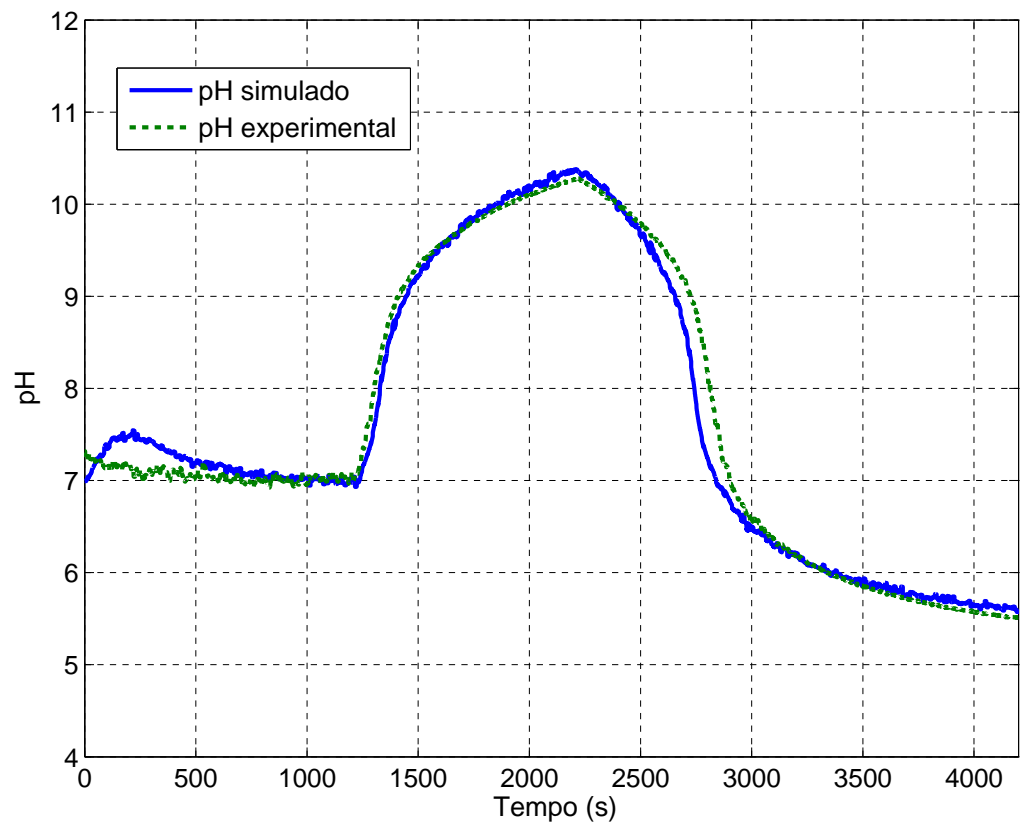

(b) Sinal de controle para a bomba dosadora

(c) Comparação pH experimental e simu(MV).

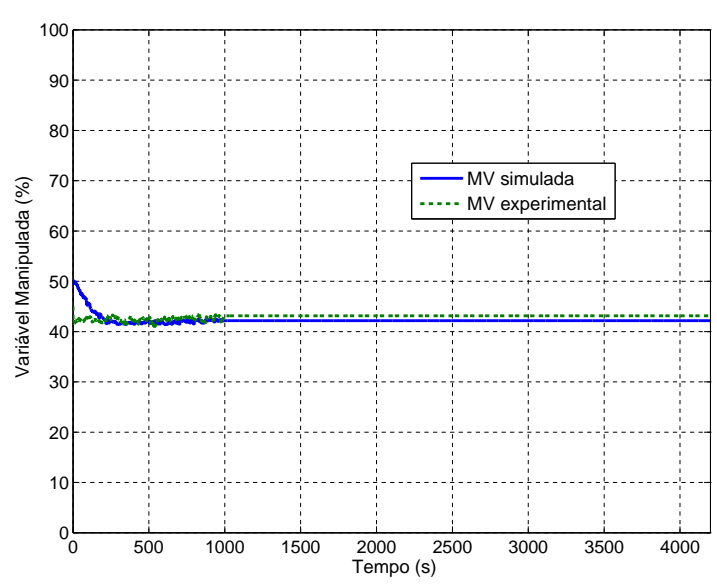

(d) Vazões dos influentes.

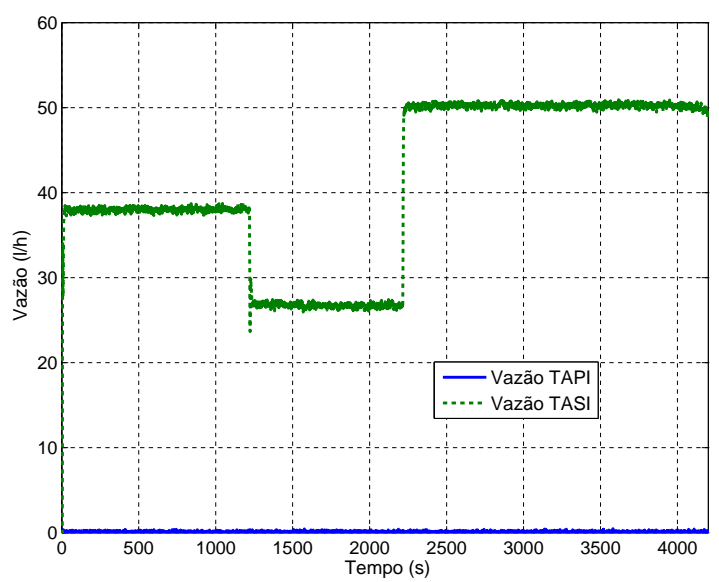
lado.

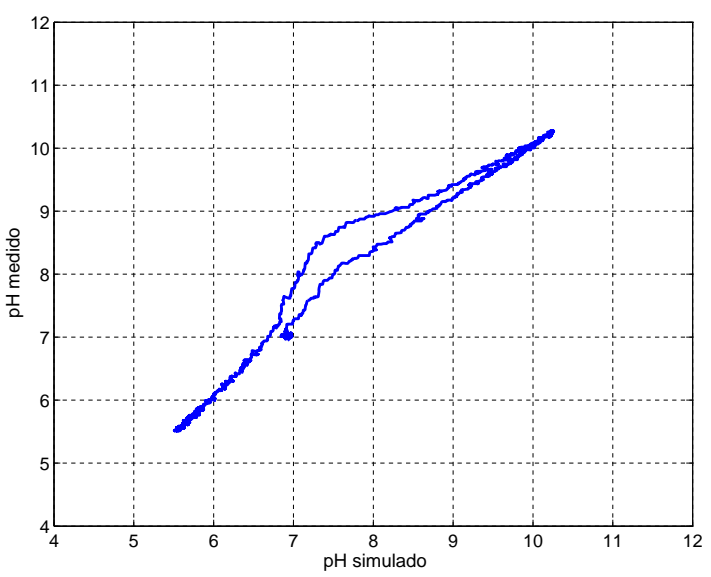

(e) Nível do TR.

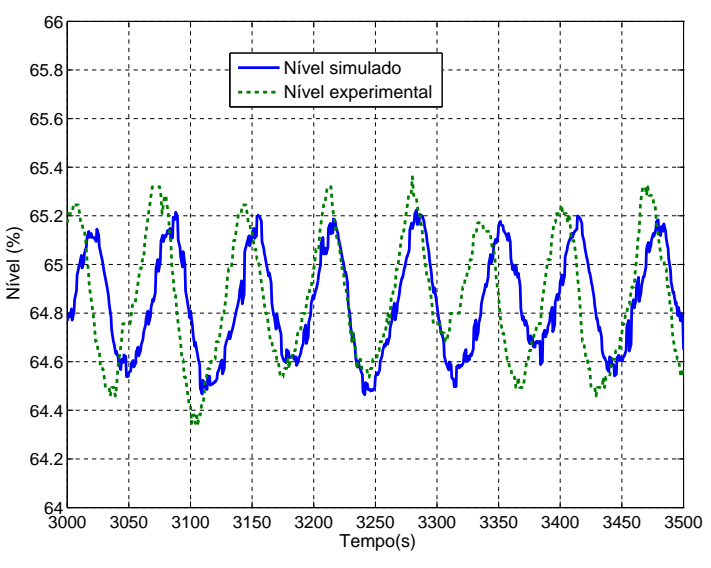

Fonte: do Autor. 


\subsection{Resultados Quantitativos dos Experimentos de Validação do Modelo de $\mathrm{pH}$}

Para obter dados quantitativos referentes ao desempenho do modelo da Planta Piloto, foram utilizados o Índice de Ajuste (fit) e o Coeficiente de Desigualdade de Theil (TIC), que são definidos como:

$$
\begin{gathered}
\text { fit }=100 \cdot\left(1-\frac{\|\hat{y}(t)-y(t)\|}{\|y(t)-\bar{y}\|}\right) \\
\mathrm{TIC}=\frac{\|y(t)-\hat{y}(t)\|}{\|y(t)\|+\|\hat{y}(t)\|},
\end{gathered}
$$

sendo $\hat{y}(t)$ o $\mathrm{pH}$ simulado, $y(t)$ o $\mathrm{pH}$ experimental e $\bar{y}$ o valor médio do $\mathrm{pH}$ experimental. Quanto mais próximo o fit é de 100, melhor o modelo matemático representa os dados experimentais. Por outro lado, valores de TIC próximos de 0 indicam que o modelo matemático representa adequadamente os dados experimentais. Como o modelo desenvolvido neste trabalho será utilizado para projeto e validação de sistemas de controle e teste de sinais de excitação para identificação de sistemas, é desejável que este apresente a melhor resposta possível, mas também, que seja simples o suficiente para ser utilizado no projeto de sistemas de controle, os quais são objetivos antagônicos. Estabeleceu-se, com base no exposto, um limite mínimo de $85 \%$ para o fit e de 0,15 para o TIC para que o modelo de pH seja considerado satisfatório. Cabe destacar que não há, na literatura referente à validação de modelos, um limite mínimo para o índice fit, o qual determine se o modelo pode ser considerado adequado ou não. Para o índice TIC, Murray-Smith (1998) sugeriu um limite máximo de 0,3 , para que um modelo seja adequado para o projeto de sistemas de controle.

Adicionalmente, para cada experimento realizado, foram calculados o erro médio absoluto de $\mathrm{pH}\left(\bar{\varepsilon}_{\mathrm{pH}}\right)$ e o erro médio absoluto do sinal de controle para a bomba dosadora $\left(\bar{\varepsilon}_{M V}\right)$, pois estas são variáveis de interesse para o projeto de sistemas de controle. $\mathrm{O}$ valor máximo admissível destes erros são: $\bar{\varepsilon}_{\mathrm{pH}}<0,3$ e $\bar{\varepsilon}_{M V}<3,3$, os quais correspondem a duas vezes a precisão do medidor de pH e a quatro vezes a precisão dos medidores de vazão dos influentes, respectivamente.

A Tabela 6.4 apresenta as comparações quantitativas referentes aos experimentos de validação do modelo de $\mathrm{pH}$ em malha aberta (MA) e fechada (MF), conforme as Figuras 6.1 a 6.6. Pode-se verificar que todos os índices de comparação ficaram abaixo dos limites estabelecidos anteriormente e, portanto, conclui-se que o modelo matemático desenvolvido para a Planta Piloto é satisfatório.

A Tabela 6.5 apresenta as concentrações das perturbações das curvas de titulação que foram utilizadas no modelo, para cada experimento de validação. Percebe-se que os valores estão dentro da faixa observada na Seção 5.5, validando as simulações. Estes dados 
Tabela 6.4 - Comparações quantitativas entre o modelo e os dados experimentais das Figuras 6.1 a 6.6 .

\begin{tabular}{ccccccc}
\hline Experimento e & $\mathrm{MF}$ & $\mathrm{MF}$ & $\mathrm{MA}_{\mathrm{HCl}}$ & $\mathrm{MA}_{\mathrm{HCl}}$ & $\mathrm{MA}_{\mathrm{CH}_{3} \mathrm{COOH}}$ & $\mathrm{MA}_{\mathrm{CH}_{3} \mathrm{COOH}}$ \\
nível do TR & $75 \%$ & $65 \%$ & $75 \%$ & $65 \%$ & $75 \%$ & $65 \%$ \\
\hline fit & 92,39 & 90,41 & 89,91 & 95,46 & 94,11 & 92,35 \\
TIC & 0,01 & 0,01 & 0,02 & 0,01 & 0,01 & 0,02 \\
$\bar{\varepsilon}_{\mathrm{pH}}$ & 0,09 & 0,10 & 0,19 & 0,12 & 0,17 & 0,16 \\
$\bar{\varepsilon}_{M V}$ & 2,41 & 2,42 & 0,08 & 0,65 & 0,27 & 1,46 \\
\hline \multicolumn{6}{c}{ Fonte: do Autor. }
\end{tabular}

evidenciam novamente que a Planta Piloto possui parâmetros variantes no tempo, sendo que a tentativa de modelá-la através de um modelo com parâmetros fixos acarretará em desvios. O usuário deste modelo deve simular diversas concentrações para as perturbações das curvas de titulação, levando-se em consideração os erros de modelagem no projeto de controladores de $\mathrm{pH}$.

Tabela 6.5 - Concentrações das perturbações das curvas de titulação utilizadas nos experimentos de validação.

\begin{tabular}{ccccccc}
\hline Experimento e & $\mathrm{MF}$ & $\mathrm{MF}$ & $\mathrm{MA}_{\mathrm{HCl}}$ & $\mathrm{MA}_{\mathrm{HCl}}$ & $\mathrm{MA}_{\mathrm{CH}_{3} \mathrm{COOH}}$ & $\mathrm{MA}_{\mathrm{CH}} \mathrm{COOH}$ \\
nível do TR & $75 \%$ & $65 \%$ & $75 \%$ & $65 \%$ & $75 \%$ & $65 \%$ \\
\hline$\alpha(\mathrm{mol} / \mathrm{l})$ & $4 \cdot 10^{-5}$ & $3 \cdot 10^{-5}$ & $5 \cdot 10^{-5}$ & $5 \cdot 10^{-5}$ & $5 \cdot 10^{-5}$ & $5 \cdot 10^{-5}$ \\
$\lambda(\mathrm{mol} / \mathrm{l})$ & $1,5 \cdot 10^{-4}$ & $1,6 \cdot 10^{-4}$ & $2 \cdot 10^{-4}$ & $3,2 \cdot 10^{-4}$ & $2 \cdot 10^{-4}$ & $2,2 \cdot 10^{-4}$ \\
$\beta(\mathrm{mol} / \mathrm{l})$ & $2 \cdot 10^{-4}$ & $2,4 \cdot 10^{-4}$ & $7 \cdot 10^{-4}$ & $4,1 \cdot 10^{-4}$ & $5 \cdot 10^{-4}$ & $5,2 \cdot 10^{-4}$ \\
$\gamma(\mathrm{mol} / \mathrm{l})$ & $8 \cdot 10^{-5}$ & $2 \cdot 10^{-4}$ & $2 \cdot 10^{-4}$ & $4,2 \cdot 10^{-4}$ & $2,5 \cdot 10^{-4}$ & $2 \cdot 10^{-4}$ \\
$\zeta(\mathrm{mol} / \mathrm{l})$ & $2 \cdot 10^{-5}$ & $2 \cdot 10^{-5}$ & $1 \cdot 10^{-5}$ & $2 \cdot 10^{-5}$ & $1 \cdot 10^{-5}$ & $1 \cdot 10^{-5}$ \\
\hline
\end{tabular}

\section{Fonte: do Autor.}

Observação: notação conforme Tabela 5.3.

\subsection{Experimento para Validação do Modelo de Nível}

O procedimento experimental para a validação do modelo de nível do TR consistiu em abrir as malhas de controle de $\mathrm{pH}$ e nível e variar o nível do TR através da abertura da LV-16A ou da modificação da vazão de entrada de influentes. Ainda, verificou-se a influência do agitador mecânico na medição de nível do TR, alternando-se o estado de funcionamento do agitador mecânico (MZ-81) em determinados momentos. O procedimento experimental utilizado para a validação do modelo de nível do TR pode ser visto na Tabela 6.6.

Os resultados do experimento estão apresentados na Figura 6.7. Pode-se perceber que, apesar de existirem desvios, o modelo de nível apresenta uma resposta próxima dos dados experimentais. Ainda, na faixa de nível entre $65 \%$ e $75 \%$, o modelo teve uma resposta que mais se aproximou dos dados experimentais, o que é desejável, visto que o valor de referência do controlador de nível se situa nesta faixa. 
Tabela 6.6 - Procedimento para validação do modelo de nível.

\begin{tabular}{cccccc}
\hline $\begin{array}{c}\text { Tempo } \\
\mathrm{s}\end{array}$ & $\begin{array}{c}F_{T A P I} \\
\mathrm{l} / \mathrm{h}\end{array}$ & $\begin{array}{c}F_{T A S I} \\
\mathrm{l} / \mathrm{h}\end{array}$ & $F_{T B B}$ & LV-16A & $\begin{array}{c}\text { MZ-81 } \\
\mathrm{pH}\end{array}$ \\
\hline 3300 & 0 & 0 & 0 & Fechada & Ligado \\
3600 & 0 & 0 & 0 & Fechada & Desligado \\
3900 & 0 & 0 & 0 & Fechada & Ligado \\
4200 & 0 & 50 & 0 & Fechada & Ligado \\
4500 & 0 & 0 & 0 & Fechada & Ligado \\
4800 & 0 & 0 & 0 & Fechada & Desligado \\
5100 & 0 & 0 & 0 & Fechada & Ligado \\
5400 & 50 & 50 & 0 & Fechada & Ligado \\
5700 & 0 & 0 & 0 & Fechada & Ligado \\
6000 & 0 & 0 & 0 & Fechada & Desligado \\
6300 & 0 & 0 & 0 & Fechada & Ligado \\
7200 & 0 & 0 & 0 & Fechada & Desligado \\
7500 & 0 & 0 & 0 & Fechada & Ligado \\
7600 & 0 & 0 & 0 & Aberta & Ligado \\
7780 & 0 & 0 & 0 & Fechada & Ligado \\
7900 & 0 & 0 & 0 & Aberta & Ligado \\
8080 & 0 & 0 & 0 & Fechada & Ligado \\
8200 & 0 & 0 & 0 & Aberta & Ligado \\
8380 & 0 & 0 & 0 & Fechada & Ligado \\
\hline \multicolumn{5}{c}{ Fonte: do Autor. } &
\end{tabular}

Figura 6.7 - Experimento de validação do modelo de nível do TR.

(a) Nível do TR.

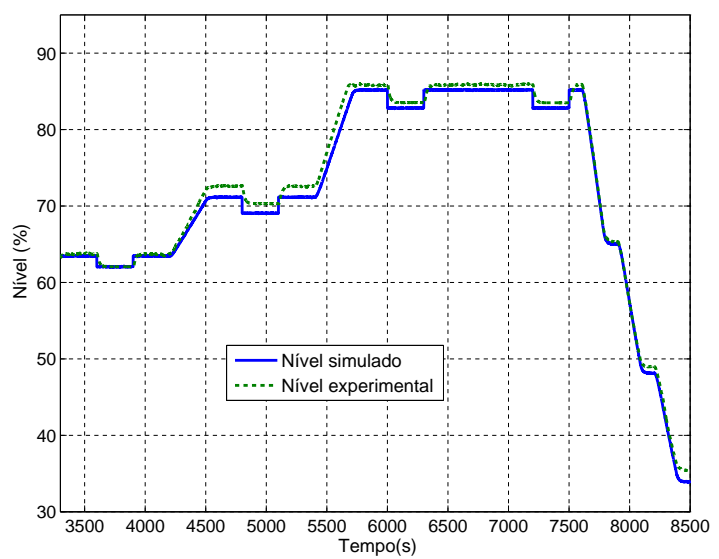

(b) Vazões dos influentes.

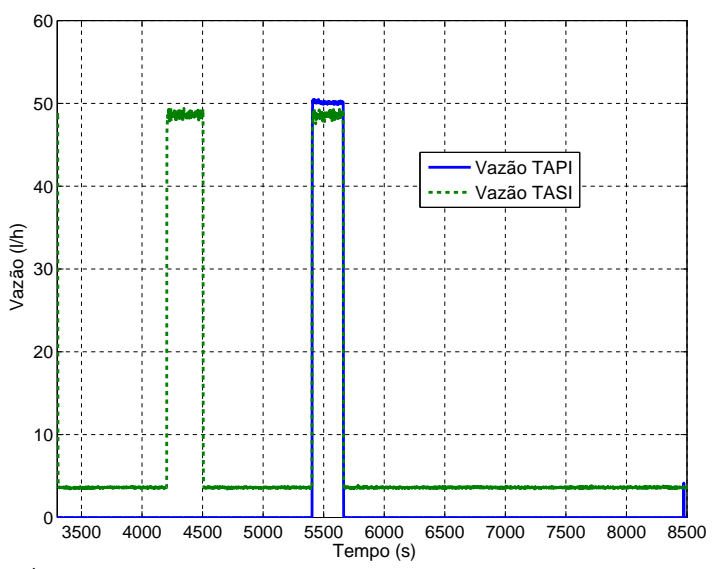

Fonte: do Autor.

O nível foi modelado a partir de inúmeras aproximações, como por exemplo a área útil da seção transversal do TR, que foi aproximada como sendo constante e o coeficiente de vazão da válvula, que foi estimado experimentalmente. Assim, um erro médio de até $5 \%$ do volume nominal do TR é considerado admissível. Este erro de volume equivale a 2,3 l, que corresponde a um desvio médio máximo de nível de 1,85\%. Como o erro médio de nível do experimento mostrado na Figura 6.7 é de 1,62\%, o modelo de nível foi considerado satisfatório. 


\section{Projeto e Validação do Sistema de Controle de $\mathrm{pH}$}

Neste capítulo o projeto do sistema de controle de $\mathrm{pH}$ é descrito, bem como é apresentado seu desempenho através de simulações e experimentos. O controle de nível do TR foi mantido conforme descrito no Capítulo 6, pois trata-se de um sistema de controle simples e que já apresenta um desempenho satisfatório.

\subsection{Descrição do Problema de Controle}

O problema de controle é, essencialmente, manter o $\mathrm{pH}$ do TR igual a um determinado valor de referência, compensando eventuais perturbações. As perturbações frequentemente consideradas nos trabalhos realizados na Planta Piloto são variações na vazão do ácido clorídrico. Para tornar o problema de controle mais desafiador, são utilizadas duas soluções ácidas distintas, considerando-se que a concentração de ácido clorídrico e de hidróxido de sódio são conhecidas previamente, porém a concentração de ácido acético é desconhecida, sendo este outro tipo de perturbação. Adicionalmente, verificou-se na Seção 5.5 que a resposta da Planta Piloto é variante no tempo, devido às pequenas variações nas concentrações de determinados compostos químicos presentes nas soluções (denominadas perturbações das curvas de titulação), sendo este outro tipo de distúrbio que deve ser considerado no projeto do sistema de controle de $\mathrm{pH}$.

Os requisitos do sistema de controle de pH são:

i Erro zero em regime permanente;

ii Sobressinal máximo de $0,5 \mathrm{pH}$;

iii Tempo de acomodação (a 98\% do valor final) máximo de 900 segundos;

iv Robustez em relação às perturbações das curvas de titulação, dentro dos limites observados na Seção 5.5;

v Capacidade de compensar as soluções de ácido acético provenientes do TAS, sem possuir nenhuma informação prévia sobre sua concentração. Caso ocorram mudanças bruscas na concentração de ácido acético, os requisitos (i), (ii) e (iii) podem ser violados por um período máximo de 1000 segundos, que é um tempo aceitável para que o controlador se adapte à nova condição de operação; 
vi Apresentar índice de desempenho ISE (do Inglês, Integrated Squared Error) menor ou igual ao controlador PID 2DOF (Controlador Proporcional Integral Derivativo com 2 Graus de Liberdade) com feedforward, projetado por Romanus e Giovaninni (2014), o qual é denominado controlador de referência.

O índice de desempenho ISE é definido como:

$$
\mathrm{ISE}=\int_{t_{i}}^{t_{f}}\left(\mathrm{pH}_{T R}(t)-\mathrm{pH}_{S P}(t)\right)^{2} \mathrm{~d} t
$$

sendo $\mathrm{pH}_{T R}$ o $\mathrm{pH}$ medido no $\mathrm{TR}, \mathrm{pH}_{S P}$ o valor de referência para o $\mathrm{pH}$ do $\mathrm{TR}$ e $t_{i}$ e $t_{f}$ os tempos inicial e final do teste.

Para atender aos requisitos de controle, decidiu-se utilizar um observador de estados não-linear, para estimar a concentração de ácido acético presente no TAS, em conjunto com um controlador não-linear baseado em modelo, o qual é indicado para processos de neutralização de $\mathrm{pH}$, dada sua resposta altamente não-linear. O projeto do observador de estados e do controlador são apresentados nas Seções 7.3 e 7.4.

\subsection{O Controlador de Referência}

O controlador PID 2DOF com feedforward, projetado por Romanus e Giovaninni (2014), foi selecionado como o de referência, pois foi o controlador linear que, até o presente momento, apresentou o melhor desempenho em modo regulatório. No entanto, deve-se destacar que este controlador foi projetado para operar com ácido clorídrico, apenas, sendo esperado que ele não apresente um bom desempenho quando o influente possuir ácido acético em sua composição.

A equação, no domínio de Laplace, do PID 2DOF é:

$$
\begin{aligned}
& V M(s)=K_{c}\left(b \cdot S P(s)-V C(s)+\frac{1}{T_{i} \cdot s}(S P(s)-V C(s))+\right. \\
&\left.T_{d} \cdot s(c \cdot S P(s)-V C(s))\right),
\end{aligned}
$$

que pode ser reescrita como:

$$
\begin{aligned}
V M(s)=K_{c}\left(1+\frac{1}{T_{i} \cdot s}+T_{d} \cdot s\right) \cdot(S P(s) & -V C(s))- \\
& -K_{c} \cdot\left((1-b)+(1-c) T_{d} \cdot s\right) S P(s),
\end{aligned}
$$

sendo $K_{c}$ o ganho proporcional, $T_{i}$ o tempo integral, $T_{d}$ o tempo derivativo, $S P(s)$ o valor de referência, $b$ e $c$ são parâmetros utilizados para otimizar a resposta no modo servo, $V M(s)$ a variável manipulada e $V C(s)$ a variável controlada. Os parâmetros do PID 2DOF foram obtidos através da busca exaustiva, utilizando-se o modelo desenvolvido no Capítulo 5, para obter os parâmetros que minimizam o tempo de acomodação e o sobressinal. A 
sintonia ótima do PID 2DOF para a Planta Piloto, obtida por Romanus e Giovaninni (2014), está apresentada na Tabela 7.1.

Tabela 7.1 - Parâmetros do Controlador PID 2DOF.

\begin{tabular}{ccccc}
\hline$K_{c}$ & $T_{i}$ & $T_{d}$ & $b$ & $c$ \\
\hline 3,5 & 150 & 120 & 0 & 0 \\
\hline
\end{tabular}

Fonte: Romanus e Giovaninni (2014).

O ramo feedforward do controlador foi sintonizado através de modelos lineares aproximados da Planta Piloto. O diagrama de blocos utilizado para o projeto do ramo feedforward está apresentado na Figura 7.1, onde o bloco PID 2DOF representa o controlador com a sintonia descrita anteriormente, o bloco $G_{p u m p}(s)$ é a função de transferência da bomba dosadora, o bloco $G_{p}(s)$ é a função de transferência da planta, que corresponde à resposta dinâmica do $\mathrm{pH}$ do $\mathrm{TR}$, em relação às variações da vazão de base, o bloco $G_{p e r t}(s)$ é a função de transferência da perturbação, que corresponde à resposta dinâmica do pH do TR em relação às variações na vazão de ácido clorídrico, $d(s)$ é vazão total de influente ácido, os blocos $H_{\text {flow }}(s)$ e $H_{\mathrm{pH}}(s)$ são as funções de transferência dos transmissores de vazão (FIT-31/32) e do transmissor de pH (AITY-40), respectivamente e o bloco $C_{f f}(s)$ corresponde à função de transferência do controlador feedforward.

Figura 7.1 - Diagrama de blocos considerado no projeto do ramo feedforward do controlador de referência.

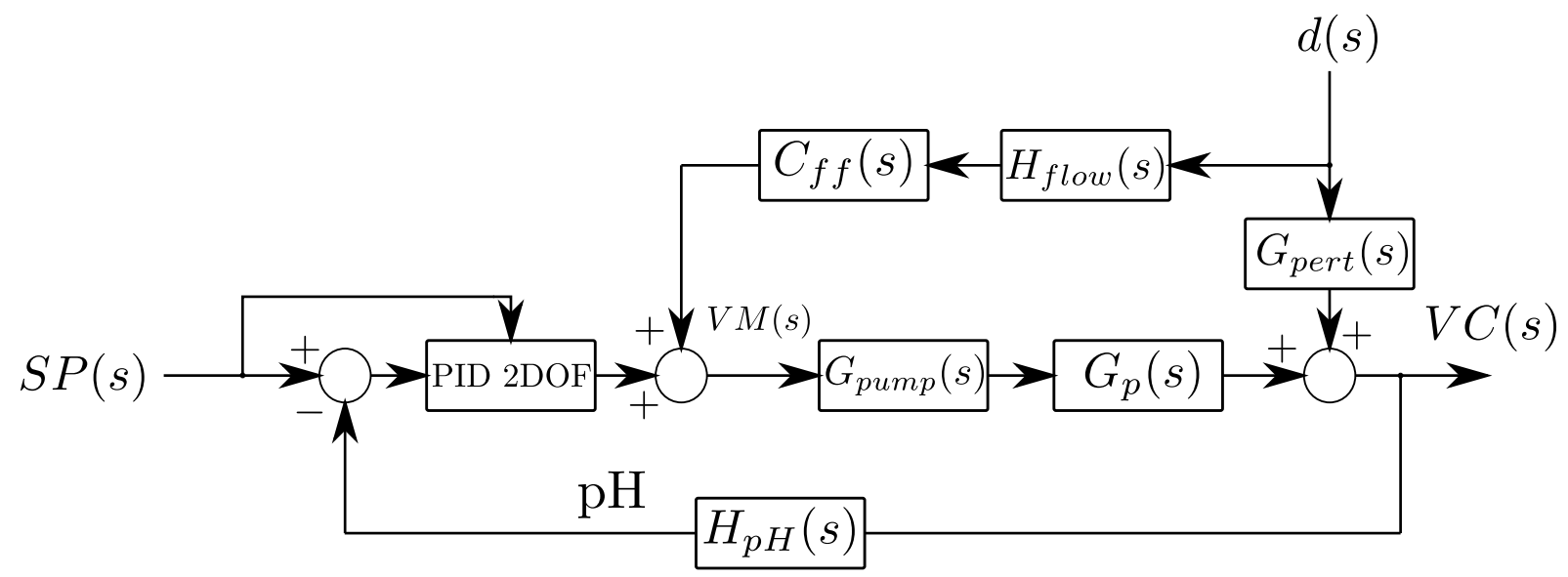

Adaptado de: Romanus e Giovaninni (2014).

As funções de transferência da planta, da bomba dosadora, dos transmissores e da perturbação foram obtidos por meio de experimentos de identificação de sistemas, 
realizados no modelo desenvolvido no Capítulo 5 e são (ROMANUS; GIOVANINNI, 2014):

$$
\begin{aligned}
G_{\text {pert }}(s) & =-\frac{405}{177 \cdot s+1}\left[\frac{\mathrm{pH}}{\mathrm{l} / \mathrm{s}}\right] \\
G_{p}(s) \cdot G_{\text {pump }}(s) & =\frac{1,82}{2340 \cdot s+1}\left[\frac{\mathrm{pH}}{\%(\mathrm{bomba})}\right] \\
H_{\text {flow }}(s) & =3,6 \cdot 10^{3}\left[\frac{\mathrm{l} / \mathrm{h}}{\mathrm{l} / \mathrm{s}}\right] .
\end{aligned}
$$

Considerando-se apenas o ramo referente à perturbação, a função de transferência em malha fechada do diagrama de blocos da Figura 7.1 é:

$$
\frac{V C(s)}{d(s)}=G_{p e r t}(s)+H_{f l o w}(s) \cdot G_{p u m p}(s) \cdot G_{p}(s) \cdot C_{f f}(s) .
$$

Portanto, para eliminar a influência da perturbação (ou seja, $V C(s) / d(s)=0$ ), basta escolher $C_{f f}(s)$ tal que:

$$
C_{f f}(s)=-\frac{G_{\text {pert }}(s)}{H_{\text {flow }}(s) \cdot G_{\text {pump }}(s) \cdot G_{p}(s)}=-0,0062 \frac{2340 s+1}{177 s+1} .
$$

\subsection{Projeto do Observador de Estados}

A estrutura e as propriedades matemáticas do observador de estados são descritas nesta seção. Ainda, para o desenvolvimento do observador, é necessário simplificar o modelo da Planta Piloto, de forma que seja viável analisar suas propriedades matemáticas. O projeto do observador teve como base o trabalho de Glaria et al. (2012), salvo alguns ajustes e adequações.

\subsubsection{Simplificação do Modelo Matemático da Planta Piloto}

O primeiro passo para projetar o observador de estados da Planta Piloto é obter seu modelo simplificado. Considerando que a Planta Piloto possui tempo de mistura igual a zero, seu balanço de massa pode ser escrito como:

$$
V_{a_{T R}} \dot{\mathbf{x}}=-F_{s} \mathbf{x}+F_{T A P I} \mathbf{w}_{T A P I}+F_{T A S I} \mathbf{w}_{T A S I}+F_{T B B} \mathbf{w}_{T B B}
$$

sendo $\mathbf{x} \in \Re^{n}$ o vetor de invariantes de reação do $\mathrm{TR}, V_{a_{T R}}$ o volume ativo do TR, $F_{s}$ a vazão de saída do TR, $F_{T A P I}$ a vazão do TAPI para o TR, $F_{T A S I}$ a vazão do TASI para o TR, $F_{T B B}$ a vazão do TBB para o TR e $\mathbf{w}_{T A P I}, \mathbf{w}_{T A S I}$ e $\mathbf{w}_{T B B} \in \Re^{n}$ os vetores de invariantes de reação do TAPI, TASI e TBB, respectivamente. Como o TR opera com nível aproximadamente constante, pode-se aproximar a vazão de saída como $F_{s}=F_{T A P I}+F_{T A S I}+F_{T B B}$, resultando em:

$$
V_{a_{T R}} \dot{\mathbf{x}}=-\left(F_{T A P I}+F_{T A S I}+F_{T B B}\right) \mathbf{x}+F_{T A P I} \mathbf{w}_{T A P I}+F_{T A S I} \mathbf{w}_{T A S I}+F_{T B B} \mathbf{w}_{T B B} .
$$


Realizando-se as transformações:

$$
\begin{aligned}
F_{T A P I} & =F_{T A P I_{0}}+\Delta F_{T A P I} \\
F_{T A S I} & =F_{T A S I_{0}}+\Delta F_{T A S I} \\
F_{T B B} & =F_{T B B_{0}}+\Delta F_{T B B},
\end{aligned}
$$

a Eq. (7.8) pode ser reescrita como:

$$
\begin{array}{r}
V_{a_{T R}} \dot{\mathbf{x}}=-\left(F_{T A P I_{0}}+F_{T A S I_{0}}+F_{T B B_{0}}\right) \mathbf{x}-\left(\Delta F_{T A P I}+\Delta F_{T A S I}+\Delta F_{T B B}\right) \mathbf{x}+ \\
F_{T A P I} \mathbf{w}_{T A P I}+F_{T A S I} \mathbf{w}_{T A S I}+F_{T B B} \mathbf{w}_{T B B} .
\end{array}
$$

A Eq. (7.10) pode ser reescrita na forma matricial:

$$
\dot{\mathbf{x}}=A \mathbf{x}+B u+H \mathbf{d}+f(\mathbf{x}, \Delta u, \Delta \mathbf{d})
$$

sendo:

$$
\begin{gathered}
A=\left[\begin{array}{ccc}
-a_{0} & & 0 \\
& \ddots & \\
0 & & -a_{0}
\end{array}\right], \text { onde } a_{0}=\frac{F_{T A P I_{0}}+F_{T A S I_{0}}+F_{T B B_{0}}}{V_{a_{T R}}} \\
B=\left[\mathbf{w}_{T B B}\right] \div V_{a_{T R}} \quad H=\left[\mathbf{w}_{T A P I} \vdots \mathbf{w}_{T A S I}\right] \div V_{a_{T R}} \\
u=F_{T B B_{0}}+\Delta F_{T B B}=u_{0}+\Delta u \\
\mathbf{d}=\left[\begin{array}{c}
F_{T A P I_{0}} \\
F_{T A S I_{0}}
\end{array}\right]+\left[\begin{array}{l}
\Delta F_{T A P I} \\
\Delta F_{T A S I}
\end{array}\right]=\mathbf{d}_{0}+\Delta \mathbf{d} \\
f(\mathbf{x}, \Delta u, \Delta \mathbf{d})=-\left(\frac{\Delta u+\Delta d_{1}+\Delta d_{2}}{V_{a_{T R}}}\right) \mathbf{x} .
\end{gathered}
$$

É possível simplificar o sistema, agrupando-se os termos de controle, $u$, e distúrbio, $d$, em uma única variável, $q$ :

$$
\begin{aligned}
M & =[H \vdots B] \\
\mathbf{q} & =\left[\begin{array}{c}
\mathbf{d} \\
\cdots \\
u
\end{array}\right]=\mathbf{q}_{0}+\Delta \mathbf{q} .
\end{aligned}
$$

Assim, o balanço de massa da Planta Piloto pode ser reescrito como:

$$
\dot{\mathbf{x}}=A \mathbf{x}+M \mathbf{q}+f(\mathbf{x}, \Delta \mathbf{q})
$$

Utilizando-se as Eq. (4.34) e (4.35), da Subseção 4.1.7, pode-se obter a relação matemática entre os invariantes de reação e o pH do Reator:

$$
h(\mathbf{x}, y)=j(y)-x_{1}-\sum_{\mathrm{i}=1}^{n-1} x_{\mathrm{i}+1} l_{\mathrm{i}}(y)=0,
$$


onde $y$ é o pH do TR, a função $h$ é a relação entre o pH do TR e os invariantes de reação e as funções $j(y)$ e $l_{\mathrm{i}}(y)$ são as funções $A(\mathrm{pH})$ e $a_{\mathrm{i}}(\mathrm{pH})$, respectivamente, definidas na Eq. (4.35).

A dinâmica dos instrumentos pode ser desprezada, pois ela é muito mais rápida que a dinâmica da Planta Piloto. Desprezando-se, portanto, a dinâmica dos instrumentos, o modelo simplificado da Planta Piloto é:

$$
\left\{\begin{array}{l}
\dot{\mathbf{x}}=A \mathbf{x}+M \mathbf{q}+f(\mathbf{x}, \Delta \mathbf{q}) \\
h(\mathbf{x}, y)=0
\end{array}\right.
$$

A Figura 7.2 apresenta uma comparação das respostas dos modelos completo (descrito no Capítulo 5) e simplificado da Planta Piloto, para um experimento em malha fechada, conforme descrito na Seção 6.1. Percebe-se que o modelo simplificado apresenta uma resposta muito semelhante ao modelo completo, tendo um Índice de Ajuste (fit) de $96,3 \%$.

Figura 7.2 - Comparação das respostas dos modelos completo e simplificado.

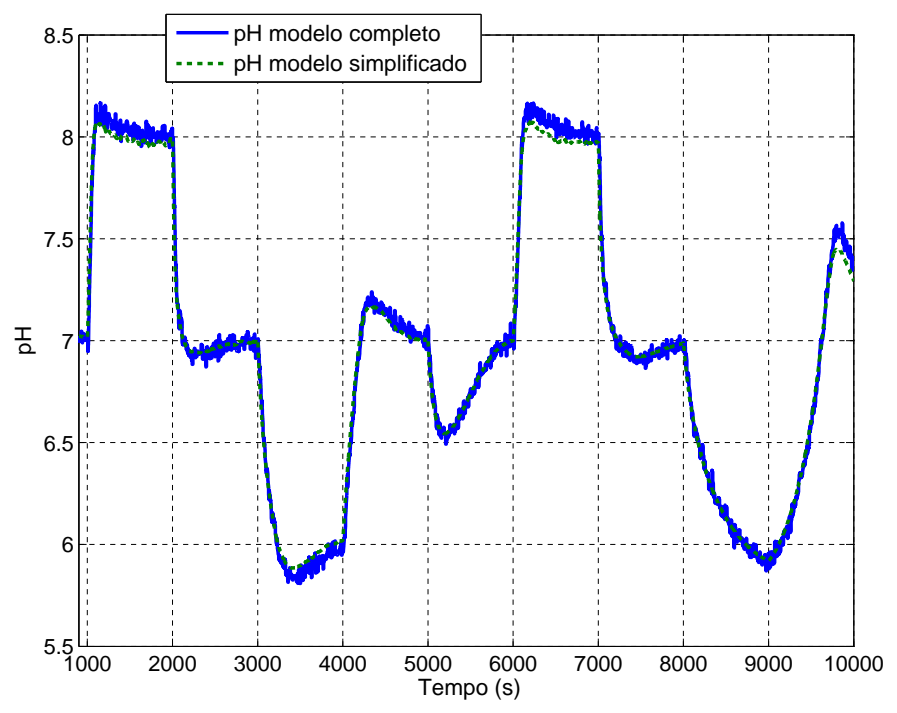

Fonte: do Autor.

\subsubsection{A Estrutura e as Propriedades do Observador de Estados}

Apesar de não-linear, a estrutura escolhida para o observador é similar aos observadores lineares, sendo de simples aplicação prática. No entanto, a análise de suas propriedades matemáticas é mais complexa que a dos observadores lineares. A estrutura do observador é igual ao modelo simplificado da Planta Piloto, conforme Eq. (7.16), com a adição de um termo para correção de desvios (GLARIA et al., 2012):

$$
\dot{\hat{\mathbf{x}}}=A \hat{\mathbf{x}}+M \mathbf{q}+f(\hat{\mathbf{x}}, \Delta \mathbf{q})+L(h(\mathbf{x}, y)-h(\hat{\mathbf{x}}, y))
$$


Levando-se em consideração que, por definição, $h(\mathbf{x}, y)=0$ :

$$
\dot{\hat{\mathbf{x}}}=A \hat{\mathbf{x}}+M \mathbf{q}+f(\hat{\mathbf{x}}, \Delta \mathbf{q})-L h(\hat{\mathbf{x}}, y)
$$

Para o projeto de qualquer observador de estados, é de primordial importância ter conhecimento a respeito da observabilidade do sistema, a qual determina se é possível reconstruir seus estados internos, a partir de medições de sua saída. Para sistemas nãolineares, introduz-se o conceito de indistinguibilidade (NIJMEIJER; SCHAFT, 1990): dois estados $x_{1}, x_{2} \in M$ são indistinguíveis se, para toda função de entrada admissível $q$, a função de saída $h(\mathbf{x}, y)$ apresenta resultados idênticos, para os estados iniciais $x_{1}$ ou $x_{2}$. O sistema é observável se for indistinguível apenas para $x_{1}=x_{2}$.

De forma mais restritiva - e mais próxima do conceito de observabilidade para sistemas lineares - é definido o conceito de observabilidade local (NIJMEIJER; SCHAFT, 1990): considere $V \subset M$ contendo $x_{1}$ e $x_{2}$. Os estados $x_{1}$ e $x_{2}$ são ditos $V$-indistinguíveis se, para qualquer entrada constante admissível $q$, a saída do sistema, $h(\mathbf{x}, y)$, for idêntica para qualquer um dos estados iniciais $x_{1}$ e $x_{2}$ e a solução $x(t)$ permanecer dentro do subespaço $V$. Dito de forma mais simples, um sistema é localmente observável se cada estado puder ser distinguível de seus estados vizinhos, para uma determinada trajetória de saída, $h(\mathbf{x}, y)$. Em uma análise intuitiva, a Planta Piloto não é localmente observável, pois inúmeras combinações vizinhas de um determinado estado, resultam no mesmo valor de saída da função $h(\mathbf{x}, y)$.

Matematicamente, a condição de observabilidade local do sistema é satisfeita, se a matriz $\mathcal{O}$ possuir posto pleno (NIJMEIJER; SCHAFT, 1990):

$$
\mathcal{O}(\mathbf{x}, y)=\left[\begin{array}{c}
\frac{\partial h(\mathbf{x}, y)}{\partial \mathbf{x}} \\
\frac{\partial h(\mathbf{x}, y)}{\partial \mathbf{x}} A \\
\vdots \\
\frac{\partial h(\mathbf{x}, y)}{\partial \mathbf{x}} A^{n-1}
\end{array}\right]
$$

sendo $\mathbf{x} \in \Re^{n}$. Note que o Jacobiano da função de saída terá sempre a estrutura:

$$
\frac{\partial h(\mathbf{x}, y)}{\partial \mathbf{x}}=\left[\begin{array}{llll}
-1 & -l_{1}(y) & \cdots & -l_{n-1}(y)
\end{array}\right] .
$$

Levando-se em consideração que a função $l_{\mathrm{i}}(y)$ representa o grau de dissociação do ácido fraco i, portanto: $l_{\mathrm{i}}(y) \in(0, j)$, sendo $j$ o número de prótons dissociáveis e que a matriz $A$ é diagonal, conclui-se que o posto da matriz $\mathcal{O}$ é sempre 1 , ou seja, o sistema não é localmente observável. No entanto, esta conclusão não significa que o observador de estados não irá fornecer informações úteis, mas sim que o observador, caso seja estável, irá fornecer informações tão precisas quanto é o modelo da Planta Piloto em malha aberta.

Se o modelo da Planta Piloto fosse observável, os requisitos iv e v do sistema de controle poderiam ser atendidos com a utilização de um observador de estados. No 
entanto, pelo fato do modelo não ser observável, o observador não irá fornecer estimativas confiáveis relativas às concentrações dos invariantes de reação que variam no tempo $\left(\mathrm{H}_{2} \mathrm{CO}_{3}\right.$, $\mathrm{NH}_{4}{ }^{+}$e $\mathrm{H}_{3} \mathrm{PO}_{4}$ ). Assim, decidiu-se utilizar o observador de estados apenas para estimar a concentração de ácido acético no TAS, que será utilizada pelo controlador não-linear, para atender ao requisito $\mathrm{v}$ do sistema de controle.

Para estimar a concentração de ácido acético no TAS, é necessário criar um estado adicional no modelo. Assim, a nova estrutura do modelo simplificado - e consequentemente de seu observador de estados - da Planta Piloto é (note-se que o ácido acético corresponde ao segundo estado, conforme o Capítulo 5):

$$
\dot{\hat{\mathbf{x}}}=\left[\begin{array}{c}
-a_{0} \hat{x}_{1}-\frac{\Delta q_{1}+\Delta q_{2}+\Delta q_{3}}{V_{a_{T R}}} \hat{x}_{1}+\frac{q_{1}}{V_{a_{T R}}} w_{1_{T A P I}}+\frac{q_{2}}{V_{a_{T R}}} w_{1_{T A S I}}+\frac{q_{1}}{V_{a_{T R}}} w_{1_{T B B}} \\
-a_{0} \hat{x}_{2}+\frac{q_{2_{0}}}{V_{a_{T R}}} \hat{x}_{5}-\frac{\Delta q_{1}+\Delta q_{2}+\Delta q_{3}}{V_{a_{T R}}} \hat{x}_{2}+\frac{\Delta q_{2}}{V_{a_{T R}}} \hat{x}_{5}+\frac{q_{1}}{V_{a_{T R}}} w_{2_{T A P I}}+\frac{q_{3}}{V_{a_{T R}}} w_{2_{T B B}} \\
-a_{0} \hat{x}_{3}-\frac{\Delta q_{1}+\Delta q_{2}+\Delta q_{3}}{V_{a_{T R}}} \hat{x}_{3}+\frac{q_{1}}{V_{a_{T R}}} w_{1_{T A P I}}+\frac{q_{2}}{V_{a_{T R}}} w_{1_{T A S I}}+\frac{q_{1}}{V_{a_{T R}}} w_{1_{T B B}} \\
-a_{0} \hat{x}_{4}-\frac{\Delta q_{1}+\Delta q_{2}+\Delta q_{3}}{V_{a_{T R}}} \hat{x}_{4}+\frac{q_{1}}{V_{a_{T R}}} w_{1_{T A P I}}+\frac{q_{2}}{V_{a_{T R}}} w_{1_{T A S I}}+\frac{q_{1}}{V_{a_{T R}}} w_{1_{T B B}} \\
-a_{0} \hat{x}_{5}-\frac{\Delta q_{1}+\Delta q_{2}+\Delta q_{3}}{V_{a_{T R}}} \hat{x}_{5}+\frac{q_{1}}{V_{a_{T R}}} w_{1_{T A P I}}+\frac{q_{2}}{V_{a_{T R}}} w_{1_{T A S I}}+\frac{q_{1}}{V_{a_{T R}}} w_{1_{T B B}} \\
0
\end{array}\right] .
$$

Portanto, os termos das Eq. (7.16) e (7.17) são:

$$
\begin{aligned}
& A=\left[\begin{array}{cccccc}
-a_{0} & 0 & 0 & 0 & 0 & 0 \\
0 & -a_{0} & 0 & 0 & 0 & \frac{q_{2}}{V_{a_{T R}}} \\
0 & 0 & -a_{0} & 0 & 0 & 0 \\
0 & 0 & 0 & -a_{0} & 0 & 0 \\
0 & 0 & 0 & 0 & -a_{0} & 0 \\
0 & 0 & 0 & 0 & 0 & 0
\end{array}\right], \text { onde } a_{0}=\frac{q_{1_{0}}+q_{2_{0}}+q_{3_{0}}}{V_{a_{T R}}} \\
& M=\left[\begin{array}{ccc}
w_{1_{T A P I}} & w_{1_{T A S I}} & w_{1_{T B B}} \\
w_{2_{T A P I}} & 0 & w_{2_{T B B}} \\
w_{3_{T A P I}} & w_{3_{T A S I}} & w_{3_{T B B}} \\
w_{4_{T A P I}} & w_{4_{T A S I}} & w_{4_{T B B}} \\
w_{5_{T A P I}} & w_{5_{T A S I}} & w_{5_{T B B}} \\
0 & 0 & 0
\end{array}\right] \div V_{a_{T R}} \\
& f(\hat{\mathbf{x}}, \Delta \mathbf{q})=-\left(\frac{\Delta q_{1}+\Delta q_{2}+\Delta q_{3}}{V_{a_{T R}}}\right) a_{1} \hat{\mathbf{x}}+\frac{\Delta q_{2}}{V_{a_{T R}}} a_{2} \hat{\mathbf{x}} \\
& a_{1}=\left[\begin{array}{cccccc}
1 & 0 & 0 & 0 & 0 & 0 \\
0 & 1 & 0 & 0 & 0 & 0 \\
0 & 0 & 1 & 0 & 0 & 0 \\
0 & 0 & 0 & 1 & 0 & 0 \\
0 & 0 & 0 & 0 & 1 & 0 \\
0 & 0 & 0 & 0 & 0 & 0
\end{array}\right] \quad a_{2}=\left[\begin{array}{cccccc}
0 & 0 & 0 & 0 & 0 & 0 \\
0 & 0 & 0 & 0 & 0 & 1 \\
0 & 0 & 0 & 0 & 0 & 0 \\
0 & 0 & 0 & 0 & 0 & 0 \\
0 & 0 & 0 & 0 & 0 & 0 \\
0 & 0 & 0 & 0 & 0 & 0
\end{array}\right] .
\end{aligned}
$$


Note que esta nova estrutura do modelo aumenta o posto da matriz de observabilidade, $\mathcal{O}$, em um. Isto ocorre pois o estado adicional não interfere diretamente na saída do sistema, como os outros estados, o que pode ser visto no novo Jacobiano da função de saída:

$$
\frac{\partial h(\mathbf{x}, y)}{\partial \mathbf{x}}=\left[\begin{array}{lllll}
-1 & -l_{1}(y) & \cdots & -l_{n-1}(y) & 0
\end{array}\right]
$$

Assim, pode-se concluir que o estado adicional, incluído para estimar a concentração de ácido acético no TAS, é observável.

Como existem inúmeros estados não observáveis no sistema, deve-se obter uma matriz de correção $L$ que garanta a estabilidade do observador de estados. Para tanto, considere a equação dinâmica do erro do observador de estados (GLARIA et al., 2012):

$$
\begin{gathered}
\mathbf{e}=\mathbf{x}-\hat{\mathbf{x}} \\
\dot{\mathbf{e}}=\dot{\mathbf{x}}-\dot{\hat{\mathbf{x}}}=A \mathbf{x}+M \mathbf{q}+f(\mathbf{x}, \Delta \mathbf{q})-A \hat{\mathbf{x}}-M \mathbf{q}-f(\hat{\mathbf{x}}, \Delta \mathbf{q})-L(h(\mathbf{x}, y)-h(\hat{\mathbf{x}}, y)) .
\end{gathered}
$$

Pode-se aplicar o teorema do valor diferencial médio no termo de correção do observador, o qual afirma que para dois vetores $\mathbf{a}, \mathbf{b} \in \Re^{n}$ e uma função $\varphi: \Re^{n} \rightarrow$ $\Re$, diferenciável em todo o invólucro convexo $C o(\mathbf{a}, \mathbf{b})$, existe um vetor constante $\mathbf{z} \in$ $C o(\mathbf{a}, \mathbf{b}), \mathbf{z} \neq \mathbf{a}, \mathbf{z} \neq \mathbf{b}$, tal que (ZEMOUCHE; BOUTAYEB; BARA, 2005):

$$
\varphi(\mathbf{a})-\varphi(\mathbf{b})=\left(\frac{\partial \varphi}{\partial \mathbf{x}}(\mathbf{z})\right)(\mathbf{a}-\mathbf{b}),
$$

onde $C o(\mathbf{a}, \mathbf{b})$ é o invólucro convexo do conjunto $\{\mathbf{a}, \mathbf{b}\}$, como por exemplo:

$$
C o(\mathbf{a}, \mathbf{b})=\lambda \mathbf{a}+(1-\lambda) \mathbf{b}, \lambda \in[0,1] .
$$

Utilizando-se o teorema do valor diferencial médio, o termo de correção do observador pode ser reescrito como:

$$
h(\mathbf{x}, y)-h(\hat{\mathbf{x}}, y)=\left(\frac{\partial h}{\partial \mathbf{x}}(\mathbf{z}, y)\right) \mathbf{e},
$$

sendo $\mathbf{z} \in C o(\mathbf{x}, \hat{\mathbf{x}})$. Definindo-se:

$$
\begin{gathered}
g_{i}(t)=\left(\frac{\partial h}{\partial x_{i}}(\mathbf{z}, y)\right) \quad g(t)=\left[g_{1}(t), \ldots, g_{n}(t)\right] \\
\mathcal{C}(g(t))=\sum_{i=1}^{n} g_{i}(t) e_{n}^{T}(i)=\left(\frac{\partial h}{\partial x}(\mathbf{z}, y)\right)
\end{gathered}
$$

onde $e_{n}(i)$ é a base canônica do espaço vetorial $\Re^{n}$,

$$
E_{n}=\left\{e_{n}(i) \mid e_{n}(i)=[0, \ldots, 1, \ldots, 0]^{T}, i=1, \ldots, n\right\},
$$


pode-se reescrever o termo de correção do observador:

$$
h(\mathbf{x}, y)-h(\hat{\mathbf{x}}, y)=\mathcal{C}(g(t)) \mathbf{e}
$$

Assim, a dinâmica do erro do observador de estados é:

$$
\dot{\mathbf{e}}=\dot{\mathbf{x}}-\dot{\hat{\mathbf{x}}}=A \mathbf{x}+M \mathbf{q}+f(\mathbf{x}, \Delta \mathbf{q})-A \hat{\mathbf{x}}-M \mathbf{q}-f(\hat{\mathbf{x}}, \Delta \mathbf{q})-L \mathcal{C}(g(t)) \mathbf{e}
$$

Para estudar a estabilidade do observador, considere sua função de Lyapunov:

$$
\begin{gathered}
V(\mathbf{e})=\mathbf{e}^{T} P \mathbf{e} \\
\dot{V}(\mathbf{e})=\dot{\mathbf{e}}^{T} P \mathbf{e}+\mathbf{e}^{T} P \dot{\mathbf{e}}
\end{gathered}
$$

onde $P$ é uma matriz simétrica, positiva definida, garantindo $V(e)>0$. Substituindo-se a Eq. (7.32) na Eq. (7.33), tem-se:

$$
\begin{aligned}
\dot{V}(\mathbf{e})=[A \mathbf{e}+f(\mathbf{x}, \Delta \mathbf{q})-f(\hat{\mathbf{x}}, \Delta \mathbf{q})- & L \mathcal{C}(g(t)) \mathbf{e}]^{T} P \mathbf{e}+ \\
& \mathbf{e}^{T} P[A \mathbf{e}+f(\mathbf{x}, \Delta \mathbf{q})-f(\hat{\mathbf{x}}, \Delta \mathbf{q})-L \mathcal{C}(g(t)) \mathbf{e}] .
\end{aligned}
$$

Coletando-se os termos, tem-se:

$$
\begin{aligned}
\dot{V}(\mathbf{e})=\mathbf{e}^{T}[A-L \mathcal{C}(g(t))]^{T} P \mathbf{e}+(f(\mathbf{x}, \Delta \mathbf{q})-f(\hat{\mathbf{x}}, \Delta \mathbf{q}))^{T} P \mathbf{e}+ \\
\mathbf{e}^{T} P[A-L \mathcal{C}(g(t))] \mathbf{e}+\mathbf{e}^{T} P(f(\mathbf{x}, \Delta \mathbf{q})-f(\hat{\mathbf{x}}, \Delta \mathbf{q})) .
\end{aligned}
$$

Assim, uma das condições para o observador ser estável é:

$$
\left[\begin{array}{ll}
\mathbf{e}^{T} & \bar{f}^{T}
\end{array}\right]\left[\begin{array}{cc}
{[A-L \mathcal{C}(g(t))]^{T} P+P[A-L \mathcal{C}(g(t))]} & P \\
P & 0
\end{array}\right]\left[\begin{array}{l}
\mathbf{e} \\
\bar{f}
\end{array}\right]<0,
$$

sendo:

$$
\bar{f}=f(\mathbf{x}, \Delta \mathbf{q})-f(\hat{\mathbf{x}}, \Delta \mathbf{q})
$$

A outra condição para determinar a estabilidade do observador é relativa à função $f$. Caso esta possa ser caracterizada através de uma constante de Lipschitz, constrói-se outra condição para determinar a estabilidade do observador (GLARIA et al., 2012):

$$
\begin{gathered}
\|f(\mathbf{x}, \Delta \mathbf{q})-f(\hat{\mathbf{x}}, \Delta \mathbf{q})\| \leq \lambda_{f}\|\mathbf{x}-\hat{\mathbf{x}}\| \\
\bar{f}^{T} \bar{f} \leq \lambda_{f}^{2} \mathbf{e}^{T} \mathbf{e} .
\end{gathered}
$$

A Eq. (7.36) pode ser escrita na forma matricial:

$$
\left[\begin{array}{cc}
\mathbf{e}^{T} & \bar{f}^{T}
\end{array}\right]\left[\begin{array}{cc}
-I & 0 \\
0 & \frac{1}{\lambda_{f}^{2}} I
\end{array}\right]\left[\begin{array}{l}
\mathbf{e} \\
\bar{f}
\end{array}\right] \leq 0
$$


As Eq. (7.35) e (7.37) podem ser escritas em uma única inequação matricial linear variante no tempo (BOYD; FERON, 1994), que juntas determinam a condição necessária para a estabilidade do observador:

$$
\left[\begin{array}{ll}
\mathbf{e}^{T} & \bar{f}^{T}
\end{array}\right]\left[\begin{array}{cc}
{[A-L \mathcal{C}(g(t))]^{T} P+P[A-L \mathcal{C}(g(t))]+I} & P \\
P & -\psi \frac{1}{\lambda_{f}^{2}} I
\end{array}\right]\left[\begin{array}{l}
\mathbf{e} \\
\bar{f}
\end{array}\right]<0
$$

sendo $\psi \geq 0$, que pode ser arbitrariamente definido como $\psi \equiv 1$.

O vetor de ganhos do observador, $L$, pode ser obtido através da resolução da Eq. (7.38), para todos os valores admissíveis da função $g$. No entanto, um método mais eficiente de resolução desta inequação pode ser desenvolvido, utilizando-se a teoria de conjuntos convexos. Para tanto, assuma-se que as funções $g_{i}(t)$ são limitadas:

$$
\max _{t}\left|g_{i}(\mathbf{z}(t))\right|<\infty
$$

portanto a função $g(t)$ evolui em um domínio limitado, $\mathcal{G}_{n}$, sendo seus $\nu=2^{n}$ vértices definidos por:

$$
\mathcal{V}_{\mathcal{G}_{n}}=\left\{\alpha_{\nu}=\left[\alpha_{1}, \ldots, \alpha_{n}\right] \mid \alpha_{i} \in\left\{\underline{g}_{i}, \bar{g}_{i}\right\}, \nu=1, \ldots, 2^{n}\right\}
$$

onde:

$$
\underline{g}_{i}=\min _{t} g_{i}(t) \quad \bar{g}_{i}=\max _{t} g_{i}(t)
$$

Como o domínio gerado pelos vértices $\mathcal{V}_{\mathcal{G}_{n}}$ é convexo, deduz-se que o problema pode ser resolvido através de otimização convexa (ZEMOUCHE; BOUTAYEB; BARA, 2005; BOYD; VANDENBERGHE, 2009). Assim, o vetor de ganhos do observador deve ser tal que as LMI (do Inglês, Linear Matrix Inequality) sejam verdadeiras:

$$
\begin{array}{r}
{\left[\begin{array}{ll}
\mathbf{e}^{T} & \bar{f}^{T}
\end{array}\right]\left[\begin{array}{rr}
{\left[A-L \mathcal{C}\left(\alpha_{\nu}\right)\right]^{T} P+P\left[A-L \mathcal{C}\left(\alpha_{\nu}\right)\right]+I} & P \\
P & -\frac{1}{\lambda_{f}^{2}} I
\end{array}\right]\left[\begin{array}{l}
\mathbf{e} \\
\bar{f}
\end{array}\right]<0} \\
\forall \alpha_{\nu} \in \mathcal{V}_{\mathcal{G}_{n}} .
\end{array}
$$

Caso exista a necessidade de se obter uma taxa de convergência específica, pode-se impor que a equação de Lyapunov do observador seja $\dot{V}(\mathbf{e})<\beta V(\mathbf{e})$, resultando em (GLARIA et al., 2012):

$$
\begin{aligned}
{\left[\begin{array}{ll}
\mathbf{e}^{T} & \bar{f}^{T}
\end{array}\right]\left[\begin{array}{cc}
{\left[A-L \mathcal{C}\left(\alpha_{\nu}\right)\right]^{T} P+P\left[A-L \mathcal{C}\left(\alpha_{\nu}\right)\right]+I+\beta P} & P \\
P & -\frac{1}{\lambda_{f}^{2}} I
\end{array}\right]\left[\begin{array}{l}
\mathbf{e} \\
\bar{f}
\end{array}\right]<0 } \\
\forall \alpha_{\nu} \in \mathcal{V}_{\mathcal{G}_{n}} .
\end{aligned}
$$




\subsubsection{Determinação do Vetor de Ganho $L$}

Para determinar numericamente o vetor de ganho do observador, faz-se necessário obter o valor da constante de Lipschitz da função $f$, bem como obter o domínio convexo da função $g, \mathcal{V}_{\mathcal{G}_{n}}$.

A constante de Lipschitz pode ser calculada substituindo-se a função $f$ na Eq. (7.36):

$$
\begin{aligned}
& \|-\left(\frac{\Delta q_{1}+\Delta q_{2}+\Delta q_{3}}{V_{a_{T R}}}\right) a_{1} \mathbf{x}_{1}+\frac{\Delta q_{2}}{V_{a_{T R}}} a_{2} \mathbf{x}_{1}+ \\
& \quad+\left(\frac{\Delta q_{1}+\Delta q_{2}+\Delta q_{3}}{V_{a_{T R}}}\right) a_{1} \mathbf{x}_{2}-\frac{\Delta q_{2}}{V_{a_{T R}}} a_{2} \mathbf{x}_{2}\left\|\leq \lambda_{f}\right\| \mathbf{x}_{1}-\mathbf{x}_{2} \| .
\end{aligned}
$$

Coletando-se os termos e aplicando as propriedades da norma induzida:

$$
\begin{aligned}
\left\|\left(\frac{\Delta q_{2}}{V_{a_{T R}}} a_{2}-\frac{\Delta q_{1}+\Delta q_{2}+\Delta q_{3}}{V_{a_{T R}}} a_{1}\right)\left(\mathbf{x}_{1}-\mathbf{x}_{2}\right)\right\| & \leq \\
& \left\|\frac{\Delta q_{2}}{V_{a_{T R}}} a_{2}-\frac{\Delta q_{1}+\Delta q_{2}+\Delta q_{3}}{V_{a_{T R}}} a_{1}\right\|\left\|\mathbf{x}_{1}-\mathbf{x}_{2}\right\|
\end{aligned}
$$

e

$$
\begin{aligned}
& \left\|\frac{\Delta q_{2}}{V_{a_{T R}}} a_{2}-\frac{\Delta q_{1}+\Delta q_{2}+\Delta q_{3}}{V_{a_{T R}}} a_{1}\right\|\left\|\mathbf{x}_{1}-\mathbf{x}_{2}\right\| \leq \\
& \quad\left(\left\|\frac{\Delta q_{2}}{V_{a_{T R}}} a_{2}\right\|+\left\|-\frac{\Delta q_{1}+\Delta q_{2}+\Delta q_{3}}{V_{a_{T R}}} a_{1}\right\|\right)\left\|\mathbf{x}_{1}-\mathbf{x}_{2}\right\|,
\end{aligned}
$$

a constante de Lipschitz da função $f$ pode ser estimada, de forma conservadora, através dos valores máximos admissíveis de cada elemento do vetor $\Delta \mathbf{q}$ :

$$
\left|\frac{\Delta q_{2}}{V_{a_{T R}}}\right|\left\|a_{2}\right\|+\left|-\frac{\Delta q_{1}+\Delta q_{2}+\Delta q_{3}}{V_{a_{T R}}}\right|\left\|a_{1}\right\| \leq \lambda_{f},
$$

sendo:

$$
\begin{gathered}
\mathbf{q}_{0}=\left[\begin{array}{l}
25 / 3600 \\
25 / 3600 \\
15 / 3600
\end{array}\right] \quad[\mathrm{l} / \mathrm{s}] \\
\max \left|\Delta q_{1}\right|=25 / 3600[\mathrm{l} / \mathrm{s}] \quad \max \left|\Delta q_{2}\right|=25 / 3600[\mathrm{l} / \mathrm{s}] \quad \max \left|\Delta q_{3}\right|=15 / 3600[\mathrm{l} / \mathrm{s}] .
\end{gathered}
$$

Assim, a constante de Lipschitz da função $f$, que satisfaz a Inequação (7.46), foi calculada como $\lambda_{f}=5,394 \cdot 10^{-4}$.

Os vértices do domínio da função $g$ podem ser obtidos facilmente, notando-se que a Eq. (7.29) terá sempre a forma da Eq. (7.24). Portanto:

$$
\underline{g}_{i} \approx 0 \text { e } \bar{g}_{i} \approx j
$$


sendo $j$ o número de prótons dissociáveis.

A matriz de ganhos do observador, $L$, foi calculada solucionando-se Eq. (7.42), com a ferramenta Yalmip ${ }^{\circledR}$ do MATLAB ${ }^{\circledR}$ :

$$
\begin{aligned}
& L=\left[\begin{array}{llllll}
3,30 & 2,52 & 2,66 & 0,98 & 4,99 & 162,08
\end{array}\right]^{T} ， \\
& \operatorname{para} \beta=0,15 \text {. }
\end{aligned}
$$

\subsubsection{Simulações do Observador de Estados da Planta Piloto}

Para testar o desempenho do observador de estados da Planta Piloto, foram realizadas duas simulações em malha fechada. Como alguns invariantes de reação da Planta Piloto variam no tempo (conforme Capítulo 5), cada simulação correspondeu a uma condição extrema (mínima ou máxima) destes invariantes de reação. O procedimento da simulação está apresentado na Tabela 7.2.

Tabela 7.2 - Procedimento da simulação realizada para avaliar o desempenho do observador de estados.

\begin{tabular}{cccc}
\hline $\begin{array}{c}\text { Tempo } \\
\mathrm{s}\end{array}$ & $\begin{array}{c}F_{\text {TAPI }} \\
\mathrm{l} / \mathrm{h}\end{array}$ & $\begin{array}{c}F_{\text {TASI }} \\
\mathrm{l} / \mathrm{h}\end{array}$ & $\begin{array}{c}\mathrm{SP}(\mathrm{AIC}-40) \\
\mathrm{pH}\end{array}$ \\
\hline 0 & 50 & 0 & 7 \\
2000 & 50 & 0 & 8 \\
3000 & 50 & 0 & 7 \\
4000 & 50 & 0 & 6 \\
5000 & 50 & 0 & 7 \\
6000 & 0 & 50 & 7 \\
7000 & 0 & 50 & 8 \\
8000 & 0 & 50 & 7 \\
9000 & 0 & 50 & 6 \\
10000 & 0 & 50 & 7 \\
\hline \multicolumn{5}{c}{ Fonte: do Autor. }
\end{tabular}

Na simulação 1, o modelo da Planta Piloto teve os seguintes invariantes de reação das soluções, correspondentes aos mínimos encontrados nos Capítulos 5 e 6 :

$$
\begin{gathered}
\mathbf{w}_{T A P I}=\left[\begin{array}{lllll}
0,0056 & 0 & 1,7 \cdot 10^{-4} & 0,2 \cdot 10^{-4} & 0
\end{array}\right]^{T} \\
\mathbf{w}_{T A S I}=\left[\begin{array}{lllll}
0 & 0,0068 & 1,7 \cdot 10^{-4} & 0,2 \cdot 10^{-4} & 0
\end{array}\right]^{T} \\
\mathbf{w}_{T B B}=\left[\begin{array}{lllll}
-0,0185 & 0 & 1,7 \cdot 10^{-4} & 0,2 \cdot 10^{-4} & 0
\end{array}\right]^{T} .
\end{gathered}
$$

Na simulação 2, o modelo da Planta Piloto teve os seguintes invariantes de reação das soluções, correspondentes aos máximos encontrados nos Capítulos 5 e 6 :

$$
\begin{gathered}
\mathbf{w}_{T A P I}=\left[\begin{array}{lllll}
0,0056 & 1 \cdot 10^{-4} & 5 \cdot 10^{-4} & 2 \cdot 10^{-4} & 0,1 \cdot 10^{-4}
\end{array}\right]^{T} \\
\mathbf{w}_{T A S I}=\left[\begin{array}{llllll}
0 & 0,0068 & 5 \cdot 10^{-4} & 2 \cdot 10^{-4} & 2 \cdot 10^{-4} & 0,1 \cdot 10^{-4}
\end{array}\right]^{T} \\
\mathbf{w}_{T B B}=\left[\begin{array}{lllll}
-0,0185 & 1 \cdot 10^{-4} & 9 \cdot 10^{-4} & 2 \cdot 10^{-4} & 0,1 \cdot 10^{-4}
\end{array}\right]^{T} .
\end{gathered}
$$


Como o observador da Planta Piloto é invariante no tempo, deve-se escolher seus vetores de invariantes de reação, de forma que estes tenham a maior probabilidade possível de estarem próximos ao da Planta Piloto. Analisando-se a faixa de concentrações dos invariantes de reação, obtida nos Capítulos 5 e 6, escolheu-se os seguintes vetores de invariantes de reação para o observador da Planta Piloto, que compõem a matriz $M$ :

$$
\begin{gathered}
\mathbf{w}_{T_{A P I_{o b s}}}=\left[\begin{array}{lllll}
0,0056 & 0,5 \cdot 10^{-4} & 3 \cdot 10^{-4} & 2 \cdot 10^{-4} & 0
\end{array}\right]^{T} \\
\mathbf{w}_{T A S I_{o b s}}=\left[\begin{array}{lllll}
0 & 0 & 3 \cdot 10^{-4} & 2 \cdot 10^{-4} & 0
\end{array}\right]^{T} \\
\mathbf{w}_{T B B_{o b s}}=\left[\begin{array}{lllll}
-0,0185 & 0,5 \cdot 10^{-4} & 3 \cdot 10^{-4} & 2 \cdot 10^{-4} & 0
\end{array}\right]^{T} .
\end{gathered}
$$

Note-se que $w_{2_{\text {TASI obs }}}$ é igual a 0 , pois esta concentração está sendo estimada através do sexto estado do observador da Planta Piloto.

Os resultados das estimações do observador para as duas simulações estão apresentados nas Figuras 7.3 a 7.10. A partir das simulações, percebe-se que muitos estados estimados não convergem para o valor do modelo, mesmo com as estimativas de $\mathrm{pH}$ muito próximas do modelo. Isto já era esperado, devido ao fato do modelo da Planta Piloto ser não observável, motivo pelo qual ter sido determinado que apenas a estimativa de ácido acético $\left(\hat{x}_{6}\right)$ será utilizada pelo controlador. Analisando-se apenas a estimativa da concentração de ácido acético no TAS $\left(w_{2_{\text {TASI }}}\right)$, de 5000 até 10000 segundos, que foi quando a solução do TAS foi um influente do TR, o erro médio absoluto de estimação foi de 9,15\%, o que pode ser considerado adequado, face às condições extremas das simulações. Ainda, o tempo de acomodação da estimativa da concentração de ácido acético foi da ordem de 1000 segundos, para ambos os testes. O tempo de acomodação é importante, pois durante este tempo a estimativa será incorreta, diminuindo o desempenho do controlador. Note-se que é possível diminuir o tempo de acomodação do observador através da variável $\beta$. No entanto, um aumento no valor de $\beta$ implica em um aumento nos valores de ganho do observador, $L$, o que amplifica os eventuais ruídos de medição e consequentemente degrada as estimativas do observador. 
Figura 7.3 - Simulação 1, para teste do observador da Planta Piloto - estimação do pH.

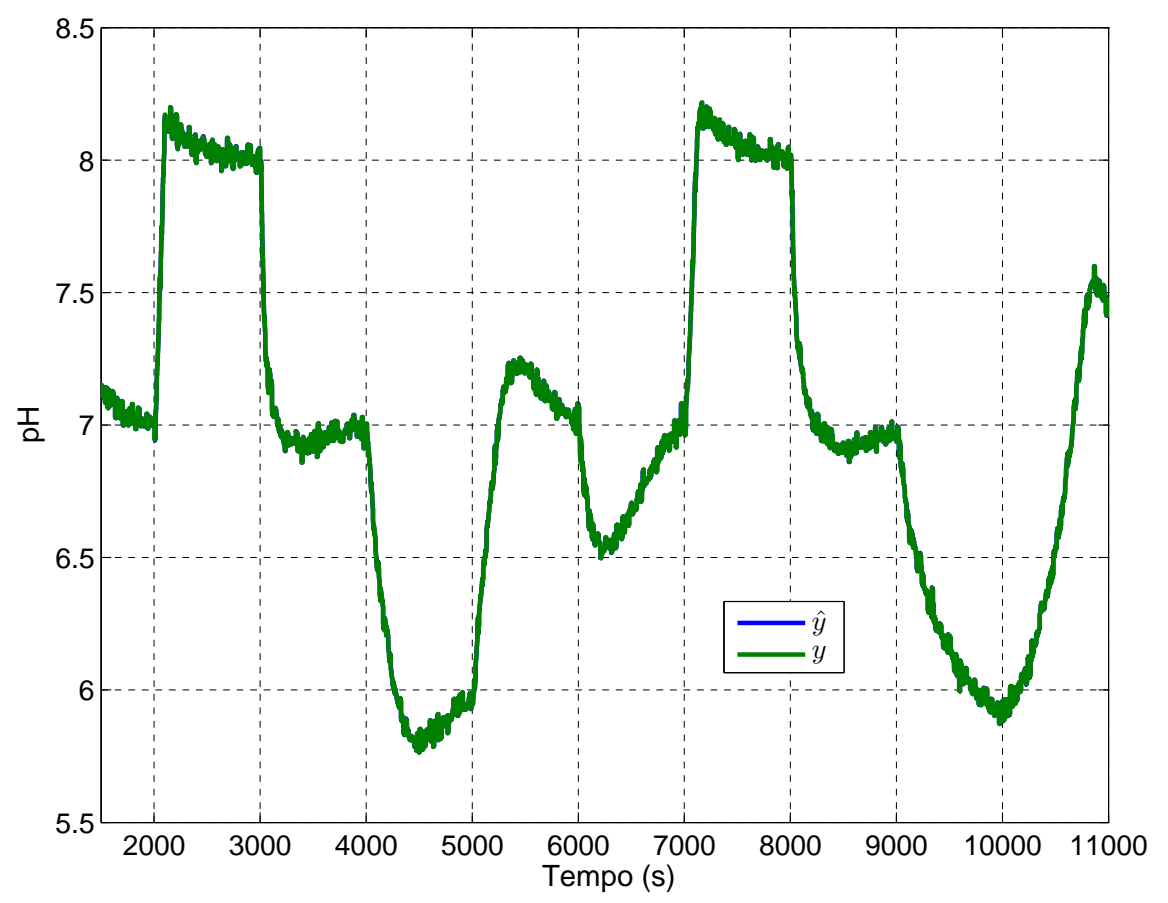

Fonte: do Autor.

Figura 7.4 - Simulação 1, para teste do observador da Planta Piloto - estimação dos invariantes de reação.

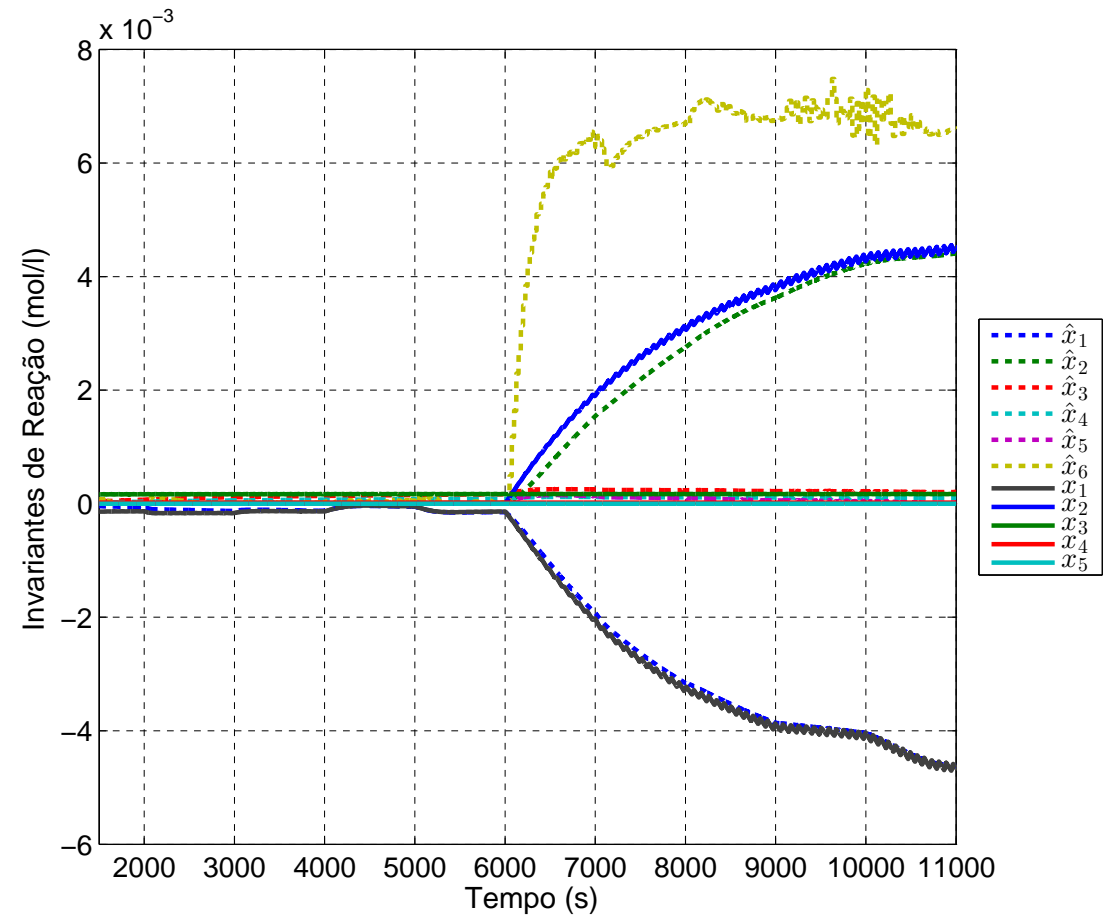

Fonte: do Autor. 
Figura 7.5 - Simulação 1, para teste do observador da Planta Piloto, com escalas ampliadas - estimação dos invariantes de reação, de 1000 até 6000 segundos.

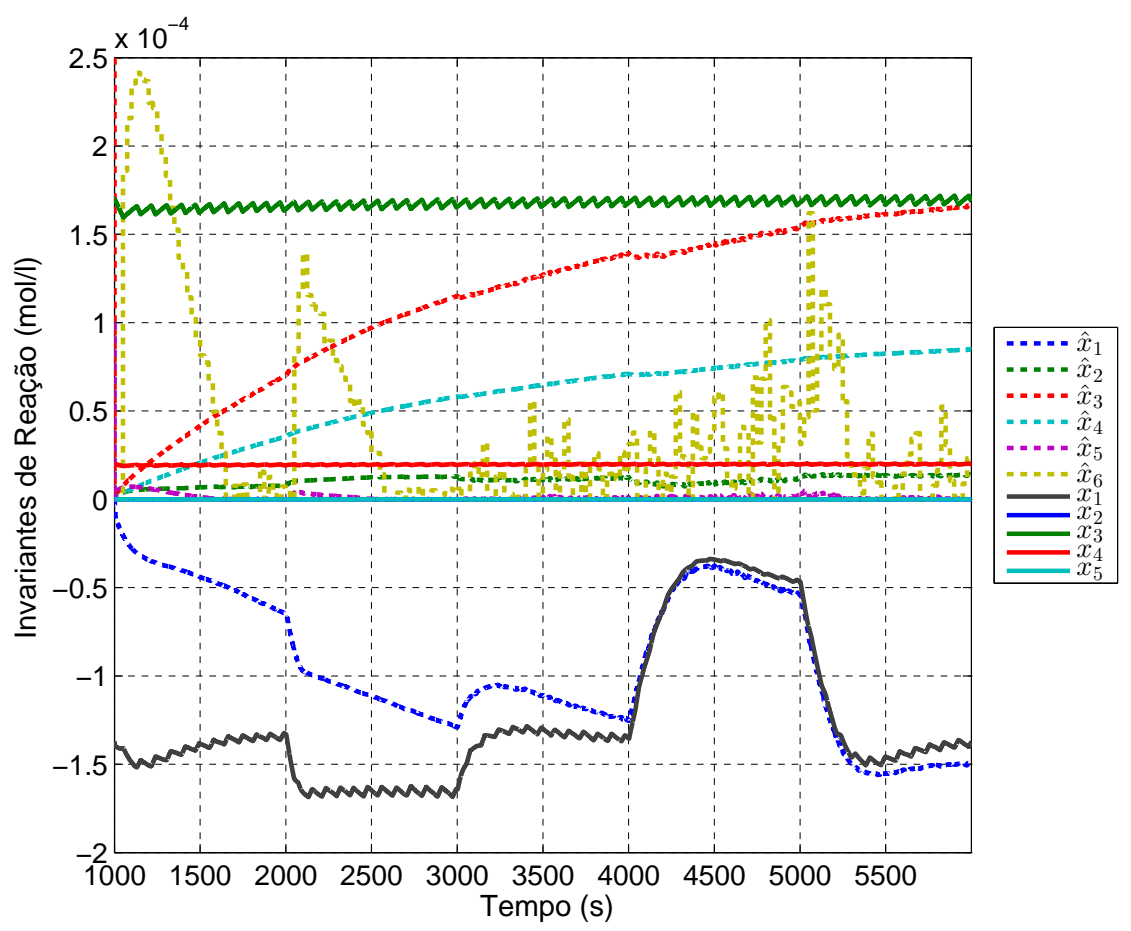

Fonte: do Autor.

Figura 7.6 - Simulação 1, para teste do observador da Planta Piloto, com escalas ampliadas - estimação dos invariantes de reação, de 6000 até 11000 segundos.

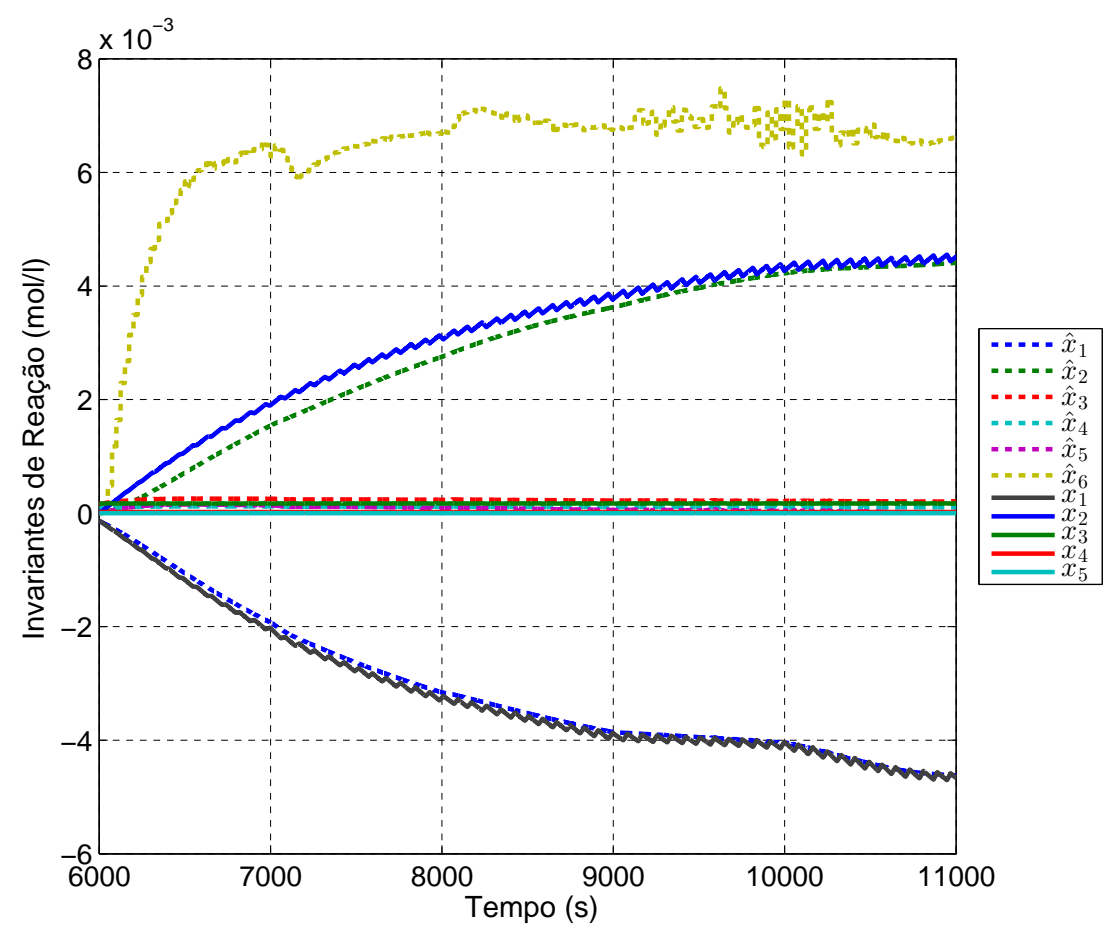

Fonte: do Autor. 
Figura 7.7 - Simulação 2, para teste do observador da Planta Piloto - estimação do pH.

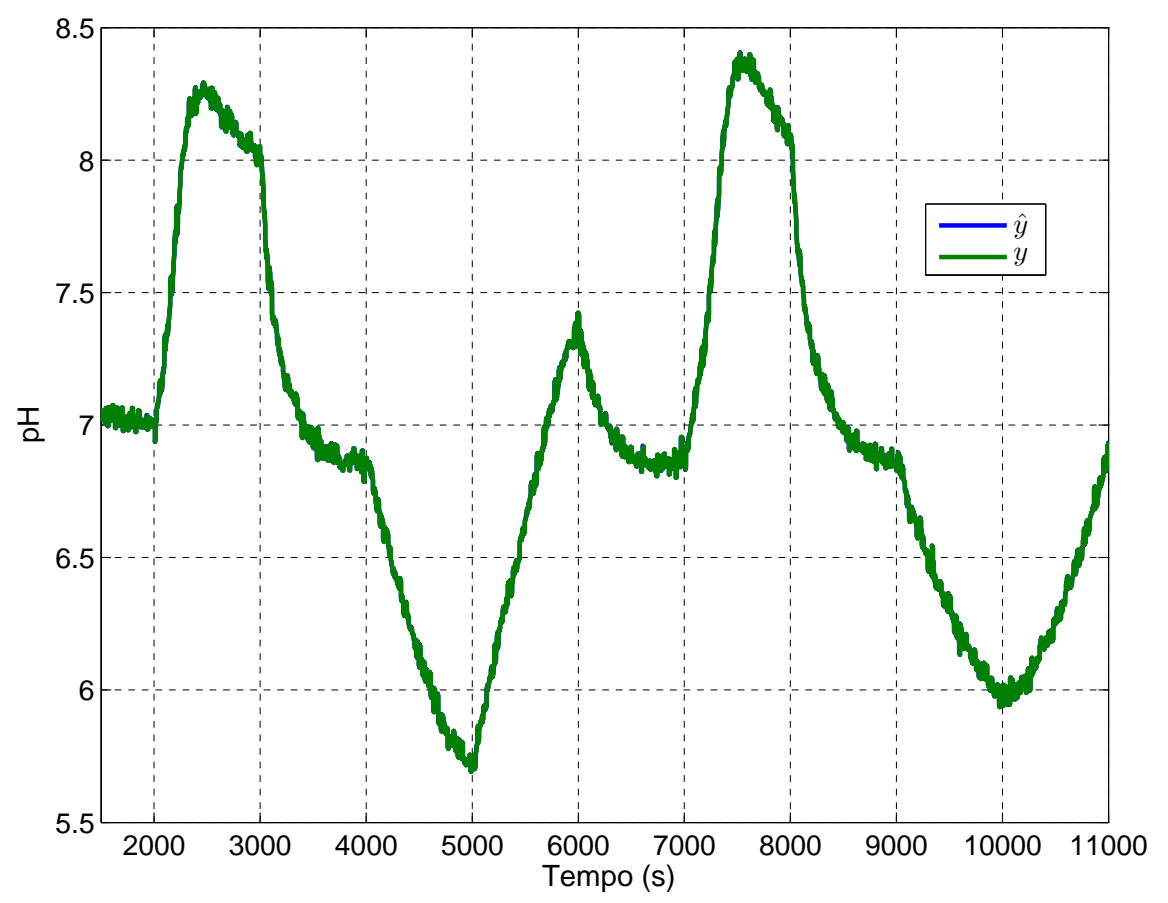

Fonte: do Autor.

Figura 7.8 - Simulação 2, para teste do observador da Planta Piloto - estimação dos invariantes de reação.

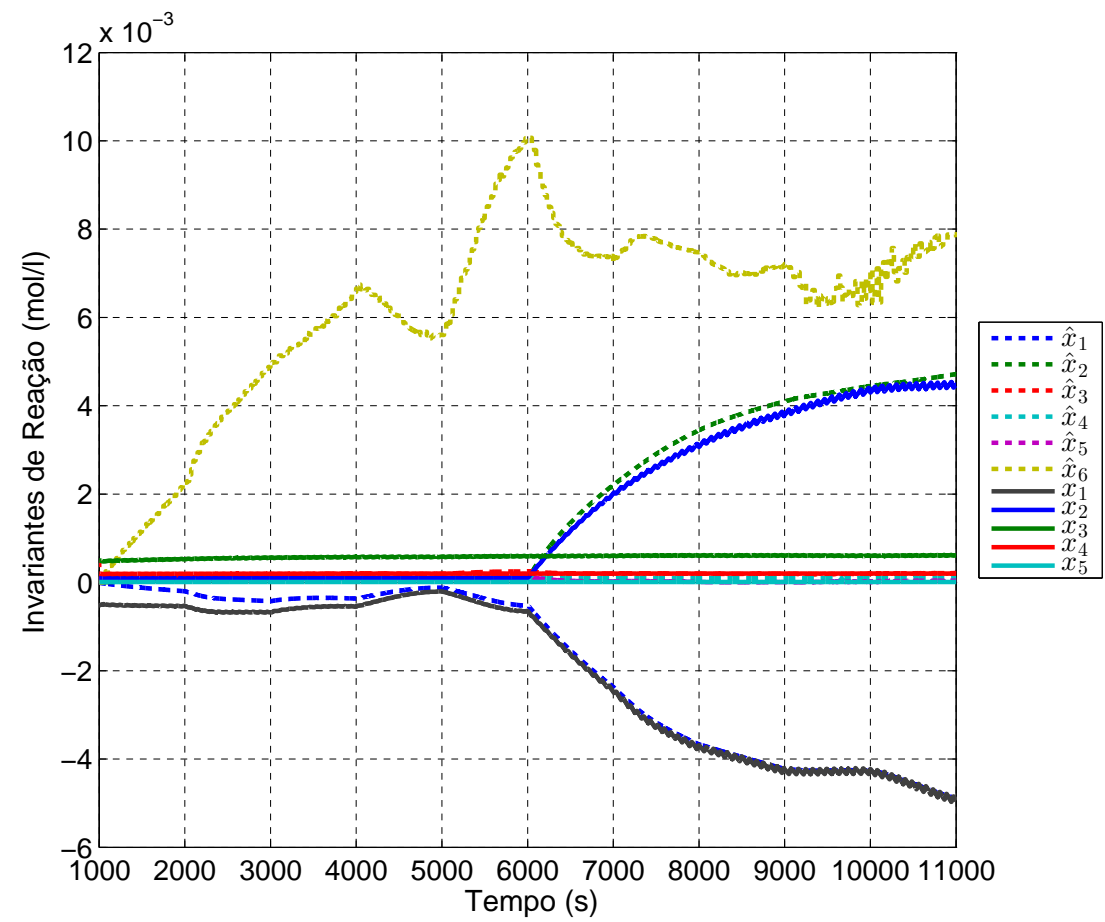

Fonte: do Autor. 
Figura 7.9 - Simulação 2, para teste do observador da Planta Piloto, com escalas ampliadas - estimação dos invariantes de reação, de 1000 até 6000 segundos.

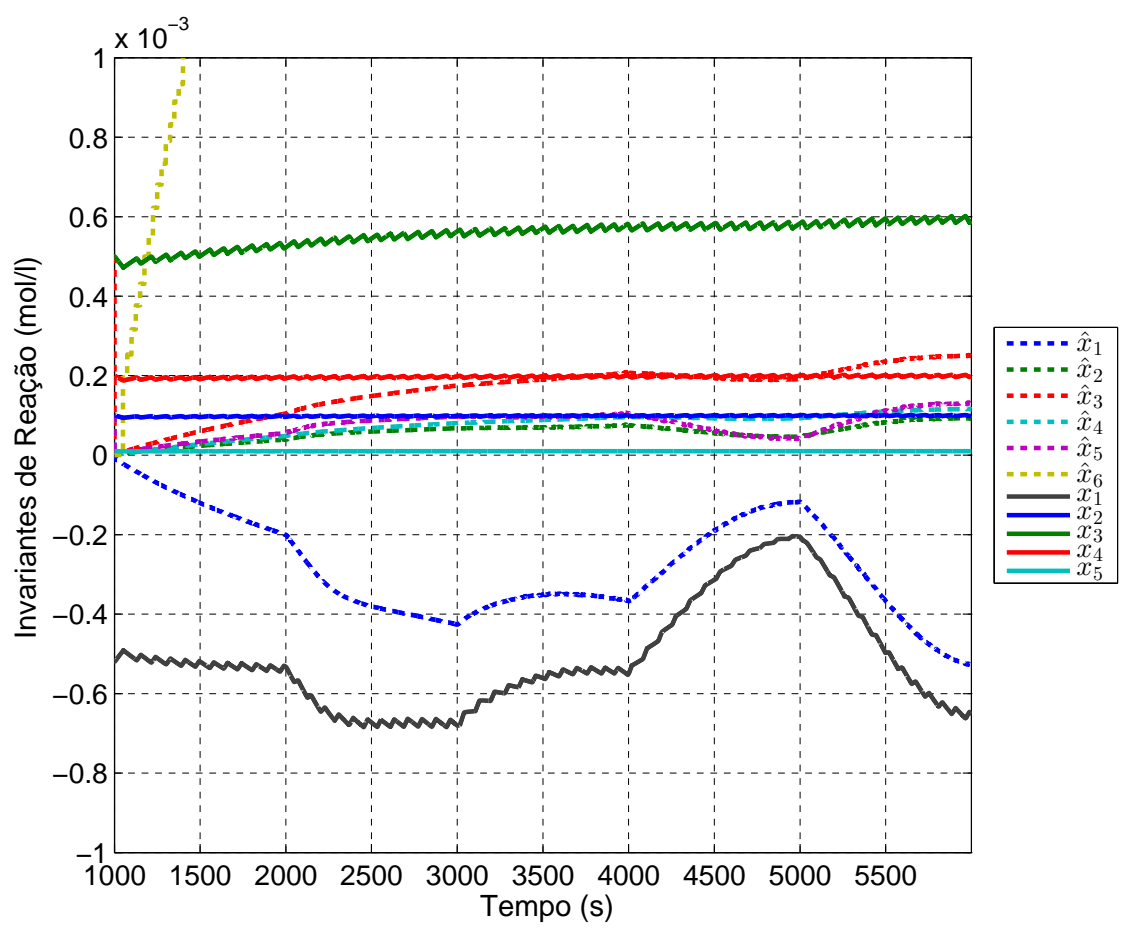

Fonte: do Autor.

Figura 7.10 - Simulação 2, para teste do observador da Planta Piloto, com escalas ampliadas - estimação dos invariantes de reação, de 6000 até 11000 segundos.

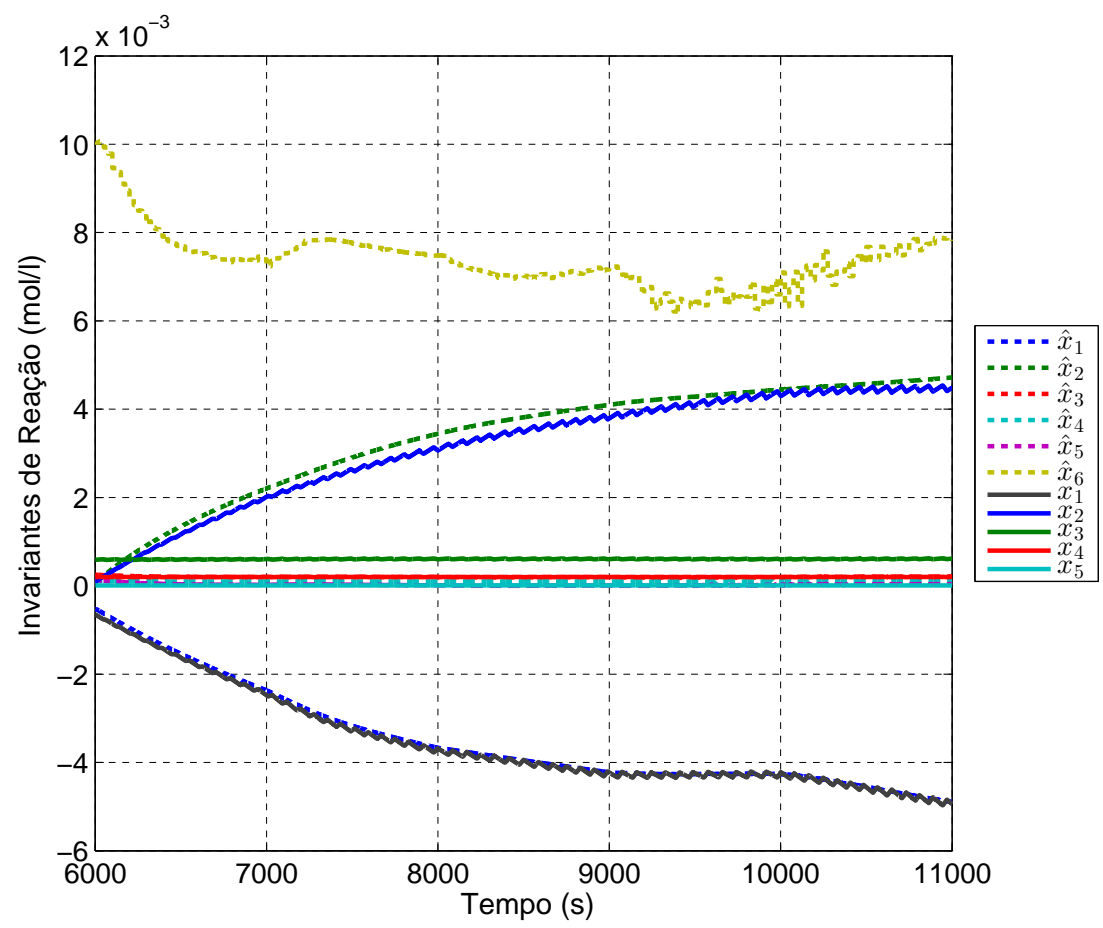

Fonte: do Autor. 


\subsection{Projeto do Controlador de $\mathrm{pH}$}

O controlador de $\mathrm{pH}$ utilizado na Planta Piloto utiliza o conceito de ácido forte equivalente e seu equacionamento foi baseado no trabalho de Wright e Kravaris (1991). Para tanto, algumas modificações devem ser realizadas no modelo da Planta Piloto, de forma a obter a lei de controle baseada em ácido forte equivalente.

\subsubsection{Reformulação do Problema de Controle}

Para reformular o problema de controle de pH, considere a modificação na equação do $\mathrm{pH}$, apresentada na Eq: (4.34):

$$
A(\mathrm{pH})+\sum_{\mathrm{i}=1}^{\alpha+1} x_{\mathrm{i}} \tilde{\mathrm{a}}_{\mathrm{i}}(\mathrm{pH})=0,
$$

sendo $\alpha$ o número de ácidos fracos que estão presentes na solução e a função $\tilde{a}_{i}(\mathrm{pH})$ definida como:

$$
\begin{aligned}
& \text { se i é um ácido, }
\end{aligned}
$$

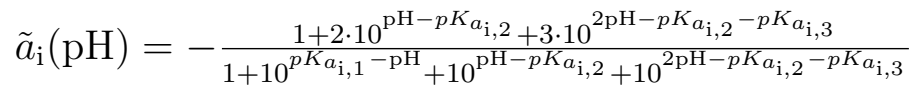

$$
\begin{aligned}
& \text { se i é uma base, }
\end{aligned}
$$

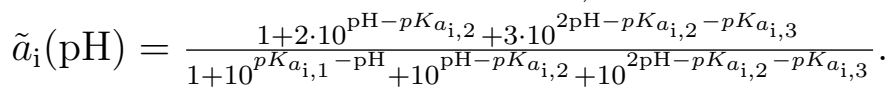

Para ácidos monopróticos, atribui-se o valor infinito para as constantes de equilíbrio $p K_{a_{i, 2}}$ e $p K_{a_{i, 3}}$. Para ácidos dipróticos, atribui-se o valor infinito para a constante de equilíbrio $p K_{a_{i, 3}}$. Para ácidos e bases fortes, atribui-se o valor menos infinito para os $j$ prótons que se dissociam completamente na faixa de $\mathrm{pH}$ das soluções aquosas, $p K_{a_{i, k}}=-\infty, k=1, \ldots, j$. De forma simples, esta nova forma de escrever a equação do $\mathrm{pH}$ consistiu em modificar a função $a_{\mathrm{i}}(\mathrm{pH})$, da Eq. (4.35), para englobar todo o vetor de invariantes de reação.

O controlador de $\mathrm{pH}$ tem por objetivo manter o $\mathrm{pH}$ do TR igual a um valor de referência, ou seja:

$$
\mathrm{pH}_{T R} \approx \mathrm{pH}_{S P}
$$

Isto ocorrerá se e somente se a Eq. (7.48) for verdadeira, para $\mathrm{pH}_{S P}$ :

$$
A\left(\mathrm{pH}_{S P}\right)+\sum_{\mathrm{i}=1}^{\alpha+1} x_{\mathrm{i}} \tilde{a}_{\mathrm{i}}\left(\mathrm{pH}_{S P}\right)=0 .
$$

Assim, define-se o ácido forte equivalente, o qual é uma função cujo resultado equivale a todos os prótons que estão efetivamente dissociados, em um determinado instante (WRIGHT; KRAVARIS, 1991):

$$
Y=-\sum_{\mathrm{i}=1}^{\alpha+1} x_{\mathrm{i}} \tilde{a}_{\mathrm{i}}\left(\mathrm{pH}_{S P}\right) .
$$

Portanto, o objetivo de controle somente será atendido quando $Y=A\left(\mathrm{pH}_{S P}\right)$, sendo este o novo problema de controle. 


\subsubsection{A Relação entre o Ácido Forte Equivalente e a Dinâmica da Planta Piloto}

Para utilizar o conceito de ácido forte equivalente, o modelo da Planta Piloto deve ser modificado. Como os invariantes de reação são lineares, os influentes ácidos (provenientes do TAPI e TASI) da Planta Piloto podem ser modelados com uma única variável:

$$
\begin{gathered}
F=F_{T A P I}+F_{T A S I} \\
\mathbf{w}_{a}=\frac{F_{T A P I} \mathbf{w}_{T A P I}+F_{T A S I} \mathbf{w}_{T A S I}}{F_{T A P I}+F_{T A S I}} .
\end{gathered}
$$

Assim, o modelo da Planta Piloto pode ser reescrito como:

$$
V_{a_{T R}} \dot{\mathbf{x}}=u\left(\mathbf{w}_{T B B}-\mathbf{x}\right)+F\left(\mathbf{w}_{a}-\mathbf{x}\right)
$$

sendo $u$ a vazão de influente básico, proveniente do TBB. Se as variáveis $\mathbf{w}_{a}$ e $\mathbf{w}_{T B B}$ não variam com o tempo, pode-se realizar as seguintes manipulações matemáticas:

$$
\begin{gathered}
V_{a_{T R}} \frac{\mathrm{d}\left(\mathbf{w}_{a}-\mathbf{x}\right)}{\mathrm{d} t}=-u\left(\mathbf{w}_{T B B}-\mathbf{x}\right)-F\left(\mathbf{w}_{a}-\mathbf{x}\right) \\
V_{a_{T R}} \frac{\mathrm{d}\left(\mathbf{w}_{a}-\mathbf{x}\right)}{\mathrm{d} t}=-u\left(\mathbf{w}_{a}-\mathbf{w}_{a}+\mathbf{w}_{T B B}-\mathbf{x}\right)-F\left(\mathbf{w}_{a}-\mathbf{x}\right) \\
V_{a_{T R}} \frac{\mathrm{d}\left(\mathbf{w}_{a}-\mathbf{x}\right)}{\mathrm{d} t}=u\left(\mathbf{w}_{a}-\mathbf{w}_{T B B}\right)-(F+u)\left(\mathbf{w}_{a}-\mathbf{x}\right) \\
V_{a_{T R}} \frac{\mathrm{d}\left(\frac{\mathbf{w}_{a}-\mathbf{x}}{\mathbf{w}_{a}-\mathbf{w}_{T B B}}\right)}{\mathrm{d} t}=u-(F+u) \frac{\mathbf{w}_{a}-\mathbf{x}}{\mathbf{w}_{a}-\mathbf{w}_{T B B}} .
\end{gathered}
$$

Definindo-se uma nova variável:

$$
\mathbf{X}=\frac{\mathbf{w}_{a}-\mathbf{x}}{\mathbf{w}_{a}-\mathbf{w}_{T B B}} \quad \text { e } \quad X_{\mathrm{i}}=\frac{w_{a_{\mathrm{i}}}-x_{\mathrm{i}}}{w_{a_{\mathrm{i}}}-w_{T B B_{\mathrm{i}}}},
$$

o modelo da Planta Piloto pode ser reescrito como:

$$
V_{a_{T R}} \dot{\mathbf{X}}=u-(F+u) \mathbf{X}
$$

sendo a nova relação entre a variável X e o pH da solução (conforme Eq. (4.34)):

$$
X_{\mathrm{i}}=\frac{A(\mathrm{pH})+\sum_{\mathrm{i}=1}^{\alpha+1} w_{a_{\mathrm{i}}} \tilde{a}_{\mathrm{i}}(\mathrm{pH})}{\sum_{\mathrm{i}=1}^{\alpha+1}\left(w_{a_{\mathrm{i}}}-w_{T B B_{\mathrm{i}}}\right) \tilde{a}_{\mathrm{i}}(\mathrm{pH})} .
$$

A Eq. (7.58) pode ser reescrita, utilizando-se a função inversa da curva de titulação do influente, definida na Eq. (4.39):

$$
T(\mathrm{pH})=-\frac{A(\mathrm{pH})+\sum_{\mathrm{i}=1}^{\alpha+1} w_{a_{\mathrm{i}}} \tilde{a}_{\mathrm{i}}(\mathrm{pH})}{A(\mathrm{pH})+\sum_{\mathrm{i}=1}^{\alpha+1} w_{T B B_{\mathrm{i}}} \tilde{a}_{\mathrm{i}}(\mathrm{pH})} .
$$


Manipulando-se a Eq. (7.58), tem-se:

$$
\begin{gathered}
X_{\mathrm{i}}=\frac{-A(\mathrm{pH})-\sum_{\mathrm{i}=1}^{\alpha+1} w_{a_{\mathrm{i}}} \tilde{\mathrm{a}}_{\mathrm{i}}(\mathrm{pH})}{A(\mathrm{pH})+\sum_{\mathrm{i}=1}^{\alpha+1} w_{T B B_{\mathrm{i}}} \tilde{a}_{\mathrm{i}}(\mathrm{pH})-A(\mathrm{pH})-\sum_{\mathrm{i}=1}^{\alpha+1} w_{a_{\mathrm{i}}} \tilde{a}_{\mathrm{i}}(\mathrm{pH})} \\
X_{\mathrm{i}}=\frac{-\frac{A(\mathrm{pH})-\sum_{\mathrm{i}=1}^{\alpha+1} w_{a_{\mathrm{i}}} \tilde{a}_{\mathrm{i}}(\mathrm{pH})}{A(\mathrm{pH})+\sum_{\mathrm{i}=1}^{\alpha+1} w_{T B B_{\mathrm{i}}} \tilde{a}_{\mathrm{i}}(\mathrm{pH})}}{\frac{A(\mathrm{pH})+\sum_{\mathrm{i}=1}^{\alpha+1} w_{T B B_{\mathrm{i}}} \tilde{a}_{\mathrm{i}}(\mathrm{pH})-A(\mathrm{pH})-\sum_{\mathrm{i}=1}^{\alpha+1} w_{a_{\mathrm{i}}} \tilde{a}_{\mathrm{i}}(\mathrm{pH})}{A(\mathrm{pH})+\sum_{\mathrm{i}=1}^{\alpha+1} w_{T B B_{\mathrm{i}}} \tilde{a}_{\mathrm{i}}(\mathrm{pH})}} .
\end{gathered}
$$

Assim, a relação entre $\mathbf{X}$ e $T(\mathrm{pH})$ é:

$$
X_{\mathrm{i}}=\frac{T(\mathrm{pH})}{1+T(\mathrm{pH})} .
$$

As Eq. (7.57) e (7.60) constituem mais uma forma de representar a Planta Piloto matematicamente. Para determinar a relação entre a variável $\mathbf{X}$ e o ácido forte equivalente, $Y$, manipula-se a Eq. (7.58):

$$
\begin{gathered}
X_{\mathrm{i}}-\frac{T\left(\mathrm{pH}_{S P}\right)}{1+T\left(\mathrm{pH}_{S P}\right)}=X_{i}-\frac{A\left(\mathrm{pH}_{S P}\right)+\sum_{\mathrm{i}=1}^{\alpha+1} w_{a_{\mathrm{i}}} \tilde{a}_{\mathrm{i}}\left(\mathrm{pH}_{S P}\right)}{\sum_{\mathrm{i}=1}^{\alpha+1}\left(w_{a_{\mathrm{i}}}-w_{T B B_{\mathrm{i}}}\right) \tilde{a}_{\mathrm{i}}\left(\mathrm{pH}_{S P}\right)}= \\
\frac{\sum_{\mathrm{i}=1}^{\alpha+1}\left(w_{a_{\mathrm{i}}}-x_{i}\right) \tilde{a}_{\mathrm{i}}\left(\mathrm{pH}_{S P}\right)-A\left(\mathrm{pH}_{S P}\right)-\sum_{\mathrm{i}=1}^{\alpha+1} w_{a_{\mathrm{i}}} \tilde{a}_{\mathrm{i}}\left(\mathrm{pH}_{S P}\right)}{\sum_{\mathrm{i}=1}^{\alpha+1}\left(w_{a_{\mathrm{i}}}-w_{T B B_{\mathrm{i}}}\right) \tilde{a}_{\mathrm{i}}\left(\mathrm{pH}_{S P}\right)}=\frac{-A\left(\mathrm{pH}_{S P}\right)-\sum_{\mathrm{i}=1}^{\alpha+1} x_{\mathrm{i}} \tilde{a}_{\mathrm{i}}\left(\mathrm{pH}_{S P}\right)}{\sum_{\mathrm{i}=1}^{\alpha+1}\left(w_{a_{\mathrm{i}}}-w_{T B B_{\mathrm{i}}}\right) \tilde{a}_{\mathrm{i}}\left(\mathrm{pH}_{S P}\right)} .
\end{gathered}
$$

Levando-se em consideração que:

$$
\left(1+T\left(\mathrm{pH}_{S P}\right)\right)=\frac{\sum_{\mathrm{i}=1}^{\alpha+1}\left(w_{T B B_{\mathrm{i}}}-w_{a_{\mathrm{i}}}\right) \tilde{a}_{\mathrm{i}}(\mathrm{pH})}{A(\mathrm{pH})+\sum_{\mathrm{i}=1}^{\alpha+1} w_{T B B_{\mathrm{i}}} \tilde{a}_{\mathrm{i}}(\mathrm{pH})}
$$

pode-se determinar a função $m: Y \mapsto \mathbf{X}$ :

$$
X_{\mathrm{i}}=\frac{T\left(\mathrm{pH}_{S P}\right)}{1+T\left(\mathrm{pH}_{S P}\right)}-\frac{-A\left(\mathrm{pH}_{S P}\right)+Y}{\left[1+T\left(\mathrm{pH}_{S P}\right)\right]\left[A\left(\mathrm{pH}_{S P}\right)+\sum_{\mathrm{i}=1}^{\alpha+1} w_{T B B_{\mathrm{i}}} \tilde{a}_{\mathrm{i}}\left(\mathrm{pH}_{S P}\right)\right]} .
$$

Pode-se determinar a equação dinâmica do ácido forte equivalente, substituindo-se 
a Eq. (7.62) na Eq. (7.57):

$$
\begin{gathered}
-V_{a_{T R}} \dot{Y} \frac{1}{\left[1+T\left(\mathrm{pH}_{S P}\right)\right] \psi}=u-(F+u)\left(\frac{T\left(\mathrm{pH}_{S P}\right)}{1+T\left(\mathrm{pH}_{S P}\right)}-\frac{-A\left(\mathrm{pH}_{S P}\right)+Y}{\left[1+T\left(\mathrm{pH}_{S P}\right)\right] \psi}\right) \\
-V_{a_{T R}} \dot{Y}=\left[1+T\left(\mathrm{pH}_{S P}\right)\right] \psi u-(F+u)\left[T\left(\mathrm{pH}_{S P}\right) \psi-\left(Y-A\left(\mathrm{pH}_{S P}\right)\right)\right] \\
-V_{a_{T R}} \dot{Y}=\psi u+T\left(\mathrm{pH}_{S P}\right) \psi u-F T\left(\mathrm{pH}_{S P}\right) \psi-T\left(\mathrm{pH}_{S P}\right) \psi u+(F+u)\left(Y-A\left(\mathrm{pH}_{S P}\right)\right) \\
\text { onde, } \\
\psi=A(\mathrm{pH})+\sum_{\mathrm{i}=1}^{\alpha+1} w_{T B B_{\mathrm{i}}} \tilde{a}_{\mathrm{i}}(\mathrm{pH}) .
\end{gathered}
$$

Definindo-se as variáveis incrementais:

$$
\begin{aligned}
& \hat{Y}=Y-Y_{S P}=Y-A\left(\mathrm{pH}_{S P}\right) \\
& \hat{u}=u-u_{S P}=u-F T\left(\mathrm{pH}_{S P}\right),
\end{aligned}
$$

obtém-se seguinte equação dinâmica para o ácido forte equivalente:

$$
V_{a_{T R}} \dot{\hat{Y}}=-\left[1+T\left(\mathrm{pH}_{S P}\right)\right] F \hat{Y}-(\psi+\hat{Y}) \hat{u} .
$$

A variável $\hat{Y}$ pode ser obtida a partir da Eq. (7.62):

$$
\begin{aligned}
\frac{T(\mathrm{pH})}{1+T(\mathrm{pH})} & =\frac{T\left(\mathrm{pH}_{S P}\right)}{1+T\left(\mathrm{pH}_{S P}\right)}-\frac{\hat{Y}}{\left[1+T\left(\mathrm{pH}_{S P}\right)\right] \psi} \\
\hat{Y} & =\psi\left(\frac{T\left(\mathrm{pH}_{S P}\right)-T(\mathrm{pH})}{1+T(\mathrm{pH})}\right) .
\end{aligned}
$$

\subsubsection{Determinação da Lei de Controle}

A lei de controle utilizada na Planta Piloto é a mesma sugerida em Wright e Kravaris (1991): um controlador PI (Proporcional Integral) linear em relação ao ácido forte equivalente. Tal controlador pode ser obtido, escolhendo-se a seguinte lei de controle:

$$
\hat{u}=\frac{K_{c}\left[\hat{Y}+\frac{1}{T_{i}} \int \hat{Y} \mathrm{~d} t\right]}{\psi+\hat{Y}} .
$$

A lei de controle pode ser reescrita de acordo com sua realização prática, substituindo-se a Eq. (7.64) na Eq. (7.65):

$$
\hat{u}=\frac{K_{c}}{T\left(\mathrm{pH}_{S P}\right)+1}\left[\left(T\left(\mathrm{pH}_{S P}\right)-T(\mathrm{pH})\right)+\frac{1+T(\mathrm{pH})}{T_{i}} \int \frac{T\left(\mathrm{pH}_{S P}\right)-T(\mathrm{pH})}{1+T(\mathrm{pH})} \mathrm{d} t\right] .
$$

Para determinar a sintonia do controlador, analisa-se sua resposta em malha fechada, substituindo-se a lei de controle na equação dinâmica do ácido forte equivalente - Eq. (7.65) e (7.63), respectivamente - resultando, no domínio de Laplace, em:

$$
V_{a_{T R}} \hat{Y} s^{2}+\left[\left(1+T\left(\mathrm{pH}_{S P}\right)\right) F+K_{c}\right] \hat{Y} s+\frac{K_{c}}{T_{i}} \hat{Y}=0 .
$$


Escolhendo-se os seguintes valores para os parâmetros dos controladores:

$$
\begin{gathered}
K_{c}=V_{a_{T R}}\left(\frac{1}{p_{1}}+\frac{1}{p_{2}}\right)-\left(1+T\left(\mathrm{pH}_{S P}\right)\right) F=\frac{V_{a_{T R}} p_{1}+V_{a_{T R}} p_{2}-p_{1} p_{2}\left(1+T\left(\mathrm{pH}_{S P}\right)\right) F}{p_{1} p_{2}} \\
T_{i}=p_{1}+p_{2}+p_{1} p_{2} \frac{\left(1+T\left(\mathrm{pH}_{S P}\right)\right) F}{V_{a_{T R}}},
\end{gathered}
$$

a Eq. (7.67) é forçada a ter os seguintes polos de malha fechada:

$$
\left(s+1 / p_{1}\right)\left(s+1 / p_{2}\right)=0 .
$$

Note que o controlador proposto, que será denominado controlador não-linear daqui em diante, possui um ramo de feedforward, pois a variável manipulada, $u$, é uma composição da lei de controle exposta nesta subseção, mais uma quantidade que corresponde à vazão de base necessária para que o influente seja neutralizado até o valor de referência do $\mathrm{pH}$.

\subsubsection{Sintonia do Controlador}

O controlador proposto tem estrutura linear, no entanto o ácido forte equivalente tem relação não-linear com o pH da solução. Isto significa que o controlador pode ser sintonizado através dos parâmetros $K_{c}$ e $T_{i}$ (ou $p_{1}$ e $p_{2}$ ), mas também pela curva de titulação dos influentes $T(\mathrm{pH})$. Assim, quanto mais próximos os vetores de invariantes de reação do controlador forem da Planta Piloto, melhor é a resposta do controlador.

Como a Planta Piloto é variante no tempo, o controlador deve ser robusto o suficiente para atender aos requisitos de controle, em qualquer situação de operação. Os vetores de invariantes de reação utilizados no controlador foram selecionados de modo que este tenha um desempenho melhor para soluções influentes que tenham sido preparadas a aproximadamente um dia, (de acordo com os Capítulos 5 e 6) visto que esta é a situação de operação mais frequente da Planta Piloto. Os parâmetros do controlador PI foram obtidos através de busca exaustiva, utilizando simulações no modelo da Planta Piloto, de forma a garantir que os requisitos de controle fossem atendidos para qualquer condição de operação da Planta Piloto. Os parâmetros do controlador são:

$$
\begin{aligned}
& p_{1}=50 \mathrm{~s} \quad \text { e } \quad p_{2}=300 \mathrm{~s} \\
& \mathbf{w}_{T A P I_{c}}=\left[\begin{array}{lllll}
0,0056 & 0,5 \cdot 10^{-4} & 3 \cdot 10^{-4} & 2 \cdot 10^{-4} & 0
\end{array}\right]^{T} \\
& \mathbf{w}_{T A S I_{c}}=\left[\begin{array}{lllll}
0 & \hat{x}_{6} & 3 \cdot 10^{-4} & 2 \cdot 10^{-4} & 0
\end{array}\right]^{T} \\
& \mathbf{w}_{T B B_{c}}=\left[\begin{array}{lllll}
-0,0185 & 0,5 \cdot 10^{-4} & 3 \cdot 10^{-4} & 2 \cdot 10^{-4} & 0
\end{array}\right]^{T} \text {, }
\end{aligned}
$$

sendo $\hat{x}_{6}$ a estimativa da concentração de ácido acético, proveniente do observador de estados.

As características construtivas do controlador são: (i) taxa de amostragem do $\mathrm{pH}$ e das vazões dos influentes de 1 segundo; (ii) taxa de amostragem da estimativa da concentração de ácido acético, $\hat{x}_{6}$, de 25 segundos, para eliminar os ruídos de estimação e 
(iii) a correção por realimentação, $\hat{u}$, foi limitada em $\pm 10 \mathrm{l} / \mathrm{h}$, tendo sido implementada a técnica de limitação da integração. Esta característica impede que o controlador se torne oscilatório para grandes variações no valor de referência do $\mathrm{pH}$.

\subsubsection{Simulações do Controlador}

A validação do desempenho do controlador foi realizada no modelo da Planta Piloto, onde simulou-se duas condições extremas para os invariantes de reação, tal como foram feitas as simulações para a validação do observador de estados. Todos os testes realizados no controlador não-linear foram repetidos, utilizando-se o controlador de referência, para efeitos de comparação.

Foram realizados dois experimentos distintos, para testar o desempenho do controlador em modo servo e regulatório. O procedimento do teste em modo servo foi igual ao apresentado na Tabela 7.2 e o procedimento do teste em modo regulatório está apresentado na Tabela 7.3 .

Tabela 7.3 - Procedimento da simulação para avaliar o desempenho do controlador em modo regulatório.

\begin{tabular}{cccc}
\hline $\begin{array}{c}\text { Tempo } \\
\mathrm{s}\end{array}$ & $\begin{array}{c}F_{\text {TAPI }} \\
\mathrm{l} / \mathrm{h}\end{array}$ & $\begin{array}{c}F_{\text {TASI }} \\
\mathrm{l} / \mathrm{h}\end{array}$ & $\begin{array}{c}\text { SP (AIC-40) } \\
\mathrm{pH}\end{array}$ \\
\hline 0 & 10 & 0 & 7 \\
2000 & 50 & 0 & 7 \\
3000 & 10 & 0 & 7 \\
4000 & 10 & 50 & 7 \\
5000 & 10 & 10 & 7 \\
6000 & 10 & 50 & 7 \\
\hline \multicolumn{4}{c}{ Fonte. do Autor. }
\end{tabular}

Os resultados das simulações estão apresentados nas Figuras 7.11 a 7.14. Em uma análise qualitativa, percebe-se que o controlador não-linear apresentou um desempenho superior ao controlador de referência, à exceção dos períodos transitórios do observador de estados - períodos em que o ácido acético começou a entrar no TR, isto é, de 6000 até 7000 segundos, para o modo servo e de 4000 até 5000 segundos, para o modo regulatório. 
Figura 7.11 - Simulação 1 em modo servo.

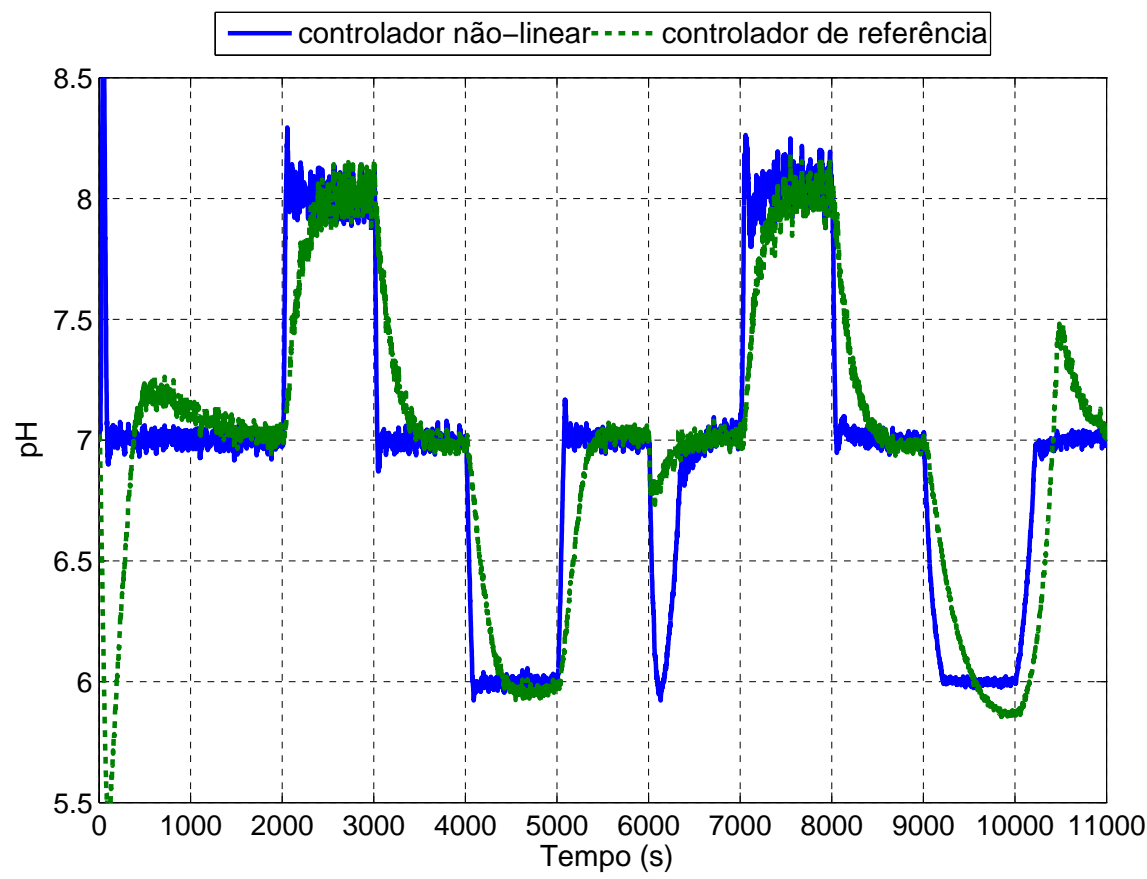

Fonte: do Autor.

Figura 7.12 - Simulação 2 em modo servo.

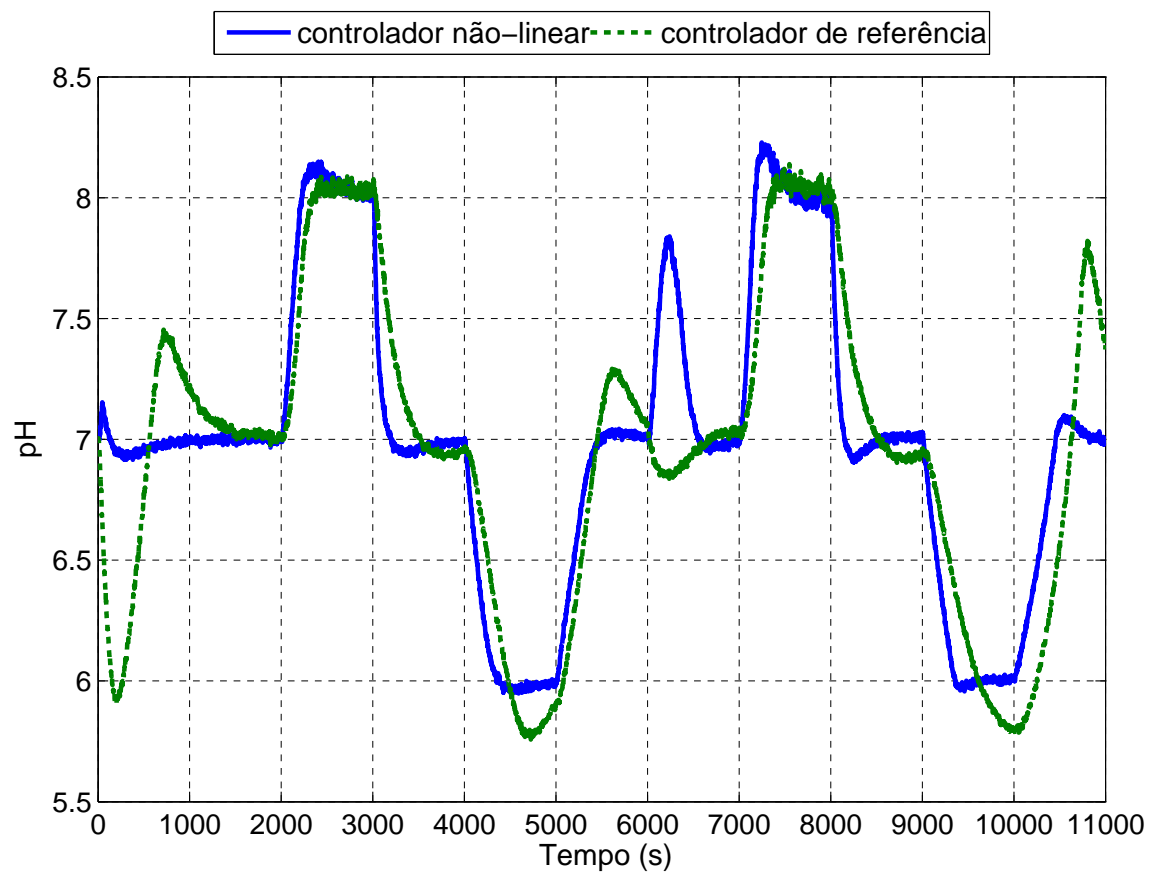

Fonte: do Autor. 
Figura 7.13 - Simulação 1 em modo regulatório.

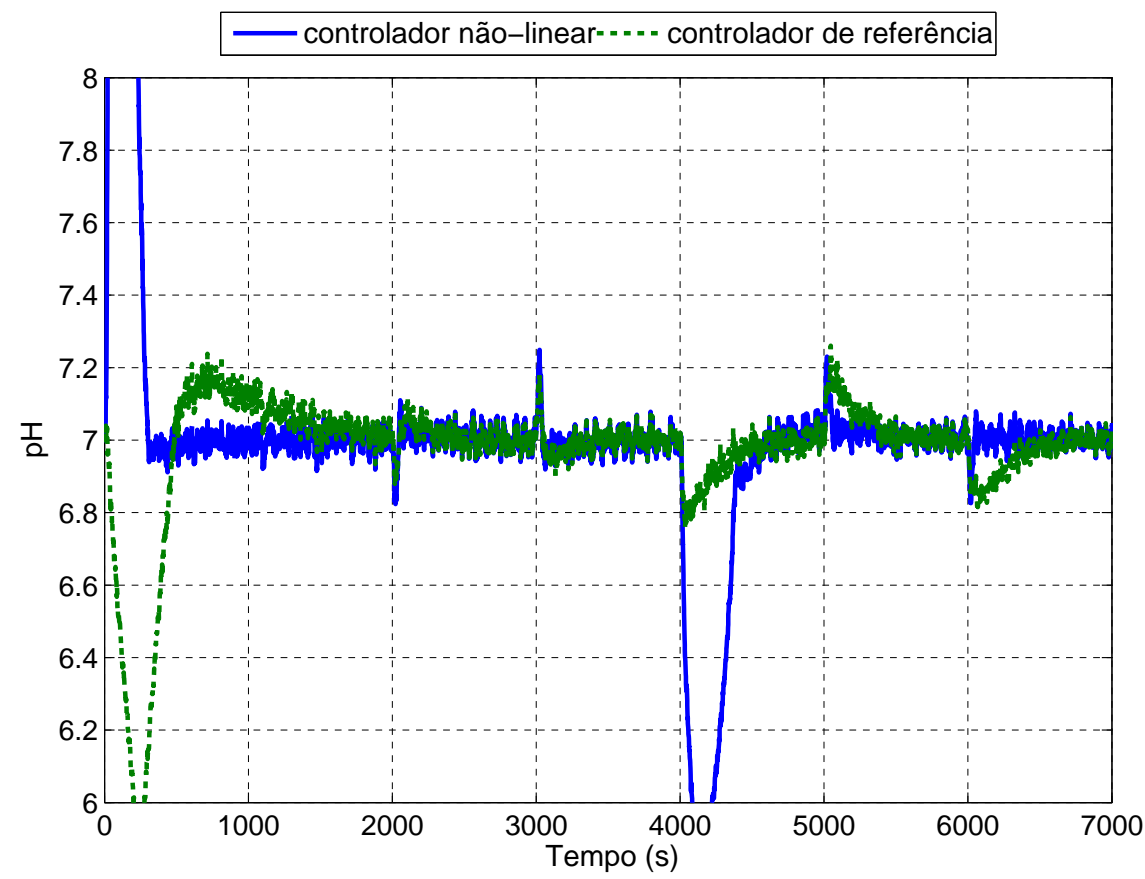

Fonte: do Autor.

Figura 7.14 - Simulação 2 em modo regulatório.

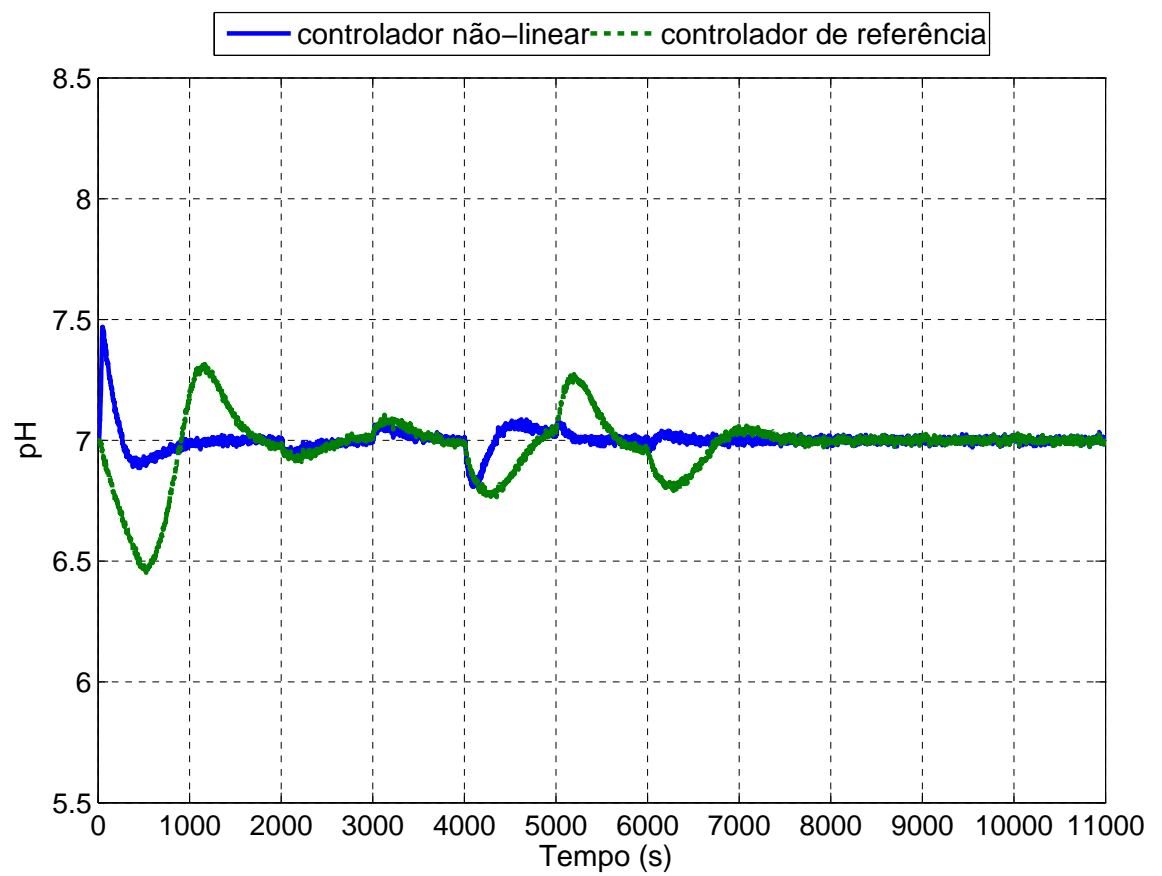

Fonte: do Autor. 
Para que o controlador não-linear seja considerado adequado, este deve atender às especificações de controle, apresentadas no início deste capítulo. O requisito (i) determina que o controlador possua erro zero em regime permanente, o que foi atendido devido à inclusão do integrador no ramo de realimentação do controlador não-linear. Ainda, pode-se verificar o atendimento a este requisito nos resultados das simulações.

O requisito (ii) é relativo ao sobressinal máximo, que deve ser de $0,5 \mathrm{pH}$. O período em que o observador apresenta sua resposta transitória será excluído desta análise, conforme a exceção disposta no requisito (v). Analisando-se as simulações no modo servo, percebe-se que o maior sobressinal foi de $0,29 \mathrm{pH}$. Já para as simulações em modo regulatório, o maior sobressinal foi de $0,28 \mathrm{pH}$. Portanto, o requisito (ii) foi atendido pelo controlador não-linear.

O requisito (iii) é relativo ao tempo de acomodação, que é o tempo decorrido para que a Planta Piloto apresente um $\mathrm{pH}$ igual ao valor de referência, $\pm 2 \%$, o qual deve ser no máximo de 900 segundos. Analisando-se os resultados das simulações, o maior tempo de acomodação foi de 470 segundos, podendo, portanto, ser considerado atendido pelo controlador não-linear.

O requisito (iv) determina que o controlador não-linear seja robusto às variações temporais, observadas na Planta Piloto. Este requisito foi atendido, visto que todos os requisitos anteriores foram atendidos para as duas condições extremas da Planta Piloto.

O requisito (v) determina que o controlador não-linear possua capacidade de compensar as soluções de ácido acético, sem possuir informação prévia alguma sobre sua concentração. Este requisito foi atendido, visto que o observador foi capaz de estimar a concentração de ácido acético no TAS, possibilitando que o controlador não-linear se adaptasse à nova condição de operação da Planta Piloto, em menos de 1000 segundos.

Por fim, o requisito (vi) determina que o controlador não-linear possua um índice de desempenho ISE menor ou igual ao controlador de referência. O ISE de cada simulação e de cada controlador pode ser visto na Tabela 7.4, de onde se percebe que o controlador não-linear apresentou um ISE menor em três das quatro simulações, além de apresentar um ISE médio menor. Ainda, é possível inferir que o controlador não-linear apresentou um ISE maior em um dos testes apenas devido ao tempo transitório do observador de estados. Desta forma, caso esta simulação perdurasse por um período maior ou a concentração de ácido acético variasse mais suavemente, o indicador ISE do controlador não-linear seria melhor. Assim, o requisito (vi) pode ser considerado atendido pelo controlador não-linear. 
Tabela 7.4 - Valores de ISE para cada simulação e controlador, calculados a partir de 2000 segundos, até o fim da simulação.

\begin{tabular}{cccccc}
\hline \multirow{2}{*}{ Controlador } & \multicolumn{5}{c}{ ISE } \\
& Servo 1 & Servo 2 & Regulatório 1 & Regulatório 2 & Média \\
\hline não-linear & 530,0 & 910,2 & 290,5 & 9,1 & 435,0 \\
referência & 1204,2 & 1841,1 & 20,1 & 58,6 & 781,0 \\
\hline
\end{tabular}

Fonte: do Autor.

\subsection{Experimentos de Validação do Controlador}

Nesta seção, o controlador não-linear é validado na Planta Piloto. São realizados dois experimentos, em modo servo e regulatório, para o controlador não-linear e o de referência. O procedimento para teste no modo servo é o mesmo da Tabela 7.2 e para o modo regulatório é o mesmo da Tabela 7.3.

Os resultados dos experimentos estão apresentados nas Figuras 7.15 a 7.22. Analisandose qualitativamente os resultados, percebe-se que o controlador não-linear apresentou um desempenho melhor que o controlador de referência, excetuando-se os períodos transitórios do observador. A partir das Figuras 7.16 e 7.20, pode-se perceber que o esforço de controle do controlador não-linear foi maior que o do controlador de referência, o que é compreensível, visto que quanto mais rápida é a resposta forçada da planta, maior é o esforço de controle. Outro comportamento merecedor de discussão é a estimativa da concentração de ácido acético no TAS, apresentado nas Figuras 7.17 e 7.20. Percebe-se que apesar de apresentar uma estimativa muito próxima do esperado no experimento em modo servo, em modo regulatório houve um desvio considerável no período de 5000 até 6000 segundos. Uma hipótese que explica este desvio é uma possível incorreção na curva da bomba dosadora, que é utilizada para estimar a vazão de base ou uma possível medição incorreta da vazão do influente proveniente do TASI.

Em uma análise quantitativa dos experimentos, para o controlador não-linear, identifica-se que este apresentou erro zero em regime permanente, atendendo ao requisito (i). O máximo sobressinal, excetuando-se o período transitório do observador, foi de 0,18 $\mathrm{pH}$, atendendo ao requisito (ii). O maior tempo de acomodação foi de 260 segundos, respeitando o requisito (iii). O requisito (iv) foi verificado apenas computacionalmente, devido à dificuldade de se obter soluções com concentrações exatas para as perturbações das curvas de titulação. O requisito (v) foi considerado atendido pois, apesar de um pequeno período de incorreção, o sistema observador mais controlador foi capaz de neutralizar, com bom desempenho, a solução de ácido acético. Ademais, o controlador não-linear apresentou um índice ISE de 579,9 e 69,1 para os modos servo e regulatório, respectivamente. Já o controlador de referência apresentou um índice ISE de 1405,2 e 38,1 para os modos servo e regulatório, respectivamente. Assim, o controlador não-linear apresentou um índice ISE 
maior que o controlador de referência, para o modo regulatório. No entanto, note-se que isto ocorreu devido ao período transitório do observador, sendo que se o experimento perdurasse por um longo período, com inúmeras perturbações ou se a perturbação do experimento fosse mais suave, certamente o índice ISE do controlador não-linear no modo regulatório seria menor. Pode-se verificar esta hipótese calculando-se o índice ISE do experimento no modo regulatório, sem considerar o período transitório do observador de estados, (de 4000 até 5000 segundos) resultando em um ISE de 7,2 e 28,8, para os controladores não-linear e de referência, respectivamente. Portanto, pode-se considerar que o requisito (vi) também foi atendido adequadamente.

Figura 7.15 - Experimento no modo servo - pH do TR.

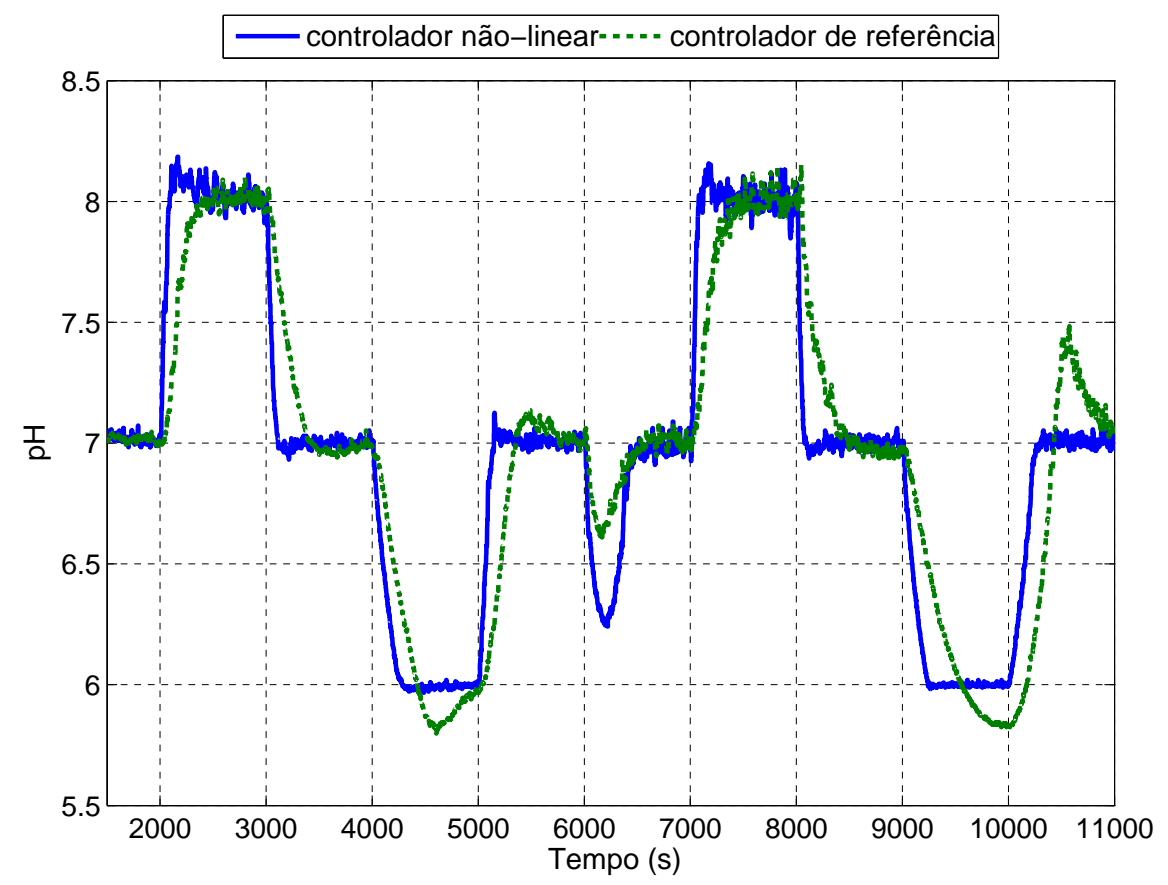

Fonte: do Autor. 
Figura 7.16 - Experimento no modo servo - Variável Manipulada (VM).

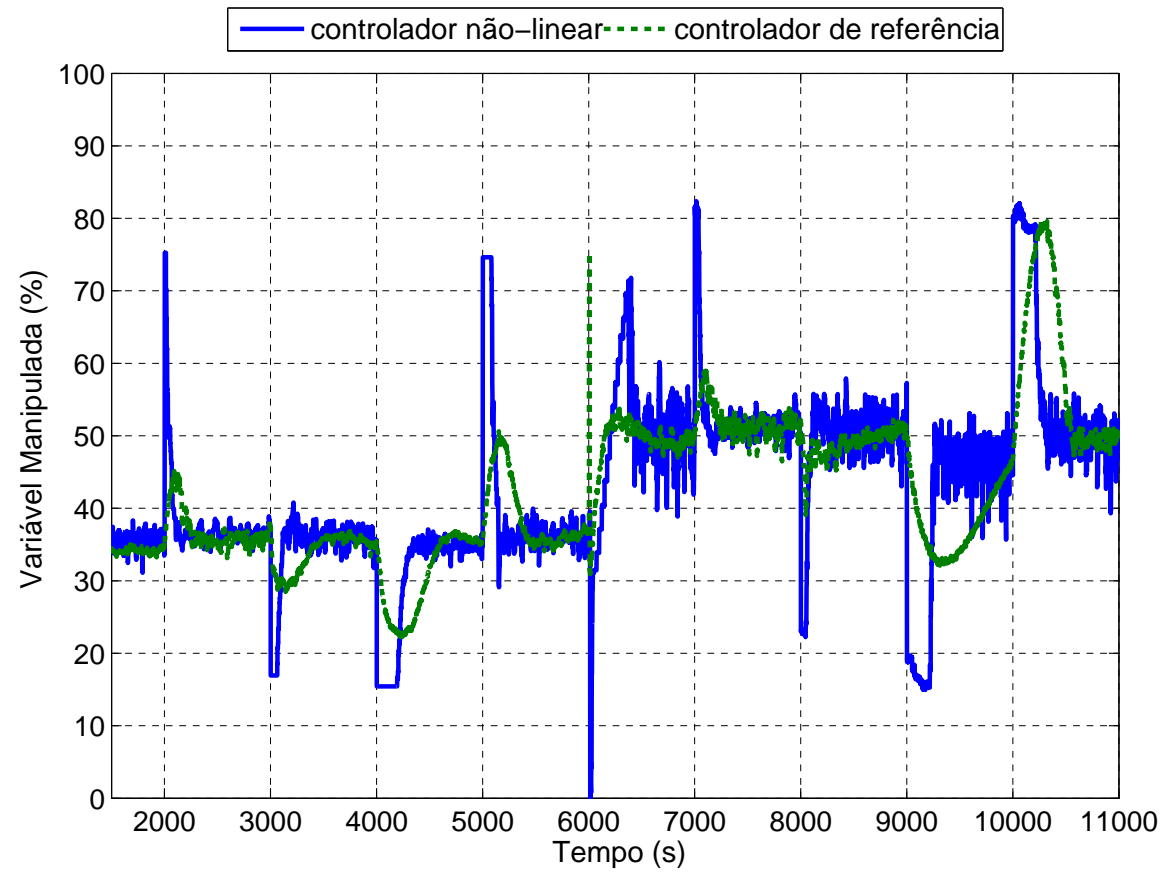

Fonte: do Autor.

Figura 7.17 - Experimento no modo servo - Estimação da concentração de ácido acético no TAS, $\hat{x}_{6}$.

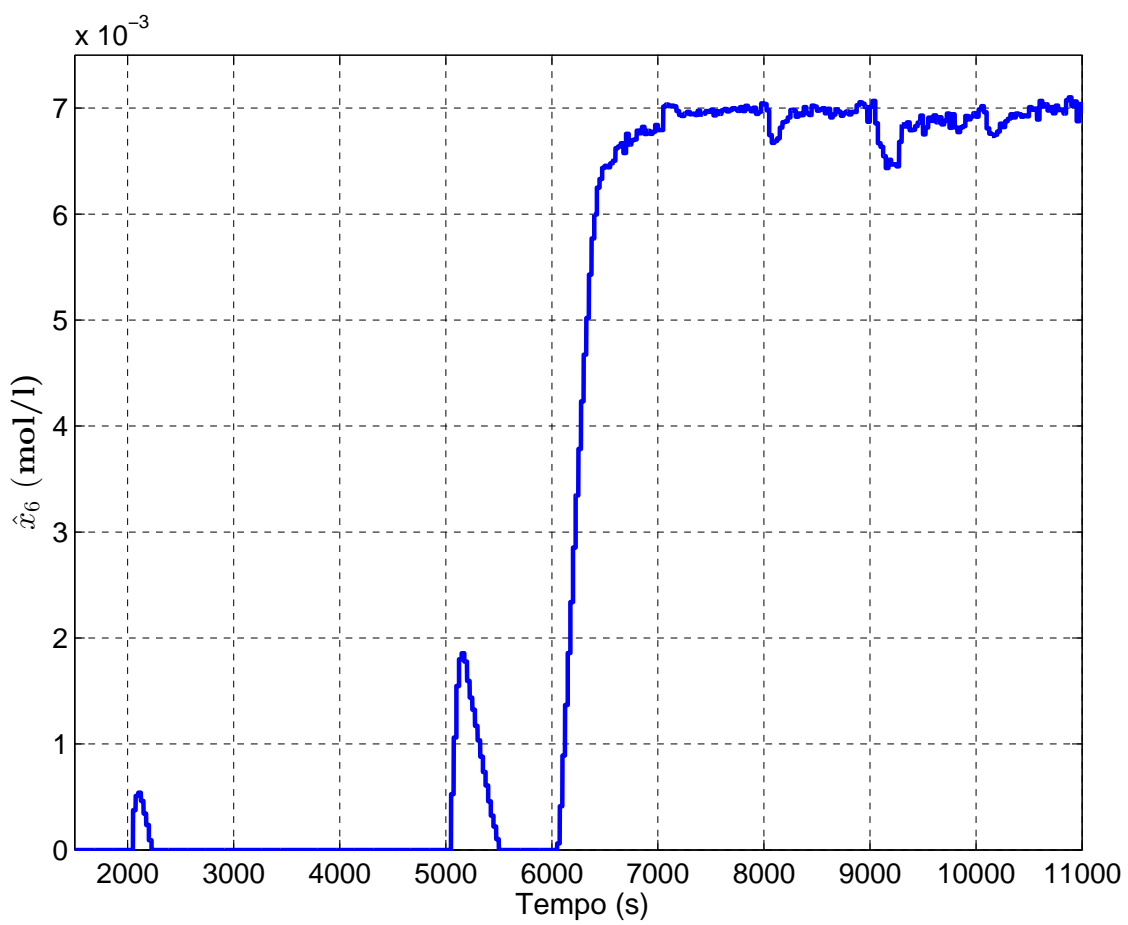

Fonte: do Autor. 
Figura 7.18 - Experimento no modo servo - Vazões dos influentes e nível do TR.

(a) Vazões dos influentes (índice nl para controlador não-linear e ref para o controlador de referência).

(b) Nível do TR.
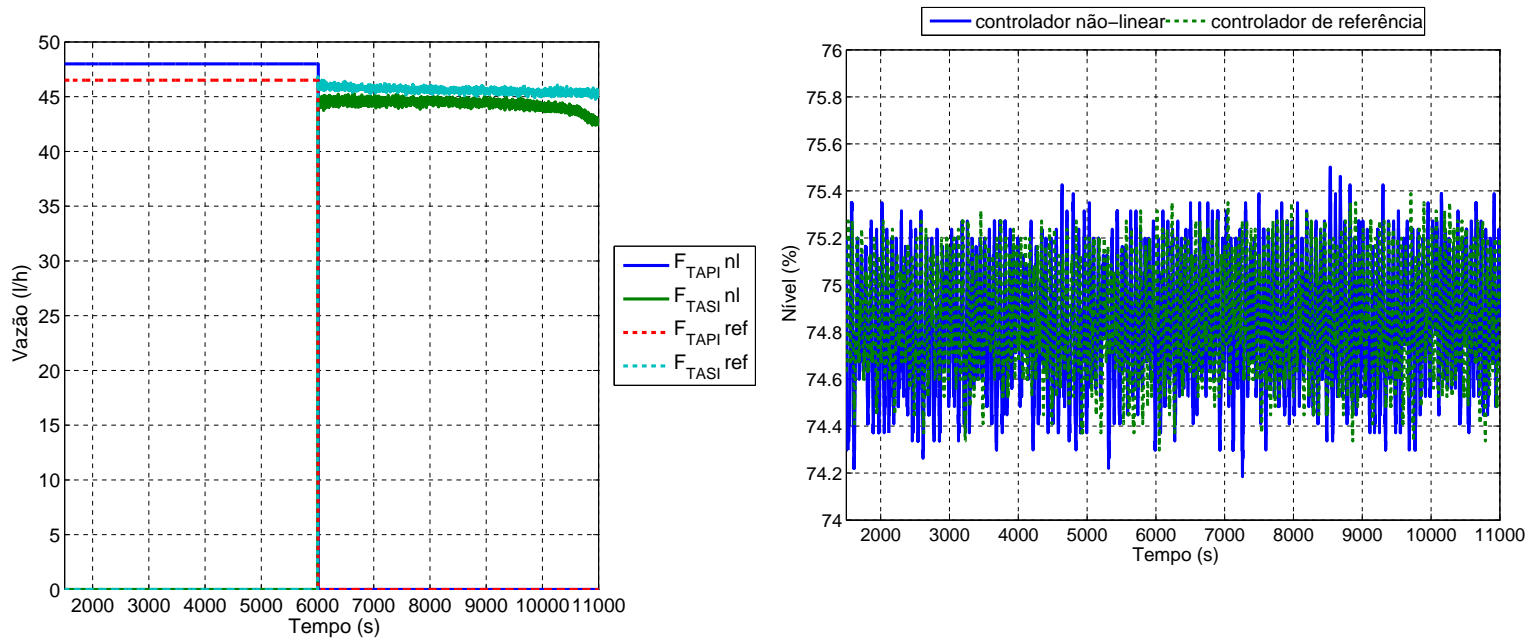

Fonte: do Autor.

Figura 7.19 - Experimento no modo regulatório - pH do TR.

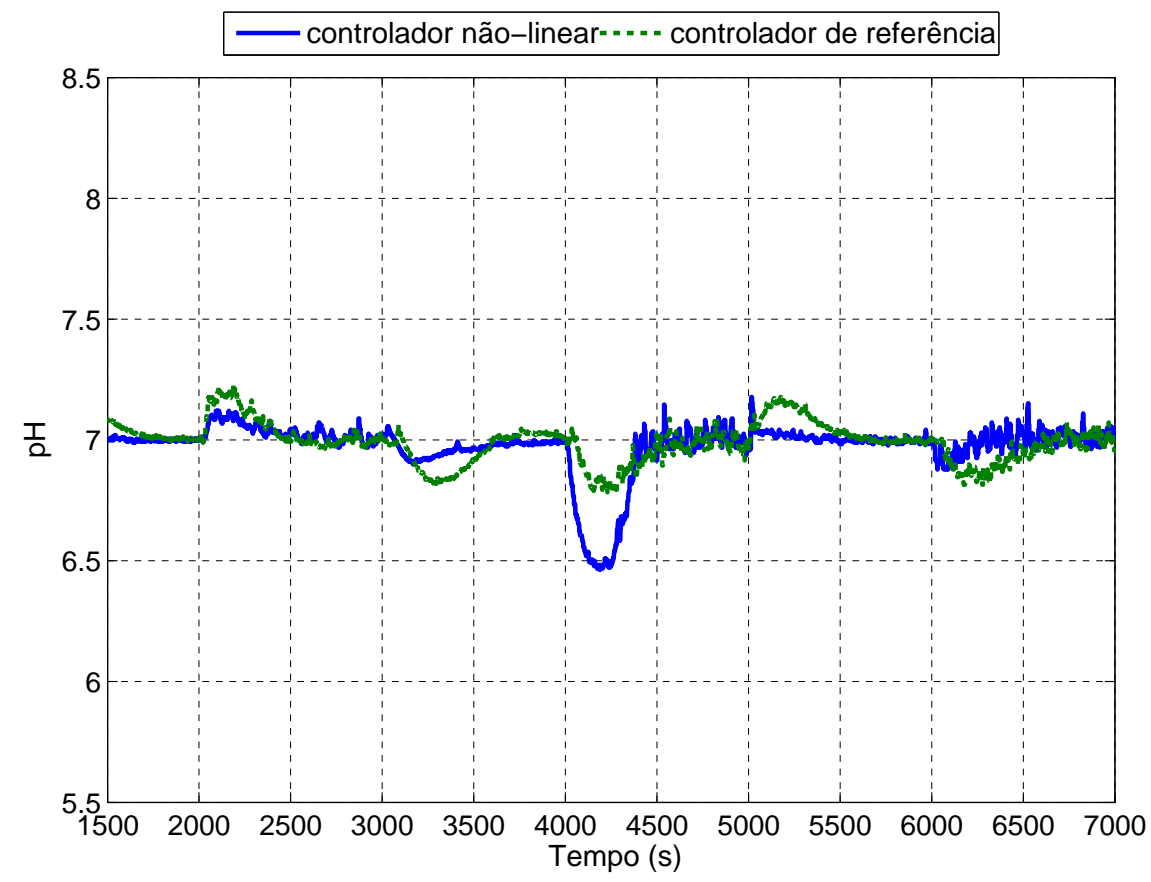

Fonte: do Autor. 
Figura 7.20 - Experimento no modo regulatório - Variável Manipulada (VM).

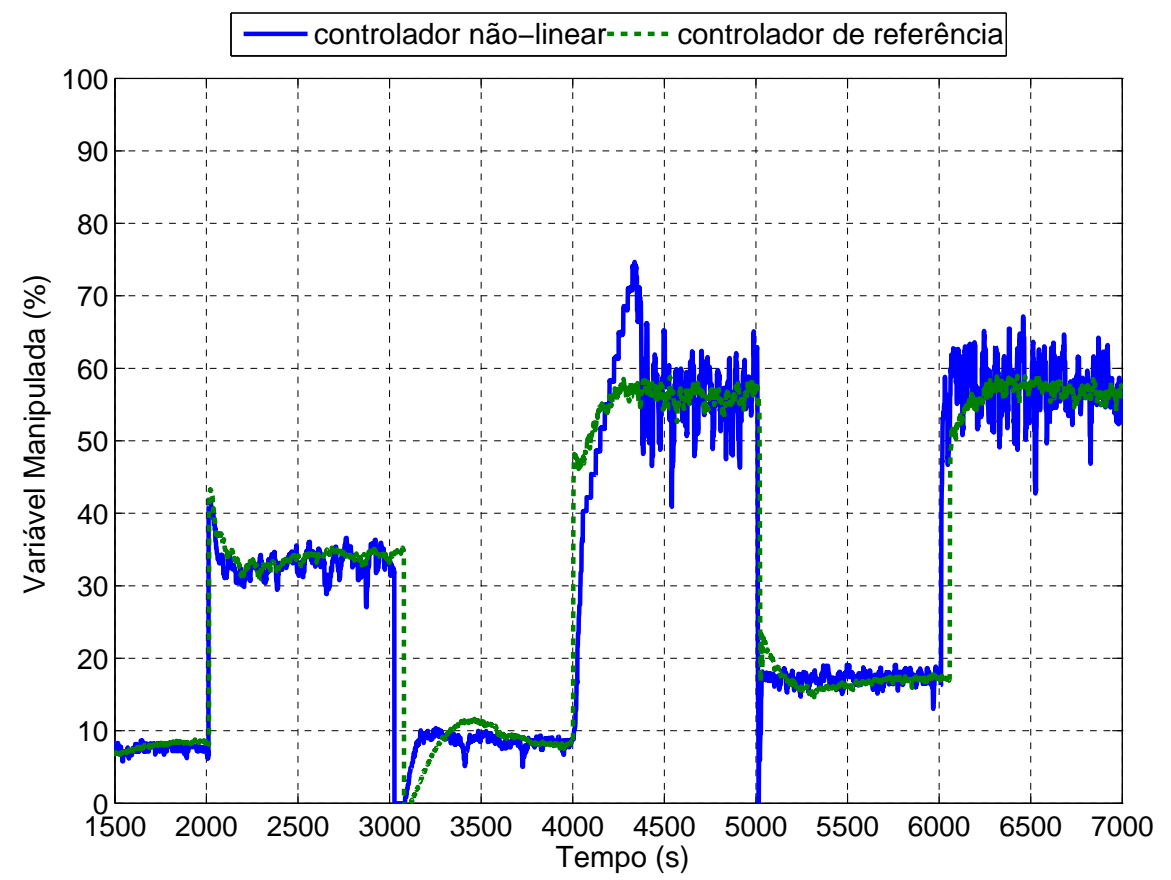

Fonte: do Autor.

Figura 7.21 - Experimento no modo regulatório - Estimação da concentração de ácido acético no TAS, $\hat{x}_{6}$.

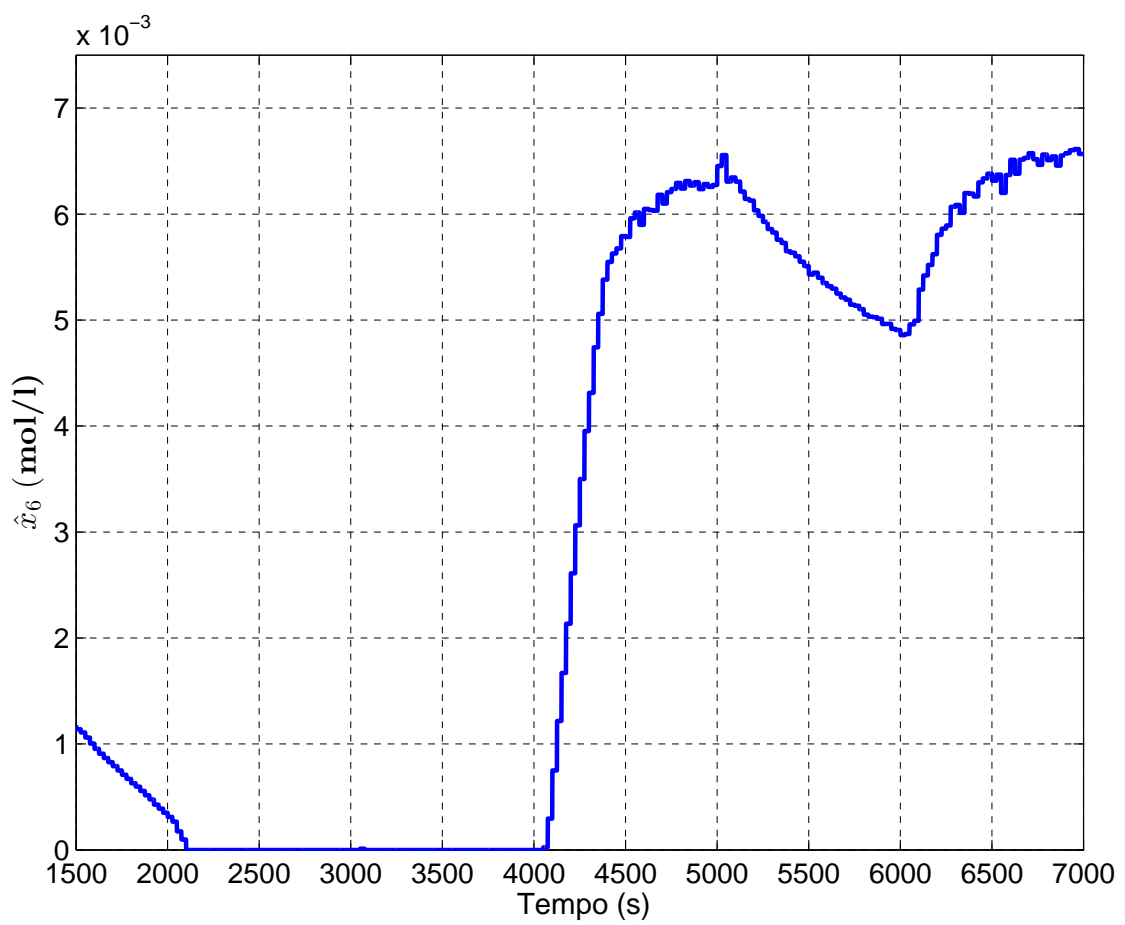

Fonte: do Autor. 
Figura 7.22 - Experimento no modo regulatório - Vazões dos influentes e nível do TR.

(a) Vazões dos influentes (índice nl para controlador não-linear e ref para o controlador de referência).

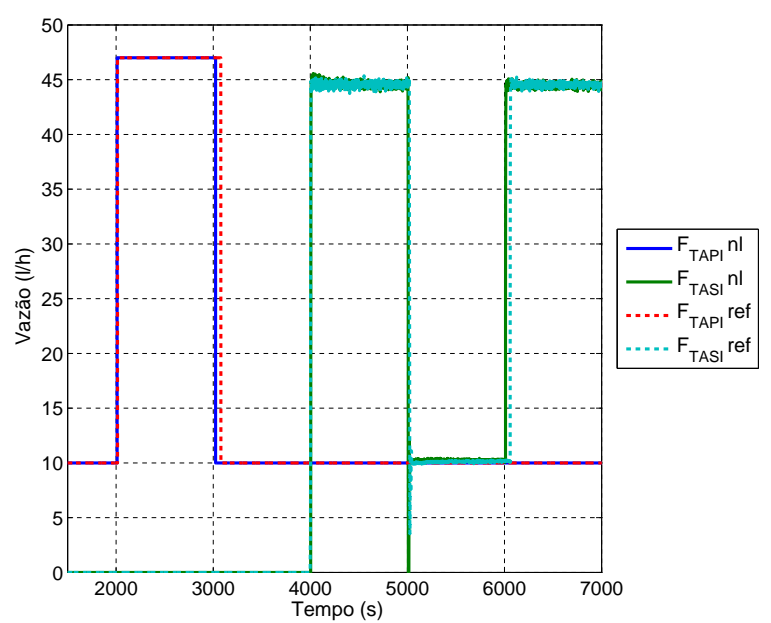

(b) Nível do TR.

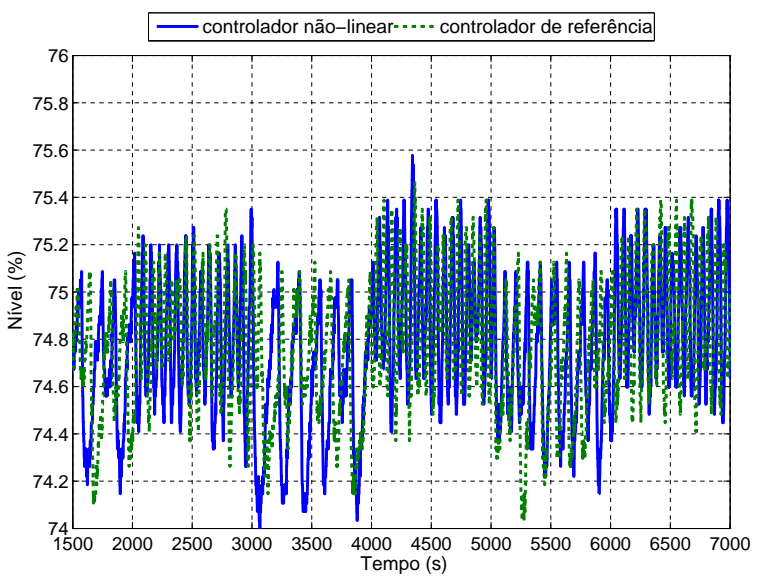

Fonte: do Autor. 


\section{Conclusões e Perspectivas de Trabalhos Fu- turos}

As conclusões finais deste trabalho são apresentadas neste capítulo, complementando as discussões e análises realizadas ao longo dos capítulos referentes ao desenvolvimento desta pesquisa. Adicionalmente, são apresentadas as perspectivas de trabalhos futuros.

\subsection{Conclusões}

Os objetivos gerais da pesquisa foram alcançados, visto que o modelo matemático da Planta Piloto foi desenvolvido com sucesso e foi utilizado para o projeto do controlador não-linear, o qual também apresentou um desempenho satisfatório. Adicionalmente, o trabalho de (ROMANUS; GIOVANINNI, 2014), que consistiu na comparação de diversos algoritmos de controle na Planta Piloto, utilizou com sucesso o modelo desenvolvido nesta pesquisa, para a sintonia dos diversos controladores, evidenciando a utilidade do modelo da Planta Piloto para o projeto de controladores.

A metodologia utilizada para a modelagem da Planta Piloto consistiu em modelar, isoladamente, a fluidodinâmica do reator e suas reações químicas, para então agrupá-las em um momento posterior. Para a modelagem da fluidodinâmica do reator foram utilizados experimentos de DTR e para a modelagem das reações de neutralização foram utilizadas curvas de titulação da Planta Piloto. Esta metodologia se mostrou eficiente e capaz de ser utilizada em outras aplicações práticas de modelagem de $\mathrm{pH}$.

Particularmente para reações de neutralização em que os ácidos e bases possuam uma concentração baixa (inferiores a $1 \mathrm{~mol} / \mathrm{l}$ ), a resposta estática do $\mathrm{pH}$, pode sofrer grandes desvios em relação à teoria. Isto ocorre pois mesmo pequenas concentrações de ácidos e bases contaminantes, dissolvidas nas soluções, podem modificar significativamente a resposta estática do pH, a qual é bastante sensível em relação à presença de ácidos fracos, mesmo em concentrações cerca de 100 vezes menores que a dos ácidos e bases principais. Para analisar o quão próxima da teórica a resposta estática do $\mathrm{pH}$ estava, foi utilizada a forma diferencial da curva de titulação, a qual se mostrou uma ferramenta importante para a modelagem das reações de neutralização.

Além da dificuldade gerada devido à grande não-linearidade, inerente dos processos de neutralização de pH, como as soluções cáusticas absorvem o gás carbônico da atmosfera, convertendo-o em ácido carbônico, a resposta estática do $\mathrm{pH}$ tende a ser variante no tempo. Novamente, esta característica é mais evidente para soluções com baixas concentrações. Desta forma, os controladores de $\mathrm{pH}$ devem ser projetados levando-se estas características 
em consideração.

O modelo da Planta Piloto, após algumas manipulações matemáticas e simplificações, pode ser representado através de equações diferenciais não-lineares. Este tipo de representação facilita a aplicação das teorias de controle, conforme visto no projeto do sistema de controle de $\mathrm{pH}$ da Planta Piloto.

A representação da reação de neutralização através dos invariantes de reação resulta em um modelo não observável, devido a todos os estados estarem acoplados à saída do sistema, com a mesma constante de tempo. No entanto, isto não significa que a construção de um observador de estados seja improdutiva, mas sim que este fornecerá informações tão boas quanto for o modelo utilizado no observador de estados. Ainda, pode ser útil quando se tem um bom modelo matemático da planta e há necessidade de se estimar apenas um invariante de reação de uma solução.

O processo de neutralização de $\mathrm{pH}$, apesar de ser não-linear, pode ser controlado com um bom desempenho através de um controlador linear, caso as condições de operação da planta não variem significativamente. No entanto, caso se tenha um bom modelo matemático da planta, o controlador não-linear, baseado em modelo, apresenta um desempenho melhor que o linear.

\subsection{Perspectivas de Trabalhos Futuros}

O modelo da Planta Piloto pode ser estendido, visto que há possibilidade de realizar a neutralização dos influentes ácidos do TR, através de uma válvula de controle de alto atrito. Neste caso, a solução básica é armazenada em um tanque pressurizado com ar comprimido, denominado de Tanque de Base para a Válvula (TBV). Esta extensão é atrativa, pois demanda a aplicação da teoria referente à modelagem de atrito em válvulas de controle, bem como a modelagem do comportamento dinâmico da pressão à montante da válvula de controle.

A Planta Piloto pode ser operada com altas concentrações de ácido e base, minimizando a influência das perturbações das curvas de titulação. Neste caso, pode-se utilizar duas soluções básicas, com concentrações distintas, sendo a de maior concentração no TBV, e a de menor concentração no TBB. Assim, a válvula de controle e a bomba dosadora seriam utilizadas para realizar o ajuste grosso e fino, respectivamente, do $\mathrm{pH}$ no TR.

As soluções utilizadas nesta pesquisa possibilitaram a simulação de uma planta variante no tempo, visto que seu ganho varia de acordo com a composição do influente. Pode-se utilizar outros tipos de ácidos ou bases, para que a Planta Piloto apresente variações ainda maiores, impossibilitando a utilização de controladores lineares e justificando o uso de algoritmos adaptativos. 
A análise matemática do observador e controlador utilizados nesta pesquisa considerou que a Planta Piloto estava modelada perfeitamente. Assim, pode-se utilizar técnicas de controle robusto, para determinar o quanto as incertezas de modelagem afetam o desempenho deste sistema de controle.

O modelo simplificado da Planta Piloto pode ser utilizado diretamente em controladores preditivos baseados em modelo, possibilitando o estudo do desempenho e da robustez deste tipo de controlador.

Existe a possibilidade de se utilizar água destilada para gerar as soluções da Planta Piloto. Neste caso, é necessário obter-se curvas de titulação com tais soluções, para avaliar qual sua influência na resposta estática do $\mathrm{pH}$. 


\section{Referências Bibliográficas}

ÅKESSON, B. M.; TOIVONEN, H. T.; WALLER, J. B.; NYSTRÖM, R. H. Neural Network Approximation of a Nonlinear Model Predictive Controller Applied to a $\mathrm{pH}$ Neutralization Process. Computers 63 Chemical Engineering, v. 29, n. 2, p. 323-335, 2005.

ALBRIGHT, L. F. Albright's Chemical Engineering Handbook. 1. ed. New York, EUA: CRC Press, 2008.

ALVARADO, C. M.; GARCIA, C. Identification and Predictive Control of a $\mathrm{pH}$ Neutralization Pilot Plant. XX International Congress of Electrical, Electronic, Systems Engineering. Trujillo, Peru, 2013.

ALVAREZ, H.; LODOÑO, C.; SCIASCIO, F.; CARELLI, R. pH Neutralization Process as a Benchmark for Testing Nonlinear Controllers. Ind. Eng. Chem. Res., v. 40, n. 11, p. 2467-2473, 2001.

ATKINS, P.; PAULA, J. de. Physical Chemistry. 9. ed. New York, EUA: W. H. Freeman and Company, 2010.

BEQUETTE, B. W. Nonlinear Control of Chemical Processes: A Review. Ind. Eng. Chem. Res., v. 30, n. 7, p. 1391-1413, 1991.

BIAGIOLA, S. I.; FIGUEROA, L. State Estimation in Nonlinear Processes. Application to pH Process Control. Ind. Eng. Chem. Res., v. 41, n. 19, p. 4777-4785, 2002.

BOYD, S.; FERON, E. Linear Matrix Inequalities in System and Control Theory. 1. ed. Philadelphia, Pennsylvania, EUA: SIAM, 1994.

BOYD, S.; VANDENBERGHE, L. Convex Optimization. 7. ed. New York, EUA: Cambridge University Press, 2009.

CAStellan, G. W. Physical Chemistry. 3. ed. Reading, Massachusetts, EUA: Addison-Wesley Publishing Company, 1983.

CERAVOLO, F. E. Adaptação e Validação de Modelo de uma Planta de Neutralização de pH utilizando o Método de Invariantes de Reação. Monografia apresentada para obtenção do título de MBA em Automação Industrial pelo PECE - Universidade de São Paulo. São Paulo, Brasil, 2012.

CHRISTIAN, G. D. Analytical Chemistry. 6. ed. Hoboken, NJ, EUA: John Wiley \& Sons, Inc., 2004.

DEAN, J. A. Lange's Handbook of Chemistry. 15. ed. New York, EUA: McGraw-Hill, 1999. FJELD, M.; ASBJORNSEN, O. A.; ÅSTRÖM, K. J. Reaction Invariants and Their Importance in the Analysis of Eigenvectors, State Observability and Controllability of the Continuous Stirred Tank Reactor. Chemical Engineering Science, v. 29, n. 1, p. 1917-1926, 1974.

FOGLER, H. S. Elements of Chemical Reaction Engineering. 4. ed. Upper Saddle River, NJ, EUA: Prentice Hall, 2004. 
GALÁN, O.; ROMAGNOLI, J. A.; PALAZOGLU, A. Robust H $\infty$ Control of Nonlinear Plants Based on Multi-Linear Models: An Application to a Bench-Scale pH Neutralization Reactor. Chemical Engineering Science, v. 55, n. 20, p. 4435-4450, 2000.

GARCIA, C. Modelagem e Simulação. 2. ed. São Paulo, Brasil: Editora da Universidade de São Paulo, 2005.

GIRARDOT, D. M. Control of pH Based on Reaction Invariants. Tese de Doutorado University of California. Santa Barbara, EUA, 1989.

GLARIA, T.; SBARBARO, D.; JOHANSEN, T. A.; PENA, R. Observer design for linear processes model with implicit nonlinear output map. Journal of Process Control, v. 22, n. 9, p. 1647-1654, 2012.

GRENVILLE, R. K. Blending of Viscous Newtonian and Pseudo-Plastic Fluids. Tese de Doutorado — School of Mechanical Engineering, Cranfield Institute of Technology. Cranfield, Reino Unido, 1992.

GUSTAFSSON, T. K. Calculation of the pH Value of a Mixture of Solutions - An Illustrations of the Use of Chemical Reaction Invariants. Chemical Engineering Science, v. 37 , n. 9, p. 1419-1421, 1982.

GUSTAFSSON, T. K.; WALLER, K. V. Dynamic Modeling and Reaction Invariant Control of pH. Chemical Engineering Science, v. 38, n. 3, p. 389-398, 1983.

GUSTAFSSON, T. K.; WALlER, K. V. Nonlinear and Adaptive Control of pH. Ind. Eng. Chem. Res., v. 31, n. 12, p. 2681-2693, 1992.

GUSTAFSSON, T. K.; SKRIFVARS, B.; SANDSTRAM, K. V.; WALLER, K. V. Modeling of pH for Control. Ind. Eng. Chem. Res., v. 34, n. 3, p. 820-827, 1995.

HENSON, M. A.; SEBORG, D. E. Adaptive Nonlinear Control of a pH Neutralization Process. IEEE Transactions on Control Systems Technology, v. 2, n. 3, p. 169-182, 1994.

HERSHKOVITCH, H. Z.; MCAVOY, T. J.; LIAPIS, A. I. Dynamic Modeling of pH Electrodes. The Canadian Journal of Chemical Engineering, v. 56, n. 3, p. 346-353, 1978.

HIKITA, H.; ASAI, S.; TAKATSUKA, T. Aborption of Carbon Dioxide into Aqueous Sodium Hydroxide and Sodium Carbonate-Bicarbonate Solutions. The Chemical Engineering Journal, v. 11, n. 1, p. 131-141, 1976.

IBRAHIM, R. Practical Modelling and Control Implementation Studies on a $\mathrm{pH}$ Neutralization Process Pilot Plant. Tese de Doutorado - Department of Electronics and Electrical Engineering, University of Glasgow. Glasgow, Reino Unido, 2008.

JACOBS, O. L. R.; HEWKIN, P. F.; WHILE, C. Online Computer Control of pH in an Industrial Process. IEEE Proceedings D - Control Theory and Applications. v. 127, n. 4, p. 161-168, 1980.

JUliAnI, R. C. G. Adequação de Planta Piloto de Neutralização de pH a Plataforma de Pesquisa e Desenvolvimento. Trabalho de Conclusão de Curso - Departamento de Engenharia de Telecomunicações e Controle, Escola Politécnica da Universidade de São Paulo. São Paulo, Brasil, 2011. 
JUTILA, P.; ORAVA, P. J.; SALMELIN, B. A Physico-Chemical Model and Simulation of pH-Process in Continuous Stirred Tank Reactors. Mathematics and Computers in Simulation, v. 23, n. 2, p. 99-106, 1981.

JUTILA, P.; VISALA, A. Pilot Plant Testing of an Adaptive pH-Control Algorithm Based on Physico-Chemical Modelling. Mathematics and Computers in Simulation, v. 26, n. 6, p. 523-533, 1984.

KARR, C. L.; GENTRY, E. J. Fuzzy Control of pH Using Genetic Algorithms. IEEE Transactions on Fuzzy Systems, v. 1, n. 1, p. 46-53, 1993.

LEVENSPIEL, O. Chemical Reaction Engineering. 3. ed. New York, EUA: John Wiley \& Sons, 1999.

LJUNG, L. System Identification Theory for the User. 2. ed. Upper Saddle River, NJ, EUA: Prentice Hall, 1999.

MCAVOY, T. J. Time Optimal and Ziegler-Nichols Control Experimental and Theoretical Results. Ind. Eng. Chem. Process Des. Develop., v. 11, n. 1, p. 71-78, 1972a.

MCAVOY, T. J. Dynamic Models for $\mathrm{pH}$ and Other Fast Equilibrium Systems. Ind. Eng. Chem. Process Des. Develop., v. 11, n. 4, p. 630-631, 1972b.

MCAVOY, T. J.; HSU, E.; LOWENTHAL, S. Dynamics of pH in Controlled Stirred Tank Reactor. Ind. Eng. Chem. Process Des. Develop., v. 11, n. 1, p. 68-70, 1972c.

MCMILlAN, G. K.; CAMERON, R. A. Advanced pH Measurement and Control. 3. ed. EUA: The Instrumentation, Systems, and Automation Society, 2004.

MURRAY-SMITH, D. J. Methods for the External Validation of Continuous System Simulation Models: A Review. Mathematical and Computer Modelling of Dynamical Systems, v. 4, n. 1, p. 5-31, 1998.

NIJMEIJER, H.; SCHAFT, A. van der. Nonlinear Dynamical Control Systems. 1. ed. New York, NY, EUA: Springer, 1990.

PAJUNEN, G. Comparison of Linear and Nonlinear Adaptive Control of a pH-Process. IEEE Control Systems Magazine, v. 7, n. 1, p. 39-44, 1987.

POHORECKI, R.; MONIUK, W. Kinetics of Reaction Between Carbon Dioxide and Hydroxyl Ions in Aqueous Electrolyte Solutions. Chemical Engineering Science, v. 43, n. 7, p. 1677-1684, 1988.

RAMOS, P. H. T. Análise da Fluidodinâmica de Tanque de Agitação. Relatório de Iniciação Científica - Departamento de Engenharia Química, Escola Politécnica da Universidade de São Paulo. São Paulo, Brasil, 2013.

RICHTER, E. M; FORNARO, A.; LAGO, C. L.; ANGNES, L. Avaliação da Composição Química de Águas do Sistema Guarapiranga: Estudo de Caso nos Anos de 2002 e 2003. Quim. Nova, v. 30, n. 5, p. 1147-1152, 2007.

ROMANUS, E. E.; GIOVANINNI, R. V. Estudo, Implementação e Testes de Diferentes Algoritmos de Controle Aplicados a Uma Planta de Neutralização de pH. Trabalho de Conclusão de Curso - Departamento de Engenharia de Telecomunicações e Controle, Escola Politécnica da Universidade de São Paulo. São Paulo, Brasil, 2014. 
ROSEMBERG, J. L.; EPSTEIN, L. M. Schaum's Outline of Theory and Problems of College Chemistry. 8. ed. New York, EUA: McGraw-Hill, 1997.

SAlVÁtiCO, R. P. A. Controle de uma Planta de Neutralização de pH com Atraso na Medição. Monografia apresentada para obtenção do título de MBA em Automação Industrial pelo PECE — Universidade de São Paulo. São Paulo, Brasil, 2012.

SUNG, S. W.; LEE, I.-B. pH Control Using a Simple Set Point Change. Ind. Eng. Chem. Res., v. 34, n. 5, p. 1730-1734, 1995.

SUNG, S. W.; LEE, I.-B. pH Control Using an Identification Reactor. Ind. Eng. Chem. Res., v. 34, n. 7, p. 2418-2426, 1995.

TAN, W. W.; LU, F.; LOH, A. P.; TAN, K. C. Modeling and control of a pilot pH plant using genetic algorithm. Engineering Applications of Artificial Intelligence, v. 18, n. 4, p. 485-494, 2005.

WALLER, K. V.; MÄKILÄ, P. M. Chemical Reaction Invariants and Variants and Their Use in Reactor Modeling, Simulation, and Control. Ind. Eng. Chem. Process Des. Develop., v. 20, n. 1, p. 1-11, 1981.

WILLIAMS, G. L.; RHINEHART, R. R.; RIGGS, J. B. In-Line Process-Model-Based Control of Wastewater pH Using Dual Base Injection. Ind. Eng. Chem. Res., v. 29, n. 7, p. 1254-1259, 1990.

WRIGHT, R. A.; KRAVARIS, C. Nonlinear Control of pH Processes Using the Strong Acid Equivalent. Ind. Eng. Chem. Res., v. 30, n. 7, p. 1561-1572, 1991.

WRIGHT, R. A.; KRAVARIS, C. On-Line Identification and Nonlinear Control of an Industrial pH Process. Journal of Process Control, v. 11, n. 4, p. 361-374, 2001.

WRIGHT, R. A.; SOROUSH, M.; KRAVARIS, C. Strong Acid Equivalent Control of pH Processes: An Experimental Study. Ind. Eng. Chem. Res., v. 30, n. 11, p. 2437-2444, nov. 1991. ISSN 0888-5885.

YOO, A.; LEE, T. C.; YANG, D. R. Experimental Simultaneous State and Parameter Identification of a $\mathrm{pH}$ Neutralization Process Based on an Extended Kalman Filter.

Korean J. Chem. Eng., v. 21, n. 4, p. 753-760, 2004.

YOON, S. S.; YOON, T. W.; YANG, D. R.; KANG, T. S. Indirect Adaptive Nonlinear Control of a pH Process. Computers and Chemical Engineering, v. 26, n. 9, p. 1223-1230, 2002 .

ZEMOUCHE, A.; BOUTAYEB, M.; BARA, G. I. Observer design for nonlinear and systems: An approach based on the differential mean and value theorem. Proceedings of the 44th IEEE Conference on Decision and Control, and the European Control Conference, 2005. Seville, Espanha, 2005. p. 6354-6358. 


\section{APÊNDICE A - Fundamentos de Termodinâmica}

Esta apêndice é baseado nos livros de Castellan (1983) e Atkins e Paula (2010). A Termodinâmica estuda a transformação da energia, a partir da observação de propriedades macroscópicas da matéria, como a pressão, temperatura e volume. Apesar desta área do conhecimento ter sido desenvolvida originalmente para o estudo de máquinas térmicas, seus conceitos podem ser estendidos para estudar o fluxo de energia existente nas reações químicas. Adicionalmente, o conceito de equilíbrio químico, assunto de extrema importância para esta pesquisa, é decorrente das leis da Termodinâmica.

Antes de apresentar a primeira lei da termodinâmica, é necessário definir alguns conceitos. Na Termodinâmica, um sistema é a parte do universo que se deseja estudar e o ambiente é a região externa ao sistema, onde são realizadas as medições. As propriedades de um sistema são as variáveis físicas que podem ser medidas e o sistema é dito estar em um estado definido quando todas suas propriedades possuem valores definidos. O sistema pode ser aberto, fechado ou isolado. Um sistema fechado é aquele que apenas energia transpõe seus limites, enquanto um sistema aberto admite que sua massa transponha seus limites. Ainda, um sistema isolado é aquele que a matéria e a energia não podem transpor seus limites.

Duas formas de transferência de energia são particularmente importantes para a Termodinâmica, o trabalho e o calor. A energia térmica é aquela que a matéria possui devido ao movimento desordenado de suas moléculas. O calor é a transferência da energia térmica, devido ao estímulo das moléculas do sistema mais frio, por parte do sistema mais quente. A energia potencial é aquela que a matéria possui devido a sua posição em um campo de força gravitacional. O trabalho é a transferência de energia através do movimento ordenado das moléculas ao longo de um campo de força. O trabalho e o calor ocorrem apenas durante uma mudança de estado de um sistema.

A energia de um sistema pode ser interpretada como sua capacidade de realizar trabalho. A energia total de um sistema é chamada de energia interna e corresponde às energias cinética (relacionada à energia térmica) e potencial totais das moléculas do sistema. 


\section{A.1 Primeira Lei da Termodinâmica}

A primeira lei da Termodinâmica afirma que a energia total de um sistema mais o ambiente é uma constante. Se um sistema é submetido a uma transformação cíclica, o trabalho produzido pelo sistema é igual ao calor retirado do ambiente. De fato, Joule demonstrou experimentalmente que existe uma correspondência entre trabalho e calor. A primeira lei da Termodinâmica pode ser representada matematicamente como:

$$
\begin{gathered}
\oint(\delta Q-\delta W)=0, \text { ou ainda } \\
\mathrm{d} U=\delta Q-\delta W,
\end{gathered}
$$

sendo $Q$ o calor, $W$ o trabalho e $U$ a energia interna do sistema. O trabalho geralmente é expresso em função da expansão do sistema, em relação à pressão que se opõe à expansão, ou seja,

$$
W=\int_{V_{1}}^{V_{2}} P_{o p} \mathrm{~d} V,
$$

onde $V$ é o volume do sistema e $P_{o p}$ é a pressão que se opõe a expansão do sistema.

Como a Planta Piloto opera a pressão atmosférica (aproximadamente constante), os desenvolvimentos são concentrados em formulações desenvolvidas para transformações ocorrendo à pressão constante. Se a pressão que se opõe à expansão for considerada constante, a energia interna do sistema pode ser expressa como:

$$
\mathrm{d} U=\delta Q-p \mathrm{~d} V
$$

sendo $p$ a pressão constante que se opõe à expansão do sistema. Integrando esta quantidade, obtém-se:

$$
\begin{gathered}
\int_{U_{1}}^{U_{2}} \mathrm{~d} U=\int_{1}^{2} \delta Q_{p}-\int_{V_{1}}^{V_{2}} p \mathrm{~d} V, \\
U_{2}-U_{1}=Q_{p}-p\left(V_{2}-V_{1}\right) .
\end{gathered}
$$

Rearranjando-se os termos, pode-se obter:

$$
U_{2}+p V_{2}-\left(U_{1}+p V_{1}\right)=Q_{p}
$$

Introduzindo-se uma nova variável de estado, a entalpia, que é definida como $H \equiv U+p V$, obtém-se:

$$
\Delta H=Q_{p}
$$

Consequentemente, percebe-se que o calor que flui do ambiente para o sistema é equivalente ao aumento de entalpia do sistema. 
Como uma mudança na entalpia acarreta em mudanças nas propriedades do sistema, pode-se estudar as variações de entalpia em relação às variações das propriedades do sistema, como pressão e temperatura:

$$
\mathrm{d} H=\left(\frac{\partial H}{\partial T}\right)_{p} \mathrm{~d} T+\left(\frac{\partial H}{\partial p}\right)_{T} \mathrm{~d} p .
$$

Como a pressão é considerada constante, tem-se:

$$
\mathrm{d} H=\delta Q_{p}=\left(\frac{\partial H}{\partial T}\right)_{p} \mathrm{~d} T=C_{p} \mathrm{~d} T .
$$

A condutividade térmica, $C_{p}$, é uma característica específica de cada material e pode ser utilizada para determinar qual a variação de temperatura que um sistema apresenta ao receber ou perder calor.

Integrando a Eq. (A.9), resulta em:

$$
\int_{H_{1}}^{H_{2}} \mathrm{~d} H=\int_{1}^{2} \delta Q_{p}=\int_{T_{1}}^{T_{2}} C_{p} \mathrm{~d} T .
$$

Se $C_{p}$ for constante na faixa de temperatura de interesse, a Eq. (A.10) se resume na forma mais usual de se representar a entalpia:

$$
\Delta H=Q_{p}=C_{p} \Delta T .
$$

O conceito de entalpia também pode ser aplicado para determinar o calor gerado nas reações químicas. Quando uma reação química ocorre em um sistema, sua temperatura difere de sua temperatura no instante imediatamente anterior à ocorrência da reação. Se a temperatura do sistema for maior que a temperatura do ambiente, calor deve fluir do sistema para o ambiente, para que sua temperatura retorne ao valor inicial; esta situação caracteriza uma reação exotérmica. De maneira oposta, se a temperatura do sistema for menor que a temperatura do ambiente, calor deve fluir do ambiente para o sistema, para que sua temperatura volte ao valor inicial; esta situação caracteriza uma reação endotérmica.

Atribui-se o valor zero para a entalpia de elementos químicos que estão em um estado de agregação estável à pressão de 1 atm e temperatura de 298,15 K. Assim, para determinar o calor gerado em uma reação química, é necessário obter a entalpia de formação $\left(\Delta_{f} H^{\circ}=\Delta_{f} H\right.$ à pressão de $\left.1 \mathrm{~atm}\right)$ dos compostos pertencentes a reação. As entalpias de diversas reações à pressão e temperatura normais foram obtidas experimentalmente e são apresentadas em manuais de propriedades químicas, como em Dean (1999). A entalpia padrão de determinada reação química pode ser calculada a partir das entalpias de formação padrão dos compostos envolvidos na reação:

$$
\Delta_{r} H^{\circ}=\sum_{i=1}^{\alpha} \nu_{i} \Delta_{f} H_{i}^{\circ}
$$

sendo $\nu_{i}$ o coeficiente estequiométrico da substância $i$ na reação, sendo positivo para produtos e negativo para reagentes. 


\section{A.2 Segunda Lei da Termodinâmica}

Enquanto a primeira lei da Termodinâmica trata da conservação de energia, a segunda lei da Termodinâmica visa determinar a direção espontânea das transformações de energia. Existem processos que ocorrem espontaneamente, como é o caso de uma bola solta no topo de uma ladeira; é natural (espontâneo) que a bola desça a ladeira, transformando sua energia potencial em cinética. Porém, não é natural que uma bola colocada na base de uma ladeira possa subi-la espontaneamente. Contudo, realizando-se trabalho é possível posicionar a bola no topo da ladeira. Assim, um processo que ocorre naturalmente sem a necessidade de realizar trabalho é dito espontâneo, enquanto um processo que necessita de trabalho para ocorrer é dito não-espontâneo. Com respeito às reações químicas, a segunda lei fornece ferramentas para determinar se uma reação ocorre espontaneamente ou não, o que é utilizado para determinar quando uma reação está em equilíbrio.

A segunda lei da Termodinâmica afirma que é impossível construir um sistema que converta em trabalho todo o calor absorvido de uma única fonte de calor. Esta afirmação pode ser entendida considerando um processo cíclico reversível (aquele em que o sistema e o ambiente retornam para o mesmo estado após um ciclo completo), em que calor é absorvido de uma única fonte de calor. Neste caso, a primeira lei da Termodinâmica afirma que:

$$
\begin{gathered}
\Delta U_{c i}=\oint \delta Q_{c i}-\delta W_{c i}=0 \\
\delta Q_{c i}=\delta W_{c i},
\end{gathered}
$$

ou seja, se calor é absorvido de um reservatório (uma fonte infinita de calor, a temperatura constante), o trabalho total que o sistema realiza deve ser $W_{c i} \leq 0$ - devido ao fato de se realizar uma transformação cíclica e às propriedades da integral inexata. Portanto, só é possível produzir uma quantidade positiva de trabalho se houver mais de um reservatório.

A eficiência de uma máquina térmica, que realiza um processo cíclico reversível a partir da troca de calor com duas fontes de calor de diferentes temperaturas, é definida como a razão entre o trabalho produzido e o calor absorvido do reservatório de alta temperatura:

$$
\epsilon=\frac{W}{Q_{1}}
$$

sendo $Q_{1}$ o calor absorvido da fonte de calor de alta temperatura. Como $W=Q_{1}-Q_{2}$, sendo $Q_{2}$ o calor dissipado à fonte de calor de baixa temperatura, a eficiência da máquina térmica é:

$$
\epsilon=1-\frac{Q_{2}}{Q_{1}}
$$

Todas as máquinas térmicas reversíveis que operam entre estas duas fontes de calor têm a mesma eficiência. 
O calor absorvido e dissipado pela máquina térmica é proporcional à temperatura das fontes de calor. Adicionalmente, a escala de temperatura termodinâmica (absoluta) foi definida por Kelvin, a partir das propriedades de máquinas térmicas reversíveis. Desta forma, a eficiência da máquina térmica também pode ser definida com relação às temperaturas das fontes de calor:

$$
\epsilon=1-\frac{T_{2}}{T_{1}}
$$

sendo $T_{1}>T_{2}$ as temperaturas das fontes de calor.

Combinando a Eq. (A.16) e a Eq. (A.17), obtém-se:

$$
\begin{gathered}
\frac{Q_{2}}{Q_{1}}=\frac{T_{2}}{T_{1}} \\
\frac{Q_{1}}{T_{1}}-\frac{Q_{2}}{T_{2}}=0 .
\end{gathered}
$$

A Eq. (A.19) pode ser escrita como um ciclo de valor $Q / T$, escrito na forma integral:

$$
\oint \frac{\delta Q}{T}=0
$$

Como o resultado da Eq. (A.20) é zero, a quantidade $\delta Q / T$ é o diferencial de uma propriedade do sistema. Esta propriedade é a entropia, que é definida como:

$$
\mathrm{d} S \equiv \frac{\delta Q}{T} .
$$

Note que a Eq. (A.21) é válida apenas para processos reversíveis, ou seja, $\delta Q_{r e v} / T$. Nos processos irreversíveis, uma parte da energia é perdida durante as transformações, devido a interações moleculares. Assim, como a eficiência das máquinas térmicas irreversíveis sempre é menor que a de uma máquina térmica reversível (ou ideal), pode-se chegar à conclusão que:

$$
\frac{\delta Q_{r e v}}{T}>\frac{\delta Q_{i r r}}{T},
$$

sendo $Q_{i r r}$ o calor envolvido no processo irreversível. Usando a definição de entropia, obtém-se a inequação de Clausius:

$$
\mathrm{d} S>\frac{\delta Q_{i r r}}{T}
$$

Para um sistema isolado $\delta Q_{i r r}=0$. Portanto, a condição para que uma transformação ocorra espontaneamente em um sistema real isolado é que a entropia aumente de valor $\mathrm{d} S>0$.

A entropia pode ser interpretada fisicamente como a probabilidade da distribuição de energia das moléculas do sistema. No entanto, para o desenvolvimento deste trabalho, o essencial é estudar como a entropia pode ser usada para determinar a direção espontânea das reações químicas. 


\section{A.3 Terceira Lei da Termodinâmica}

A terceira lei da Termodinâmica, advinda do teorema do calor de Nernst, afirma que um material cristalino puro, com temperatura absoluta igual a zero, possui entropia igual a zero. Isto possibilita o cálculo da entropia de elementos ou componentes. Considere uma transformação ocorrendo a pressão constante, de um elemento que inicialmente estava na temperatura zero absoluto, até uma temperatura $T$, ainda abaixo da temperatura de fusão. Através das Eq. (A.10) e (A.21), obtém-se a relação:

$$
\Delta S=S_{T}-S_{0}=\int_{0}^{T} \frac{C_{p}}{T} \mathrm{~d} T .
$$

Aplicando-se a terceira lei da Termodinâmica, $S_{0}=0$. Assim, calcula-se a entropia de um sólido à temperatura $T$ :

$$
S_{T}=\int_{0}^{T} \frac{C_{p}}{T} \mathrm{~d} T
$$

É possível calcular a entropia em qualquer fase do elemento, utilizando seus valores da entalpia de fusão $\Delta_{f u s} H$ e vaporização $\Delta_{v a p} H$. A entropia padrão (à pressão $1 \mathrm{~atm}$ ) de um líquido à temperatura $T$, abaixo da temperatura de vaporização é:

$$
S_{T}^{\circ}=\int_{0}^{T_{f u s}} \frac{C_{p}^{\circ}(s)}{T} \mathrm{~d} T+\frac{\Delta_{\text {fus }} H^{\circ}}{T_{\text {fus }}}+\int_{T_{\text {fus }}}^{T} \frac{C_{p}^{\circ}(l)}{T} \mathrm{~d} T,
$$

onde $T_{\text {fus }}$ é a temperatura de fusão do elemento. De maneira análoga, a entropia padrão de um gás de temperatura $T$, acima da temperatura de vaporização é:

$$
S_{T}^{\circ}=\int_{0}^{T_{f u s}} \frac{C_{p}^{\circ}(s)}{T} \mathrm{~d} T+\frac{\Delta_{\text {fus }} H^{\circ}}{T_{\text {fus }}}+\int_{T_{\text {fus }}}^{T_{\text {vap }}} \frac{C_{p}^{\circ}(l)}{T} \mathrm{~d} T+\frac{\Delta_{\text {vap }} H^{\circ}}{T_{\text {vap }}}+\int_{T_{\text {vap }}}^{T} \frac{C_{p}^{\circ}(g)}{T} \mathrm{~d} T,
$$

onde $T_{\text {vap }}$ é a temperatura de vaporização do elemento.

A entropia padrão de vários elementos e compostos pode ser encontrada em manuais de propriedades químicas. Através destes valores, é possível calcular a variação de entropia padrão de uma reação química:

$$
\Delta_{r} S^{\circ}=\sum_{i=1}^{\alpha} \nu_{i} \Delta_{f} S_{i}^{\circ}
$$

sendo $\nu_{i}$ o coeficiente estequiométrico da substância $i$ na reação, sendo positivo para produtos e negativo para reagentes.

\section{A.4 Transformações Espontâneas}

A variação infinitesimal no ponto de equilíbrio de um sistema pode ser considerada uma transformação reversível. Desta forma, em uma transformação reversível, o sistema 
está sempre em equilíbrio. Assim, conclui-se que a reversibilidade é a condição de equilíbrio. A partir da Eq. (A.21), obtém-se matematicamente a condição de equilíbrio:

$$
T \mathrm{~d} S=\delta Q_{r e v}
$$

A inequação de Clausius define condições para que transformações espontâneas ocorram. Da Eq. (A.23), obtém-se a condição para a espontaneidade:

$$
T \mathrm{~d} S>\delta Q
$$

As condições das Eq. (A.29) e (A.30) podem ser combinadas, resultando em:

$$
T \mathrm{~d} S \geq \delta Q
$$

Rearranjando-se a Eq. (A.1), pode-se obter a equação

$$
\delta Q=\mathrm{d} U+\delta W
$$

Substituindo a relação da Eq. (A.31) na Eq. (A.32), resulta em:

$$
\begin{gathered}
T \mathrm{~d} S \geq \mathrm{d} U+\delta W, \text { ou } \\
T \mathrm{~d} S-\mathrm{d} U-\delta W \geq 0 .
\end{gathered}
$$

Quando o sistema está em equilíbrio, o lado esquerdo da Eq. (A.33) possui valor zero. Se o sistema estiver realizando uma transformação espontânea, o lado esquerdo da Eq. (A.33) possui valor maior que zero.

À pressão constante, o trabalho pode ser expandido em $\delta W=p \mathrm{~d} V+\delta W_{a}$, onde $W_{a}$ é um trabalho adicional, referente à realização de trabalho que não o de expansão, como por exemplo o transporte de cargas elétricas ao longo de um campo elétrico. Para o caso de uma transformação ocorrendo em um sistema a temperatura e pressão constantes $(p \mathrm{~d} V=\mathrm{d}(p V)$ e $T \mathrm{~d} S=\mathrm{d}(T S))$ a Eq. (A.33) resulta em:

$$
\begin{gathered}
-(\mathrm{d} U+\mathrm{d}(p V)+\mathrm{d}(T S)) \geq \delta W_{a} \\
-\mathrm{d}(U+p V-T S) \geq \delta W_{a} .
\end{gathered}
$$

A energia de Gibbs é definida como a quantidade $G=U+p V-T S=H-T S$. Assim, a condição para uma transformação espontânea é que o decréscimo da energia de Gibbs seja maior que o trabalho adicional, ou de forma similar:

$$
\mathrm{d} G_{T, p} \leq-\delta W_{a}
$$

É possível concluir ainda que uma reação não-espontânea pode ocorrer caso algum tipo de trabalho adicional seja realizado no sistema. Caso não ocorra a realização de trabalho 
adicional, a condição para que uma transformação seja considerada espontânea é que a energia de Gibbs diminua:

$$
\mathrm{d} G_{T, p} \leq 0
$$

Para determinar a variação da energia de Gibbs padrão de uma reação (à temperatura de $298 \mathrm{~K}$ e pressão de $1 \mathrm{~atm}$ ), é necessário conhecer os valores da energia de Gibbs padrão de formação dos compostos. Estes valores podem ser encontrados em manuais de propriedades químicas ou através da variação de entalpia e entropia padrões da reação:

$$
\begin{gathered}
\Delta_{r} G^{\circ}=\sum_{i=1}^{\alpha} \nu_{i}\left(\Delta_{r} H_{i}^{\circ}-T \Delta_{r} S_{i}^{\circ}\right) \\
\Delta_{r} G^{\circ}=\sum_{i=1}^{\alpha} \nu_{i} \Delta_{f} G_{i}^{\circ},
\end{gathered}
$$

sendo $\nu_{i}$ o coeficiente estequiométrico da substância $i$ na reação, sendo positivo para produtos e negativo para reagentes.

\section{A.5 Equilíbrio Químico}

Conforme uma reação espontânea à temperatura, pressão e composição constantes evolui no tempo, a energia de Gibbs do sistema segue diminuindo até que se atinja seu valor mínimo. Neste instante, as reações químicas atingem um estado chamado de equilíbrio dinâmico, onde as transformações de reagentes em produtos continuam a ocorrer, porém sem apresentar uma mudança líquida em suas concentrações. Verifica-se o equilíbrio dinâmico quando o número de reações por unidade de tempo que acontece nos sentidos direto e reverso é equivalente.

A energia de Gibbs de um sistema pode ser utilizada para determinar matematicamente o equilíbrio químico. Considere o diferencial da energia de Gibbs:

$$
\begin{gathered}
\mathrm{d} G=\mathrm{d} U+\mathrm{d}(p V)-\mathrm{d}(T S) \\
\mathrm{d} G=\mathrm{d} U+V \mathrm{~d} p+p \mathrm{~d} V-S \mathrm{~d} T-T \mathrm{~d} S .
\end{gathered}
$$

Levando em consideração a definição de entropia da Eq. (A.21), pode-se reescrever a Eq. (A.38) como:

$$
\begin{gathered}
\mathrm{d} G=T \mathrm{~d} S-p \mathrm{~d} V+V \mathrm{~d} p+p \mathrm{~d} V-S \mathrm{~d} T-T \mathrm{~d} S \\
\mathrm{~d} G=-S \mathrm{~d} T+V \mathrm{~d} p .
\end{gathered}
$$

A Eq. (A.39) prediz o comportamento da energia de Gibbs quando ocorrem variações de temperatura e pressão. Como em uma reação química a composição do sistema varia, pode-se expandir a Eq. (A.39) em derivadas parciais, levando em consideração as variações 
nas composições. Suponha uma reação química ocorrendo entre $\alpha$ compostos, com número de mols $n_{i}$. Neste caso, a energia de Gibbs pode ser expandida em derivadas parciais, em função da temperatura, pressão e das concentrações dos dois compostos:

$$
\mathrm{d} G=\left(\frac{\partial G}{\partial T}\right)_{p, n_{i}} \mathrm{~d} T+\left(\frac{\partial G}{\partial p}\right)_{T, n_{i}} \mathrm{~d} p+\sum_{i=1}^{\alpha}\left(\frac{\partial G}{\partial n_{i}}\right)_{T, p, n_{j \neq i}} \mathrm{~d} n_{i} .
$$

Ao comparar as Eq. (A.39) e (A.40), observa-se que os dois primeiros termos são equivalentes:

$$
\left(\frac{\partial G}{\partial T}\right)_{p, n_{i}}=-S \quad \text { e }\left(\frac{\partial G}{\partial p}\right)_{T, n_{i}}=V .
$$

Através da Eq. (A.41) e da definição de uma nova variável,

$$
\mu_{i}=\left(\frac{\partial G}{\partial n_{i}}\right)_{T, p, n_{j \neq i}}
$$

é possível reescrever a Eq. (A.40) como

$$
\mathrm{d} G=-S \mathrm{~d} T+V \mathrm{~d} p+\sum_{i=1}^{\alpha} \mu_{i} \mathrm{~d} n_{i} .
$$

A Eq. (A.42) é fundamental para o estudo do equilíbrio químico.

\section{A.5.1 Potencial Químico de Gases Ideais}

A energia de Gibbs padrão de um gás a uma pressão maior que 1 atm e temperatura constante, é obtida integrando-se a Eq. (A.42),

$$
\int_{p^{\circ}}^{p} \mathrm{~d} G=\int_{p^{\circ}}^{p} V \mathrm{~d} p
$$

que resulta em

$$
G=G^{\circ}(T)+\int_{p^{\circ}}^{p} V \mathrm{~d} p
$$

Utilizando-se a lei dos gases ideais, $p V=n R T$, a integral da Eq. (A.43) é:

$$
\begin{gathered}
G=G^{\circ}(T)+n R T \int_{p^{\circ}}^{p} \frac{\mathrm{d} p}{p} \\
\frac{G}{n}=\frac{G^{\circ}(T)}{n}+R T \ln p .
\end{gathered}
$$

A energia de Gibbs de um sistema em equilíbrio, composto de uma mistura a pressão e temperatura constantes, pode ser calculada através da integração da Eq. (A.42) ao longo de todo o volume do sistema:

$$
\int_{V} \mathrm{~d} G=\sum_{i=1}^{\alpha} \int_{V} \mu_{i} \mathrm{~d} n_{i}
$$


Como o sistema está em equilíbrio, a quantidade $\mu_{i}$ pode ser considerada constante e portanto,

$$
G=\sum_{i=1}^{\alpha} n_{i} \mu_{i}
$$

Para um sistema com apenas uma substância, a Eq. (A.46) é

$$
\mu=\frac{G}{n} \text {. }
$$

A quantidade $\mu_{i}$ é conhecida como o potencial químico (ou tendência de escape) da substância $i$. Assim, da Eq. (A.44), obtém-se o potencial químico de um gás ideal, a uma pressão $p$,

$$
\mu(T, p)=\mu^{\circ}(T)+R T \ln p
$$

\section{A.5.2 Potencial Químico do Solvente em Soluções Diluídas Ideais}

Solução é uma mistura homogênea de fase única, possuindo substâncias dispersadas em uma escala molecular de forma homogênea. Apesar das soluções existirem em qualquer fase, como a Planta Piloto utiliza soluções na fase líquida, este tipo de solução é enfatizado. De maneira geral, uma solução é composta por um solvente, que é a substância de maior concentração, e um ou mais solutos, que são as substâncias com as menores concentrações.

Os gases reais se comportam como um gás ideal quando a pressão se aproxima de zero. Observou-se experimentalmente que, para fins práticos, os gases reais têm comportamento próximo do real quando a pressão é próxima de zero. Assim, os gases ideais são aqueles que se comportam de acordo com a lei dos gases ideais para qualquer pressão.

O mesmo raciocínio foi usado para determinar o comportamento de soluções líquidas ideais. Quando um líquido volátil puro é colocado em um recipiente fechado onde previamente havia vácuo, parte do líquido tende a evaporar. Analisando-se a condição de equilíbrio dinâmico, onde a taxa de condensação é igual à taxa de vaporização, observa-se uma determinada pressão de vapor, $p^{\circ}$, na fase vapor. Caso o mesmo experimento seja repetido utilizando uma solução, obtida através da mistura do mesmo líquido volátil utilizado anteriormente e um soluto não volátil, observa-se que a pressão de vapor da solução é menor que a observada anteriormente. Como o soluto não é volátil, o vapor é constituído de solvente, apenas. A lei de Raoult afirma que a pressão de vapor de uma solução, $p$, é igual à pressão de vapor do solvente puro, $p^{\circ}$, multiplicado pela fração molar do solvente $x$ :

$$
p=p^{\circ} x
$$

De maneira similar aos gases ideais, uma solução real se aproxima da lei de Raoult quanto maior a fração molar do solvente. As soluções ideais são aquelas que se comportam de acordo com a lei de Raoult para qualquer fração molar de solvente. 
Conforme considerado anteriormente, na condição de equilíbrio dinâmico, a pressão de vapor é decorrente do solvente, apenas. Ainda, na condição de equilíbrio, a variação da energia de Gibbs do sistema é zero, o que equivale a dizer que o potencial químico da fase vapor e da fase líquida são iguais, $\mu_{l i q}=\mu_{v a p}$. Considerando-se a fase vapor como um gás ideal,

$$
\mu_{l i q}(T, p)=\mu_{v a p}(T, p)=\mu_{v a p}^{\circ}+R T \ln p
$$

Considerando a condição de equilíbrio para o solvente puro,

$$
\mu_{\text {liq }}^{\circ}=\mu_{v a p}^{\circ}+R T \ln p^{\circ}
$$

e a lei de Raoult, a Eq. (A.50) torna-se:

$$
\mu=\mu^{\circ}(T, p)+R T \ln x
$$

onde $\mu$ é o potencial químico do solvente na solução e $\mu^{\circ}(T, p)$ é o potencial químico do solvente puro a uma determinada temperatura e pressão.

\section{A.5.3 Potencial Químico dos Solutos em Soluções Diluídas Ideais}

Considere o diferencial da Eq. (A.46),

$$
\mathrm{d} G=\sum_{i=1}^{\alpha}\left(\mathrm{d} n_{i} \mu_{i}+\mathrm{d} \mu_{i} n_{i}\right)
$$

Igualando-se as Equações (A.53) e (A.42), resulta na equação de Gibbs-Duhem

$$
\begin{aligned}
-S \mathrm{~d} T+V \mathrm{~d} p+\sum_{i=1}^{\alpha} \mu_{i} \mathrm{~d} n_{i} & =\sum_{i=1}^{\alpha}\left(\mathrm{d} n_{i} \mu_{i}+\mathrm{d} \mu_{i} n_{i}\right) \\
-S \mathrm{~d} T+V \mathrm{~d} p & =\sum_{i=1}^{\alpha} n_{i} \mathrm{~d} \mu_{i} .
\end{aligned}
$$

Para temperatura e pressão constantes, a Eq. (A.54) é

$$
\sum_{i=1}^{\alpha} n_{i} \mathrm{~d} \mu_{i}=0 .
$$

Supondo um sistema composto de apenas um soluto e um solvente, tem-se:

$$
n_{1} \mathrm{~d} \mu_{1}+n_{2} \mathrm{~d} \mu_{2}=0
$$

sendo o índice 1 correspondente ao solvente e o índice 2 correspondente ao soluto. Isolandose $\mathrm{d} \mu_{2}$, resulta:

$$
\mathrm{d} \mu_{2}=-\frac{n_{1}}{n_{2}} \mathrm{~d} \mu_{1}=-\frac{x_{1}}{x_{2}} \mathrm{~d} \mu_{1}
$$


Derivando-se a Eq. (A.52), considerando a pressão e temperatura constantes, tem-se:

$$
\mathrm{d} \mu_{1}=R T \frac{\mathrm{d} x_{1}}{x_{1}}
$$

que pode ser substituída na Eq. (A.57),

$$
\mathrm{d} \mu_{2}=-R T \frac{\mathrm{d} x_{1}}{x_{2}} \mathrm{~d} \mu_{1}
$$

Como $\mathrm{d} x_{1}=-\mathrm{d} x_{2}$,

$$
\mathrm{d} \mu_{2}=R T \frac{\mathrm{d} x_{2}}{x_{2}}
$$

Integrando-se a Eq. (A.59), resulta:

$$
\mu_{2}=R T \ln x_{2}+C_{\text {int }}
$$

Se $x_{2}=1$, o soluto é puro e portanto, $C_{i n t}=\mu_{2}^{\circ}$. Assim,

$$
\mu_{2}=\mu_{2}^{\circ}(T, p)+R T \ln x_{2}
$$

É importante mencionar que a Eq. (A.61) é válida também para solventes voláteis, através da lei de Henry, que relaciona a pressão do soluto na fase vapor com a fração molar do soluto na solução:

$$
p_{j}=K_{j} x_{j}
$$

sendo que o índice $j$ é referente ao soluto $j$ da solução e $K_{j}$ uma constante, dependente da temperatura e do soluto $j$. A lei de Henry é válida para soluções diluídas, assim como a lei de Raoult. A partir da lei de Henry, pode-se desenvolver o mesmo argumento utilizado para obter a equação do potencial químico de solventes, resultando em uma relação similar à Eq. (A.52).

\section{A.5.4 Potencial Químico de Solutos em Função de Concentrações}

As equações referentes a potencial hidrogeniônico utilizam concentração molar, diferentemente das equações desenvolvidas anteriormente, que utilizam fração molar. Desta forma, é conveniente obter relações entre as concentrações dos solutos e seus respectivos potenciais químicos. Por definição, a fração molar é:

$$
x_{j}=\frac{n_{j}}{n_{1}+\sum_{j=2}^{\alpha} n_{j}},
$$

onde $x_{j}$ é a fração molar do soluto $j, n_{j}$ é o número de mols do soluto $j, n_{1}$ é o número de mols do solvente e $\alpha$ corresponde ao número de solutos presentes na solução. 
A molalidade é, por definição, o número de mols de $j$ por unidade de massa do solvente:

$$
m_{j}=\frac{n_{j}}{n_{1} M_{1}} \Longrightarrow n_{j}=n_{1} M_{1} m_{j}
$$

sendo $m_{j}$ a concentração molal em mol $/ \mathrm{kg}$ do soluto $j$ e $M_{1}$ é a massa molar do solvente em kg/mol. Substituindo-se a Eq. (A.64) na Eq. (A.63):

$$
x_{j}=\frac{n_{1} M_{1} m_{j}}{n_{1}+n_{1} M_{1} \sum_{j=2}^{\alpha} m_{j}}=\frac{M_{1} m_{j}}{1+M_{1} \sum_{j=2}^{\alpha} m_{j}} .
$$

Na condição de solução diluída $\sum m_{j} \rightarrow 0$, portanto:

$$
\lim _{m_{j} \rightarrow 0}\left(\frac{x_{j}}{m_{j}}\right)=\lim _{m_{j} \rightarrow 0} \frac{M_{1}}{1+M_{1} \sum_{j=2}^{\alpha} m_{j}} \approx M_{1} \quad \Longrightarrow \quad x_{j}=M_{1} m_{j} .
$$

Já a molaridade é definida como o número de mols de $j$ por unidade de volume do solvente:

$$
\tilde{c}_{j}=\frac{n_{j}}{V_{1}}=\frac{n_{1} M_{1} m_{j}}{V_{1}}
$$

onde $\tilde{c}_{j}$ é a concentração molar do soluto $j \mathrm{em} \mathrm{mol} / \mathrm{m}^{3}$ e $V_{1}$ é o volume da solução em $\mathrm{m}^{3}$. Utilizando a definição de densidade,

$$
\rho_{1}=\frac{W_{1}}{V_{1}}
$$

sendo $\rho_{1}$ a densidade do solvente em $\mathrm{kg} / \mathrm{m}^{3}$ e $W_{1}$ a massa do solvente em $\mathrm{kg}$. A massa do solvente pode ser reescrita como:

$$
W_{1}=n_{1} M_{1}+\sum_{j=2}^{\alpha} n_{j} M_{j}=n_{1} M_{1}+\sum_{j=2}^{\alpha} n_{1} M_{1} m_{j} M_{j} .
$$

Portanto, o volume do solvente, $V_{1}$, é equivalente a:

$$
V_{1}=\frac{n_{1} M_{1}}{\rho_{1}}\left(1+\sum_{j=2}^{\alpha} m_{j} M_{j}\right)
$$

Substituindo-se a nova definição de volume do solvente na Eq. (A.67),

$$
\tilde{c}_{j}=\frac{m_{j} \rho_{1}}{1+\sum_{j=2}^{\alpha} m_{j} M_{j}} .
$$

Para soluções diluídas, $m_{j} \rightarrow 0$, portanto:

$$
\lim _{m_{j} \rightarrow 0} \frac{\tilde{c}_{j}}{m_{j}}=\lim _{m_{j} \rightarrow 0} \frac{\rho_{1}}{1+\sum_{j=2}^{\alpha} m_{j} M_{j}} \approx \rho_{1}
$$


Assim, a relação entre a concentração molar do soluto e sua molalidade é:

$$
\tilde{c}_{j} \approx \rho_{1} m_{j}
$$

Os resultados sugerem que a fração molar no cálculo do potencial químico de solutos e solvente pode ser substituída pela molalidade ou pela molaridade. No entanto, os valores de potencial químico padrão devem ser utilizados na unidade correta. Adicionalmente, não é correto extrair o logaritmo neperiano de valores dimensionais. Assim, a molalidade de um soluto pode ser escrita como:

$$
x_{j}=M_{1} m_{j}=M_{1} m^{\circ} \frac{m_{j}}{m^{\circ}},
$$

sendo $m^{\circ}=1 \mathrm{~mol} / \mathrm{kg}$ a concentração molal padrão. Portanto, o potencial químico do soluto $j$ é:

$$
\begin{gathered}
\mu_{j}=\mu_{j}^{\circ}(T, p)+R T \ln M_{1} m^{\circ} \frac{m_{j}}{m_{j}^{\circ}} \\
\mu_{j}=\mu_{j}^{\circ}(T, p)+R T \ln M_{1} m^{\circ}+R T \ln \frac{m_{j}}{m^{\circ}} .
\end{gathered}
$$

Pode-se definir $\mu_{j}^{*}=\mu_{j}^{\circ}(T, p)+R T \ln M_{1} m_{j}^{\circ}$, como sendo o valor do potencial químico do soluto na condição de molalidade unitária na solução, considerando que a solução se comporte como ideal nestas concentrações (ou seja, a Lei de Raoult e a Lei de Henry são válidas nesta condição).

De maneira similar, utilizando-se a relação entre a molalidade e a concentração molar,

$$
\frac{m_{j}}{m^{\circ}}=\frac{\tilde{c}^{\circ}}{\rho_{1} m^{\circ}} \frac{\tilde{c}_{j}}{\tilde{c}^{\circ}}=\frac{\tilde{c}^{\circ}}{\rho_{1} m^{\circ}} \frac{c_{j}}{c^{\circ}}
$$

sendo $c_{j}$ a concentração molar do soluto $j$ em mol/l, $c^{\circ}=1 \mathrm{~mol} / \mathrm{l}$ a concentração molar padrão em mol $/ 1$ e $\tilde{c}^{\circ}=10^{3} \mathrm{~mol} / \mathrm{m}^{3}$. Substituindo na Eq. (A.75), tem-se:

$$
\begin{gathered}
\mu_{j}=\mu_{j}^{*}(T, p)+R T \ln \frac{\tilde{c}^{\circ}}{\rho_{1} m^{\circ}}+R T \ln \frac{c_{j}}{c^{\circ}} \\
\mu_{j}=\mu_{j}^{* *}(T, p)+R T \ln \frac{c_{j}}{c^{\circ}},
\end{gathered}
$$

onde $\mu_{j}^{* *}(T, p)$ é o potencial químico que o soluto teria se estivesse na concentração de 1 $\mathrm{mol} / \mathrm{l}$, caso a solução se comportasse como ideal nesta faixa de concentração.

\section{A.5.5 Equilíbrio Dinâmico de Reações Químicas}

Considere uma reação ocorrendo a temperatura e pressão constantes. A reação pode ser descrita pela equação:

$$
\nu_{1} A_{1}+\nu_{2} A_{2}+\cdots+\nu_{k} A_{k} \longrightarrow \nu_{k+1} A_{k+1}+\nu_{k+2} A_{k+2}+\cdots+\nu_{\alpha} A_{\alpha}
$$


sendo $\nu_{i}$ o coeficiente estequiométrico da substância $i$ e $A_{i}$ a fórmula química da substância i. A reação pode ser reescrita como:

$$
\sum_{i=1}^{\alpha} \nu_{i} A_{i}=0
$$

onde $\nu_{i}$ é negativo para reagentes e positivo para produtos.

Para determinar se a reação ocorre no sentido direto ou reverso, basta determinar se a energia de Gibbs da reação é negativa ou positiva, respectivamente. Conforme a reação evolui, a energia de Gibbs segue diminuindo, até que ela alcance um valor mínimo, que corresponde ao equilíbrio dinâmico. Como a reação ocorre a temperatura e pressão constantes, a Eq. (A.42) é:

$$
\mathrm{d} G=\sum_{i=1}^{\alpha} \mu_{i} \mathrm{~d} n_{i}
$$

Conforme a reação avança $\xi$ mols, o número de mols de cada substância envolvida na reação pode ser escrita como:

$$
n_{i}=n_{i}^{0}+\nu_{i} \xi
$$

sendo $n_{i}^{0}$ o número de mols da substância $i$, antes da reação ter avançado. Calculando-se o diferencial da Eq. (A.81), tem-se:

$$
\mathrm{d} n_{i}=\nu_{i} \mathrm{~d} \xi
$$

que pode ser substituída na Eq. (A.80), resultando em:

$$
\mathrm{d} G=\mathrm{d} \xi \sum_{i=1}^{\alpha} \mu_{i} \nu_{i}
$$

Portanto, a variação da energia de Gibbs em relação ao avanço da reação é:

$$
\left(\frac{\partial G}{\partial \xi}\right)_{T, p}=\sum_{i=1}^{\alpha} \mu_{i} \nu_{i} .
$$

Na condição de equilíbrio, a variação da energia de Gibbs deve ser zero, portanto:

$$
\left(\frac{\partial G}{\partial \xi}\right)_{T, p, e q}=0 \quad \text { e } \quad \sum_{i=1}^{\alpha} \mu_{i} \nu_{i}=0 .
$$

Adicionalmente, a condição de equilíbrio da Eq. (A.85) é chamada de variação de energia de Gibbs da reação, pois é similar à definição de variação de energia de Gibbs padrão de uma reação, apresentada na Eq. (A.37). Portanto, a condição de equilíbrio para qualquer reação química é:

$$
\Delta_{r} G=\left(\sum_{i=1}^{\alpha} \mu_{i} \nu_{i}\right)_{e q}=0
$$




\section{A.5.6 Equilíbrio Dinâmico de Reações Químicas em Soluções Diluídas}

Considere uma reação química ocorrendo em uma solução a temperatura e pressão constantes:

$$
\nu_{1} A_{1}+\nu_{2} A_{2} \longrightarrow \nu_{3} A_{3}+\nu_{4} A_{4}
$$

Para determinar o equilíbrio químico, é necessário calcular a variação da energia de Gibbs da reação, que pode ser calculada através das definições de potencial químico de solutos:

$$
\mu_{i}=\mu_{i}^{\circ}+R T \ln x_{i}
$$

Assim, a variação da energia de Gibbs da reação pode ser escrita como:

$$
\begin{aligned}
& \Delta_{r} G=\nu_{3} \mu_{3}^{\circ}+\nu_{3} R T \ln x_{3}+\nu_{4} \mu_{4}^{\circ}+\nu_{4} R T \ln x_{4}-\nu_{1} \mu_{1}^{\circ}-\nu_{1} R T \ln x_{1}-\nu_{2} \mu_{2}^{\circ}-\nu_{2} R T \ln x_{2} \\
& \Delta_{r} G=\nu_{3} \mu_{3}^{\circ}+\nu_{4} \mu_{4}^{\circ}-\nu_{1} \mu_{1}^{\circ}-\nu_{2} \mu_{2}^{\circ}+R T\left(\nu_{3} \ln x_{3}+\nu_{4} \ln x_{4}-\nu_{1} \ln x_{1}-\nu_{2} \ln x_{2}\right) .
\end{aligned}
$$

O primeiro termo da Eq. (A.89) é a energia de Gibbs padrão da reação, $\Delta_{r} G^{\circ}$. Agrupando-se os termos nas funções logarítmicas, obtém-se:

$$
\Delta_{r} G=\Delta_{r} G^{\circ}+R T \ln \frac{x_{3}^{\nu_{3}} x_{4}^{\nu_{4}}}{x_{1}^{\nu_{1}} x_{2}^{\nu_{2}}}
$$

Na condição de equilíbrio, $\Delta_{r} G=0$, portanto:

$$
\Delta_{r} G^{\circ}=-R T \ln \frac{x_{3}^{\nu_{3}} x_{4}^{\nu_{4}}}{x_{1}^{\nu_{1}} x_{2}^{\nu_{2}}}
$$

Generalizando-se as equações, a condição de equilíbrio é:

$$
\Delta_{r} G^{\circ}=-R T \ln K
$$

sendo o quociente (ou constante) de equilíbrio das frações molares, $K$, definido como:

$$
K=\prod_{i=1}^{\alpha} x_{i}^{\nu_{i}}
$$

onde $\nu_{i}$ é o coeficiente estequiométrico da substância $i$, sendo positivo para produtos e negativo para reagentes.

Adicionalmente, é possível utilizar o quociente de equilíbrio de molalidades ou molaridades, utilizando-se valores apropriados para a energia de Gibbs da reação:

$$
\begin{aligned}
\Delta_{r} G^{*} & =-R T \ln K_{m} \text { (molalidade) } \\
\Delta_{r} G^{* *} & =-R T \ln K_{c} \text { (molaridade) }
\end{aligned}
$$

sendo $\Delta_{r} G^{*}$ e $\Delta_{r} G^{* *}$ as energias de Gibbs da reação em unidades apropriadas, conforme Eq. (A.75) e (A.77), respectivamente, $K_{m}$ é o quociente de equilíbrio de molalidades e $K_{c}$ é o quociente de equilíbrio de molaridades. 


\section{A.5.7 As Variações da Constante de Equilíbrio Devido a Variações na Tempe- ratura}

Conforme visto anteriormente, a variação da energia de Gibbs em relação à temperatura é igual à entalpia, com sinal invertido:

$$
\left(\frac{\partial G}{\partial T}\right)_{p}=-S
$$

Diferenciando-se a função $G / T$ com relação à temperatura, resulta em:

$$
\left(\frac{\partial G / T}{\partial T}\right)_{p}=\frac{1}{T}\left(\frac{\partial G}{\partial T}\right)+\frac{G}{T^{2}} \frac{\partial T}{\partial T} .
$$

Substituindo-se a Eq. (A.96), tem-se:

$$
\left(\frac{\partial G / T}{\partial T}\right)_{p}=-\frac{T S+G}{T^{2}},
$$

que a partir da definição da energia de Gibbs, $G=H-T S$, é simplificada em:

$$
\left(\frac{\partial G / T}{\partial T}\right)_{p}=-\frac{H}{T^{2}}
$$

Generalizando-se a Eq. (A.99) para a variação da energia de Gibbs:

$$
\left(\frac{\partial\left(\Delta_{r} G^{\circ} / T\right)}{\partial T}\right)_{p}=-\frac{\Delta_{r} H^{\circ}}{T^{2}} .
$$

A constante de equilíbrio é definida como na Eq. (A.92):

$$
\ln K=-\frac{\Delta_{r} G^{\circ}}{R T}
$$

Diferenciando-se com relação à temperatura, obtém-se:

$$
\frac{\mathrm{d} \ln K}{\mathrm{~d} T}=-\frac{1}{R} \frac{\mathrm{d}\left(\Delta_{r} G^{\circ} / T\right)}{\mathrm{d} T} .
$$

Substituindo-se o resultado da Eq. (A.100), resulta em:

$$
\frac{\mathrm{d} \ln K}{\mathrm{~d} T}=\frac{\Delta_{r} H^{\circ}}{R T^{2}} .
$$

A Eq. (A.103) pode ser integrada para determinar as variações na constante de equilíbrio devido às mudanças de temperatura.

\section{A.5.8 O Conceito de Atividade para Soluções Reais}

Uma solução real apresenta um comportamento diferente do predito pelas equações de potencial químico desenvolvidas até o momento. Isto ocorre pois quando os solutos 
passam a ter concentrações maiores, as interações moleculares começam a ser mais significativas. Desta forma, introduz-se o conceito de atividade, utilizado para representar matematicamente sistemas reais. O potencial químico de um soluto em um sistema ideal é:

$$
\mu_{j}^{i d}(T, p, m)=\mu_{j}^{*}(T, p)+R T \ln m_{j}
$$

sendo o índice $j$ referente a solutos, $m_{j}$ a concentração molal do soluto $j$ em mol/L e $m u_{j}^{*}$ o potencial químico do soluto a uma concentração molal unitária, caso este se comportasse idealmente até esta concentração.

O potencial químico de um sistema real é definido como:

$$
\mu_{j}^{r e}(T, p, a)=g_{j}(T, p)+R T \ln a_{j}
$$

sendo $g_{j}(T, p)$ uma função da temperatura e pressão e $a_{j}$ a atividade do soluto, que é uma função da temperatura, pressão, substância e concentração. Considerando-se $g_{j}(T, p)=$ $\mu_{j}^{*}(T, p)$ e subtraindo-se a Eq. (A.104) da Eq. (A.105), resulta:

$$
\mu_{j}^{r e}-\mu_{j}^{i d}=R T \ln \frac{a_{j}}{m_{j}} .
$$

O coeficiente de atividade do soluto, $\gamma_{j}$, é definido como:

$$
\gamma_{j}=\frac{a_{j}}{m_{j}}
$$

Quanto mais diluída, a solução deve se comportar idealmente, ou:

$$
m_{j} \rightarrow 0 \quad \Rightarrow \quad \gamma_{j} \rightarrow 1 \quad \Rightarrow \quad \mu_{j}^{r e} \rightarrow \mu_{j}^{i d}
$$

\section{A.5.9 Atividade em Soluções Eletrolíticas}

As soluções eletrolíticas necessitam de um equacionamento específico, pois as interações coulombianas entre íons ocorre a distâncias maiores que a força de van der Waals. Desta forma, as soluções eletrolíticas podem apresentar um comportamento diferente do ideal, mesmo a baixas concentrações. Suponha um sistema composto por um eletrólito totalmente dissociado em uma solução a temperatura e pressão constantes. A energia de Gibbs do sistema é:

$$
G=n_{1} \mu_{1}+n_{+} \mu_{+}+n_{-} \mu_{-},
$$

sendo $n_{+}$e $n_{-}$o número de mols dos íons positivos e negativos, respectivamente e $\mu_{+}$e $\mu_{-}$ o potencial químico dos íons positivos e negativos, respectivamente. Cada mol do eletrólito $j$ se dissocia em íons positivos e negativos, portanto:

$$
n_{+}=\nu_{+} n_{j} \quad \text { e } \quad n_{-}=\nu_{-} n_{j}
$$


Assim, a energia de Gibbs do sistema pode ser reescrita como:

$$
G=n_{1} \mu_{1}+n_{j}\left(\nu_{+} \mu_{+}+\nu_{-} \mu_{-}\right) .
$$

Se $\mu_{j}$ é o potencial químico do eletrólito na solução, a energia de Gibbs do sistema também pode ser escrita como:

$$
G=n_{1} \mu_{1}+n_{j} \mu_{j}
$$

Ou seja, $\mu_{j}=\nu_{+} \mu_{+}+\nu_{-} \mu_{-}$. O número total de mols de íons produzidos por um mol de eletrólito é $\nu=\nu_{+}+\nu_{-}$. O potencial químico médio dos íons, $\mu_{ \pm}$, é definido como:

$$
\mu_{ \pm}=\frac{\nu_{+} \mu_{+}+\nu_{-} \mu_{-}}{\nu} .
$$

Por definição, a atividade do eletrólito e dos íons é:

$$
\begin{aligned}
& \mu_{j}=\mu_{j}^{*}+R T \ln a_{j} \\
& \mu_{ \pm}=\mu_{ \pm}^{*}+R T \ln a_{ \pm} \\
& \mu_{+}=\mu_{+}^{*}+R T \ln a_{+} \\
& \mu_{-}=\mu_{-}^{*}+R T \ln a_{-},
\end{aligned}
$$

onde $a_{ \pm}$é a atividade média iônica, $a_{+}$e $a_{-}$são as atividades dos cátions e ânions, respectivamente. Os coeficientes de atividade são definidos como:

$$
\begin{aligned}
& a_{ \pm}=\gamma_{ \pm} m_{ \pm} \\
& a_{+}=\gamma_{+} m_{+} \\
& a_{-}=\gamma_{-} m_{-} .
\end{aligned}
$$

A partir destas definições, pode-se encontrar a relação entre as atividades e coeficientes de atividade:

$$
\begin{gathered}
a_{ \pm}=a^{1 / \nu} \\
a_{ \pm}=\left(a_{+}^{\nu_{+}} a_{-}^{\nu_{-}}\right)^{1 / \nu} \\
\gamma_{ \pm}=\left(\gamma_{+}^{\nu_{+}} \gamma_{-}^{\nu_{-}}\right)^{1 / \nu} \\
m_{ \pm}=\left(m_{+}^{\nu_{+}} m_{-}^{\nu_{-}}\right)^{1 / \nu} .
\end{gathered}
$$

Ainda, como $m_{+}=\nu_{+} m_{j}$ e $m_{-}=\nu_{-} m_{j}$, obtém-se a relação:

$$
m_{ \pm}=\left(\nu_{+}^{\nu_{+}} \nu_{-}^{\nu_{-}}\right)^{1 / \nu} m_{j}
$$

Assim, a equação para o cálculo do potencial químico com relação a atividade iônica média é:

$$
\begin{gathered}
\mu_{j}=\mu_{j}^{*}+R T \ln a_{ \pm}^{\nu} \\
\mu_{j}=\mu_{j}^{*}+R T \ln \left(\nu_{+}^{\nu_{+}} \nu_{-}^{\nu_{-}}\right)+\nu R T \ln m_{j}+\nu R T \ln \gamma_{ \pm} .
\end{gathered}
$$


Ainda, como o segundo termo é uma constante, é usual agrupá-lo com o primeiro termo:

$$
\mu_{j}=\mu_{j}^{*}+\nu R T \ln m+\nu R T \ln \gamma_{ \pm}
$$

Debye-Hückel desenvolveram um modelo, baseando-se nas forças de interação coulombianas entre os íons, para estimar as variações no coeficiente de atividade dos eletrólitos, o qual apresenta melhores resultados quanto mais diluída for a solução. Na prática, os resultados são bons para concentrações até $0,01 \mathrm{~mol} / 1$ de eletrólito, aproximadamente. Um modelo estendido de Debye-Hückel é (DEAN, 1999):

$$
-\log \gamma_{\iota}=\frac{A z_{\iota}^{2} \sqrt{I}}{1+B \stackrel{\sqrt{I}}{I}},
$$

sendo $\gamma_{\iota}$ o coeficiente de atividade do íon $\iota, z_{\iota}$ é a valência do íon $\iota$, å é o raio iônico efetivo do íon em $\AA$, $I$ é a força iônica da solução e $A$ e $B$ são constantes que dependem da temperatura e da constante dielétrica da solução, podendo ser obtidos em manuais de propriedades químicas. A força iônica da solução, $I$, é definida como o somatório da concentração de todos os íons da solução, multiplicado pelo quadrado da valência de todos os íons da solução:

$$
I=\frac{1}{2} \sum_{j=1}^{\alpha} c_{j} z_{j}^{2},
$$

onde $c_{j}$ é a concentração molar do íons $j$ em mol/l.

Outra possibilidade de se obter os coeficientes de atividade iônica é através de valores obtidos experimentalmente, encontrados em manuais de propriedades químicas. Desta forma, é possível estimar o valor do coeficiente de atividade iônica do sistema através de dados tabelados.

\section{A.5.10 Constante de Equilíbrio em Soluções Eletrolíticas}

A interação entre os íons diminui a energia de Gibbs dos íons na solução. Isto significa que os íons têm menos energia disponível para realizar trabalho adicional. Assim, os íons possuem menor mobilidade em uma solução eletrolítica - de fato, o potencial químico dos íons diminui ao considerar o coeficiente de atividade iônica. As consequências podem ser vistas na constante de equilíbrio de uma reação. Suponha uma reação de dissociação eletrolítica ocorrendo em uma solução diluída:

$$
\mathrm{HA} \rightleftharpoons \mathrm{H}^{+}+\mathrm{A}^{-}
$$

A constante de equilíbrio da reação, $K$, é:

$$
K=\frac{a_{H^{+}} a_{A^{-}}}{a_{H A}}=\frac{\gamma_{H^{+}} m_{H^{+}} \gamma_{A^{-}} m_{A^{-}}}{\gamma_{H A} m_{H A}} .
$$


Considerando-se que $\gamma_{ \pm}^{2}=\gamma_{H^{+}} \gamma_{A^{-}}$e levando-se em consideração que substâncias apolares em soluções diluídas tendem a se comportar idealmente, $\gamma_{H A} \rightarrow 1$, resulta:

$$
K=\gamma_{ \pm}^{2} \frac{m_{H^{+}} m_{A^{-}}}{m_{H A}}
$$

Assim, conclui-se que o aumento na concentração de íons na solução causa uma diminuição no valor do coeficiente de atividade e este, por sua vez, acarreta na diminuição da constante de dissociação da reação. 


\section{APÊNDICE B - Medição de pH}

O elemento sensor de pH da Planta Piloto é do tipo eletrodo de vidro, que atua de maneira similar a uma célula galvânica, sendo necessários conhecimentos em eletroquímica para entender seu funcionamento. O eletrodo de vidro apresenta uma dinâmica complexa, dependendo de inúmeras variáveis, conforme visto na modelagem feita por Hershkovitch, McAvoy e Liapis (1978), o que dificulta o desenvolvimento de um modelo fiel ao fenômeno físico, sendo que a dinâmica dos eletrodos de vidro são modeladas, empiricamente, como um sistema de primeira ordem mais tempo morto. Desta forma, o objetivo deste apêndice é expor o princípio de funcionamento do eletrodo de vidro, bem como discutir a dinâmica das medições de pH através de eletrodos de vidro, evidenciando as principais dificuldades da medição de $\mathrm{pH}$.

\section{B.1 Fundamentos de Eletroquímica}

A Eletroquímica é o estudo de reações químicas em que íons cruzam a interface entre duas fases da matéria, que de maneira geral são um metal (eletrodo) e uma solução condutora (eletrólito). A região de interface entre duas fases da matéria possui um desbalanço de carga local, chamado de dupla camada elétrica, que ocorre a pequenas distâncias, de apenas alguns raios atômicos.

Quando um metal é submergido em água, é ionizado, gerando um desbalanço entre a carga elétrica do eletrodo e do eletrólito, sendo este sistema chamado de meia célula eletroquímica. Suponha uma barra de zinco em água, parte de suas moléculas ionizam e se dissolvem na água, deixando elétrons livres na barra,

$$
\mathrm{Zn}_{(\mathrm{s})} \rightleftharpoons \mathrm{Zn}_{(\mathrm{aq})}^{2+}+2 \mathrm{e}^{-}
$$

Conforme a reação avança infinitesimalmente, $\mathrm{d} \xi$, a variação da energia de Gibbs do sistema segue a Eq. (A.84):

$$
\frac{\partial G}{\partial \xi}=\Delta_{r} G=\mathrm{d} W_{e l}
$$

onde $W_{e l}$ é o trabalho elétrico. O potencial elétrico é a capacidade que um corpo carregado tem para realizar trabalho, ou seja, atrair ou repelir outros corpos carregados:

$$
\mathrm{d} W_{e l}=-E \mathrm{~d} q
$$

onde $E$ é o potencial elétrico, o qual geralmente depende de sua localização no espaço e $q$ é a carga elétrica do corpo. No caso, $E$ é o potencial elétrico gerado pelo desbalanço de 
carga local. A transferência de cargas devido ao avanço da reação pode ser escrito como:

$$
\mathrm{d} q=-\nu F \mathrm{~d} \xi
$$

onde $F$ é a constante de Faraday em $\mathrm{C} / \mathrm{mol}$ e $\nu$ é o coeficiente estequiométrico dos elétrons. Substituindo-se as Eq. (B.3) e (B.4) na Eq. (B.2), resulta em:

$$
\Delta_{r} G=-\nu F E
$$

Quanto maior o potencial elétrico, mais negativa a energia de Gibbs do sistema, mais espontânea é a reação e maior sua capacidade de conduzir elétrons através de um circuito externo.

A energia de Gibbs da reação da meia célula da Eq. (B.1) pode ser calculada através da Eq. (A.90), resultando em:

$$
\nu F E=-\Delta_{r} G^{\circ}-R T \ln K
$$

Pode-se definir $E^{\circ}=-\Delta_{r} G^{\circ} /(\nu F)$, que é o potencial elétrico da meia célula quando a atividade dos produtos e reagentes é igual à unidade, resultando na Equação de Nernst:

$$
E=E^{\circ}-\frac{R T}{\nu F} \ln K
$$

A equação de Nernst é importante, pois relaciona o potencial elétrico de uma determinada meia célula com sua respectiva constante de equilíbrio químico.

Note que o potencial elétrico de uma meia célula não pode ser observado diretamente, pois é impossível conectar uma ponta de prova na dupla camada elétrica. Assim, o potencial de uma meia célula só pode ser observado com a utilização de uma outra meia célula. A meia célula utilizada como referência, empregada para medir os valores de potencial elétrico padrão das inúmeras outras meia células, é a de hidrogênio, sendo atribuído o valor zero para seu potencial elétrico.

\section{B.2 O Eletrodo de Vidro}

O eletrodo de vidro é um equipamento que utiliza os princípios da eletroquímica para determinar a atividade de determinado íon em uma solução. São construídos para serem sensíveis apenas a determinado íon, portanto são seletivos. Os eletrodos sensíveis aos íons de hidrogênio consistem em uma membrana de bulbo de vidro, que reage com os íons $\mathrm{H}_{3} \mathrm{O}^{+}$, desenvolvendo um potencial elétrico entre suas faces interna e externa, de acordo com o pH da solução de interesse. O dióxido de silício - principal composto do vidro - dá à membrana a sensibilidade ao $\mathrm{pH}$. Quando o bulbo de vidro é exposto à água, forma-se uma camada de gel hidratada de aproximadamente $10 \mathrm{~nm}$ de espessura e alguns 
compostos do grupo $\mathrm{Si}-\mathrm{O}$ - aceitam prótons provenientes da água, ocorrendo uma reação do tipo:

$$
\mathrm{Si}-\mathrm{O}-_{(\mathrm{s})}+\mathrm{H}_{3} \mathrm{O}_{(\mathrm{aq})} \rightleftharpoons \mathrm{Si}-\mathrm{O}-\mathrm{H}^{+}{ }_{(\mathrm{s})}+\mathrm{H}_{2} \mathrm{O}_{(\mathrm{l})}
$$

Como qualquer reação onde há troca iônica e ocorre entre duas fases distintas, surge um potencial elétrico de interface, que segue a equação de Nernst.

O potencial elétrico que se desenvolve na membrana externa do bulbo, quando em contato com uma solução, é a variável de interesse para a medição de pH. No entanto, não é possível que se meça diretamente esta variável, sendo necessários outros dois eletrodos para realizar esta medição. O bulbo de vidro é conectado a um cilindro isolante, o qual aloja um eletrodo que geralmente é composto de prata-cloreto de prata. O volume interno do bulbo e cilindro é preenchido com uma solução eletrolítica (eletrólito), podendo ser hidróxido de cloro ou cloreto de potássico, entre outras. Assim, na face interna do bulbo também se desenvolve um potencial elétrico constante, devido à concentração constante do composto eletrolítico. Existe ainda a necessidade de um segundo eletrodo, chamado de eletrodo de referência, necessário para a medição do potencial da face externa do bulbo, geralmente constituído de eletrodo e solução eletrolítica de mesma composição que o eletrodo de medição, pois assim cancelam-se as variações no potencial elétrico dos eletrodos devido a variações de temperatura. A condutividade elétrica entre as duas faces do bulbo é mantida através de íons de sódio - um dos componentes do vidro é o óxido de sódio - que possuem certa mobilidade dentro da estrutura molecular do vidro (MCMILLAN; CAMERON, 2004). A Figura B.1 apresenta um eletrodo de vidro e seus principais potenciais elétricos.

Os potenciais elétricos $E_{1}-E_{2}$ seguem a equação de Nernst,

$$
\begin{aligned}
& E_{1}=E_{1}^{\circ}-\frac{R T}{\nu F} \ln \frac{a_{\mathrm{Si}-\mathrm{O}-\mathrm{H}^{+}}{ }_{e}}{a_{\mathrm{Si}-\mathrm{O}-{ }_{e}} a_{\mathrm{H}_{3} \mathrm{O}^{+}}{ }_{e}} \\
& E_{2}=E_{2}^{\circ}-\frac{R T}{\nu F} \ln \frac{a_{\mathrm{Si}-\mathrm{O}-\mathrm{H}^{+}}{ }_{p}}{a_{\mathrm{Si}-\mathrm{O}-{ }_{p}} a_{\mathrm{H}_{3} \mathrm{O}^{+}{ }_{p}}},
\end{aligned}
$$

onde $E_{1}$ é o potencial elétrico da face externa da membrana, $E_{2}$ é o potencial elétrico da face interna da membrana, $E_{1}^{\circ}$ e $E_{2}^{\circ}$ são o potencial elétrico padrão da face externa e interna da membrana, respectivamente e, os índices e e $p$ correspondem à camada de gel hidratada interna ao eletrodo e de contato com o processo, respectivamente. É plausível admitir que os materiais das membranas interna e externa possuem composições idênticas, portanto, $E_{1}^{\circ}=E_{2}^{\circ}$. Adicionalmente, a atividade dos compostos $\mathrm{Si}-\mathrm{O}-$ pode ser aproximada à unidade. Portanto, levando em consideração a mudança de bases da função logarítmica, o potencial $E_{1}-E_{2}$ pode ser escrito como:

$$
E_{1}-E_{2}=-\frac{2,303 R T}{F}\left(\log a_{\mathrm{Si}-\mathrm{O}-\mathrm{H}^{+}}-\log a_{\mathrm{Si}-\mathrm{O}-\mathrm{H}^{+}}+\log a_{\mathrm{H}_{3} \mathrm{O}^{+}}{ }_{e}-\log {a_{\mathrm{H}_{3} \mathrm{O}^{+}}}_{p}\right) .
$$


Figura B.1 - Os potenciais elétricos de um eletrodo de vidro.

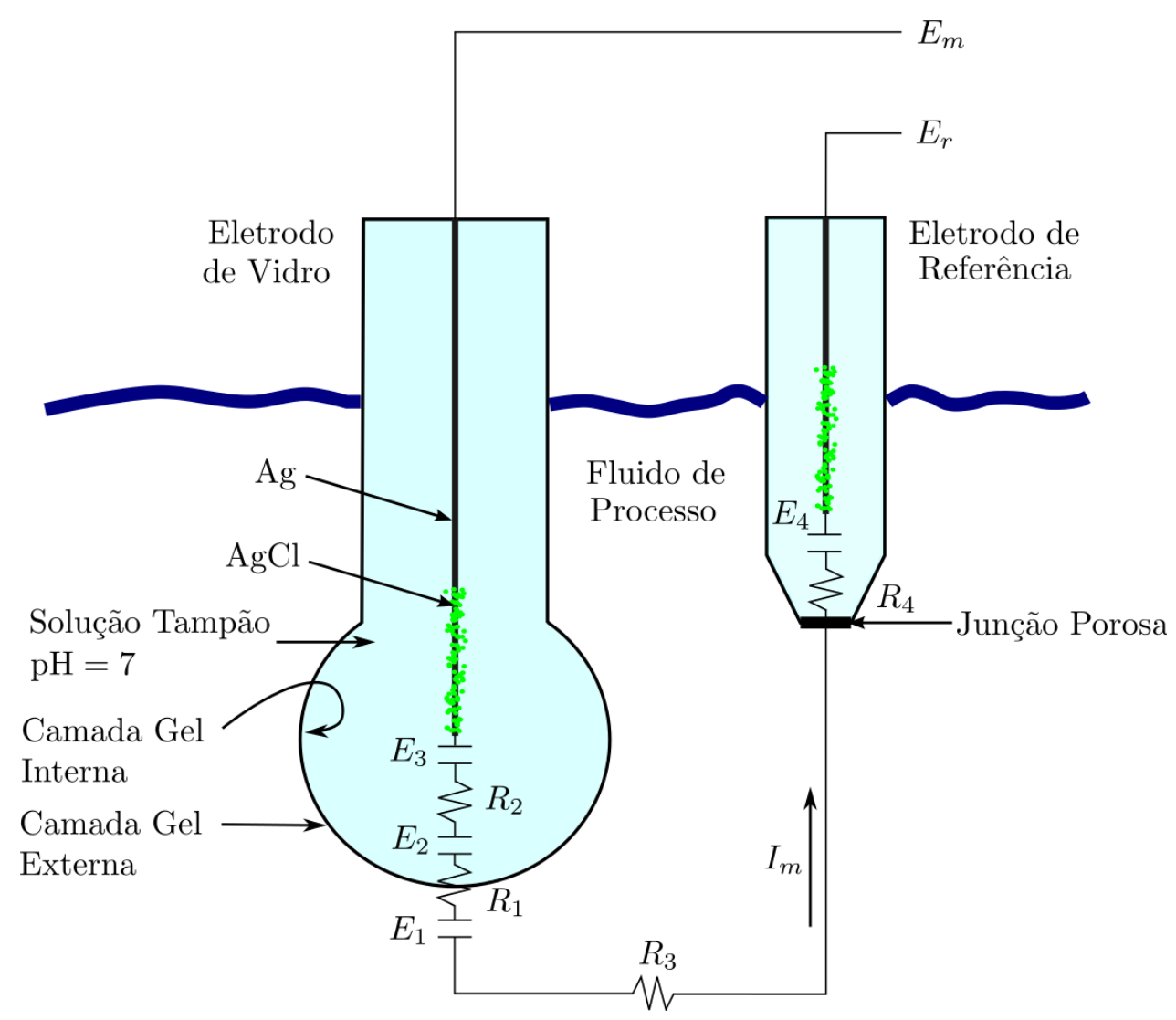

Adaptado de: McMillan e Cameron (2004).

Devido à solução interna ao eletrodo de vidro ser uma solução tampão de pH neutro, sabe-se que $-\log a_{\mathrm{H}_{3} \mathrm{O}^{+}}=7$. Ainda, a quantidade $\log a_{\mathrm{Si}-\mathrm{O}-\mathrm{H}^{+}}{ }_{e}-\log a_{\mathrm{Si}-\mathrm{O}-\mathrm{H}^{+}}$é aproximadamente zero. Assim, substituindo os valores das constantes de Faraday e do gás ideal, a Eq. (B.9) resulta em:

$$
E_{1}-E_{2}=1,985 \cdot 10^{-4} T\left(7-\mathrm{pH}_{p}\right)
$$

Assim, a diferença de potencial entre as duas faces da membrana de vidro é proporcional ao pH da solução, tendo valor igual a zero quando o pH do fluido de processo for neutro.

A medição do diferencial de potencial $E_{1}-E_{2}$ através do circuito externo é:

$$
E_{r}-E_{m}=E_{i}=E_{1}-E_{2}-E_{3}+E_{4}-I_{i}\left(R_{1}+R_{2}+R_{3}+R_{4}\right) .
$$

Substituindo-se a Eq. (B.11) na Eq. (B.10) e considerando-se

$$
E_{\text {médio }}=-E_{3}+E_{4}-I_{i}\left(R_{1}+R_{2}+R_{3}+R_{4}\right),
$$

resulta em:

$$
\mathrm{pH}_{p}=7-\frac{E_{i}-E_{m e ́ d i o}}{1,985 \cdot 10^{-4} T} .
$$


Os pHmetros digitais oferecem algoritmos para correção da medição do pH com relação a temperatura do fluido de processo, conforme a Eq. (B.12). Adicionalmente, alguns pHmetros digitais possuem algoritmos para compensar também as variações nas constantes de dissociação devido às variações na temperatura do fluido de processo, no entanto consistem apenas em aproximações através de equações quadráticas. Como estas aproximações são imprecisas, geralmente estes algoritmos são desabilitados pelos usuários.

Note que a dinâmica do eletrodo de vidro é bastante complexa, dependendo de inúmeras variáveis, além da temperatura do fluido de processo (HERSHKOVITCH; MCAVOY; LIAPIS, 1978). Para que o pH da solução seja efetivamente medido, é necessário que os íons estejam próximos ao eletrodo, para que estes possam reagir com a membrana de vidro. Além dos fenômenos de difusão e convecção, os íons dependem dos gradientes de campo elétrico da solução para se moverem. A dupla camada elétrica dificulta a aproximação dos íons ao eletrodo, sendo que ácidos e bases fracos tendem a se aproximar com maior facilidade quando estão associados, pois não possuem carga elétrica. Assim, ácidos e bases fracos tendem a apresentar uma resposta mais rápida às variações no pH e a presença de íons na solução tende a modificar a dinâmica do eletrodo de vidro. Adicionalmente, a velocidade do fluido de processo também interfere na convecção dos íons, interferindo na dinâmica do eletrodo de vidro.

Os eletrodos de vidro são construídos de forma a serem sensíveis a apenas o íon de interesse, no entanto, ainda continuam a apresentar uma sensibilidade - mesmo que pequena - a outros tipos de íons, podendo causar variações nas medições do eletrodo de vidro.

A camada gel hidratada do vidro é de grande importância na sensibilidade ao $\mathrm{pH}$ da solução. Qualquer tipo de material que agrida ou adsorva na superfície do eletrodo de vidro ou mesmo da junção porosa do eletrodo de referência irá causar variações na dinâmica do eletrodo de vidro. Adicionalmente, o próprio processo de envelhecimento do eletrodo causa um aumento da espessura da camada gel hidratada, aumentando seu tempo de resposta.

A modelagem fenomenológica do eletrodo de vidro é, portanto, uma tarefa complexa, sendo empiricamente substituída por uma função de transferência de primeira ordem com tempo morto. No entanto, percebe-se que este tipo de modelagem não apresentará grande aderência à realidade, para todas as condições operacionais da planta. 